\title{
Report on \\ a Strategic Approach to Research Publishing in South Africa
}


Published by the Academy of Science of South Africa

ISBN 0-620-36105-0

March 2006

P O Box 72135

Lynnwood Ridge 0040

(Pretoria, South Africa)

Didacta Building

211 Skinner Street

Pretoria

Web: www.assaf.co.za

Phone: 0123929393

Fax: 0123202099

e-mail: fundi@assaf.nrf.ac.za

Copyright: Academy of Science of South Africa

Reproduction is permitted provided the source is acknowledged

Layout, typesetting, cover design, reproduction and printing Marketing Support Services (012) 346-2168

The Academy of Science of South Africa (ASSAf) was inaugurated in May 1996 in the presence of then President Nelson Mandela, the Patron of the launch of the Academy. It was formed in response to the need for an Academy of Science consonant with the dawn of democracy in South Africa: activist in its mission of using science for the benefit of society, with a mandate encompassing all fields of scientific enquiry in a seamless way, and including in its ranks the full diversity of South Africa's distinguished scientists.

The Parliament of South Africa passed the Academy of Science of South Africa Act, Act 67 in 2001, and the Act came into operation on 15 May 2002.

This has made ASSAf the official Academy of Science of South Africa, recognised by Government and representing South Africa in the international community of science academies. 


\section{Preface}

Two strands of influence have affected the publication of local scholarly journals in South Africa in the recent past. The first of these was the establishment of the Bureau of Scientific Publications that subsidized the publication of a number of journals that had been established during the $20^{\text {th }}$ century. The 'Bureau journals' were an attempt to foster academic publication in South Africa and to make their products available to an international readership - quality of material was to be coupled to quality of production. In this respect the establishment of the Bureau was mimicking a similar development in Australia and could be seen as a mechanism for fostering home-grown talent. The second influence was a new mechanism of funding universities, which rewarded them directly for the academic publications that they produced. Both of these influences had a significant impact on the development of local journals, the behaviour of individuals, the financial sustainability of learned societies that produced the journals, and the institutions that received the 'output' subsidy.

The Bureau was recently closed, with only one journal, The South Africa Journal of Science, continuing to receive support through the Academy of Science of South Africa on the basis of its international impact. The funding for 'outputs' of the tertiary institutions has continued, although in a modified form that includes a reward for completed masters and doctoral degrees. These developments raised two related questions. The first was whether it was appropriate for the state to support the publication of (some) learned journals in the interest of fostering intellectual exchange. The second question was whether all of the articles, published in journals recognized for the output subsidy of universities, deserved to receive recognition, in view of the wide variation in quality of the material produced. The Academy was commissioned in 2001 in this context by the Department of Arts, Culture, Science and Technology (now the Department of Science and Technology) to undertake a study to address these two questions, with a view to making recommendations for the optimal development of policy in the future.

The effect of globalization on knowledge exchange, which is mediated very largely through scientific journals being published in English, and having their origins in Europe and North America, has resulted in the neglect of regional journals. It has also led to the development of benchmarks based on bibliometric analysis of publication patterns that has resulted in global ranking of tertiary institutions. These trends are being countered in the African context, with its relatively neglected tertiary sector, by a need that is expressed by the African Academies of Science that are members of the Network of African Scientific Academies (NASAC), to consider the publication of high-quality journals that report work of significance to African scientists. The degree to which such a project is feasible, and whether it could be successfully implemented both in South Africa and elsewhere on the continent, needs to be explored after the release of this report.

Although the report was prepared at the request of, and with funding from the Department of Science and Technology, in order amongst other matters to address specific questions that had been raised about the subsidy for scholarly outputs, its potential impact both in understanding international trends in scholarly knowledge production and in giving guidance to those who would like to foster the publication of indigenous journals, will be great if careful attention is given to the recommendations that are contained in this study.

The report was developed and has been guided to a successful conclusion by Prof Wieland Gevers who initiated it during his tenure as President of the Academy and has now brought it to fruition as the Academy's Executive Officer, with the invaluable assistance of Dr Xola Mati as study director. He and the authors of the various chapters are thanked for the care and attention with which they have produced a seminal analysis of South African publication patterns. They will receive their reward in full measure through the impact that this report will have on the further development of the National System of Innovation.

\section{Robin M. Crewe}

President, Academy of Science of South Africa (ASSAf) 



\section{Acknowledgments}

The authors wish to acknowledge the patient support of Mr Mosibudi Mangena, Minister of Science and Technology, as well as Dr Rob Adam and Dr Adi Paterson of the Department of Science and Technology, throughout this extended project. The 5-year contract with the Department had three parts - this Study now finally completed, the development of a new cycle of vigorous life for the South African Journal of Science, and the establishment of a significant new science magazine: Quest - Science for South Africa. Our partners have stood by these three ventures steadfastly and decisively.

We also owe much to Prof Robin Crewe, current President of the Academy of Science of South Africa, to Dr Philemon Mjwara, its General Secretary, and all other members of the Academy Council and ASSAf staff.

Thanks are also due to Dr Molapo Qhobela of the Department of Education; the late Dr Prem Naidoo of the Council on Higher Education; Dr Andrew Kaniki of the NRF; Dr William Blankley of the HSRC; Dr Graham Baker, Editor of the South African Journal of Science; and Prof Michael Cherry, South African correspondent of "Nature". They provided support and valuable inputs and consultations in respect of key stakeholders.

Dr Nicolaas Claassen assisted with the detailed statistical analysis of the Editors' survey. Dr Richard Clark carried out detailed proof-reading in liaison with the chief author and the printer. 



\section{Contents}

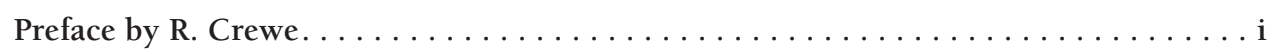

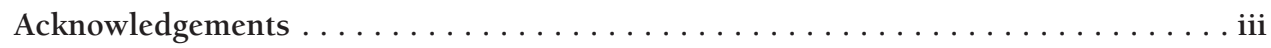

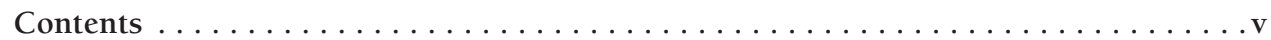

Executive Summary: Recommendations at a glance . . . . . . . . . . . . . vii

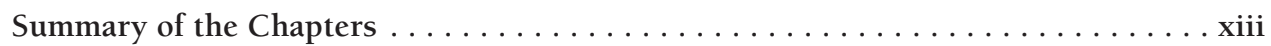

CHAPTER 1

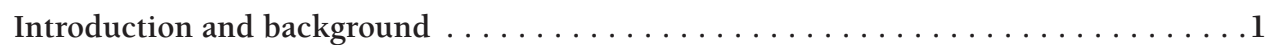

Wieland Gevers

\section{CHAPTER 2}

A bibliometric assessment of South African research publications

included in the internationally indexed database of Thomson ISI

Anastassios Pouris

\section{CHAPTER 3}

A comprehensive analysis of South African research journals

Johann Mouton, Nelius Boshoff and Robert Tijssen

\section{CHAPTER 4}

Survey of editors' opinions and related information . . .

Xola Mati

\section{CHAPTER 5}

Global eResearch trends and their implications for South African research publishing in print and online

Roy Page-Shipp and Monica Hammes

\section{CHAPTER 6}

Conclusions and recommendations for a strategically

enhanced role of research publishing in South Africa

Wieland Gevers, Xola Mati, Johann Mouton, Roy Page-Shipp, Monica Hammes,

and Anastassios Pouris

About the Authors .

About the Academy of Science of South Africa 



\section{EXECUTIVE SUMMARY \\ Recommendations at a Glance}

Following the closure of the erstwhile Bureau for Scientific Publications (BSP) and the termination of the policy of state subsidisation of selected flagship research journals, the Academy of Science of South Africa (ASSAf) signed a contract with the then Department of Arts, Culture, Science and Technology (DACST, now the Department of Science and Technology, DST) in December, 2001. The contract required ASSAf to recommend and support a new strategic framework for South Africa's research journals, on the basis of evidence and comparative information; ASSAf was to work in partnership with a number of organisations.

The main objectives of this strategic framework were to:

- promote/enhance the standing and effectiveness of South Africa's research journals, nationally and internationally;

- improve the productivity/efficacy of publication through different modalities (e.g. electronic publication);

- establish the South African Journal of Science (SAJS) as a "national asset" of high quality; and

- ensure that discoveries and insights gained through research published in South African journals were made known to a wider public than the research community itself.

The strategic goal that is the point of departure for this ensuing six-chapter Report is to help develop and maintain a robust national system of innovation that contributes materially to the sustainable prosperity of all South Africa's people. In other words, a scenario where large numbers of lively, enquiring and enterprising people have scope for productive careers and involvement as leaders in science-based efforts to promote the development of the whole nation's skills and resources.

Research publishing fits into this demanding vision, in the context of rapid change, through its core role as the documented vehicle of science-based progress and effective attainment of sufficient high-level human capacity to address the most challenging problems and to provide inspiration to the brightest minds amongst the youth. In addition, it plays a key role in training by furnishing the most rigorous tests of resolve and originality. It also connects the people carrying the science system of a country with the best of their international counterparts, and helps to establish a country's reputation to attract investment and foreign support.

Recommendation No 1: that all stakeholders in the South African research enterprise should each in their own way support local/national research journals that actively seek to be of international quality and are indexed in an internationally recognised, bibliometrically accessible database, through following best-practice in editorial discernment and peer review, including adaptations

that address inherent problems and capitalise on technological innovations;

- that judiciously enrich content to promote coherence and value-adding functions;

- that provide the local scholarly community with opportunities for participating in the full range of scholarship-enhancing activities associated with the process of publishing original research outputs;

- that vigorously seek financial sustainability from multiple income streams; and

that accept systemic peer review and periodic audit which has a marked developmental focus.

(The rationale for this broad recommendation is fully laid out in the chapters of this Report. In respect of financial viability of South Africa research journals, the general acceptance, in the special South African context where accredited institutional publication outputs are subsidised, of a per-article institutional charge system (linked in the case of higher education institutions to an agreed fraction of output publication subsidies, and in the case of other research-producing
The strategic goal

that is the point

of departure for

this ensuing six-

chapter Report is

to help develop and

maintain a robust

national system

of innovation that

contributes materially

to the sustainable

prosperity of all South

Africa's people 
institutions to adapted budgeting practice), would produce marked benefits at minimum cost, and naturally lead to a more rapid expansion of the Open Access mode of online publication, on the basis of "institution pays (a little), the whole nation/world benefits (a lot)". Key actors in bringing about the necessary policy and organisational frameworks would be research funders and supporters, including the Departments of Education and Science and Technology, the NRF and the MRC, all working with the Academy of Science of South Africa in downstream implementation mode following the release and general discussion of this Report. Data presented in this Report show that a fixed per-article institutional charge of R 1000, by an accredited journal that should be able annually to publish at least 100 articles, would provide a reliable income stream to that journal of R 100 000, which when added to subscription and other existing and probably expandable income streams, would create a basis for sustainable publication not now in place for most South African research journals. At the same time, the diversion to research journals of $1.43 \%$ of the publication subsidy stream would be insignificant against the benefits of the improvement in the quality and visibility of the publication outputs of the institutions concerned, not to mention the secondary benefits of enhanced scholarly functioning in general.)

The accreditation function has to be credible, transparent, well-administered and generally promotive of higher standards and greater general utility and significance, nationally and internationally
Recommendation No 2: that both high-level (Departments of Education and of Science and Technology, CHE/HEQC, NACI and NRF) and wide-ranging (higher education institutions, science councils) discussions be held to design a robust, well-informed and accountable mechanism for the accreditation of research journals (and probably also of books and other outputs of scholarship), that will meet the different although often convergent requirements of the multiple stakeholders in the national system of innovation.

(The current accreditation system of the Department of Education is not designed to meet the needs of other participants in the national system of innovation. Thus the accreditation step in respect of every single research publication, over which the DoE has complete control, feeds decisively into the policy frameworks of other organisations such as the CHE/HEQC (in terms of its functions of quality assurance of research and postgraduate training at higher education institutions), the NRF (for general grant-making and bursaries at the same institutions), the Department of Science and Technology, NACI and the scientometric compilers of annual S\&T indicators (as one of the key determinants of output units), and the higher education institutions and science councils (in terms of internal planning and resourcing policies and reward systems), not to mention the journals themselves. The accreditation function has to be credible, transparent, well-administered and generally promotive of higher standards and greater general utility and significance, nationally and internationally. A developmental approach to the accreditation of research journals requires implementation through a combination of widely accepted best-practice guidelines and quality promotion, with periodic peer review and assessment against criteria that can meet the needs of ALL the users of the system as listed above. If the Academy is to be involved in the national research publishing system in related, significant ways (see recommendation below for a quality assurance system for South African research journals, and for a general development programme for publishers, editors and reviewers, both coordinated and overseen by the Academy), this needs to be taken into account by the important stakeholders in the system when designing a robust, accountable and effective accreditation system for national research journals that satisfies their individual but mostly converging requirements to the greatest degree possible.)

Recommendation No 3: that the proposed best-practice guidelines presented in Chapters 1 and 6 of this Report be widely discussed under the aegis of the Academy of Science of South Africa, formulated into a concise readable document, and then publicly adopted by editors and publishers throughout South Africa, especially those relating to effective peer review and wise and appropriate editorial discernment.

(Particularly important aspects are the training/guidance of editors and reviewers in their critical respective functions in the publication process, and the enhancement of recognition of 
this kind of work in general academic reward mechanisms. The Academy of Science of South Africa could work with a number of different institutions to ensure that a spread of courses, workshops and online offerings is available on a regular basis, that a national editors' network is formed, and that it mediates in conveying the collective or individual concerns of publishers and editors to the relevant authorities.)

Recommendation No 4: that the quality assurance system now being put into place by the Council of Higher Education/Higher Education Quality Committee (CHE/HEQC) be used by that agency and by its partner higher education institutions to promote bestpractice in publishing of original research work, and to emphasise and enhance the training function served by the whole exercise of publishing original papers in the peerreviewed literature.

(The CHE/HEQC has achieved much in its best-practice guidelines for teaching and learning in higher education institutions, and is currently approaching postgraduate education and associated training in the same manner. Amongst the publication-related aspects of the latter, much good would come if all stakeholders emphasised the desirable and necessary relationship of conference presentations and dissertations to peer-reviewed publications emanating from the same work or study. A second benefit would come from systematically removing the perception that the (valuable) translation of research results into public benefits necessarily means that proper publication of the work concerned is not needed or should enjoy much lower priority.)

Recommendation No 5: that ASSAf be mandated jointly by the Departments of Education and Science and Technology to carry out external peer review and associated quality audit of all South African research journals in 5-year cycles, probably best done in relation to groups of titles sharing a particular broad disciplinary focus, in order to make recommendations for improved functioning of each journal in the national and international system.

(A light-touch but robust review and audit system, analogous to the periodic quality assurance reviews of the functioning of higher education institutions now routinely conducted by the Council on Higher Education/Higher Education Quality Committee, would help greatly to address problem areas and encourage enhanced functioning of research journals published in South Africa. Such functioning would include: quality of editorial and review process; fitness of purpose; positioning in the global cycle of new and old journals listed and indexed in databases; financial sustainability; and scope and size issues. Following on the momentum generated by the activities carried out as part of its research journals project and the production of this Report, the Academy of Science of South Africa would be the most suitable agency to oversee and be accountable for this work, obtaining system support for the best-practice guidelines, and appointing review panels and managing their work; some of the reviews could be done in respect of groups of journals with broadly similar focus.)

Recommendation No 6: that the Department of Science and Technology takes responsibility for ensuring that Open Access initiatives are promoted to enhance the visibility of all South African research articles and to make them accessible to the entire international research community. Specifically:

- online, open access ("Gold route") versions of South African research journals should be funded in significant part through a per-article charge system (linked in the case of higher education institutions to an agreed fraction of output publication subsidies, and in the case of other research-producing institutions to adapted budgeting practice), but publishers should still sell subscriptions to print copies and should maximise other sources of income to lower the article-charge burden;
A light-touch but robust review

and audit system, analogous to the periodic quality assurance reviews of the functioning of higher education institutions now routinely conducted by the Council on Higher Education/ Higher Education Quality Committee, would help greatly to address problem areas and encourage enhanced functioning of research journals published in South Africa 
The clear need for caution in assessing the presently somewhat vaguely defined business models for open access systems should not prevent the country from moving forward resolutely with a well-resourced programme for expanding its electronic access to the global and national scientific literature a federation of institutional Open Access repositories, adhering to common standards, should be established ("Green route"), with resources made available to help institutions in the preliminary stage, this virtual repository to be augmented by a central repository for those institutions which are unable to run a sustainable repository;

national harvesting of South African Open Access repositories should be undertaken as a matter of urgency, preferably by the NRF; and the importance of affordable bandwidth for research communications for this purpose be drawn to the attention of DST officials negotiating for better rates.

(This proposal holds significant logistic implications for the development and maintenance of adequate broadband connectivity and related infrastructure, but the imminent high-speed/ broadband national system or "superhighway", envisaged for use by research-active institutions and others, will make things possible that have only been dreamt of up to the present time. The virtual repository would capitalise on institutional efforts, provided agreed standards were adopted, and provide a publication route for researchers in institutions without such a repository. The emphasis should be on "leapfrogging" the present turmoil and confusion in the system. The clear need for caution in assessing the presently somewhat vaguely defined business models for open access systems should not prevent the country from moving forward resolutely with a well-resourced programme for expanding its electronic access to the global and national scientific literature.)

Recommendation No 7: that a consortium of agencies be asked by the Department of Science and Technology to form a virtual "national research publications information and research centre", probably best overseen by the Academy of Science of South Africa, which will continuously gather and analyse information on South African journals as well as on publications in foreign journals emanating from authors working in this country, following up on the studies presented in this Report and in the (rather few) previous relevant publications. This entity could also be used to support the training function envisaged in Recommendation 2.

(The proposed managed consortium would supply a number of government departments with reliable information for policy implementation purposes - the Department of Education and/or ASSAf, for accreditation of local journals; the National Research Foundation, for assisting valuebased grant-making; the Council on Higher Education/Higher Education Quality Committee, for enhanced quality assurance at research-active institutions; agencies carrying out large-scale evaluations of R\&D such as the HSRC, reliable bases for validating output data; and higher education institutions and other research producers, for accelerated researcher development and overall research planning.)

Recommendation No 8: that a wide-ranging project be initiated by the national Department of Education and the provincial education authorities that will sharply increase the exposure of teachers, teachers-in-training and learners to local science journals and magazines that present the country's foremost scientific work in accessible form, and are effectively linked to the media.

(One of the most cogent reasons for publishing research journals locally is the opportunity beneficially to reach the next generation in ways that are not possible with expensive international periodicals; this needs to be planned in partnership mode, however, and will not happen without strong top-down sponsorship and appropriate resourcing.)

Recommendation No 9: that the Department of Science and Technology should assume responsibility for seeing to it that the South African science/innovation community, 
including itself and other government agencies, becomes involved in international action to promote the rapid but evolutionary development of a non-commercial, expanded, diversified and more inclusive international listing and indexing system for research journals, including those published in developing countries, within the evolving electronic knowledge-disseminating and -archiving system.

(There are clear needs for a new, consultative and collaborative approach to meeting the requirements of developing as well as developed countries; of countries using languages other than English as vehicles for doing and reporting research; of disciplines with systems of scholarly practice differing from the "natural sciences standard"; in a system that provides full transparency and low-cost access to data in terms of the databases to be used and maintained. It could be argued that this need is on a par with other more well-publicised and public requirements to level the playing fields in a structurally unequal world (ICSU Report on "Scientific Data and Information", 2004). The lead organisations in this effort should be the Departments of Science and Technology and of Education and the NRF, working closely with the Academy in terms of its international partners and other relevant agencies.)

Recommendation No 10: that the findings and recommendations contained in this Report be presented to key stakeholders in a series of consultative workshops, and that the outcomes and the impact of the publication of the Report be evaluated in three years time.

(This Report could have made radical proposals and recommendations supported by evidence presented in the various chapters. This approach has not been taken, however, because of the large number of inter-dependent stakeholders, the extreme fluidity of the sector in global terms, and the conviction of the authors that only a consultative process is likely to achieve the recommended results. We believe the present Report provides a necessary but obviously not sufficient basis for important reforms and considerable advancement of South Africa's research potential and actual performance - joint downstream efforts will be needed, at both the widely distributed knowledge production and more focussed governance levels.)
We believe the

present Report

provides a necessary

but obviously not

sufficient basis for

important reforms

and considerable

advancement of

South Africa's

research potential

and actual

performance

- joint downstream

efforts will be

needed, at both the

widely distributed

knowledge production

and more focussed

governance levels 



\section{Summary of the chapters}

\section{CHAPTER ONE: Introduction and background (W Gevers)}

1.1 South Africa occupies the paradoxical position in the arena of research publishing of being a dwarf internationally and a giant on the African continent. About 3500 listed papers with at least one South African author address were published worldwide in 2000, representing about $0.5 \%$ ( 5 in every 1000 ) of all papers in the three major databases of the ISI system, which covers over 5500 selected international journals in Science, Engineering and Medicine, 1800 in the Social Sciences, and 1200 in the Arts and Humanities. South African research journals constituted only 19-23 (depending on the year) of the indexed journals on the combined databases in $2002(0.2 \%$, or 2 in every 1 000) containing about 350 papers of the ISI total for the country ( 1 in every 10), and the rest of Africa, only 2. South Africa's share of world citations in this database was 0.31 (just over 3 per very 1000 ) for the period 1997-2001, while only $0.15 \%$ (1.5 per 1000 ) of the $1 \%$ of top-cited articles had one or more South African addresses. Altogether, about 7 000 research articles are published annually from South African addresses in ISI-indexed journals or in un-indexed journals accredited by the Department of Education.

1.2 Recent surveys of the South African Science and Technology (S\&T) indicators put the total number of potentially publishing researchers in the country at about 16000 . The active researchers in this group are the producers of the 3500 ISI-listed papers per year mentioned above, as well as the approximately 3500 that are not so listed but are accredited by the DoE. In summary, 16000 researchers publish about 7000 papers a year, or on average about 0.4 papers per researcher per year.

1.3 A journal is regarded in this Report as being South African if its main, physical publishing address is within the country, if it is published by a South African scientific or professional association or other research organisation; and/or if its Editor and Editorial Board are largely drawn from South African scholars.

1.4 Following the closure of the erstwhile Bureau for Scientific Publications (BSP) and the termination of the policy of state subsidisation of selected flagship research journals, the Academy of Science of South Africa (ASSAf) signed a contract with the then Department of Arts, Culture, Science and Technology (DACST) in December, 2001. The contract required ASSAf to recommend and support a new strategic framework for South Africa's research journals, on the basis of evidence and comparative information.

1.5 The first point of departure of the Journals Project has been that science publishing should take place inside South Africa on a significant scale, because of the beneficial effects this has on the research system,

- in promoting the active participation of South African scholars in editing journals (both as editors and as members of editorial boards), and in refereeing/reviewing and improving submitted papers;

- in networking local scholars and their research students through research publication in a working context smaller than the massively diffused international system;

in facilitating the contribution of South African research and scholarship to the general body of scientific knowledge;

in reflecting local focus, depth and strength in particular fields, thus showcasing the country's scientific activity in a concentrated way; and

- in allowing the context and potential impact of original research papers to be highlighted through professional editorial enrichment of the content in terms inter alia of peer analysis, background review, and evidence-focussed correspondence.

1.6 The second point of departure was that local journals should be of high quality, and should therefore meet a number of important specifications, in that they should

- be competently edited by an editor(s) of high academic standing, supported by an effective editorial board, with proper peer review (by more than one peer expert in the case of each submitted paper);
South Africa occupies

the paradoxical position

in the arena of research

publishing of being a

dwarf internationally

and a giant on the

African continent

In summary, 16000

researchers publish

about 7000 papers

a year, or on average

about 0.4 papers per

researcher per year

The first point of

departure of the

Journals Project has

been that science

publishing should

take place inside

South Africa on a

significant scale

The second point of

departure was that

local journals should

be of high quality 
No analysis of research publishing can avoid underlining the critical role of editing and peer review in the maintenance of the global system of knowledge production, accumulation and use
- be published regularly and frequently; each issue should contain enough articles to further and broaden the understanding of readers more than would happen through the reading of singly reprinted/downloaded articles;

- have guaranteed financial viability through a reliable and sustainable set of revenue streams;

- showcase the South African scientific enterprise by having a wide international distribution, and achieving recognition through listing on a reputable database (such as ISI) as well as through Internet publication (both accompanying print versions, or as the sole modality).

The importance of the second point of departure was that in principle it established preconditions for the validity of the first; this cannot be over-emphasised, as all or most of the arguments for in-country research publishing become counter-arguments for NOT investing resources of time, effort and money in this area, if the journals that are published in the country are of poor quality in the sense of the criteria listed above.

1.7 A number of members of ASSAf (including some members of the then Council) agreed to serve on a Steering Committee for the Project: Professors Wieland Gevers (Convener); Tony Mbewu; Walter Claassen; Krish Bharuth-Ram; Marie Muller; and Iqbal Parker. A number of other persons with a direct interest in South African science journals were also recruited: Dr Molapo Qhobela (Department of Education (DoE), Higher Education branch); Dr Andrew Kaniki (Knowledge Management, National Research Foundation); Prof Johann Mouton (Centre for Research on Science and Technology (CREST), Stellenbosch University); Dr William Blankley (Knowledge Management Research Programme, Human Sciences Research Council, HSRC); Prof Michael Cherry (South African correspondent for "Nature", Stellenbosch University); and Mr Prem Naidoo (research quality assurance project, Council on Higher Education (CHE)/ Higher Education Quality Committee (HEQC). This created an 11-person Steering Committee, capable of launching the Project and taking care of sub-projects.

1.8 The ASSAf Council decided that the open symposium/workshop accompanying its Annual General Meeting in 2002 should be devoted to the Research Journals Project, and brought together as many participants in the national "journals system" as could be assembled. The main conclusions of this exploratory workshop were

- that the total number of (learned) journals published in South Africa relative to the number of publishing scholars was extraordinarily high;

that the commercial exploitation of journal publications in the electronic realm (without paying attention to the quality dimension) posed great risks, insofar as greatly increased access to potentially poor-quality articles through the huge, searchable Internet space may not reflect well on SA research and scholarship;

- that different authorities with an operational interest in article publication stood to gain from a successful ASSAf Project on the strategic management of SA research journals;

- that the Project needed "buy-in" from editors, publishers and researchers alike, but appropriate policy development could be a powerful driver; and

that moving from the national to the continental dimension, while feasible, should not be done in a unilateral manner from a South African base.

1.9 No analysis of research publishing can avoid under-lining the critical role of editing and peer review in the maintenance of the global system of knowledge production, accumulation and use. The essential requirement is for responsible and fair editorial oversight exercised to ensure that

an editorial policy exists and is accessible to authors;

- submitted manuscripts are examined with a view to the selection of appropriate peer reviewers;

- reviews are carefully assessed to decide whether, individually and summatively, they constitute the basis for the publication of the article in question, or whether publication should follow if certain improvements are effected and/or further work done and reported on; or whether the paper should be refused; special statistical review is sought, if needed; 
the focus of the journal is protected; misconduct is detected if at all possible; errata and retractions are properly managed and made part of the record; and

- the journal as a whole contextualises reported findings in its editorial and supplementary sections.

1.10 Peer reviewers in turn must fulfil a range of functions in the system of global knowledge accumulation. They have especially to

- scrutinise the methods and results in terms of consistency, interpretability and likely reproducibility;

- identify gaps that can or should be filled to enhance the interpretability and strength of the findings;

- suggest how the paper can be improved in terms of style, length and focus;

assess the proper citation and referencing of previous studies (as outlined above the "principles" section), including the critical issue of the originality of the work;

contest conclusions not justified by the results presented; and

- "place" the work in the existing matrix of knowledge in the relevant area or field.

\section{CHAPTER TWO: A bibliometric assessment of South African research publications included in the internationally indexed database of Thomson ISI (A. Pouris)}

2.1 Incorporation in the three citation indices of the ISI system - the Science Citation Index, the Social Sciences Citation Index and the Arts and Humanities Citation Index - is currently the most widespread and well-recognised approach to the bibliometric assessment of journals in relation to international standards. As a group, the ISI-indexed set of journals represents an elite body of internationally influential research publications, but it is not a comprehensive cataloguing of the entire world's research journals, nor of all peer- reviewed journals. The reason for this is that it is ISI's intention to index that part of the journal literature that exerts a disproportionate influence, based on Bradford's Law of Scattering, which asserts that a relatively small group of journals will account for the large majority of important and influential research in a given field.

2.2 All South African publications indexed by ISI in 106 selected research disciplines were analysed with a view to identifying the absolute numbers of articles published in each discipline, and trends over four 5-year periods stretching from 1981 to 2004. Three disciplines produced more than 1000 publications in the period 2000-2004: plant sciences (2182 publications), animal sciences (2108 publications) and environment ecology (1187 publications). The fastest-growing disciplines were clinical immunology and infectious diseases (+ 967\%), and the public health and health care sciences (+ 891\%, starting, however, from a relative small basis of 23 publications during 1981-85). The contrasting substantial decline in the number of publications in "general and internal medicine" from 2337 publications during 1981-1985, to 566 publications during 20002004 was striking.

2.3 Citation rates for different disciplines are known to vary, inter alia as a function of the total numbers of articles published and the typical length of bibiliographies. The average citation rates of world publications was determined in each of the same 106 disciplines, varying from 0.10 (art and architecture) to 14.66 (cell and developmental biology). The impact of South African articles relative to world output per scientific discipline (defined as the citation impact for the country's discipline divided by the citation impact of the world for the particular discipline) was also determined for each discipline and for a number of aggregated groups of disciplines within this set: in 22 disciplines, South African articles had a relative impact equal to, or higher than the world impact. Oncology had the highest relative impact (2.17) during the most recent five years, followed by anthropology and classical studies, with relative impacts 1.99 and 1.80 , respectively.

2.4 New information has been provided about the detailed citation records, per discipline, of all international journals which are included in the Science Citation Index and the Social Sciences Citation Index; in each case, this includes the number of total cites, the median and aggregate impact factors, the aggregate immediacy index, the aggregate cited half-life, the number of journals in the category, and the number of articles published.
As a group, the ISI-indexed set of journals represents an elite body of internationally influential research publications, but it is not a comprehensive cataloguing of the entire world's research journals, nor of all peerreviewed journals 
In summary, the bibliometric analysis of South African publications in the ISI system points to a clear need for support of selected local journals to improve and entrench their position in the ISI system
For example, in both indexes, the subject of andrology was represented by the smallest number of journals (5) while the subject of biochemistry and molecular biology was covered by 261 journals (the largest group), with analogous large differences in the total numbers of articles published and consequential differences in the bibliometric indicators (the aggregate impact factors in the Science Citation Index varying over 66-fold, from 0.135 in the case of marine engineering to 8.989 for multi-disciplinary sciences, and those in the Social Sciences Citation Index varying only over 6.6-fold, from 0.394 for area studies to 2.601 for psychiatry.)

2.5 The South African research journals indexed in ISI had aggregate impact factors for the period 2000-2004 varying from 0.113 for a total of 66 articles (South African Journal of Minerals and Metallurgy) to 1.111 for 30 articles (South African Journal of Geology). Only 4 journals exceeded the median Impact Factor for all world journals in their disciplinary group - the South African Journal of Geology, the South African Journal of Science, Social Dynamics and the South African Medical Journal.

2.6 In terms of the number of journals indexed as emanating from individual countries, South Africa with 20 journals shared position 26 with Sweden, way behind the USA with 2288 indexed journals; Egypt and Kenya from the African continent had 1 journal each. The intrusion of multi-national publishing houses into regional research publishing has made the figures for some countries artificially high (e.g. the Netherlands).

2.7 In summary, the bibliometric analysis of South African publications in the ISI system points to a clear need for support of selected local journals to improve and entrench their position in the ISI system, and the existence of possible opportunities for locally published journals in a number of new areas which must, however, be carefully contextualized in terms of their potential appeal to international authors as well as to South African scholars willing to transfer their papers to high-quality local journals.

\section{CHAPTER THREE: A comprehensive analysis of South African research journals (J. Mouton, N. Boshoff and R. Tijssen)}

3.1 There are currently 255 South African scientific or scholarly journals recognized by the Department of Education (DoE) as meeting the minimum requirements for state subsidy under the policy of supply-side support for authors (and their institutions) who publish in these journals. Of these journals, 23 appear in one of the ISI Citation Indexes, 14 are indexed in the International Bibliography of the Social Sciences (2 journals appear in both), while the remaining 220 journals are "accredited" separately by the Department (2003 list) on the basis of having the main purpose of disseminating research results and content that supported high-level learning, teaching and research in the subject areas concerned; having an ISSN; being published regularly; having an editorial board of high standing and expertise in the field; using peer review; and wide distribution.

3.2 SA Knowledgebase is a dynamic database of public science in South Africa, developed by the Centre for Research on Science and Technology (CREST) at the University of Stellenbosch. It collects bibliographic information (excluding citations) on articles, with any South African author addresses, which have appeared in journals accredited by the South African Department of Education (including those included in the ISI and IBSS indexes); it also captures information on every article title, full authorship, journal name, publishing details, and keywords, and other websites. At present, almost 100000 articles are included in SA Knowledgebase, which not only covers articles produced by the South African higher education sector, but also those produced by the science councils, national research facilities and government research organizations located in South Africa. The database also provides author-specific information by disaggregating the article output by selected demographic variables (gender, race, year of birth, highest qualification, areas of specialisation and institutional affiliation).

3.3 Novel journal citation analyses were conducted for this Report with CWTS's bibliometric version of Thomson Scientific's Citation Index-database (CI-database). The current version of the CWTS/CI-database is an integrated information system comprising the CD/ROM-editions of the ISI's Science Citation Index, Social Sciences Citation Index, Arts and Humanities Citation Index, and six Specialty Citation Indices; it covers the years 


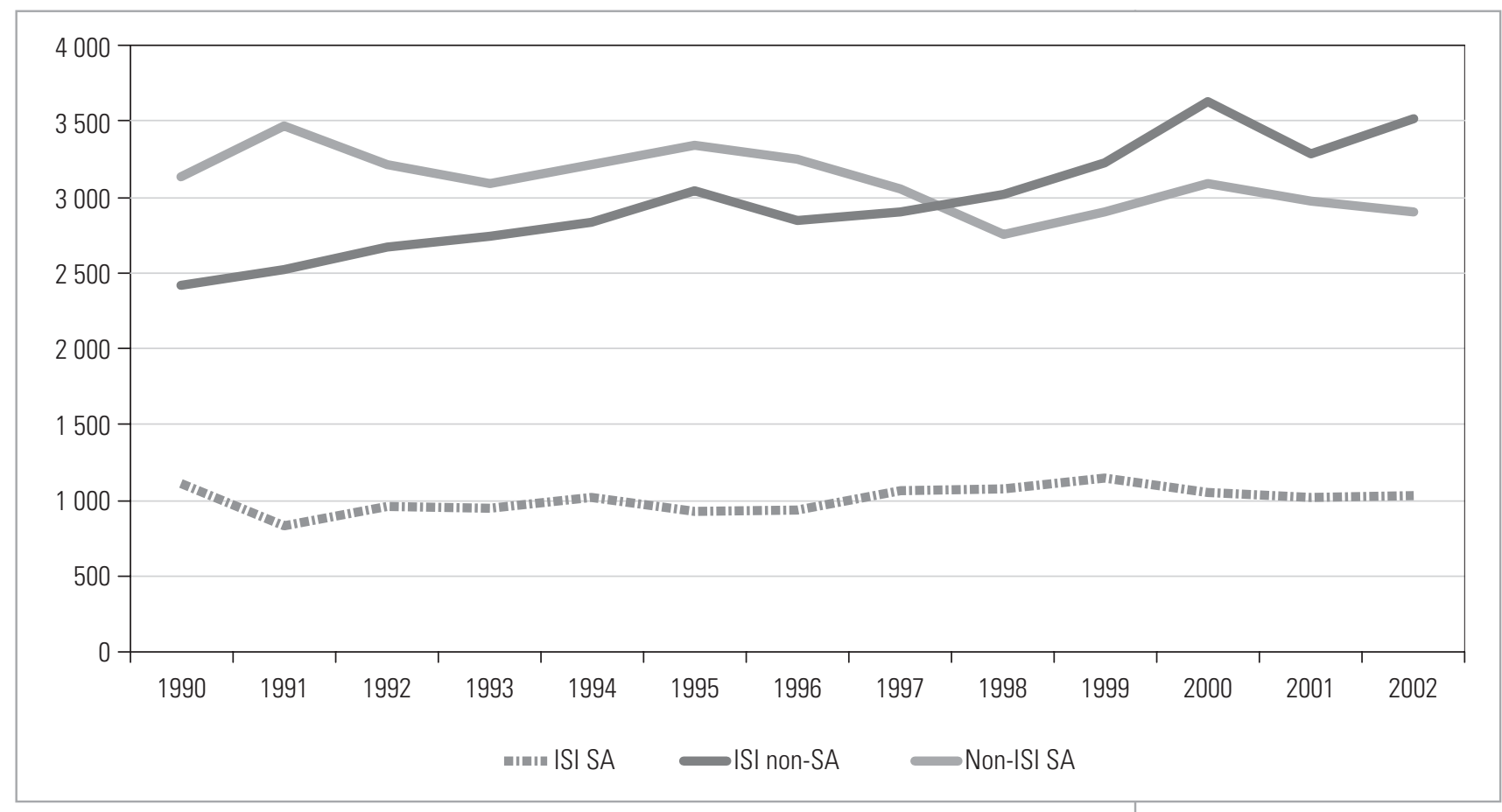

1980-2004/5 and consists of some 10,000 peer-reviewed journals, including conference proceedings published in journals. This database enables one to find out if, how heavily, and by whom, research publications in SA journals (both ISI-indexed, non-indexed, or partially indexed journals) are cited in the international scientific literature, permitting quantitative measures to characterize and compare SA journals according to their international scientific impact. Most importantly, it has made possible, for the first time, a comparison of ISI-indexed SA journals and non-indexed journals in terms of citation impact within the ISI system.

3.4 Of all the South African-authored articles in the SAK database, 56176 (or 57\%) appeared in ISI journals and the remaining 43\% in non-ISI journals. Distributed differently, 55157 (or 57\%) appeared in local journals and $43 \%$ in foreign journals. Three quite different trends for each of the "index type" journals was observed over the 13-year period: the number of articles in South African ISI-journals remained stable (red line), while the number of South African authored articles in South African journals not indexed in ISI declined steadily (green line) as the number of articles in ISI-journals increased. The numbers of articles in foreign and local journals nearly converged by 2002; great strides have been made in breaking out of the isolation mould or 1990 when only $36 \%$ of articles were in foreign journals.

A wide range of publication patterns was found between and even within a scientific field, as shown by a breakdown of all articles for the period by main field:

In the engineering sciences, the majority (58\%) of articles during this period appeared in foreign ISIjournals; if the additional 604 articles that appeared in South African ISI-journals were added, an overall total of $67 \%$ or two-thirds appeared in ISI-indexed journals. The profile for publications in the natural sciences was not dissimilar, the vast majority (21664 or $61 \%$ ) of all articles appearing in foreign ISI-indexed journals; if articles appearing in South African ISIjournals (8523) were added, an overall total of $85 \%$ of articles appeared in ISI-journals. A very similar profile emerged in the medical and health sciences (Figure 8) where 12749 articles or 64\% appeared in foreign

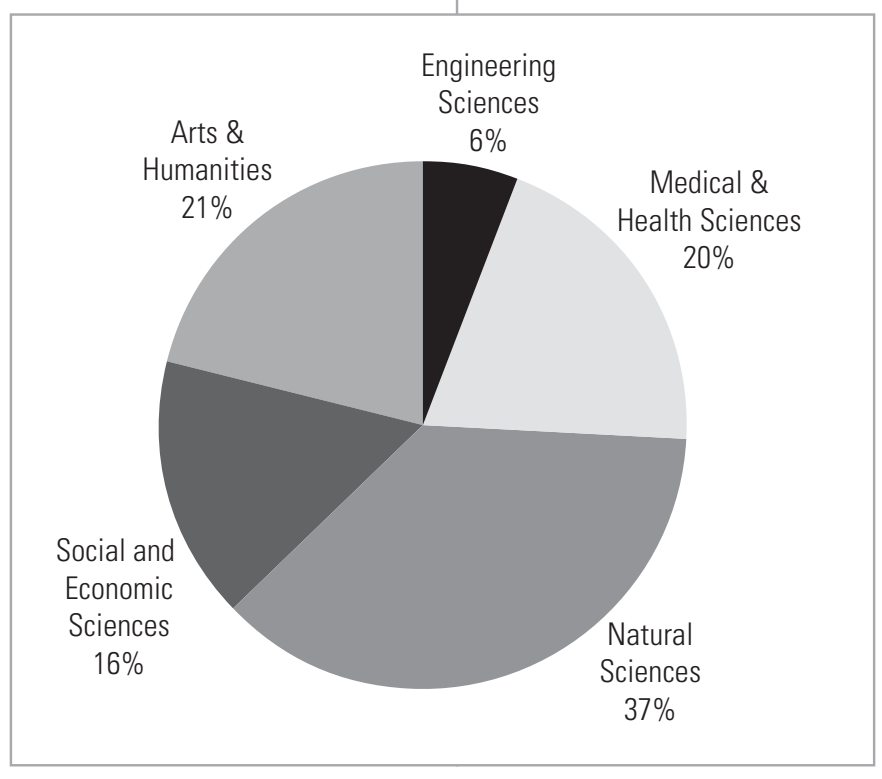

Figure 3: Journal articles by Index type by year (1990-2002)

Figure 5: SA articles by main scientific field (1990-2003) 
There was a clear correlation between the "size" of an institution's research activity, measured in terms of total article equivalents, and the number of journals in which staff at that university published their papers or overseas journals, articles in SA ISI-journals adding another 3112 to bring the total proportion of articles in ISI-journals to nearly $80 \%$. Not surprisingly, the profiles for the human sciences were quite different; in the social and economic sciences, the vast majority of articles (11826 or $77 \%$ ) appeared in local, non-ISI journals, while in the arts and humanities, an even higher proportion (90\% or 18642) articles were published in local, non-ISI journals during this period.

3.5 The spread of journals was assessed where scholars in a particular field published their papers; as a measure of "spread" the number of journals was counted in which 50\% of the articles over this period appeared. A total of 15339 articles appeared in 734 journals that were classified as "social and economic sciences"; $50 \%$ of these articles appeared in 21 journals only, all of them local and only 2 ISI-indexed. A total of 20383 articles appeared in 611 journals that were classified as "arts and humanities" over the period 1990 - 2003; 50\% of these articles appeared in 25 journals only, implying a high degree of concentration, especially in law. A contrasting picture was afforded by the more laboratory-oriented disciplines. A total of 135499 articles appeared in 2357 journals that were classified as "natural sciences"; $50 \%$ appeared in 90 journals only, of which local ISIjournals represented 17 of the top 34 on the ranked list. A total of 19983 articles appeared in 1677 journals that were classified as "medical and health sciences"; 50\% of these articles appeared in 63 journals only, as much as a quarter appearing in only 6 journals. A total of 6352 articles appeared in 576 journals that were classified as "engineering sciences"; $50 \%$ of these articles appeared in 16 journals only, half of them South African.

3.6 The question was examined as to whether systematic trends (even biases) in publication patterns existed across institutions as far as journals used for publication of peer-reviewed articles was concerned. Nine universities were selected with the highest research output over the past 13 years. There was a clear correlation between the "size" of an institution's research activity, measured in terms of total article equivalents, and the number of journals in which staff at that university published their papers; for example, staff at the Universities of Cape Town, the Witwatersrand and Stellenbosch each published their articles in more than 2000 journals over the study period. Two other indicators measured the degree of "internationalisation" of academic output at each university, either as the proportion of total article output that appeared in South African journals or the number of foreign journals that appeared in the list of the 50 most-used journals by that institution. The historically English-speaking, research-active universities ranked highest on both counts.

3.7 Another question examined referred to institutional authorship patterns of publication in South African journals which had published 300 or more articles over the past 13 years. Some disturbing trends were evident, in that a single institution contributed $30 \%$ or more of the article content to 21 of these journals; in 11 of these cases, the journal concerned was published by the same institution/unit that produced the majority of articles. More reassuring was the fact that 5 local journals had percentages of foreign authors in the range of $6-11 \%$.

3.8 It is now generally known that there is a significant ageing cohort of actively publishing scientists in the South African science system. The analysis of authorship by age against Journal Index Category revealed that the age profile of authors in South African ISIjournals (predominantly natural sciences) shifted from $22.4 \%$ of authors above the age of 50 in 1990 to $47.4 \%$ in 2002. For the foreign ISI-journals, South African-authored articles showed a similar but lesser shift: from 23.8\% of authors over the age of 50 in 1990 to $41.6 \%$ of authors over the age of 50 in 2002. For local, non-ISI journals (predominantly social sciences and humanities), a similar shift occurred from $18.8 \%$ of authors over 50 in 1990, to $45.4 \%$ of authors over 50 in 2002. Gender authorship trends between the two ISI categories (South African ISI and Foreign ISI) showed a substantive increase in female authorship from around $13 \%$ to $24 \%$ and $13 \%$ to $23 \%$, respectively. The increase in female-authored articles in local South African journals was more substantive, however, with an increase from 19\% in 1990 to $20 \%$ in 2002.

3.9 Citations used in research publications in peer-reviewed international scholarly journals, of research articles produced by South African scientists and scholars enables one to gauge the 
impact of SA research publication within the international scientific community, defined for this purpose as those scientists and scholars who publish papers in ISI-listed and indexed, peer-reviewed, research journals. This approach can also be used to assess the impact and international visibility of South African journals whose articles were cited in journals indexed by ISI. The titles of 225 such South African journals were entered into the CWTS/CI-database to gather the citation frequencies to articles in these journals during recent years. A total of 166 South African journals had in fact received citations. The citation data for the citing years 2002-2003 and the cited years 1994-2002 clearly supported the notion that structural differences between fields of science affected citation rates. Although the 39 journals in the natural sciences showed a wide range in citation frequencies, this field accounted for no fewer than 7 out of the 8 most highly cited journals. The arts and humanities, on the other hand, accounted for 12 of the 18 less-cited journals.

3.10 In order to cope with small numbers in determining impact factors, the citation window was extended to eight years and two consecutive citing years (in this case, 2002 and 2003 were merged in order to reduce the possibility of large yearly fluctuations). The resulting Composite Extended Journal Impact Factor (denoted as 'CE-JIF 2002/2003') enabled one to obtain a more reliable measure of the citation impact of local journals than ISI's standard Impact Factor. The impact factor analysis using CE-JIF 2002/2003 was restricted to the subset of 107 local journals that received at least 1 citation during the interval 1994-2002 and where the frequency data on the annual number of publications during the same time-interval was available. Only 6 of the journals surpassed a "modified impact factor" (CE-JIF) score of 0.50, all in the natural sciences and all indexed by ISI. There were 45 journals with CE-JIF scores ranging from 0.25 to 0.50 , including 5 nonISI journals from fields other than the natural sciences which attracted relatively high quantities of citations in the ISI-indexed journal literature: "Concrete", "African Journal of Range and Forage Science", "South African Journal for Enology and Viticulture", "Social Dynamics" and the "South African Journal of Psychology". Conversely, a few ISI-indexed local journals were cited at a rather low level, given their elevated status. The Composite Extended Journal Impact Factor may be useful to developing countries other than South Africa which have relatively large research journal systems but limited penetration of the "Bradford barrier" to international databases such as the ISI.

3.11 This bibliometric analysis presents a general picture of South African journals as being differentiated into several categories: there is a small cluster of South African journals (both ISI and non-ISI, mostly in the natural and health sciences but also in some of the social science and humanities) that have "acceptable" impact factors, record moderate to high citations from non-South African authors and generally present an "international" profile. At the other extreme, there is a substantive cluster (perhaps affecting as many as half of all South African journals) that does not have any international visibility in that articles in these journals are not cited outside South Africa, and the production of content is dominated by one or two institutions and in some cases by the same institution (or department) that publishes the journal.

\section{CHAPTER 4: A survey of editors' opinions and related information (X.Mati)}

4.1 As a significant process of targeted consultation with a constituency that has a large stake in the future of research publishing in South Africa, a questionnaire was sent to the editors of all journals accredited by the Department of Education, DoE. The intention was to obtain relevant opinions and related information from this sector, focusing on draft criteria for the accreditation of South African research journals drawn up by the Steering Committee for this Project. Of the 213 journals captured in the database, five journals were listed in the International Bibliography of the Social Sciences (IBSS), and 15 in the Thomson Scientific (Thomson ISI) databases, while the other 193 South African journals were accredited only by the DoE.

4.2 All but 2 of the journals had a functioning editorial board, mostly comprising under 20 members and turning over every $2-5$ years; the great majority of the editors rated the performance of both the chairpersons and the boards themselves as being excellent or good.
There is a substantive cluster (perhaps affecting as many as half of all South African journals) that does not have any international visibility in that articles in these journals are not cited outside South Africa 
The overall acceptance rate for submitted articles was over $70 \%$, although in more than half of these cases, minor or major revisions were first required. Peer review of an entire journal was not practised in a single instance

Journals sourced their income from a mix of revenue streams and the great majority had considerable difficulty in making ends meet
4.3 In almost all cases, independent peer review was used to assess the acceptability for publication of submitted articles; two or three peer reviewers were used per article. In most cases, peer reports were from two to three pages, which in the circumstances of skilled, voluntary work of this kind suggested that considerable care was usually taken in carrying out the review and reporting on it. A core panel of peer reviewers was maintained by 141 of the 213 editors, of whom 171 believed they used a "blind" peer-review system, mostly referring to anonymous referees. 70 journals regularly published a full list of contributing peer reviewers, which may be one of the ways in which this essential and highly skilled service can be better recognised. The overall acceptance rate for submitted articles was over $70 \%$, although in more than half of these cases, minor or major revisions were first required. Peer review of an entire journal was not practised in a single instance.

4.4 Most journals were published bi-annually and this was closely followed by those appearing annually or quarterly. The survey was unable to distinguish whether infrequent publication was caused by financial stringencies or cost considerations in general, or by lack of sufficient articles of sufficient quality or of editorial time, or combinations of these and other factors. ISI-indexed journals did considerably better in this respect than did most of the DoE-listed journals; the ISI criteria for listing journals include frequency, regularity and on-time publication (which amongst other things implies a healthy backlog of good articles) as amongst the most important considerations. The average number of peer-reviewed, original articles per issue was between 5 and 12 in most cases, half of all journals containing 9 articles or less.

4.5 A majority of journals (about 55-60\%) catered generally for the Social Sciences, Social Studies, Law and Education; many represented specialised sub-fields, but editors were generally cool about the benefits of possible consolidation of titles to increase the flow of good manuscripts and the frequency of publication.

4.6 Journals sourced their income from a mix of revenue streams, with the largest contributions coming from subscriptions, subsidy (from various sources) and page charges, followed by advertisements, donations and sale of electronic copies; the great majority had considerable difficulty in making ends meet.

4.7 An average of between 75 and $80 \%$ of journal content (but with wide variations) was said to be devoted to peer-reviewed scientific articles, indicative of a clear focus on the dissemination of original scholarly work.

4.8 The print runs of $75 \%$ of South African journals were below 1000 copies, and institutional subscriptions numbered below 200 in the large majority; generally, South African institutions had ready access to most of the journals in the set.

4.9 The editors took considerable trouble in completing the questionnaires, with a return rate of $100 \%$. They appear as a group to devote much time and effort to their task, few being professionally trained or provided with significant office/logistic support.

\section{CHAPTER 5: Global e-Research trends and their implications for South African research publishing in print or online (R. Page-Shipp and M. Hammes)}

5.1 The advent of affordable global connectivity via the World Wide Web could in principle virtually recreate the original mode where communication between groups of scholars in small but intellectually lively regions was inter-personal and near-immediate (1650 to about $1900 \mathrm{AD}$ ). The current century-old, branded, print journal-dominated mode has been a response to specific conditions that existed prior to the Internet's recent emergence. Innovative alternatives are now emerging of which "Open Access" on the Internet is perhaps the most important one, with restoration of the inter-personal and immediate mode of collegial communication and collaboration, this time on a global scale. Broad-band connectivity, high-performance computing, digital data capture and data mining have created opportunities for hitherto unimaginable global collaborative research projects, often with an interdisciplinary, multi-disciplinary or trans-disciplinary nature. Researchers in all disciplines are increasingly able to undertake a variety of research-associated tasks online, including access to each other's data, models, graphical objects, knowledge tools and applications and computing capacity. 
5.2 Some of the problems in developing a new publishing paradigm arise from the fact that the different functions of formal scholarly communication are not responding evenly to the potential for renewal offered by the Internet. These functions are: Registration, which allows claims of precedence for a scholarly finding; Certification, which establishes the validity of a registered scholarly claim; Awareness, which allows actors in the scholarly system to remain aware of new claims and findings, and also signals their availability for collaborative projects; Archiving, which preserves the scholarly record over time; and Rewarding, so that researchers benefit from their performance in the science communication system. The first four of these functions are at present still performed in a more or less linear fashion by the publishers of research journals in spite of the fact that registration could in principle be better served by early sharing and debating of results with colleagues which would lead to a shorter research cycle and entail certification in the form of peer review by broad segments of the scientific communities who "own" the research. Growing dissatisfaction with the current system's slowness, the crisis that has developed around the affordability of journals with consequent exclusion of many researchers through diminished access to the best information, geographic bias in peer review, and lack of flexibility could be overcome if the core functions are unbundled and performed by more role players in novel ways.

All these developments have highlighted problematic aspects of current scholarly discourse and publishing that must be reviewed and reformed if researchers are to continue to benefit from the core functions of the published literature in the eResearch era. Peer review combined with expert editorial discretion is fundamental to the mechanism of the entire knowledge production and growth enterprise; the Internet simply raises the issue as to whether the coming cyber-enriched system of research publishing can provide improvements and refinements that make peer review and editorial discretion more effective and less open to criticisms such as those cited above.

5.3 Twenty-first century researchers will likely expect to find their journals online; there is increasing agreement that online journals could in principle be superior to print versions in terms of international reach, speed of publication, additional capabilities, reduced costs, convenience, searchability, linking and archiving. Major publishers already regard the online versions of their journals as the principal copies and print copies as a necessary inconvenience to be endured for another few years. They have made huge infrastructure investments and are in the process of digitizing all their back copies. Online publishing is not simpler than print, and new skills are needed to perform it well enough to create the environments that users are coming to expect.

5.4 Two major cost issues are raised by the Internet revolution in research publishing, the costs of getting an article published, and the costs of access to published work (licences/ subscriptions/ infrastructure). Publishing costs in the online environment may have been reduced by the greatly improved logistics of electronic peer review and the overall editing function, plus associated savings on printing, packaging and distribution. The cost of (ongoing) investment in information technology infrastructure at the user end, however, and the absence of established business models at the publishing end, as well as the need for long-term preservation of the digital copies, create new problems. For example, the model of restrictive licensing implies multiple payments in that universities and research institutions pay for subscriptions, and additionally for copyright and other permissions to use the articles they need; indeed, they could pay for access to the articles published by their own researchers. The so-called "Big Deal" subscriptions preserve the revenue streams of major multinational publishers but tend to take over the bulk of library budgets, leaving little money for other journals and for books, feeding into an unhealthy cycle where important publishers are pushed to the sidelines, often becoming the victims of unnecessary takeovers. A healthy and widespread debate over these issues has brought new stakeholders to the table: university administrators, research funders, governments, and international bodies, who have begun to throw their weight behind the Open Access movement. The position taken by the Wellcome Trust is typical: "to fund research and give no thought to its dissemination is a job left unfinished; that is why the organisations which fund research have a vested interest in ensuring that the most

\section{All these}

developments

have highlighted

problematic aspects

of current scholarly

discourse and

publishing that must

be reviewed and

reformed if researchers

are to continue to

benefit from the

core functions of the

published literature in

the eResearch era.

Peer review combined

with expert editorial

discretion is

fundamental to the

mechanism of the

entire knowledge

production and growth

enterprise; the Internet

simply raises the issue

as to whether the

coming cyber-enriched

system of research

publishing can provide

improvements and

refinements that

make peer review and

editorial discretion

more effective and less

open to criticisms such

as those cited above 
Open Access is based on the philosophy that the research literature, which is not written for profit but for the advancement of science and which is largely funded by public money, is

a public good and should be accessible

to everyone who has a need for the information efficient and effective method is used to disseminate that research and should contribute funding to that dissemination."

5.5 The term Open Access encompasses a specific online publication business model as well as a range of channels for making research literature available to everybody at no cost. It is based on the philosophy that the research literature, which is not written for profit but for the advancement of science and which is largely funded by public money, is a public good and should be accessible to everyone who has a need for the information. Strictly speaking, only open access journals qualify as "publishing"; archiving on homepages and in repositories is a form of dissemination or secondary publishing.

What Open Access is: The Open Access research literature is composed of free, online copies of peer-reviewed journal articles and conference papers as well as technical reports, theses and working papers; in most cases there are no licensing restrictions on their use by readers and they can therefore be used freely for research, teaching and other purposes.

What Open Access is not: It is not self-publishing, nor a way to bypass peer-review and publication, nor a kind of second-class, cut-price publishing route. It is simply a means to make research results freely available online to the whole research community.

How is Open Access provided? A researcher can place a copy of each article in an Open Access archive or repository (known as the green route), or can publish articles in Open Access journals (known as the gold route). In addition, a researcher may place a copy of each article on a personal or institutional website.

Open Access archives or repositories are digital collections of research articles that have been placed there by their authors. In the case of journal articles this may be done either before (preprints) or after publication (postprints, depending on the terms of the publisher); this is known as 'self-archiving'.

Many Open Access journals are now in existence, with numbers growing daily; on 16 Sept 2005 there were 1763 journals listed in the Directory of Open Access Journals (http:// www.doaj.org/), of which 439 were searchable at article level. Many use the "author pays" principle, which essentially means that the entire "universe of users" acquire access at a minimal cost in the system.

5.6 The practice of self-archiving on personal or departmental/institutional websites has been widespread since the start of the WWW. The pioneering, subject-specific repository was the physics archive, arXiv, which started in 1999; this was created as a response to researchers' need to share information at an early stage of their investigations. All Open Access respositories may be configured to be globally interoperable through the use of the OAI Protocol for Metadata Harvesting (PMH), internationally defined by the Open Archive Initiative. Open Access repositories are listed on web sites such as Registry of Institutional Open Access Repositories, and OpenDOAR. All are searchable by specialist search engines such as AOIster, as well as the general Internet search engines. The majority (over 90\%) of publishers allow self-archiving with various restrictions, including strict control of the time of publication in relation to their process.

5.7 The value of Open Access lies in the fact that through maximising research access it maximises visibility, usage, uptake, impact and hence research progress; these have been defined as Early advantage, Usage advantage and Selectivity Advantage. Early advantage mostly applies to preprints and refers to the head start of articles which are accessible before being published. Usage advantage refers to increased downloads and citations, by anywhere between 25\%-300\%; if all research articles were in Open Access mode, researchers all over the world would have the Selectivity advantage to use and cite the best and most relevant work. Realization of this utopian aspiration is unlikely in the short term, but significant benefits would be forthcoming if a determined attempt is made to implement as many of the necessary enabling reforms as soon as possible.

5.8 Besides these compelling advantages for authors, and the advancement of science in general, Open Access may also have the following benefits: 
- Visibility and promotion of the research output of institutions;

more complete records of scholarship;

access for the wider public including teachers, students, tax-payers;

alleviation of the serious access problems of the developing world;

- creation of flexible and free re-use options for articles (Open Access articles may be read, downloaded, copied, distributed, printed, searched, linked to, and translated, as long as authorship is acknowledged and they are not used for profit making);

- international access to research generated in developing countries which is currently invisible to the developed world and which is important for research on global problems;

alleviation of the budgetary problems of libraries all over the world, especially in the developing world;

- contribution to the digital preservation of scholarship;

a shift to competition for authors rather than for subscribers;

- facilitation of peer review and other forms of quality control by giving reviewers, supervisors and examiners easy access to all the papers referred to in a new manuscript; and

- early reporting of failed research avenues or blind alleys.

5.9 The uptake of Open Access in the broad science system has been unexpectedly slow. This has been ascribed to the untested business model, uncertainties about its recognition in reward models, and under-developed marketing and sub-critical mass. In the case of institutional repositories, the problems appear to lie with indexing services and standards and copyright issues; mandated publication has significantly increased compliance and is the obvious driving factor behind a system that needs to be widespread to yield full benefits. To be able to interpret publishers' policies correctly, authors need to take note of the fact that copyright to a pre-refereeing preprint belongs to the author, who may selfarchive it if the publisher permits. Once the article has been peer-reviewed, copy-edited and accepted for publication (the so-called post print), however, it may be self-archived only with the permission of the publisher if the author has assigned exclusive copyright to the latter.

5.10 South African researchers are particularly disadvantaged, in global communication terms, by the high cost of Internet bandwidth and in many cases by poor institutional infrastructure. This has promoted adherence to the local print publication medium whereas our developed country counterparts are moving steadily towards online publication. Significant movement to online publication has been made, however, although not in a form that really provides the benefits of Open Access. An important player on the local scene is Sabinet Online, which launched a platform, SA ePublications on which to date 192 journals (15 on the ISI databases, and 84 of them DoE-listed) have been incorporated. Sabinet Online seeks to add value by aggregating the titles from many different publishers under one interface and search system, while simultaneously increasing market awareness of the publications, both locally and abroad, and growing their revenue streams; no role in peer review and content definition is played by the host organization. From 2002 - 2003 there was a doubling in downloads from the Sabinet Online e-journals, which is a good indication of use although it is also influenced by increased content. In financial terms, most publishers have gained from going the eroute; journal subscriptions have increased, and in 2005 Sabinet Online paid out a total of R1 million in royalties to the publishers, many of whom had never been able to make any margin before. Another prominent and competitive player is NISC-SA in Grahamstown; in addition to being the full-service, online publisher of ten South African journals, NISC-SA also hosts African Journals online (AJOL), a high-potential catalogue and current awareness service to increase the visibility of African journals (195 journals offering over 13000 articles) amongst the global research community. The success rate for archiving articles in institutional repositories has so far been extremely low, and no local university yet has an institutional repository for archiving locally produced journal articles either as pre- or post-prints. Harvesting of South African OA repositories has also not received concerted attention, so far. A few South African
The uptake of Open

Access in the broad

science system has

been unexpectedly

slow. This has been

ascribed to the

untested business

model, uncertainties

about its recognition

in reward models, and under-developed marketing and subcritical mass

\section{South African}

researchers

are particularly

disadvantaged, in

global communication

terms, by the high cost of Internet bandwidth

and in many cases

by poor institutional

infrastructure 
Strategic management of national publication policy should be aimed at the future, not at the present or the past

The test of continuing relevance of core best practice in a changing world publishing system has been confirmed, despite the urgent need for that core to undergo a safe passage into an evolved and adapted model in the modern cyber-world repositories are listed in the Registry of Institutional Open Access Repositories and are harvested by OAIster.

5.11 The academic research system in SA is currently strongly driven by the Department of Education's (supply-side) subsidy system which pays institutions a subsidy per publication in one of the peer-reviewed Journals listed in the two accredited international databases (ISI and IBSS) and in the DoE list of accredited journals. Open Access publishing will need to attract benefits if researchers are to be induced to use this mode; incentives for self-archiving and harvesting should be considered; for example, it could be a precondition for subsidy and for NRF and other agency grant-funding. Support will also need to be given to the creation and maintenance of the necessary repositories and networked infrastructure.

5.12 In summary, this is a rapidly changing scene and strategic management of national publication policy should be aimed at the future, not at the present or the past. The application of national and institutional resources (people, energy, money) should be aligned as far as possible with the agreed strategic objectives. Nationally coordinated efforts are required to provide infrastructural services cost-effectively (e.g. digital curation; shared negotiation for access rights (institutional and national subscriptions); aggregation of 'atomised' journals and of their editorial, subscription and production needs; aligned standards and possibly locations for digital repositories; and national harvesting of Open Access repositories). Encouragement and incentives are required for South African authors to publish in recognized Open Access journals by way of increased awareness and the provision in grants of cover for author fees. There needs, however, to be recognition of the fact that Open Access and other online initiatives merely make innovative and systemimproving alternatives possible: for researchers to be willing to participate, a thoughtful and enlightened set of 'carrot and stick' incentives will be needed. Finally, there needs to be a strategic decision on the best balance between visibility in global terms and local relevance and capacity building.

\section{CHAPTER 6: Conclusions and recommendations for a strategically enhanced role of research publishing in South Africa (W. Gevers, X. Mati, J. Mouton, R. Page-Shipp, M. Hammes and A. Pouris).}

6.1 This Report (Chapter 1 ) begins with a description and analysis of the present state of research publishing in South Africa, and presents a number of generic assertions on different but inter-related aspects of the subject, most of which can justifiably be said to have stood the test of empirical investigation described in the following chapters by their respective independent but collaborating authors. Most importantly, the test of continuing relevance of core best practice in a changing world publishing system has been confirmed, despite the urgent need for that core to undergo a safe passage into an evolved and adapted model in the modern cyber-world. The challenge of updating conclusions and strategic recommendations in the light of the outcomes of the investigations reported in Chapters 2-5 is now taken up in a serial consideration of the assumed individual perspectives of important stakeholders in the field, building up from this a defining set of aggregate strategic recommendations that can most benefit the whole South African system of innovation, and our society and polity in general.

6.2 The research-producing sector at higher education and other institutions is one which sees research journals as "core business" and has a tremendous stake in what is often called the "literature". This is true across a wide spectrum of different disciplines and their characteristic approaches to enquiry. What they all have in common is

- a need to publish their work in journals that are respected for high standards of editorial discretion, peer review and accurate presentation;

- to reach the largest possible readership (preferably everybody who matters to the authoring scholar), in order to achieve the five core functions of registration, certification, making aware (inviting collaboration), archiving and reward- seeking; and

to stimulate and hone the scientific effort by requiring the periodic publication of completed parts of work in a format that requires extreme rigour, reproducibility of results, appropriate reference to the work published previously by others, robust 
interaction with critically constructive reviewers and editors, and a tight relationship between the evidence presented and the conclusions drawn from them.

In this sense, research journals are the life-blood of living and evolving science, whether they are print and/or online, and wherever they are published. Good textbooks and reviews cannot be written in the absence of the published evidence and insight traceable in the "literature". Publications are the "open domain" of continued scientific progress through verification by others, (occasional but necessary) retractions and errata, citations and cross-references, and the building up of "bigger and more accurate pictures", always subject to the test of "consistency with hypothesis".

6.3 International journals (i.e. those that are listed and indexed in important databases used internationally, and/or those which are distinctly international in terms of article authorships and circulation to subscribers and libraries) present attractive targets for South African researchers who seek the publication functionalities described above. Most attractive, of course, are the journals with high impact factors, nearly all published in the USA and in Europe, which enjoy the highest degree of visibility and the most emphatic attainment of core functionalities. In these circumstances, the issue of developing countries being or becoming significant publishers of (local but internationally accessible) research journals requires attention, as South Africa is aspiring to be precisely such a "bigger producer". Clearly, South African journals can satisfy many of the needs of local (as well as international) researchers if they meet the listing and indexing criteria of international databases such as those of Thomson ISI, but gate-keeping biased against developing countries could prevent many South African journals not currently listed/ indexed from becoming "international journals" defined in this way. Good local journals that do achieve admission are able to provide "double value" to local scientists/scholars in combining the virtues of international indexing with those of playing a significant local role. The importance of "visibility" of publications cannot be exaggerated; in a haystack of hundreds of thousands of items, the proverbial "needle" must be found by as many as possible of the people to whom the author(s) is speaking, wittingly or unwittingly, locally or internationally. Such visibility is maximised by use of indexed journals, by publication in high-profile/impact/circulation journals or in widely read, focused, mono-disciplinary, usually large-size journals; and/or by e-publication in Open Access mode, in journals or repositories that are amenable to intelligent search and harvesting by a wide variety of users.

6.4 What the research community strategically requires of the national publishers of research journals is that they should aspire to the same quality as their international comparators, through editorial best-practice and the use of a mix of both international and local reviewers, tested and tried by the editor(s) for full compliance with best-practice peerreviewing. Local journals, besides their print versions, should provide electronic access (preferably in Open Access mode) to ensure the widest distribution of potential readers, and should provide the enrichment features that give them their special local value, namely

wide participation of the foremost South African scholars in publishing, editing and peer reviewing;

- effective networking of local scholars and research trainees;

- presenting local research to others in a high-impact way;

- accessibly reflecting local focus, depth and strength in particular fields;

professional enrichment and expert contextualisation of content;

- fostering of disciplinary coherence; and

maintaining and sustaining demonstrably high quality.

Local journals should further seek indexing in international databases in order to enhance their impact, make themselves amenable to judicious bibliometric analysis, and enable our researchers to be internationally recognised, funded and generally connected. Local journals should also accept that peer review of their overall functionality and quality will be a natural component of the national system, ensuring that articles in local journals can be considered for most policy purposes to be, in effect and in context, broadly and reliably equivalent to those appearing in international journals. They would also represent
Research journals are the life-blood of living and evolving science, whether they are print and/or online, and wherever they are published

\section{Good local journals} that do achieve admission are able to provide "double value" to local scientists/scholars in combining the virtues of international indexing with those of playing a significant local role

\section{What the research} community

strategically requires

of the national

publishers of research journals is that they should aspire to the same quality as their international comparators, through editorial best-practice 
The accreditation step in respect of every single research publication, over which the DoE has complete control, feeds decisively into the policy frameworks of other organisations such as the CHE/ HEQC, the NRF, the Department of Science and Technology, NACl and the scientometric compilers of annual S\&T indicators and the higher education institutions and science councils, not to mention the journals themselves

It is obvious that the important stakeholders in the system need jointly to contribute to the design of a robust, accountable and effective accreditation system for national research journals that satisfies their individual but mostly converging requirements to the greatest degree possible; it is also obvious that the present system does not fulfil its basic function in this way a critical part of the national effort to train young scientists and enhance the quality and scope of research activity and innovation generally, distributed across South Africa.

6.5 The issue of the accreditation system of the Department of Education will need to be addressed in the system. The accreditation step in respect of every single research publication, over which the DoE has complete control, feeds decisively into the policy frameworks of other organisations such as the CHE/HEQC (in terms of its functions of quality assurance of research and postgraduate training at higher education institutions), the NRF (for general grant-making and bursaries at the same institutions), the Department of Science and Technology, NACI and the scientometric compilers of annual S\&T indicators (as one of the key the determinants of output units), and the higher education institutions and science councils (in terms of internal planning and resourcing policies and reward systems), not to mention the journals themselves. In this sense, the accreditation function is critically important for the entire national system of innovation (NSI): it has to be credible, transparent, well-administered and generally promotive of higher standards and greater utility and significance, nationally and internationally.

As in the institutional accreditation models of the CHE/HEQC, a developmental approach to the accreditation of research journals requires implementation through a combination of widely accepted best-practice guidelines and quality promotion, with periodic peer review and assessment against criteria that can meet the needs of ALL the users of the system as listed above. The issue is whether as a result of this Report, the interaction between the policy-making functions of the Department of Education and the research-based competence of the Academy should be strengthened and formalised, especially if the Academy is to be involved in the research publishing system in related, significant ways (see below for proposals for a quality assurance system for South African research journals, possibly conducted by ASSAf, and proposals for a general development programme for publishers, editors and reviewers coordinated and overseen by the Academy). It is obvious that the important stakeholders in the system need jointly to contribute to the design of a robust, accountable and effective accreditation system for national research journals that satisfies their individual but mostly converging requirements to the greatest degree possible; it is also obvious that the present system does not fulfil its basic function in this way.

6.6 Research publications are highly significant outputs of research activity, together with dissertations (a proxy for the number of newly qualified researchers), patents, technical reports and applications in society. In order to support research in a strategic way, funders have to be able to determine the likelihood that resources will be effectively and efficiently used, and that the public goods of productive research will be generated to the greatest possible extent, in the short, medium and long term. The double role played by original, peer-reviewed research publications in the research system (see 6.4), means that reliable assumptions as to their quality and value-added character are fundamental to any policy approach that seeks to foster the national system of innovation. From the perspective of government departments, (especially the DST and the Department of Education), and that of funding and support agencies (especially the NRF, MRC and other research funding bodies), an integrated approach to the assessment of publications is essential - no simple (and evidently incorrect) assumption of "international papers are good, local papers are bad" will suffice. An integrated approach taking into account all the appropriate contextual value-judgements is needed.

6.7 The points of departure for funders and supporters of research, as well as quality assurers looking at research activity in institutional settings, are that research work that is unpublished (or, worse, unpublishable) is essentially valueless, in that it

- cannot be replicated or validated by others;

- has not been subjected to the rigorous process of drafting, review and editorial discretion;

is not in the open domain of scientific knowledge; and

amounts to a null return on the funding and support investment.

Results presented at conferences and publicised only as un-reviewed abstracts are similarly of little systemic value in the knowledge matrix, apart from their value in giving young 
researchers experience in presentation and public discussion of their work. Dissertations (especially at the doctoral level) that are not published in the peer-reviewed literature are little better, despite the efforts that have been made to collect them in repositories. To this point must be added the fact that failure to publish work from a doctoral project means the project has failed in one of its most important experiential training intentions. The translational aspect of research output must be seen to be distinct from the publication aspect, i.e. the effort that must ideally go into turning most research into public benefit is not an excuse for not publishing the work in the open literature.

6.8 The successful implementation of the new South African quality assurance system for Higher Education institutions by the Council on Higher Education (CHE) and its Higher Education Quality Committee (HEQC) suggests that a smaller-scale, analogously structured quality assurance system for (clustered) research journals would also be both effective and acceptable to all stakeholders as a value-adding exercise. The consultative approach adopted in setting up principles for quality assessment and guidelines for best practice before the start of the actual audit/review programme, creates a sound basis for an organisation such as ASSAf to be entrusted with a national research journals quality assurance programme. This would be informed by principles and guidelines developed in this Report and sustained by continual observation and analysis of the realm of research publishing in the national and international domains.

6.9 Beneficiaries of research that is published in research journals include government departments and agencies that are looking for research-based solutions to important practical problems (whether social, technical or in some other domain), and industrial undertakings looking for sources of possible product or process innovation. Other categories of beneficiary are no less important; publication-quality research in the social and human sciences is a reliable source of direction and good practice for community-based and non-governmental organisations, international and national development agencies, educational institutions; and civil society at large. Another form of beneficiation is that of producing large numbers of well-trained, research-experienced thinkers and doers for the national economy; these will be immeasurably more capable in their various enterprises if they have become accustomed to the rigour and discipline of regularly publishing original research work in the recognised literature. Well-edited and -distributed local journals can be a significant resource for the different kinds of beneficiaries mentioned above, in providing a concentrated source of information about local research projects and possibilities, points of contact between end-users and researchers, and signs of real capacity in the whole "iceberg" of activities that makes the published research papers possible.

6.10 Enormous voluntary efforts are made to edit and publish a very large number of local research journals, many appearing infrequently, containing few articles, and drawing few citations in articles appearing in other journals. The editors of these journals mostly believe that they are doing something that is important, and are trying to do the best job possible, often finding novel survival solutions to keep going.

Few editors referred to financial difficulties in their responses to the survey questionnaire, but it was evident that each has had to address the issue of financial and logistic sustainability. They have employed a wide-ranging set of approaches and partial or temporary solutions, of which page charges and subsidies from host institutions or associations have probably been most important. The device of putting out infrequent issues of a journal, and with thin content is widely deployed; ad hoc financing and sponsorship have become a way of life in some quarters; and some journals may continue to exist only because of the subsidy paid to higher education institutions for articles in accredited journals.

6.11 The advent of online publishing has significantly changed the way in which the editors and publishers of South African research journals view their future. Costs can be greatly reduced if a decision to stop print publishing is made in favour of the online mode. An entirely different distribution/readership model can be generated with new and different commercial interests being introduced as conventional advertising revenues fall and a (perhaps still to be fully documented) world-wide market for both article sales and online subscriptions begins to dominate business plans.
Beneficiaries of

research that

is published in

research journals

include government

departments and

agencies that are

looking for research-

based solutions to

important practical

problems (whether

social, technical or in

some other domain),

and industrial

undertakings looking

for sources of

possible product or

process innovation 
Inputs in terms of funding and human resources must be compared with outputs that are valid in terms of verifiable standards or criteria

Estimates of R\&D expenditure have the notorious shortcoming that they cannot readily be linked to productivity and thus yield efficiency indicators

The fact that a developing country has examined its researchpublishing activity in fine detail, and particularly that this has been done partly through engaged or consultative research, partly through stakeholder consultation, and partly through the internal debates of a committed team brought together by the Academy of Science of South Africa, may be significant in the global context
6.12 Summarising the requirements of the editors and publishers of South African research journals can be done by presenting a scenario that embeds the perspectives of this particular group of stakeholders in the wider system. This would essentially mean that

the editors and editorial boards of South African research journals would subscribe to an agreed, general code of best practice;

- indexing in internationally recognised databases would be energetically sought (and supported by relevant agencies);

online publishing, with or without print, would be standard;

- Open Access, in both Gold and/or Green Route mode, would be a prime target, with "author" payments, contributed by the respective host institutions as part of a nationally agreed model, enabling universal free-on-line access;

- local journals would provide a significant amount of enrichment content to enhance their value to their different stakeholders;

- substantive editing and peer-reviewing work would be recognised in the general reward systems as valuable and highly skilled service;

- training programmes would readily be available for all kinds of aspects of the industry;

- the possible expansion of (private sector) consolidated editorial and publishing services would be explored, to permit editors to concentrate on their critical editorial functions;

and training and skills-upgrading opportunities for editors, editorial assistants and aspirant professionals in the field would be available in the country.

6.13 Increasing importance is now attached to the analysis and evaluation of research activity, in all its facets, inter alia to make judgments about the effectiveness and efficiency of the system, to identify significant trends, and to assess the need for new policy or resourcing. It goes without saying that indicators can be useful only if they reflect real quanta. Inputs in terms of funding and human resources must be compared with outputs that are valid in terms of verifiable standards or criteria. For example, diverse conference presentations and student dissertations are not easy to accept as outputs because there is no agreed quality standard. Publications in the peer-reviewed literature, on the other hand, are much easier to accept because there is (nearly always) a quality-process standard; (if listed and indexed) bibliometric analysis is possible; and the results and conclusions can be confirmed, rebutted or built on, in the vast matrix of published science.

6.14 Estimates of R\&D expenditure have the notorious shortcoming that they cannot readily be linked to productivity and thus yield efficiency indicators. Amongst the many outputs of research activity, peer-reviewed original publications are the most direct and quantifiable, especially if also treated to informed bibliometric and other scientometric analyses. Use of bibliometric indicators for South African purposes makes assumptions, however, for example that the main contribution to the research that has been reported was made by an author(s) who has actually done the work (mostly, or all of it) in South Africa or while affiliated with a South African institution; the journal concerned has met criteria for good editorial and peer review practice, even if not internationally listed and indexed; and information available in the public domain about impact factors and citation rates is not ignored simply because these indicators cannot be derived for a significant subset of articles in the sample (i.e. the unlisted/unindexed literature). From the point of view of evaluation and analysis of large research systems, there can be no doubt that the best model would be one that

reflects a pervasive culture that places a premium on high-quality publication of all research and associated training that has been performed;

- regards locally published research journals as potential winners, in terms of both international AND national exposure (provided that best-practice norms are observed); and

- sees publication outputs as important but not exclusive forms of return on the overall investment of funds and effort, along with patents, highly skilled postgraduate qualifiers, and translated socio-economic benefits.

The fact that a developing country has examined its research-publishing activity in fine detail, and particularly that this has been done partly through engaged or consultative 
research, partly through stakeholder consultation, and partly through the internal debates of a committed team brought together by the Academy of Science of South Africa, may be significant in the global context. It may be an example of a country "pulling itself up by its bootstraps", and contributing significantly to the global debate around critical issues in science in the modern era - the widening North-South divide, the problems of brain drain, and the crucial issue of whether developing countries (especially those located in Africa) can be more than passengers on the $21^{\text {st }}$ Century train.

6.15 The role of South African research journals in the life and times of schoolchildren and their teachers can at present be said to be minimal, possibly miniscule. That does not mean that this role could or should not be expanded with great benefit to all concerned and the nation at large. As the perceived gap in scientific achievement between developed and developing countries widens, few things can be more important than to make learners aware

- that significant research is being done and reported in South Africa,

- that people like themselves have worked hard to establish their research groups and activities inside the country, and

- that it may be possible to make a personal contribution to positioning South Africa as a major (and distinctly African) player in the modern world.

Teachers obviously need to be aware of what is being done and reported in South African science and technology to introduce this effectively into their classrooms as project work, reading assignments and individual mentoring activities.

6.16 International journals and magazines are not sufficiently focused on science and technology produced in this country, nor connected to everyday topics and media happenings, to exert the full range of potentially good effects that high-quality local journals and science magazines could, if they were skilfully used in the entire schoolbased teaching-and-learning system. The presumption, however, is that the local journals and magazines would succeed in presenting their content in ways that enhanced their utilisation as partially listed above, through regularity and accompanying high visibility and trust; high-quality content matched to general disciplines (as opposed to extreme specialisation); enhancing features; attractive presentation; relevant advertising; and (most important) low cost.

\section{AGGREGATED AND INTEGRATED RECOMMENDATIONS}

We now come to the final task of framing recommendations in this Report that can satisfy the original brief (see Chapter 1) and provide a strategic approach to the question of research publishing in South Africa.

A strategy is a future-directed, broad-based plan to reach a particular goal. In this case, the goal could be said to be to develop and maintain a robust national system of innovation which contributes materially to the sustainable prosperity of all South Africa's people. In other words, a scenario where large numbers of lively, enquiring and enterprising people have scope for productive careers and involvement as leaders in science-based efforts to promote the development of the whole nation's skills and resources.

How does research publishing fit into such a demanding vision, especially in the context of rapid change? It has its place, and an important one, through its role as the actual vehicle of science-based progress and effective attainment of sufficient high-level human capacity to address the most challenging problems and to provide inspiration to the brightest minds amongst the youth. In addition, it plays a key role in training by furnishing the most rigorous tests of resolve and originality. It also connects the people carrying the science system of a country to the best of their international counterparts. Not trivially, it helps establish a country's reputation and thereby attracts investment and foreign support.

Recommendation No 1: that all stakeholders in the South African research enterprise should each in their own way support local/national research journals that actively seek to be of international quality and are indexed in an internationally recognised, bibliometrically accessible database, through following best-practice in editorial discernment and peer review, including adaptations
An example of a

country "pulling itself

up by its bootstraps",

and contributing

significantly to the

global debate around

critical issues in

science in the modern

era - the widening

North-South divide, the

problems of brain drain,

and the crucial issue

of whether developing

countries (especially

those located in

Africa) can be more

than passengers on

the $21^{\text {st }}$ Century train

The goal could be

said to be to develop

and maintain a robust

national system of

innovation which

contributes materially

to the sustainable

prosperity of all South

Africa's people. In

other words, a scenario

where large numbers

of lively, enquiring

and enterprising

people have scope for

productive careers and

involvement as leaders

in science-based

efforts to promote

the development of

the whole nation's

skills and resources 
that address inherent problems and capitalise on technological innovations;

that judiciously enrich content to promote coherence and value-adding functions;

that provide the local scholarly community with opportunities for participating in the full range of scholarship-enhancing activities associated with the process of publishing original research outputs;

- that vigorously seek financial sustainability from multiple income streams; and

that accept systemic peer review and periodic audit which has a marked developmental focus.

(The rationale for this broad recommendation has been fully laid out in the chapters of this Report. In respect of financial viability of South Africa research journals, the general acceptance, in the special South African context where accredited institutional publication outputs are subsidised, of a per-article charge system (linked in the case of higher education institutions to an agreed fraction of output publication subsidies, and in the case of other research-producing institutions to adapted budgeting practice), would produce marked benefits at minimum cost, and naturally lead to a more rapid expansion of the Open Access mode of online publication, on the basis of "institution pays (a little), the whole nation/world benefits (a lot)". Key actors in bringing about the necessary policy and organisational frameworks would be research funders and supporters, including the Departments of Education and Science and Technology, the NRF and the MRC, all working with the Academy of Science of South Africa in downstream implementation mode following the release and general discussion of this Report. Data presented in this Report show that a fixed per-article institutional charge of R 1000 , by an accredited journal that should be able annually to publish at least 100 articles, would provide a reliable income stream to that journal of R 100 000, which when added to subscription and other existing and probably expandable income streams, would create a basis for sustainable publication not now in place for most South African research journals. At the same time, the diversion to research journals of $1.43 \%$ of the publication subsidy stream would be insignificant against the benefits of the improvement in the quality and visibility of the publication outputs of the institutions concerned, not to mention the secondary benefits of enhanced scholarly functioning in general.)

Recommendation No 2: that both high-level (Departments of Education and of Science and Technology, CHE/HEQC, NACI and NRF) and wide-ranging (higher education institutions, science councils) discussions be held to design a robust, well-informed and accountable mechanism for the accreditation of research journals (and probably also of books and other outputs of scholarship), that will meet the different although often convergent requirements of the multiple stakeholders in the national system of innovation.

(The current accreditation system of the Department of Education is not designed to meet the needs of other participants in the national system of innovation. Thus the accreditation step in respect of every single research publication, over which the DoE has complete control, feeds decisively into the policy frameworks of other organisations such as the CHE/HEQC (in terms of its functions of quality assurance of research and postgraduate training at higher education institutions), the NRF (for general grant-making and bursaries at the same institutions), the Department of Science and Technology, NACI and the scientometric compilers of annual S\&T indicators (as one of the key determinants of output units), and the higher education institutions and science councils (in terms of internal planning and resourcing policies and reward systems), not to mention the journals themselves. The accreditation function has to be credible, transparent, well-administered and generally promotive of higher standards and greater general utility and significance, nationally and internationally. A developmental approach to the accreditation of research journals requires implementation through a combination of widely accepted best-practice guidelines and quality promotion, with periodic peer review and assessment against criteria that can meet the needs of ALL the users of the system as listed above. If the Academy is to be involved in the national research publishing system in related, significant ways (see recommendation below for a quality assurance system for South 
African research journals, and for a general development programme for publishers, editors and reviewers, both coordinated and overseen by the Academy), this needs to be taken into account by the important stakeholders in the system when designing a robust, accountable and effective accreditation system for national research journals that satisfies their individual but mostly converging requirements to the greatest degree possible.)

Recommendation No 3: that the proposed best-practice guidelines presented in Chapters 1 and 6 of this Report be widely discussed under the aegis of the Academy of Science of South Africa, formulated into a concise readable document, and then publicly adopted by editors and publishers throughout South Africa, especially those relating to effective peer review and wise and appropriate editorial discernment.

(Particularly important aspects are the training/guidance of editors and reviewers in their critical respective functions in the publication process, and the enhancement of recognition of this kind of work in general academic reward mechanisms. The Academy of Science of South Africa could work with a number of different institutions to ensure that a spread of courses, workshops and online offerings is available on a regular basis, that a national editors' network is formed, and that it mediates in conveying the collective or individual concerns of publishers and editors to the relevant authorities.)

Recommendation No 4: that the quality assurance system now being put into place by the Council of Higher Education/Higher Education Quality Committee (CHE/HEQC) be used by that agency and by its partner higher education institutions to promote best-practice in publishing of original research work, and to emphasise and enhance the training function served by the whole exercise of publishing original papers in the peer-reviewed literature.

(The CHE/HEQC has achieved much in its best-practice guidelines for teaching and learning in higher education institutions, and is currently approaching postgraduate education and associated training in the same manner. Amongst the publication-related aspects of the latter, much good would come if all stakeholders emphasised the desirable and necessary relationship of conference presentations and dissertations to peer-reviewed publications emanating from the same work or study. A second benefit would come from systematically removing the perception that the (valuable) translation of research results into public benefits necessarily means that proper publication of the work concerned is not needed or should enjoy much lower priority.)

Recommendation No 5: that ASSAf be mandated jointly by the Departments of Education and Science and Technology to carry out external peer review and associated quality audit of all South African research journals in 5-year cycles, probably best done in relation to groups of titles sharing a particular broad disciplinary focus, in order to make recommendations for improved functioning of each journal in the national and international system.

(A light-touch but robust review and audit system, analogous to the periodic quality assurance reviews of the functioning of higher education institutions now routinely conducted by the Council on Higher Education/Higher Education Quality Committee, would help greatly to address problem areas and encourage enhanced functioning of research journals published in South Africa. Such functioning would include: quality of editorial and review process; fitness of purpose; positioning in the global cycle of new and old journals listed and indexed in databases; financial sustainability; and scope and size issues. Following on the momentum generated by the activities carried out as part of its research journals project and the production of this Report, the Academy of Science of South Africa would be the most suitable agency to oversee and be accountable for this work, obtaining system support for the best-practice guidelines, and appointing review panels and managing their work; some of the reviews could be done in respect of groups of journals with broadly similar focus.) 
Recommendation No 6: that the Department of Science and Technology takes responsibility for ensuring that Open Access initiatives are promoted to enhance the visibility of all South African research articles and to make them accessible to the entire international research community. Specifically:

- online, open access ("Gold route") versions of South African research journals should be funded in significant part through a per-article charge system (linked in the case of higher education institutions to an agreed fraction of output publication subsidies, and in the case of other research-producing institutions to adapted budgeting practice), but publishers should still sell subscriptions to print copies and should maximise other sources of income to lower the article-charge burden;

- a federation of institutional Open Access repositories, adhering to common standards, should be established ("Green route"), with resources made available to help institutions in the preliminary stage, this virtual repository to be augmented by a central repository for those institutions which are unable to run a sustainable repository;

national harvesting of South African Open Access repositories should be undertaken as a matter of urgency, preferably by the NRF; and

the importance of affordable bandwidth for research communications for this purpose be drawn to the attention of DST officials negotiating for better rates.

(This proposal holds significant logistic implications for the development and maintenance of adequate broadband connectivity and related infrastructure, but the imminent high-speed/ broadband national system or "superhighway", envisaged for use by research-active institutions and others, will make things possible that have only been dreamt of up to the present time. The virtual repository would capitalise on institutional efforts, provided agreed standards were adopted, and provide a publication route for researchers in institutions without such a repository. The emphasis should be on "leapfrogging" the present turmoil and confusion in the system. The clear need for caution in assessing the presently somewhat vaguely defined business models for open access systems should not prevent the country from moving forward resolutely with a well-resourced programme for expanding its electronic access to the global and national scientific literature.)

Recommendation No 7: that a consortium of agencies be asked by the Department of Science and Technology to form a virtual "national research publications information and research centre", probably best overseen by the Academy of Science of South Africa, which will continuously gather and analyse information on South African journals as well as on publications in foreign journals emanating from authors working in this country, following up on the studies presented in this Report and in the (rather few) previous relevant publications. This entity could also be used to support the training function envisaged in Recommendation 2.

(The proposed managed consortium would supply a number of government departments with reliable information for policy implementation purposes - the Department of Education and/or ASSAf, for accreditation of local journals; the National Research Foundation, for assisting valuebased grant-making; the Council on Higher Education/Higher Education Quality Committee, for enhanced quality assurance at research-active institutions; agencies carrying out large-scale evaluations of R\&D such as the HSRC, reliable bases for validating output data; and higher education institutions and other research producers, for accelerated researcher development and overall research planning.)

Recommendation No 8: that a wide-ranging project be initiated by the national Department of Education and the provincial education authorities that will sharply increase the exposure of teachers, teachers-in-training and learners to local science journals and magazines that present the country's foremost scientific work in accessible form, and are effectively linked to the media. 
(One of the most cogent reasons for publishing research journals locally is the opportunity beneficially to reach the next generation in ways that are not possible with expensive international periodicals; this needs to be planned in partnership mode, however, and will not happen without strong top-down sponsorship and appropriate resourcing.)

Recommendation No 9: that the Department of Science and Technology should assume responsibility for seeing to it that the South African science/innovation community, including itself and other government agencies, becomes involved in international action to promote the rapid but evolutionary development of a non-commercial, expanded, diversified and more inclusive international listing and indexing system for research journals, including those published in developing countries, within the evolving electronic knowledge-disseminating and -archiving system.

(There are clear needs for a new, consultative and collaborative approach to meeting the requirements of developing as well as developed countries; of countries using languages other than English as vehicles for doing and reporting research; of disciplines with systems of scholarly practice differing from the "natural sciences standard"; in a system that provides full transparency and low-cost access to data in terms of the databases to be used and maintained. It could be argued that this need is on a par with other more well-publicised and public requirements to level the playing fields in a structurally unequal world (ICSU Report on "Scientific Data and Information", 2004). The lead organisations in this effort should be the Departments of Science and Technology and of Education and the NRF, working closely with the Academy in terms of its international partners and other relevant agencies.)

Recommendation No 10: that the findings and recommendations contained in this Report be presented to key stakeholders in a series of consultative workshops, and that the outcomes and the impact of the publication of the Report be evaluated in three years time.

(This Report could have made radical proposals and recommendations supported by evidence presented in the various chapters. This approach has not been taken, however, because of the large number of inter-dependent stakeholders, the extreme fluidity of the sector in global terms, and the conviction of the authors that only a consultative process is likely to achieve the recommended results. We believe the present Report provides a necessary but obviously incomplete basis for important reforms and considerable advancement of South Africa's research potential and actual performance - joint downstream efforts will be needed, at both the widely distributed knowledge production and more focused governance levels.) 



\section{CHAPTER 1 \\ Introduction and background}

by Wieland Gevers ${ }^{1}$

South Africa occupies the paradoxical position in the arena of research publishing of being a dwarf internationally and a giant on the African continent. Pouris' (2003) bibliometric analysis of the country's research publications captured on the Journal Citation Reports (JCR) of the Institute for Scientific Information, ISI (now Thomson Scientific) showed that about 3500 listed papers with at least one South African author address were published in 2000, representing about $0.5 \%$ ( 5 in every 1000 ) of all papers in the three major databases of that system, covering over 5500 selected international journals in Science, Engineering and Medicine, 1800 in the Social Sciences, and 1200 in the Arts and Humanities. South African research journals (see definition below) constituted only 19-23 (depending on the year) of the indexed journals on the combined databases in 2002-4 (0.2\%, or 2 in every 1000$)$ containing about 350 papers of the ISI total for the country ( 1 in every 10), and the rest of Africa, only 2 (Pouris, 2005). A different analysis by King (2004) put South Africa's share of world citations in this database at 0.31 (just over 3 per very 1000 ) for the period 1997-2001, while only $0.15 \%$ (1.5 per 1000 ) of the $1 \%$ of top-cited articles had one or more South African addresses.

Analysis of the comprehensive S A Knowledgebase (SAK) hosted by the Centre for Research in Science and Technology (CREST) at the University of Stellenbosch (see Chapter 3 for details) yields a stable figure of about 7000 articles published per year from South African addresses; these include the 3500 papers published in ISI-listed journals (see above), as well as papers published in South African or foreign journals not listed in the ISI system but accredited by the Department of Education (DoE) as subsidisable research outputs. (Articles published abroad in journals not indexed in the ISI databases or accredited by the DoE, and papers appearing in South African journals not accredited by the DoE, are not yet included in any database, partly due to the lack of accepted criteria for which of them can reliably be classified as "peerreviewed reports of original research". The total number of papers published annually in all kinds of South African journals thus actually lies well above the SAK figure of approximately 3850 per annum.)

Recent surveys of the South African Science and Technology (S\&T) indicators put the total number of potentially publishing researchers in the country at just under 16300 (Kraak, 2005). The active researchers in this group are the producers of the 3500 ISI-listed papers per year mentioned above, as well as the approximately 3500 that are not so listed but are accredited by the DoE. In summary, just over 16000 researchers publish about 7000 papers a year, or on average about 0.4 papers per researcher per year.

In this Report, a research journal will be regarded as being "South African" (even if owned by a multi-national company), if:

- its main, physical publishing address is within the country;

- it is published by a South African association or other organisation; and/or

- its Editor and Editorial Board are largely drawn from South African scholars.

Assessment of a country's research productivity by the proxy of international bibliometric and other forms of survey analysis based on peer-reviewed publications in research journals may not be adequate from a number of different points of view, but there appear to be few alternatives. Amongst the accepted confounding issues are language, coverage of a particular field of knowledge, and national/regional focus. While the JCR contains journals published in 36 languages, all of which meet the system's requirements for English-language translated indexing components, none of South Africa's Afrikaans journals are included. Afrikaans has

1 wieland@telkomsa.net, Academy of Science of South Africa

\section{A research journal will be regarded as being "South African" (even if owned by a multi- national company), if its main, physical publishing address is within the country; it is published by a South African association or other organisation; and/or its Editor and Editorial Board are largely drawn from South African scholars}


An impressive "urge

to publish" appears to be expressed at the level of journals rather than at that of single articles, as the actual number of articles published in the enormous range of South African unindexed titles is only roughly equivalent to the number that is published in ISIindexed journals world-wide

\section{The contract required} ASSAf to recommend and support a new strategic framework for South Africa's research journals, on the basis of evidence and comparative information been developed to a full-vocabulary scientific reporting language and there is no prima facie reason why an Afrikaans journal should not be indexed if it meets the general selection criteria. (It is not known if any have been submitted for consideration; see chapter 3 for more details). The second issue of coverage of particular fields of knowledge comes up in the policy of international databases like ISI to limit inclusion of otherwise acceptable journals if the number of listed journals in that field would thereby become disproportionately large (Testa, 2004). The third, probably much bigger issue of geographic readership focus comes up constantly in discussions of the publishing strategies of local scientists/scholars: do I/we go for international or local/national publication? Remarkable in the latter connection is that there may be as many as 300 "research journals" published in South Africa that are not listed in an international database like the ISI, of which the Department of Education accredited no fewer than 219 as part of its institutional research output funding policy in 2004. An impressive "urge to publish" appears to be expressed at the level of journals rather than at that of single articles, as the actual number of articles published in the enormous range of South African un-indexed titles is only roughly equivalent to the number that is published in ISI-indexed journals world-wide (the overwhelming majority of these appear in journals not published in South Africa.). The stark fact seems to be that the many un-indexed South African titles either appear infrequently and/or contain few articles per issue, often represent highly specialised sub-disciplines or near mono-institutional outputs, and are mostly poorly (or not ever) cited in the world literature (see Chapter 3 for details). Publication of many of these journals appears to be justified on the basis of providing in each case a significant user base with a useful, locally driven and accessible, multi-purpose product, i.e. their primary purpose may not be communication and documentation of original research in a global knowledge system.

This project has examined how and why periodicals purporting to be research journals published in South Africa present the above surprising picture, in order to suggest ways in which this undoubtedly important activity can be changed to support the growth on home ground of internationally significant research activity, make research programmes more costeffective, help to ensure that young researchers develop to their full capacity, and translate these gains into national progress and welfare. At the same time, the fact that sustainable and locally useful "journals" of a broader, multi-purpose type can productively co-exist with those reporting mainly original research, will be recognised, and improvements in this sector may also be of value in the context of the same group of objectives.

\section{TOWARDS A NEW STRATEGIC FRAMEWORK FOR SOUTH AFRICA'S RESEARCH JOURNALS}

Following the closure of the erstwhile Bureau for Scientific Publications (BSP) and the termination of the policy of state subsidisation of selected flagship research journals, the Academy of Science of South Africa (ASSAf) signed a contract with the then Department of Arts, Culture, Science and Technology (DACST) in December, 2001. The contract required ASSAf to recommend and support a new strategic framework for South Africa's research journals, on the basis of evidence and comparative information; ASSAf was to work in partnership with a number of organisations.

The main objectives of this strategic framework were to:

promote/enhance the standing and effectiveness of South Africa's research journals, nationally and internationally;

- improve the productivity/efficacy of publication through different modalities (e.g. electronic publication);

- establish the South African Journal of Science (SAJS) as a "national asset" of high quality; and

- ensure that discoveries and insights gained through research published in South African journals were made known to a wider public than the research community itself.

ASSAf has accordingly sought through this project to develop a broad strategic approach to research (learned) journals published in South Africa, to achieve a situation in which:

the South African Journal of Science (SAJS) is an internationally recognised, high-readership, high-impact, multi-disciplinary journal reflecting and projecting South Africa's scientific capacity and special contributions in an imaginative and highly professional way; 
other internationally recognised, lower-volume but also high-impact journals are sustainably published to make known significant, peer-reviewed research contributions from South Africa and the Southern African region generally, as well as further afield;

- the proceedings or abstracts of research symposia or conferences held in South Africa are published in ways that ensure wide distribution;

- cutting-edge South/Southern African research is appropriately reflected in educational publications as well as local and international media;

- electronic distribution of journal contents is expanded;

- the impact and inherent value of South African research journals is continuously assessed with a view to improvement and better communications; and

- a participatory and responsive policy-making environment for research/learned journals has been established for the benefit of the scientific community, the education and training system, and for civil society in general.

\section{POINTS OF DEPARTURE}

The first point of departure of the Journals Project was that science publishing should take place inside South Africa on a significant scale, because of the beneficial effects this has on the research system:

- Active participation of South African scholars in editing journals (both as editors and as members of editorial boards), and in refereeing/reviewing and improving submitted papers;

- Networking local scholars and their research students through research publication, in a working context smaller than the massively diffused international system;

- Facilitating the contribution of South African research and scholarship to the general body of scientific knowledge;

- Reflecting local focus, depth and strength in particular fields, thus showcasing the country's scientific activity in a concentrated way; and

- Allowing the context and potential impact of original research papers to be high-lighted through professional editorial enrichment of the content in terms inter alia of peer analysis, background review, and evidence-focused correspondence.

A second point of departure was that local publications should be of high quality, and should therefore meet a number of important specifications:

- They should be competently edited (by an editor(s) supported by an effective editorial board), with proper peer review (by more than one peer expert in each case) done for two purposes: (1) objectively to recommend Yes/No decisions on publication, and (2) to improve the papers concerned through their expert comment;

- They should also be published regularly and frequently (such as at least quarterly or six times per annum), in order to build up habits of regular reading and contributing on the part of practising academics/researchers (a criterion emphasised by the ISI in assessing the value of a proposed inclusion in their databases is whether the journal appears regularly, "on time", purportedly reflecting a good volume of submitted, acceptable papers (Testa, 2004));

- Each issue should contain enough articles to further and broaden the understanding of readers more than would happen through the reading of singly reprinted/downloaded articles;

- The financial viability of a journal should be guaranteed through a reliable and sustainable set of revenue streams;

- Journals should showcase the South African scientific enterprise; and

- Journals should have a wide international distribution, and achieve recognition through listing on a reputable database (such as ISI) as well as through Internet publication (both accompanying print versions, or as the sole modality).

The importance of the second point of departure was that in principle it established preconditions for the validity of the first; this cannot be over-emphasised, as all or most of the arguments for in-country research publishing become inverted, counter-arguments for NOT investing resources of time, effort and money in this area, if the journals that are published in the country are of poor quality in the sense of the criteria listed above. 


\section{NECESSITY OF A NEW STRATEGIC APPROACH TO SOUTH AFRICA'S RESEARCH JOURNALS}

World trends in research dissemination include a massive proliferation of titles; rampant and above-general cost inflation; resulting crises in the budgets of every academic library ; the persistence of a culture of "publish or perish" for academic promotion and recognition, despite serious attempts to wean the academic sector off over-reliance on this parameter ; increasing dominance of English, even in countries with fully developed, technically complete languages; formal acceptance of the value and relevance of bibliometrics; virtually universal availability to subscribers (and, after waiting periods, to all users via the internet) of electronic versions of highly regarded print journals; a determined effort to introduce new high-quality journals that are "free-on-line" because costs are met through author charges and other revenue-generating modes; insistence by major funders that all accepted papers should be placed on one or more, freely accessible repositories; an increasingly problematic and overloaded peer review system, with resulting quality concerns; and (of major concern to this project) a serious reduction in the viability of local/regional journals not listed on well-maintained international databases, at the same time that their contents have, or can in theory become, increasingly visible through internet-based dissemination.

Many of these trends will receive more detailed treatment in the chapters to follow. The original points of departure summarised above will also be re-examined, as well as some of the assumptions and principles used in this introductory chapter, and a general strategic approach developed to the question of the publication of research journals in South Africa, with recommendations for both producers of publishable research information, and for funders and policy-driven promoters of the national research system.

\section{FORMATION OF A PROJECT STEERING COMMITTEE}

A number of members of ASSAf (including some members of Council) initially agreed to serve on a Steering Committee for the Project: Professors Wieland Gevers (Convener); Tony Mbewu; Walter Claassen; Krish Bharuth-Ram; Marie Muller; and Iqbal Parker. A number of other persons with a direct interest in South African science journals were also recruited: Dr Molapo Qhobela (Department of Education (DoE), Higher Education branch); Prof Johann Mouton (Centre for Research on Science and Technology (CREST), Stellenbosch University); Dr William Blankley (Knowledge Management Research Programme, Human Sciences Research Council, HSRC); Prof Michael Cherry (South African correspondent for "Nature", Stellenbosch University); and Mr Prem Naidoo (research quality assurance project, Council on Higher Education (CHE)/ Higher Education Quality Committee (HEQC). This created an 11-person Steering Committee, capable of launching the Project and taking care of sub-projects. The Steering Committee met for the first time early in September, 2002, and continued its work through occasional meetings and electronic exchanges of opinion and information until near the end of 2004 (when the present Report writing team was constituted).

\section{CONSULTATIVE WORKSHOP, SEPTEMBER 2002}

The ASSAf Council decided that the symposium/workshop accompanying its Annual General Meeting in 2002 should be devoted to the research journals project, and brought together as many participants in the national "journals system" as could be assembled. Amongst the topics presented and discussed were:

the evaluation and subsidisation of higher education research outputs (publications) by the Department of Education;

research quality and South African publications;

the recognition of local publications by the NRF and other Science Councils together with problems in citation analysis;

- strengths and weaknesses of the research journals currently published in SA (usually only annually or 2/4 times a year);

the future of electronic publishing;

the place and value of a "national science publications information centre"; and

conference abstracts and related non-peer reviewed publications.

The main conclusions of this exploratory workshop were as follows: 
- The total number of (learned) journals published in South Africa relative to the number of publishing scholars was extraordinarily high;

- Amongst the reasons for the continuing proliferation of journals were: the atomisation of disciplines into specialised sub-fields; the award to higher education institutions of "publication output subsidy" reflecting quantity rather than quality; fiefdoms dominated by individual scholars and/or their departments or institutions; Afrikaans co-existing with English as a fully developed language of scholarly discourse; and the ease and commercial returns of establishing electronic scientific journals;

- The commercial exploitation of journal publications in the electronic realm (without paying attention to the quality dimension) posed great risks, insofar as greatly increased access to potentially poor-quality articles through the huge, searchable Internet space may not reflect well on SA research and scholarship;

- Different authorities with an operational interest in articles publications stood to gain from a successful ASSAf Project on the strategic management of SA research journals;

- The Project needed "buy-in" from editors, publishers and researchers alike, but appropriate policy development could be a powerful driver; and

- Moving from the national to the continental dimension, while feasible, should not be done in a unilateral manner from a South African base.

\section{SUB-PROJECTS WITHIN THE LARGER ASSAF JOURNALS PROJECT}

A number of potential "sub-projects" of the main Journals Project were already on course as initiatives of other organisations, e.g. the research output subsidy project of the Department of Education (DoE): research quality assurance by the Council on Higher Education (CHE) and its Higher Education Quality Committee (HEQC); funding in terms of grants and bursaries by the National Research Foundation (NRF); evaluations and analyses of Science and Technology (S\&T) indicators being conducted by a number of agencies, etc. The ASSAf Project sought to link up with these key initiatives in a productive and integrative way. From the point of view of project design a number of the most important "sub-projects" were conceptually brought into a single framework:

- Development of refined accreditation criteria for the subsidisation of research outputs (publications) of higher education institutions: In this connection, it was gratifying that the DoE agreed to identify the ASSAf Journals Project in its subsidy funding framework as an/the main agent for refining the criteria for accreditation of research outputs of higher education institutions.

- Establishing some kind of sustainable registry and monitoring system for all research journals published in South Africa.

- Assessing research quality in higher education institutions: The Steering Committee believed that the Project would make it possible for the CHE/HEQC to create valid criteria for research quality measurement at institutions, in emphasising the centrality of peer-reviewed publication of research results and analyses as the yardstick of real productivity.

- Developing the South African Journal of Science (SAJS) as a "Nature-like" national asset: this important agenda was already on course through the appointment of a new editorial board and management committee, widening the scope through editorial adoption of the Academy's broad definition of "Science" (accepted as including all forms of enquiry based on evidence, and the active search for support for, or disproof of, hypotheses arising from systematic observation and/or experimentation).

- Examining the strategic future and sustainability of other science journals currently published in South Africa, and devising a system of targeted financial support of journals published in the country that meet refined criteria and are able to generate significant income on their own, including page charges. The new DoE policy for the funding of research outputs, which increased the unit subsidy for accredited publications from about R 20000 to over R 70 000, has created an obvious source of legitimate revenue for accredited journals in page charges. It would be fair to contemplate a system in which a subset of the country's research journals (perhaps between 40 and 80) might be accredited according to refined criteria to emerge from the ASSAf Journals Project, and would be rendered financially viable through reliable income streams provided by a combination of page charges, differentiated
A number of potential

"sub-projects" of the main Journals Project

were already on course as initiatives of other organisations, e.g. the research output subsidy project of the Department of Education (DoE): research quality assurance by the Council on Higher Education (CHE) and its Higher Education Quality Committee (HEQC); funding in terms of grants and bursaries by the National Research Foundation (NRF); evaluations and analyses of Science and Technology (S\&T) indicators being conducted by a number of agencies, etc. 
It is thus evident that the functionality of a research journal produced locally is enhanced by the inclusion of a minor but significant proportion of supplementary material that plays a catalytic role in the otherwise "uncomplicated", globally systematic process of reporting and interpreting findings new to ALL of science, the primary purpose of a "research journal" (and the generally accepted criterion for being regarded as such.)

\section{An impressive} degree of order has been afforded to a potentially chaotic world knowledge system by the explicit or tacit acceptance by virtually all participants of a set of principles that regulate the publishing of research findings or ideas subscriptions (high overseas, lower locally), advertising, sponsorship, fees from electronic article distribution, and direct subsidy from state sources.

- Electronic publishing: There is much concern that the ease with which electronic publication of existing or new journals can be effected may act as a "life-saver" for weak journal titles, and may frustrate efforts to order the system in a strategic manner: the many benefits of electronic publishing must be obtained without an avalanche of published rubbish.

- Publishing for "Public Communication of (South African) Science": The ASSAf Council decided in 2004 to establish a new science magazine ("Quest: Science for South Africa") to showcase local scientific achievements and pre-occupations (published in South African and foreign journals) to a wide audience of senior school-based learners, higher educations institutions and science councils, overseas readers, and the general South African public.

\section{THE ISSUE OF THE PRIMARY PURPOSE OF A RESEARCH PERIODICAL OR JOURNAL}

Mention has been made above of the impressive effort made in South Africa to publish a very large number of "journals", many in apparent response to perceived or real needs that cannot be met from the huge international menu of research journals listed in the three indexes of the ISI, or the locally published journals that have achieved indexing. The kinds of agendas served by many of these periodicals can be deduced both from their content and context. For example, there are well-edited law journals that contain a mix of original, peer-reviewed research; instructive (local) case reports; topical jurisprudential analysis; and other professional material and information. The principal medical journal of the country contains, apart from peerreviewed articles, house-journal material for the national association of medical practitioners, news of pharmaceutical innovation in the market and generally; extensive correspondence; continuing education reviews, best practice guidelines, and guest editorials. (In this it bears some resemblance to the best-known and -highly ranked international journals). The South African Journal of Science is a local "Nature" or "Science" in keeping its readers abreast of important national and international science developments at the same time as most of the pages are taken up with primary-purpose original, peer-reviewed content.

It is thus evident that the functionality of a research journal produced locally is enhanced by the inclusion of a minor but significant proportion of supplementary material that plays a catalytic role in the otherwise "uncomplicated", globally systematic process of reporting and interpreting findings new to ALL of science, the primary purpose of a "research journal" (and the generally accepted criterion for being regarded as such.) We will examine the applicability of this criterion in the national system, focusing on those South African journals that have already been recognised by international indexing (ISI) or national accreditation (DoE) (see Chapter 4).

\section{FUNDAMENTAL PRINCIPLES OF RESEARCH PUBLISHING PROVIDING THE BUILDING STONES OF THE MATRIX OF HUMAN KNOWLEDGE}

An impressive degree of order has been afforded to a potentially chaotic world knowledge system by the explicit or tacit acceptance by virtually all participants of a set of principles that regulate the publishing of research findings or ideas. Some of the most important of these are:

- The reported findings must be original, in the sense that they are the first report of such findings. This perhaps most fundamental principle pre-supposes that authors submitting manuscripts containing "new findings" will have had access to the universe of relevant existing literature and will not knowingly suppress the fact that the findings have in fact been reported before. A key function of multiple peer review is to ensure that the knowledge of peers as to this situation is also tested before publication of the "new findings". A frequently vexed question is whether there is in fact exact replication of existing information, or whether the context and/or detail of the new findings are sufficiently different to merit addition to the matrix of knowledge through publication: the discretion of peers and that of the editor is exercised here, but irritating grey cases are found frequently in every publishing scientist's career. Despite this intrinsic weakness, originality of published research is a key criterion for true research literature as opposed to other forms of publication.

- Reports must contain, or permit reference to, sufficient detail of the methods and materials used in the study to permit replication in the hands of other scholars. 
- Integrity of reporting requires that no inconsistent data are omitted or fabricated data presented.

- The statistical treatment of data must be thorough and the conclusions reasonable.

- The existing relevant literature must be appropriately and fairly cited; in this respect reference efforts are always made to ensure that reference is made to the first report of a finding rather than a later elaboration.

- Authorship must conform to the notions of responsibility and credit,

- Special attention must be given to the first "lead" author (sometimes explicitly shared), and the inclusion in the authorship listing only of persons who have contributed directly to the production of the work at an intellectual/conceptual level.

- Speculative deductions and postulations must be clearly specified and kept to a minimum.

- Acknowledgement of funding sources and possible conflict of interest must be complete, and author affiliations provided which reflect both the period of the study and the present situation.

- While priority is accorded from the date of publication of an article, not from its date of submission, i.e. the peer review must have already taken place, both dates are always given in the published version.

- Post-publication detection of errors and falsifications must always be retracted in print in the same journal.

- Finally, there is a strong "best-practice" rule that studies addressing a particular question should not be broken up into a series of scattered short publications but preferably be presented once as a full record of the work and its results.

\section{THE CORE ROLE OF THE EDITOR AND THE PEER REVIEW SYSTEM}

No analysis of research publishing can avoid under-lining the critical role of editing and peer review in the maintenance of the global system of knowledge production, accumulation and use (see, for example, the papers presented at the Fifth International Conference on Peer Review and Biomedical Publication, at http://www.ama-assn.org/public/peerhome.htm). While there may be large or small editorial teams in charge of the production of particular journals, and variable designations of the participants, the essential requirement is for responsible and fair editorial oversight, exercised to ensure that:

an editorial policy exists and is accessible to authors;

- submitted manuscripts are carefully examined with a view to the selection of appropriate peer reviewers;

- reviewer reports are carefully assessed to decide whether, individually and summatively, they constitute the basis for the publication of the article in question, or whether publication should follow if certain improvements are effected and/or further work done and reported on; or whether the paper should be refused;

- special statistical review is sought, if needed;

the focus of the journal is protected;

misconduct is detected if at all possible (e.g. presentation of data, graphs or figures already published elsewhere; inconsistent data sets; plagiarism);

- errata and retractions are properly managed and made part of the record; and

- the journal as a whole contextualises reported findings in its editorial and supplementary sections (see above).

Peer reviewers in turn must fulfil a range of functions in the system of global knowledge accumulation. They have especially to:

- scrutinise the methods and results in terms of consistency, interpretability and likely reproducibility;

- identify gaps that could or should be filled to enhance the interpretability and strength of the findings;

- suggest how the paper can be improved in terms of style, length and focus;

- assess the proper citation and referencing of previous studies (as outlined above the "principles" section), including the critical issue of the originality of the work;

- contest conclusions not justified by the results presented; and

- "place" the work in the existing matrix of knowledge in the relevant area or field.
No analysis of research publishing can avoid underlining the critical role of editing and peer review in the maintenance of the global system of knowledge production, accumulation and use 
This study has proceeded from the strongly-held conviction that the core functions of journal editorship and peer review are fundamental to the global system of ordered knowledge accumulation and cannot be diluted or lost in any set of recommendations for the future viability of South Africa's public research system

It is therefore necessary to take stock of the fastmoving technological revolution spreading over the sciencepublishing world, and projecting into the short- and even medium-term future, how the research journal function in South Africa might best and most strategically be organised and supported from now onwards
This study has proceeded from the strongly-held conviction that the core functions of journal editorship and peer review are fundamental to the global system of ordered knowledge accumulation and cannot be diluted or lost in any set of recommendations for the future viability of South Africa's public research system. This is not to say that new and better ways of achieving the objectives of editorship and peer review cannot or should not be found or implemented, or that the publishing system of a relatively small, but emerging country cannot and should not be held hostage to the momentum of a lop-sided current world system of science production, it is just to emphasise how important these fundamentals are, and will always be to achieving real quality in our own National System of Innovation, earning international recognition that goes along with contributing significantly to the development of our country and continent.

\section{THE COMING WORLD OF ELECTRONIC DISSEMINATION OF RESEARCH INFORMATION}

This Study cannot only look backwards at a fast-vanishing print system of international and local journals, publishing huge numbers of articles submitted (at no cost) by authors, reviewed (at no cost) by other scientists, and sold back to the scholarly community at increasingly exorbitant cost, through library and/or personal subscription. In this system, general access to information has declined precisely when the needs of new producers (mainly, but not only in developing countries) have become key to the kind of expansion of science activity across the globe that is universally regarded as essential for the economic and social development of these nations.

It is therefore necessary to take stock of the fast-moving technological revolution spreading over the science-publishing world, and projecting into the short- and even medium-term future, how the research journal function in South Africa might best and most strategically be organised and supported from now onwards. This will entail more than just a change of "medium", from printed paper to networked cyberspace, with nothing in the actual evolved and stable present mechanism of knowledge publication/dissemination changing; there will surely be novelty and heightened efficiency brought about by the vastly greater flexibility, scope and speed of the new medium. But, as pointed out in the previous section, the basic system of peer-reviewed publication, of previously unpublished findings, under the watchful eye of a responsible and capable editor, is in principle so critical to the edifice of the modern science endeavour (with all its admitted faults, like democracy in its context, still the best available way of moving humanity forward) that the evolution of new mechanisms of publication and dissemination will have to be carefully controlled and evaluated, internationally and nationally, without constraining the benefits and evident possibilities of a newly evolving global science communication order geared to inclusion rather than exclusion of emerging players.

This Report will accordingly contextualise its findings and recommendations in a full exploration of the coming scenarios of internet-based research communication, so that the lessons of the past are pre-emptively located in the future (Chapter 5).

\section{REFERENCES}

King, D. A. (2004) The scientific impact of nations. Nature 430: 311-316

Kraak, A. (2005) The quality of the academic workforce. In Synthesis Paper: Human Resources fro Knowledge Production in South Africa, Departments of Science and Technology, and of Education, 8-10

Pouris, A. (2003) South Africa's research publication record: the last ten years. South African Journal of Science 99: $425-428$

Pouris, A. (2005) An assessment of the impact and visibility of South African journals. Scientometrics 62: 213-222

Testa, J. (2004) The ISI database: the journal selection process, viewed 10 October, 2004 at http://www.isinet. com/essays/selectionofmaterialforcoverage/199701.html/ 


\section{A bibliometric assessment of South African research publications included in the internationally indexed database of Thomson ISI}

by Anastassios Pouris ${ }^{1}$

This chapter aims to provide new analytical information related to South African research publications and journals indexed by the company called Thomson Scientific, previously the Institute for Scientific Information (henceforth called the ISI in this Chapter); such information can inform the development later in this Report of appropriate approaches to the promotion of South African research journals, as ISI presently covers the most influential and selected global body of reputable research journals (but see Roth, 2005 and Jacso, 2005, for comparative details of Scopus and Google Scholar, locatable at http://www.info.scopus.com/aboutscopus/contentcoverage/ index.shtml, and http://scholar.google.com/scholar/about.html, respectively).

The ability of scholarly and scientific journals to reach their target audiences and to become internationally visible, to a large extent determines their long term significance throughout the world. For this purpose, incorporation in the three citation indices of ISI -the Science Citation Index, the Social Sciences Citation Index and the Arts and Humanities Citation Index - is currently still the most suitable approach currently available for the bibliometric assessment of journals in relation to international standards.

All journals indexed by ISI are peer-reviewed. As a group, the ISI indexed set of journals represents an elite body of internationally influential research publications, but it does not represent a comprehensive cataloguing of the entire world's research journals, nor of all peerreviewed journals. The reason for this is that it is ISI's intention to index that part of the journal literature that exerts a disproportionate influence. The principle involved in this coverage strategy is based on the well-known concept in bibliometrics, Bradford's Law of Scattering, which asserts that a relatively small group of journals will account for the large majority of important and influential research in a given field.

The information provided in this chapter is made up of three components. The first component is an analysis of the number of South African publications (i.e. articles where at least one author gives a South African address) captured in the ISI databases according to scientific discipline and sub-discipline for the period 1981 to 2004. These have been classified in the ISI set of 106 selected fields and subsequently aggregated into 20 science fields, four social sciences fields and 10 fields in arts and humanities. The number of South African publications in each of the three citation indices over the period is a key parameter.

The second issue covered in the chapter is related to the citation impacts (see below) of indexed South African articles in the various fields. The citation impact of these articles has been identified for the scientific disciplines and sub-disciplines mentioned above, for the period 1981 to 2004

The third component provides information related to all the journals which are included in each field in the Science Citation Index and the Social Sciences Citation Index, and compares the South African journals listed in the two indices with their peer journals in the field.
The ability of scholarly and scientific journals to reach their target audiences and to become internationally visible, to a large extent determines their long term significance throughout the world

It is ISI's intention to index that part of the journal literature that exerts a disproportionate influence 


\section{TRENDS IN SOUTH AFRICAN RESEARCH PUBLICATIONS: 1981-2004}

The number of publications produced in different scientific disciplines in theory is a critical factor indicating what kind of national or regional journals could potentially be sustainably supported by local researchers; there would have to be a minimum number of research publications in a field before the establishment of a local research journal could be justified, even though such a threshold quantity is only a necessary but not a sufficient condition for the establishment and or support of a journal (for example, local researchers may prefer to publish in an established international journal rather than in a new local one). Best practice would nevertheless indicate that a new local journal could thrive in a niche scientific area in which the local community has particular expertise, especially if there were a limited number of alternative (international) journals covering the specialty concerned.

Table 1 shows the number of South African publications indexed in 106 ISI pre-selected research disciplines. The table shows the number of publications during four 5-year periods - 1981 to 1985 , 1990 to $1994 ; 1995$ to 1999 and 2000 to 2004; the table also identifies the percentage changes in the number of publications from period to period. The research disciplines are ranked in descending order according to the number of indexed publications during the period 2000-2004. Three disciplines produced more than 1000 publications during the 2000-2004 period i.e. plant sciences (2182 publications), animal sciences (2108 publications) and environment ecology (1187 publications). If we assume for the moment that at least 100 publications per year is the hypothetical threshold supporting the existence of a local journal (i.e. 500 publications per 5-year period), then there were 11 scientific disciplines which produced that number of publications in the country.

The column indicating changes in the number of publications over time indicates that the fastest-growing disciplines were clinical immunology and infectious diseases (+967\%), and the public health and health care sciences $(+891 \%)$; it should, however, be mentioned that the latter group of discipline started from a relative small basis (23 publications during 1981 85). The contrasting substantial decline in the number of publications in "general and internal medicine" (from 2337 publications during 1981-1985 to 566 publications during 2000-2004) is strikingly apparent.

Table 1: South African publications in ISI and change over time

\begin{tabular}{|c|c|c|c|c|c|c|c|c|c|}
\hline \multirow[b]{2}{*}{ Rank } & \multirow[b]{2}{*}{ Discipline } & \multicolumn{4}{|c|}{ Number of publications } & \multicolumn{4}{|c|}{ Change in number of publications over time } \\
\hline & & 81-85 & $90-94$ & $95-99$ & 00-04 & $\begin{array}{c}\% \text { change } \\
81-85 \text { to } \\
90-94\end{array}$ & $\begin{array}{c}\% \text { change } \\
90-94 \text { to } \\
95-99\end{array}$ & $\begin{array}{c}\% \text { change } \\
95-99 \text { to } \\
00-04\end{array}$ & $\begin{array}{c}\% \text { Change } \\
81-85 \text { to } \\
00-04\end{array}$ \\
\hline 1 & Plant Sciences & 882 & 2,274 & 2,144 & 2,182 & $158 \%$ & $-6 \%$ & $2 \%$ & $147 \%$ \\
\hline 2 & Animal Sciences & 1,928 & 2,180 & 1,786 & 2,108 & $13 \%$ & $-18 \%$ & $18 \%$ & $9 \%$ \\
\hline 3 & Environment/Ecology & 437 & 758 & 959 & 1,187 & $73 \%$ & $27 \%$ & $24 \%$ & $172 \%$ \\
\hline 4 & Earth Sciences & 288 & 617 & 807 & 984 & $114 \%$ & $31 \%$ & $22 \%$ & $242 \%$ \\
\hline 5 & Space Science & 436 & 662 & 856 & 854 & $52 \%$ & $29 \%$ & $0 \%$ & $96 \%$ \\
\hline 6 & Multidisciplinary & 443 & 638 & 567 & 659 & $44 \%$ & $-11 \%$ & $16 \%$ & $49 \%$ \\
\hline 7 & General \& Internal Medicine & 2,337 & 1,153 & 888 & 566 & $-51 \%$ & $-23 \%$ & $-36 \%$ & $-76 \%$ \\
\hline 8 & Physics & 285 & 500 & 569 & 559 & $75 \%$ & $14 \%$ & $-2 \%$ & $96 \%$ \\
\hline 9 & Aquatic Sciences & 249 & 554 & 490 & 557 & $122 \%$ & $-12 \%$ & $14 \%$ & $124 \%$ \\
\hline 10 & Microbiology & 237 & 396 & 433 & 545 & $67 \%$ & $9 \%$ & $26 \%$ & $130 \%$ \\
\hline 11 & Appl Phys/Cond Matt/Mat Sci & 265 & 497 & 475 & 513 & $88 \%$ & $-4 \%$ & $8 \%$ & $94 \%$ \\
\hline 12 & Veterinary Med/Animal Health & 465 & 514 & 455 & 475 & $11 \%$ & $-11 \%$ & $4 \%$ & $2 \%$ \\
\hline 13 & Food Science/Nutrition & 156 & 212 & 326 & 436 & $36 \%$ & $54 \%$ & $34 \%$ & $179 \%$ \\
\hline 14 & Animal \& Plant Sciences & 298 & 418 & 348 & 392 & $40 \%$ & $-17 \%$ & $13 \%$ & $32 \%$ \\
\hline 15 & Entomology/Pest Control & 141 & 272 & 333 & 391 & $93 \%$ & $22 \%$ & $17 \%$ & $177 \%$ \\
\hline 16 & Physical Chem/Chemical Phys & 158 & 330 & 313 & 373 & $109 \%$ & $-5 \%$ & $19 \%$ & $136 \%$ \\
\hline 17 & Pharmacology \& Toxicology & 185 & 273 & 316 & 364 & $48 \%$ & $16 \%$ & $15 \%$ & $97 \%$ \\
\hline 18 & Spectrosc/Instrum/Analyt Sci & 158 & 300 & 380 & 361 & $90 \%$ & $27 \%$ & $-5 \%$ & $128 \%$ \\
\hline
\end{tabular}




\begin{tabular}{|c|c|c|c|c|c|c|c|c|c|}
\hline \multirow[b]{2}{*}{ Rank } & \multirow[b]{2}{*}{ Discipline } & \multicolumn{4}{|c|}{ Number of publications } & \multicolumn{4}{|c|}{ Change in number of publications over time } \\
\hline & & 81-85 & $90-94$ & $95-99$ & 00-04 & $\begin{array}{c}\% \text { change } \\
81-85 \text { to } \\
90-94\end{array}$ & $\begin{array}{c}\% \text { change } \\
90-94 \text { to } \\
95-99\end{array}$ & $\begin{array}{c}\% \text { change } \\
95-99 \text { to } \\
00-04\end{array}$ & $\begin{array}{c}\% \text { Change } \\
81-85 \text { to } \\
00-04\end{array}$ \\
\hline 19 & Biology & 73 & 162 & 190 & 358 & $122 \%$ & $17 \%$ & $88 \%$ & $390 \%$ \\
\hline 20 & Medical Res General Topics & 209 & 302 & 347 & 353 & $44 \%$ & $15 \%$ & $2 \%$ & $69 \%$ \\
\hline 21 & Clin Immunol \& Infect Dis & 33 & 91 & 210 & 352 & $176 \%$ & $131 \%$ & $68 \%$ & $967 \%$ \\
\hline 22 & Psychology & 144 & 282 & 433 & 346 & $96 \%$ & $54 \%$ & $-20 \%$ & $140 \%$ \\
\hline 23 & Medical Res Organs \& Syst & 283 & 410 & 324 & 344 & $45 \%$ & $-21 \%$ & $6 \%$ & $22 \%$ \\
\hline 24 & Materials Sci and Engn & 160 & 333 & 309 & 343 & $108 \%$ & $-7 \%$ & $11 \%$ & $114 \%$ \\
\hline 25 & Neurosciences \& Behavior & 106 & 146 & 192 & 334 & $38 \%$ & $32 \%$ & $74 \%$ & $215 \%$ \\
\hline 26 & Organic Chem/Polymer Sci & 207 & 302 & 258 & 326 & $46 \%$ & $-15 \%$ & $26 \%$ & $57 \%$ \\
\hline 27 & Geol/Petrol/Mining Engn & 211 & 291 & 255 & 323 & $38 \%$ & $-12 \%$ & $27 \%$ & $53 \%$ \\
\hline 28 & Immunology & 60 & 106 & 210 & 298 & $77 \%$ & $98 \%$ & $42 \%$ & $397 \%$ \\
\hline 29 & Chemistry & 318 & 317 & 335 & 291 & $0 \%$ & $6 \%$ & $-13 \%$ & $-8 \%$ \\
\hline 30 & Cardiovasc \& Respirat Syst & 195 & 271 & 227 & 288 & $39 \%$ & $-16 \%$ & $27 \%$ & $48 \%$ \\
\hline 31 & Mathematics & 184 & 220 & 286 & 275 & $20 \%$ & $30 \%$ & $-4 \%$ & $49 \%$ \\
\hline 32 & Biochemistry \& Biophysics & 249 & 278 & 212 & 271 & $12 \%$ & $-24 \%$ & $28 \%$ & $9 \%$ \\
\hline 33 & Elect \& Electronic Engn & 154 & 252 & 304 & 266 & $64 \%$ & $21 \%$ & $-13 \%$ & $73 \%$ \\
\hline 34 & Medical Res Diag \& Treatmt & 238 & 345 & 287 & 254 & $45 \%$ & $-17 \%$ & $-11 \%$ & $7 \%$ \\
\hline 35 & Surgery & 245 & 356 & 303 & 229 & $45 \%$ & $-15 \%$ & $-24 \%$ & $-7 \%$ \\
\hline 36 & Chemistry \& Analysis & 218 & 277 & 235 & 228 & $27 \%$ & $-15 \%$ & $-3 \%$ & $5 \%$ \\
\hline 37 & Public HIth \& Hlth Care Sci & 23 & 63 & 124 & 228 & $174 \%$ & $97 \%$ & $84 \%$ & $891 \%$ \\
\hline 38 & Molecular Biology \& Genetics & 70 & 195 & 220 & 226 & $179 \%$ & $13 \%$ & $3 \%$ & $223 \%$ \\
\hline 39 & Chemical Engineering & 80 & 119 & 210 & 222 & $49 \%$ & $76 \%$ & $6 \%$ & $178 \%$ \\
\hline 40 & Pediatrics & 68 & 163 & 183 & 215 & $140 \%$ & $12 \%$ & $17 \%$ & $216 \%$ \\
\hline 41 & Reproductive Medicine & 91 & 154 & 162 & 211 & $69 \%$ & $5 \%$ & $30 \%$ & $132 \%$ \\
\hline 42 & Political Sci \& Public Admin & 42 & 144 & 198 & 206 & $243 \%$ & $38 \%$ & $4 \%$ & $390 \%$ \\
\hline 43 & Economics & 101 & 131 & 139 & 201 & $30 \%$ & $6 \%$ & $45 \%$ & $99 \%$ \\
\hline 44 & Environmt Med \& Public HIth & 48 & 134 & 151 & 192 & $179 \%$ & $13 \%$ & $27 \%$ & $300 \%$ \\
\hline 45 & Resrch/Lab Med \& Med Techn & 100 & 138 & 202 & 190 & $38 \%$ & $46 \%$ & $-6 \%$ & $90 \%$ \\
\hline 46 & Inorganic \& Nucl Chemistry & 81 & 255 & 176 & 187 & $215 \%$ & $-31 \%$ & $6 \%$ & $131 \%$ \\
\hline 47 & Mechanical Engineering & 96 & 105 & 170 & 183 & $9 \%$ & $62 \%$ & $8 \%$ & $91 \%$ \\
\hline 48 & Environ Studies Geog \& Dev & 31 & 79 & 129 & 172 & $155 \%$ & $63 \%$ & $33 \%$ & $455 \%$ \\
\hline 49 & Experimental Biology & 104 & 146 & 124 & 160 & $40 \%$ & $-15 \%$ & $29 \%$ & $54 \%$ \\
\hline 50 & Cardiovasc \& Hematology Res & 189 & 216 & 176 & 154 & $14 \%$ & $-19 \%$ & $-13 \%$ & $-19 \%$ \\
\hline 51 & Education & 25 & 74 & 119 & 151 & $196 \%$ & $61 \%$ & $27 \%$ & $504 \%$ \\
\hline 52 & Biotechnol \& Appl Microbiol & 39 & 96 & 123 & 147 & $146 \%$ & $28 \%$ & $20 \%$ & $277 \%$ \\
\hline 53 & Agriculture/Agronomy & 58 & 96 & 114 & 143 & $66 \%$ & $19 \%$ & $25 \%$ & $147 \%$ \\
\hline 54 & Instrumentation/Measurement & 22 & 138 & 158 & 141 & $527 \%$ & $14 \%$ & $-11 \%$ & $541 \%$ \\
\hline 55 & Agricultural Chemistry & 82 & 126 & 124 & 139 & $54 \%$ & $-2 \%$ & $12 \%$ & $70 \%$ \\
\hline 56 & Philosophy & 97 & 111 & 125 & 130 & $14 \%$ & $13 \%$ & $4 \%$ & $34 \%$ \\
\hline 57 & Physiology & 76 & 127 & 111 & 128 & $67 \%$ & $-13 \%$ & $15 \%$ & $68 \%$ \\
\hline 58 & Literature & 83 & 177 & 155 & 127 & $113 \%$ & $-12 \%$ & $-18 \%$ & $53 \%$ \\
\hline 59 & Endocrinol Nutrit \& Metab & 90 & 119 & 123 & 121 & $32 \%$ & $3 \%$ & $-2 \%$ & $34 \%$ \\
\hline 60 & Oncogenesis \& Cancer Res & 103 & 163 & 134 & 119 & $58 \%$ & $-18 \%$ & $-11 \%$ & $16 \%$ \\
\hline 61 & Engineering Mathematics & 53 & 64 & 83 & 115 & $21 \%$ & $30 \%$ & $39 \%$ & $117 \%$ \\
\hline 62 & Archaeology & 19 & 33 & 64 & 113 & $74 \%$ & $94 \%$ & $77 \%$ & $495 \%$ \\
\hline
\end{tabular}




\begin{tabular}{|c|c|c|c|c|c|c|c|c|c|}
\hline \multirow[b]{2}{*}{ Rank } & \multirow[b]{2}{*}{ Discipline } & \multicolumn{4}{|c|}{ Number of publications } & \multicolumn{4}{|c|}{ Change in number of publications over time } \\
\hline & & $81-85$ & $90-94$ & $95-99$ & 00-04 & $\begin{array}{c}\% \text { change } \\
81-85 \text { to } \\
90-94\end{array}$ & $\begin{array}{c}\% \text { change } \\
90-94 \text { to } \\
95-99\end{array}$ & $\begin{array}{c}\% \text { change } \\
95-99 \text { to } \\
00-04\end{array}$ & $\begin{array}{c}\% \text { Change } \\
81-85 \text { to } \\
00-04\end{array}$ \\
\hline 63 & History & 39 & 140 & 116 & 110 & $259 \%$ & $-17 \%$ & $-5 \%$ & $182 \%$ \\
\hline 64 & Orthopedics \& Sports Med & 48 & 94 & 80 & 110 & $96 \%$ & $-15 \%$ & $38 \%$ & $129 \%$ \\
\hline 65 & Civil Engineering & 46 & 95 & 104 & 107 & $107 \%$ & $9 \%$ & $3 \%$ & $133 \%$ \\
\hline 66 & Anesthesia \& Intensive Care & 72 & 137 & 107 & 103 & $90 \%$ & $-22 \%$ & $-4 \%$ & $43 \%$ \\
\hline 67 & Cell \& Developmental Biol & 26 & 59 & 79 & 102 & $127 \%$ & $34 \%$ & $29 \%$ & $292 \%$ \\
\hline 68 & Anthropology & 23 & 72 & 83 & 100 & $213 \%$ & $15 \%$ & $20 \%$ & $335 \%$ \\
\hline 69 & Sociology \& Social Sciences & 18 & 32 & 61 & 100 & $78 \%$ & $91 \%$ & $64 \%$ & $456 \%$ \\
\hline 70 & Pharmacology/Toxicology & 84 & 112 & 109 & 97 & $33 \%$ & $-3 \%$ & $-11 \%$ & $15 \%$ \\
\hline 71 & Psychiatry & 22 & 26 & 73 & 94 & $18 \%$ & $181 \%$ & $29 \%$ & $327 \%$ \\
\hline 72 & Computer Sci \& Engineering & 32 & 50 & 57 & 93 & $56 \%$ & $14 \%$ & $63 \%$ & $191 \%$ \\
\hline 73 & Clin Psychology \& Psychiatry & 16 & 19 & 49 & 88 & $19 \%$ & $158 \%$ & $80 \%$ & $450 \%$ \\
\hline 74 & Oncology & 96 & 100 & 105 & 86 & $4 \%$ & $5 \%$ & $-18 \%$ & $-10 \%$ \\
\hline 75 & Dentistry/Oral Surgery \& Med & 99 & 91 & 89 & 85 & $-8 \%$ & $-2 \%$ & $-4 \%$ & $-14 \%$ \\
\hline 76 & Neurology & 50 & 67 & 63 & 81 & $34 \%$ & $-6 \%$ & $29 \%$ & $62 \%$ \\
\hline 77 & Environmt Engineering/Energy & 14 & 49 & 52 & 80 & $250 \%$ & $6 \%$ & $54 \%$ & $471 \%$ \\
\hline 78 & Endocrinol Metab \& Nutrit & 31 & 56 & 38 & 76 & $81 \%$ & $-32 \%$ & $100 \%$ & $145 \%$ \\
\hline 79 & Gastroenterol and Hepatology & 85 & 87 & 86 & 73 & $2 \%$ & $-1 \%$ & $-15 \%$ & $-14 \%$ \\
\hline 80 & Engineering Mgmt/General & 23 & 33 & 70 & 71 & $43 \%$ & $112 \%$ & $1 \%$ & $209 \%$ \\
\hline 81 & Library \& Information Sci & 11 & 64 & 54 & 68 & $482 \%$ & $-16 \%$ & $26 \%$ & $518 \%$ \\
\hline 82 & Radiol Nucl Med \& Imaging & 120 & 95 & 73 & 65 & $-21 \%$ & $-23 \%$ & $-11 \%$ & $-46 \%$ \\
\hline 83 & Metallurgy & 46 & 84 & 64 & 59 & $83 \%$ & $-24 \%$ & $-8 \%$ & $28 \%$ \\
\hline 84 & Optics \& Acoustics & 25 & 85 & 82 & 57 & $240 \%$ & $-4 \%$ & $-30 \%$ & $128 \%$ \\
\hline 85 & Urology & 57 & 75 & 51 & 57 & $32 \%$ & $-32 \%$ & $12 \%$ & $0 \%$ \\
\hline 86 & Management & 23 & 29 & 49 & 56 & $26 \%$ & $69 \%$ & $14 \%$ & $143 \%$ \\
\hline 87 & Al Robotics \& Auto Control & 24 & 44 & 56 & 54 & $83 \%$ & $27 \%$ & $-4 \%$ & $125 \%$ \\
\hline 88 & Social Work \& Social Policy & 6 & 25 & 36 & 54 & $317 \%$ & $44 \%$ & $50 \%$ & $800 \%$ \\
\hline 89 & Haematology & 50 & 59 & 45 & 43 & $18 \%$ & $-24 \%$ & $-4 \%$ & $-14 \%$ \\
\hline 90 & Ophthalmology & 10 & 72 & 54 & 43 & $620 \%$ & $-25 \%$ & $-20 \%$ & $330 \%$ \\
\hline 91 & Health Care Sci \& Services & 6 & 10 & 38 & 41 & $67 \%$ & $280 \%$ & $8 \%$ & $583 \%$ \\
\hline 92 & Rheumatology & 21 & 21 & 31 & 34 & $0 \%$ & $48 \%$ & $10 \%$ & $62 \%$ \\
\hline 93 & Dermatology & 28 & 46 & 44 & 33 & $64 \%$ & $-4 \%$ & $-25 \%$ & $18 \%$ \\
\hline 94 & Rehabilitation & 8 & 9 & 17 & 32 & $13 \%$ & $89 \%$ & $88 \%$ & $300 \%$ \\
\hline 95 & Religion \& Theology & 21 & 38 & 49 & 31 & $81 \%$ & $29 \%$ & $-37 \%$ & $48 \%$ \\
\hline 96 & Communication & 5 & 12 & 12 & 29 & $140 \%$ & $0 \%$ & $142 \%$ & $480 \%$ \\
\hline 97 & Info Technol \& Commun Syst & 8 & 32 & 18 & 29 & $300 \%$ & $-44 \%$ & $61 \%$ & $263 \%$ \\
\hline 98 & Otolaryngology & 35 & 45 & 50 & 29 & $29 \%$ & $11 \%$ & $-42 \%$ & $-17 \%$ \\
\hline 99 & Performing Arts & 5 & 12 & 14 & 29 & $140 \%$ & $17 \%$ & $107 \%$ & $480 \%$ \\
\hline 100 & Language \& Linguistics & 12 & 30 & 23 & 27 & $150 \%$ & $-23 \%$ & $17 \%$ & $125 \%$ \\
\hline 101 & Aerospace Engineering & 6 & 19 & 24 & 16 & $217 \%$ & $26 \%$ & $-33 \%$ & $167 \%$ \\
\hline 102 & General & 14 & 13 & 25 & 16 & $-7 \%$ & $92 \%$ & $-36 \%$ & $14 \%$ \\
\hline 103 & Nuclear Engineering & 52 & 18 & 12 & 15 & $-65 \%$ & $-33 \%$ & $25 \%$ & $-71 \%$ \\
\hline 104 & Art \& Architecture & 5 & 5 & 11 & 13 & $0 \%$ & $120 \%$ & $18 \%$ & $160 \%$ \\
\hline 105 & Classical Studies & 12 & 27 & 30 & 11 & $125 \%$ & $11 \%$ & $-63 \%$ & $-8 \%$ \\
\hline 106 & Law & 2 & 7 & 7 & 5 & $250 \%$ & $0 \%$ & $-29 \%$ & $150 \%$ \\
\hline
\end{tabular}

As journals can publish articles in one or more neighbouring or overlapping scientific disciplines, it is useful to aggregate the various disciplines into larger groups. Tables 2, 3 and 4 aggregate the number of publications to larger disciplinary groupings: Table 2 shows the number of South African publications in 20 broad natural science disciplines, while Table 3 
shows the number of publications in broad social science disciplines and Table 4 analogously the publications in broad humanities and arts disciplines.

Applying the same normative threshold (500 publications per five year period) to the larger groups, one can conclude that fourteen disciplines met the criterion in the natural sciences, while in the social sciences and in the humanities and arts no specific discipline met the threshold criterion. High growth rates in the number of publications in the social sciences and the humanities and arts (as groups) may, however, be indicative of possible opportunities for the establishment of journals covering these broad fields.

Table 2: South African Natural Science publications in ISI and change over time

\begin{tabular}{|c|c|c|c|c|c|c|c|c|c|}
\hline \multirow[b]{2}{*}{ Rank } & \multirow[b]{2}{*}{ Discipline } & \multicolumn{4}{|c|}{ Number of publications } & \multicolumn{4}{|c|}{ Change in number of publications over time } \\
\hline & & $81-85$ & $90-94$ & $95-99$ & 00-04 & $\begin{array}{c}\% \text { change } \\
81-85 \text { to } \\
90-94\end{array}$ & $\begin{array}{c}\% \text { change } \\
90-94 \text { to } \\
95-99\end{array}$ & $\begin{array}{c}\% \text { change } \\
95-99 \text { to } \\
00-04\end{array}$ & $\begin{array}{c}\% \text { Change } \\
81-85 \text { to } \\
00-04\end{array}$ \\
\hline 1 & Clinical Medicine & 4,213 & 4,035 & 3,797 & 3,684 & $-4 \%$ & $-6 \%$ & $-3 \%$ & $-13 \%$ \\
\hline 2 & Plant \& Animal Science & 2,300 & 3,628 & 3,306 & 3,621 & $58 \%$ & $-9 \%$ & $10 \%$ & $57 \%$ \\
\hline 3 & Chemistry & 1,030 & 1,640 & 1,622 & 1,744 & $59 \%$ & $-1 \%$ & $8 \%$ & $69 \%$ \\
\hline 4 & Geosciences & 497 & 897 & 1,057 & 1,302 & $80 \%$ & $18 \%$ & $23 \%$ & $162 \%$ \\
\hline 5 & Ecology/Environment & 437 & 758 & 959 & 1,187 & $73 \%$ & $27 \%$ & $24 \%$ & $172 \%$ \\
\hline 6 & Biology \& Biochemistry & 624 & 911 & 852 & 1,112 & $46 \%$ & $-6 \%$ & $31 \%$ & $78 \%$ \\
\hline 7 & Physics & 555 & 1,028 & 1,094 & 1,101 & $85 \%$ & $6 \%$ & $1 \%$ & $98 \%$ \\
\hline 8 & Engineering & 413 & 691 & 881 & 915 & $67 \%$ & $27 \%$ & $4 \%$ & $122 \%$ \\
\hline 9 & Multdisciplinary & 443 & 638 & 567 & 659 & $44 \%$ & $-11 \%$ & $16 \%$ & $49 \%$ \\
\hline 10 & Microbiology & 237 & 396 & 433 & 545 & $67 \%$ & $9 \%$ & $26 \%$ & $130 \%$ \\
\hline 11 & Agricultural Sciences & 218 & 328 & 401 & 500 & $50 \%$ & $22 \%$ & $25 \%$ & $129 \%$ \\
\hline 12 & Psychology/Psychiatry & 166 & 308 & 506 & 440 & $86 \%$ & $64 \%$ & $-13 \%$ & $165 \%$ \\
\hline 13 & Space Science & 218 & 331 & 428 & 427 & $52 \%$ & $29 \%$ & $0 \%$ & $96 \%$ \\
\hline 14 & Materials Science & 206 & 417 & 373 & 402 & $102 \%$ & $-11 \%$ & $8 \%$ & $95 \%$ \\
\hline 15 & Pharmacology & 185 & 273 & 316 & 364 & $48 \%$ & $16 \%$ & $15 \%$ & $97 \%$ \\
\hline 16 & Neurosciences \& Behavior & 106 & 146 & 192 & 334 & $38 \%$ & $32 \%$ & $74 \%$ & $215 \%$ \\
\hline 17 & Molecular Biology \& Genetics & 96 & 254 & 299 & 328 & $165 \%$ & $18 \%$ & $10 \%$ & $242 \%$ \\
\hline 18 & Immunology & 60 & 106 & 210 & 298 & $77 \%$ & $98 \%$ & $42 \%$ & $397 \%$ \\
\hline 19 & Mathematics & 184 & 220 & 286 & 275 & $20 \%$ & $30 \%$ & $-4 \%$ & $49 \%$ \\
\hline 20 & Computer Science & 40 & 82 & 75 & 122 & $105 \%$ & $-9 \%$ & $63 \%$ & $205 \%$ \\
\hline \multicolumn{2}{|c|}{ Sciences } & 12,228 & 17,087 & 17,654 & 19,360 & $40 \%$ & $3 \%$ & $10 \%$ & $58 \%$ \\
\hline
\end{tabular}

Table 3: South African Social Science publications in ISI and change over time

\begin{tabular}{|c|c|c|c|c|c|c|c|c|c|}
\hline \multirow[b]{2}{*}{ Rank } & \multirow[b]{2}{*}{ Discipline } & \multicolumn{4}{|c|}{ Number of publications } & \multicolumn{4}{|c|}{ Change in number of publications over time } \\
\hline & & $81-85$ & $90-94$ & $95-99$ & 00-04 & $\begin{array}{c}\% \text { change } \\
81-85 \text { to } \\
90-94\end{array}$ & $\begin{array}{c}\% \text { change } \\
90-94 \text { to } \\
95-99\end{array}$ & $\begin{array}{c}\% \text { change } \\
95-99 \text { to } \\
00-04\end{array}$ & $\begin{array}{c}\% \text { Change } \\
81-85 \text { to } \\
00-04\end{array}$ \\
\hline 1 & Social Sciences general & 167 & 500 & 714 & 989 & $199 \%$ & $43 \%$ & $39 \%$ & $492 \%$ \\
\hline 2 & Economics \& Business & 124 & 160 & 188 & 257 & $29 \%$ & $18 \%$ & $37 \%$ & $107 \%$ \\
\hline 3 & Education & 25 & 74 & 119 & 151 & $196 \%$ & $61 \%$ & $27 \%$ & $504 \%$ \\
\hline 4 & Law & 2 & 7 & 7 & 5 & $250 \%$ & $0 \%$ & $-29 \%$ & $150 \%$ \\
\hline \multicolumn{2}{|c|}{ Socialsciences } & 318 & 741 & 1,028 & 1,402 & $133 \%$ & $39 \%$ & $36 \%$ & $341 \%$ \\
\hline
\end{tabular}


Table 4: South African Arts \& Humanities publications in ISI and change over time

\begin{tabular}{|c|c|c|c|c|c|c|c|c|c|}
\hline \multirow[b]{2}{*}{ Rank } & \multirow[b]{2}{*}{ Discipline } & \multicolumn{3}{|c|}{ Number of publications } & \multirow[b]{2}{*}{ 00-04 } & \multicolumn{4}{|c|}{ Change in number of publications over time } \\
\hline & & 81-85 & $90-94$ & 95-99 & & $\begin{array}{c}\% \text { change } \\
81-85 \text { to } \\
90-94\end{array}$ & $\begin{array}{c}\% \text { change } \\
90-94 \text { to } \\
95-99\end{array}$ & $\begin{array}{c}\% \text { change } \\
95-99 \text { to } \\
00-04\end{array}$ & $\begin{array}{c}\% \text { Change } \\
81-85 \text { to } \\
00-04\end{array}$ \\
\hline 1 & Philosophy & 97 & 111 & 125 & 130 & $14 \%$ & $13 \%$ & $4 \%$ & $34 \%$ \\
\hline 2 & Literature & 83 & 177 & 155 & 127 & $113 \%$ & $-12 \%$ & $-18 \%$ & $53 \%$ \\
\hline 3 & Archaeology & 19 & 33 & 64 & 113 & $74 \%$ & $94 \%$ & $77 \%$ & $495 \%$ \\
\hline 4 & History & 39 & 140 & 116 & 110 & $259 \%$ & $-17 \%$ & $-5 \%$ & $182 \%$ \\
\hline 5 & Religion \& Theology & 21 & 38 & 49 & 31 & $81 \%$ & $29 \%$ & $-37 \%$ & $48 \%$ \\
\hline 6 & Performing Arts & 5 & 12 & 14 & 29 & $140 \%$ & $17 \%$ & $107 \%$ & $480 \%$ \\
\hline 7 & Language \& Linguistics & 12 & 30 & 23 & 27 & $150 \%$ & $-23 \%$ & $17 \%$ & $125 \%$ \\
\hline 8 & General & 14 & 13 & 25 & 16 & $-7 \%$ & $92 \%$ & $-36 \%$ & $14 \%$ \\
\hline 9 & Art \& Architecture & 5 & 5 & 11 & 13 & $0 \%$ & $120 \%$ & $18 \%$ & $160 \%$ \\
\hline 10 & Classical Studies & 12 & 27 & 30 & 11 & $125 \%$ & $11 \%$ & $-63 \%$ & $-8 \%$ \\
\hline \multicolumn{2}{|c|}{ Arts \& Humanities } & 307 & 586 & 612 & 607 & $91 \%$ & $4 \%$ & $-1 \%$ & $98 \%$ \\
\hline
\end{tabular}

\section{THE CITATION IMPACT OF SOUTH AFRICAN PUBLICATIONS}

Citations are in many ways the currency of science and technology (see Cronin, 2005). They inter alia reflect recognition, visibility and utility of research produced by particular research groups. (Indexed) citation analysis reflects scientific impact and provides useful supplementary tools in the evaluation of academic research (Garfield, 1955; Moed, 2005). Its application usually stimulates useful discussion among scientists and research managers about publication strategies and research directions; helps peer-reviewers to make quality judgments; and enables policy officials and science administrators to raise critical questions about aspects of scientific activity and provides insights for policy and funding decisions.

Citation Impact analysis (number of citations received per paper published) is in certain ways superior to simple publication counting or listing, and provides additional insights. Publication counts on their own may fail to "distinguish between the fluency of genius and the loud noises of empty vessels" (Nature editorial, 1970). For example, publication counting can tell us little about the effect of a laboratory's work on others, while citation analysis can assist in such efforts.

In the context of journal assessment, citation analysis provides the prevailingly most general and well-established quantitative methodology (but see Lewison, 2005); the general maxim is that journals whose articles are never or very rarely cited will eventually lose their audience and authors.

Table 5 shows the impact of South African articles relative to world output per scientific discipline over the same four 5-year periods. "Impact relative to world" is defined as the citation impact for the country's discipline divided by the citation impact of the world for the particular discipline. The table shows the 106 disciplines, the relative impact, the impact of the country's discipline, and the impact base (number of citations per paper for the world's articles in the discipline). The names of the disciplines appear in descending order according to the relative impact during 2000-2004.

The table identifies 22 disciplines with relative impact equal to, or higher than the world impact (relative impact equal to, or higher than one). Oncology had the highest relative impact (2.17) during the most recent five years. Anthropology and classical studies followed, with relative impacts 1.99 and 1.80 , respectively. It should be emphasised that the impact tables should be read in conjunction with the tables showing the actual number of publications: sets of small numbers of articles have a better chance of exhibiting high relative impacts as a large number of citations to one or two articles could artificially inflate the relative impact of the whole group. 
Table 5: Relative impact of 106 disciplines: South Africa

\begin{tabular}{|c|c|c|c|c|c|c|c|c|c|c|c|c|c|}
\hline \multirow[b]{2}{*}{ Rank } & \multirow[b]{2}{*}{ Discipline } & \multicolumn{3}{|c|}{$81-85$} & \multicolumn{3}{|c|}{ 90-94 } & \multicolumn{3}{|c|}{$95-99$} & \multicolumn{3}{|c|}{ 00-04 } \\
\hline & & $\begin{array}{c}\text { Relative } \\
\text { imp }\end{array}$ & Impact & $\begin{array}{l}\text { Imp } \\
\text { base }\end{array}$ & $\begin{array}{c}\text { Relative } \\
\text { imp }\end{array}$ & Impact & $\begin{array}{l}\text { Imp } \\
\text { base }\end{array}$ & $\begin{array}{c}\text { Relative } \\
\text { imp }\end{array}$ & Impact & $\underset{\text { base }}{\text { Imp }}$ & $\begin{array}{c}\text { Relative } \\
\text { imp }\end{array}$ & Impact & $\begin{array}{l}\text { Imp } \\
\text { base }\end{array}$ \\
\hline 1 & Aerospace Engineering & 0.00 & 0.00 & 0.55 & 0.26 & 0.16 & 0.62 & 0.90 & 0.75 & 0.83 & 0.21 & 0.19 & 0.92 \\
\hline 2 & Agricultural Chemistry & 0.92 & 2.04 & 2.21 & 1.58 & 3.48 & 2.20 & 1.05 & 2.73 & 2.60 & 0.81 & 2.70 & 3.34 \\
\hline 3 & Agriculture/Agronomy & 2.77 & 1.83 & 0.66 & 0.70 & 0.58 & 0.83 & 0.83 & 0.95 & 1.15 & 0.91 & 1.30 & 1.43 \\
\hline 4 & Al Robotics \& Auto Control & 0.62 & 0.88 & 1.42 & 0.54 & 0.64 & 1.19 & 0.60 & 0.75 & 1.24 & 0.56 & 0.89 & 1.59 \\
\hline 5 & Anesthesia \& Intensive Care & 0.86 & 2.14 & 2.50 & 0.71 & 1.67 & 2.36 & 1.06 & 3.45 & 3.26 & 0.80 & 2.79 & 3.48 \\
\hline 6 & Animal \& Plant Sciences & 0.64 & 2.03 & 3.19 & 0.44 & 1.77 & 3.98 & 0.79 & 4.00 & 5.09 & 0.40 & 2.47 & 6.10 \\
\hline 7 & Animal Sciences & 0.64 & 0.96 & 1.49 & 0.54 & 0.87 & 1.62 & 0.69 & 1.31 & 1.89 & 0.71 & 1.53 & 2.17 \\
\hline 8 & Anthropology & 1.07 & 1.30 & 1.22 & 1.25 & 1.83 & 1.46 & 1.39 & 2.00 & 1.44 & 1.99 & 3.14 & 1.58 \\
\hline 9 & Appl Phys/Cond Matt/Mat Sci & 0.66 & 1.82 & 2.76 & 0.66 & 1.94 & 2.94 & 0.69 & 1.95 & 2.83 & 0.62 & 1.93 & 3.13 \\
\hline 10 & Aquatic Sciences & 1.41 & 3.37 & 2.39 & 0.85 & 1.92 & 2.26 & 0.85 & 2.31 & 2.72 & 1.03 & 3.03 & 2.93 \\
\hline 11 & Archaeology & 0.79 & 0.63 & 0.80 & 1.46 & 1.45 & 0.99 & 1.34 & 1.27 & 0.95 & 1.37 & 1.55 & 1.13 \\
\hline 12 & Art \& Architecture & 0.00 & 0.00 & 0.11 & 2.00 & 0.20 & 0.10 & 0.00 & 0.00 & 0.09 & 0.00 & 0.00 & 0.10 \\
\hline 13 & Biochemistry \& Biophysics & 0.50 & 3.38 & 6.75 & 0.38 & 3.11 & 8.14 & 0.42 & 3.75 & 8.89 & 0.53 & 4.79 & 9.01 \\
\hline 14 & Biology & 1.83 & 4.34 & 2.37 & 0.79 & 2.49 & 3.14 & 0.89 & 3.79 & 4.25 & 0.84 & 4.28 & 5.08 \\
\hline 15 & Biotechnol \& Appl Microbiol & 1.14 & 2.38 & 2.08 & 0.58 & 1.36 & 2.35 & 0.71 & 2.07 & 2.93 & 0.74 & 3.00 & 4.04 \\
\hline 16 & Cardiovasc \& Hematology Res & 0.92 & 4.92 & 5.35 & 0.70 & 3.90 & 5.57 & 0.63 & 4.56 & 7.20 & 1.08 & 9.23 & 8.57 \\
\hline 17 & Cardiovasc \& Respirat Syst & 0.67 & 2.37 & 3.54 & 0.79 & 2.76 & 3.48 & 0.80 & 3.71 & 4.64 & 0.97 & 5.49 & 5.67 \\
\hline 18 & Cell \& Developmental Biol & 0.37 & 3.42 & 9.22 & 0.12 & 1.58 & 13.19 & 0.20 & 3.00 & 14.64 & 0.26 & 3.82 & 14.66 \\
\hline 19 & Chemical Engineering & 0.90 & 1.15 & 1.28 & 0.92 & 1.34 & 1.45 & 0.79 & 1.49 & 1.88 & 0.75 & 1.57 & 2.09 \\
\hline 20 & Chemistry & 0.63 & 1.73 & 2.73 & 0.70 & 2.26 & 3.22 & 0.46 & 1.93 & 4.16 & 0.52 & 2.82 & 5.39 \\
\hline 21 & Chemistry \& Analysis & 0.66 & 2.82 & 4.30 & 0.78 & 3.73 & 4.76 & 0.58 & 3.23 & 5.56 & 0.71 & 4.61 & 6.50 \\
\hline 22 & Civil Engineering & 1.60 & 1.39 & 0.87 & 0.74 & 0.73 & 0.99 & 0.60 & 0.69 & 1.15 & 1.13 & 1.44 & 1.28 \\
\hline 23 & Classical Studies & 0.93 & 0.25 & 0.27 & 0.34 & 0.11 & 0.32 & 0.12 & 0.03 & 0.25 & 1.80 & 0.36 & 0.20 \\
\hline 24 & Clin Immunol \& Infect Dis & 0.84 & 3.06 & 3.64 & 1.20 & 5.33 & 4.46 & 1.04 & 5.33 & 5.11 & 1.16 & 7.22 & 6.20 \\
\hline 25 & Clin Psychology \& Psychiatry & 0.34 & 1.12 & 3.29 & 0.66 & 2.32 & 3.51 & 0.92 & 4.10 & 4.44 & 0.99 & 5.58 & 5.63 \\
\hline 26 & Communication & 0.00 & 0.00 & 0.94 & 0.64 & 0.67 & 1.04 & 0.99 & 1.08 & 1.09 & 0.42 & 0.55 & 1.31 \\
\hline 27 & Computer Sci \& Engineering & 0.59 & 0.91 & 1.53 & 0.67 & 0.70 & 1.05 & 0.50 & 0.53 & 1.06 & 0.95 & 1.27 & 1.33 \\
\hline 28 & Dentistry/Oral Surgery \& Med & 0.85 & 1.22 & 1.44 & 0.81 & 1.24 & 1.54 & 0.57 & 1.17 & 2.06 & 0.72 & 1.67 & 2.33 \\
\hline 29 & Dermatology & 0.55 & 1.18 & 2.13 & 0.51 & 1.13 & 2.23 & 0.57 & 1.64 & 2.89 & 0.93 & 2.94 & 3.17 \\
\hline 30 & Earth Sciences & 1.05 & 3.04 & 2.89 & 0.98 & 2.94 & 3.00 & 0.99 & 3.41 & 3.46 & 0.89 & 3.19 & 3.58 \\
\hline 31 & Economics & 0.17 & 0.19 & 1.14 & 0.21 & 0.30 & 1.40 & 0.24 & 0.38 & 1.57 & 0.40 & 0.67 & 1.69 \\
\hline 32 & Education & 1.01 & 0.72 & 0.71 & 1.46 & 1.49 & 1.02 & 0.60 & 0.61 & 1.02 & 0.46 & 0.46 & 0.99 \\
\hline 33 & Elect \& Electronic Engn & 0.19 & 0.29 & 1.53 & 0.34 & 0.48 & 1.42 & 0.45 & 0.68 & 1.50 & 0.66 & 1.07 & 1.61 \\
\hline 34 & Endocrinol Metab \& Nutrit & 0.78 & 4.77 & 6.09 & 0.55 & 2.93 & 5.29 & 0.46 & 3.18 & 6.90 & 0.51 & 3.82 & 7.51 \\
\hline 35 & Endocrinol Nutrit \& Metab & 0.61 & 3.21 & 5.27 & 0.75 & 4.18 & 5.54 & 0.64 & 3.94 & 6.20 & 0.84 & 5.87 & 6.99 \\
\hline 36 & Engineering Mathematics & 0.76 & 0.81 & 1.07 & 0.90 & 0.92 & 1.02 & 1.43 & 1.47 & 1.03 & 0.75 & 0.93 & 1.24 \\
\hline 37 & Engineering Mgmt/General & 0.84 & 0.57 & 0.68 & 1.13 & 0.70 & 0.62 & 0.57 & 0.47 & 0.83 & 0.56 & 0.55 & 0.99 \\
\hline 38 & Entomology/Pest Control & 0.44 & 0.57 & 1.31 & 0.70 & 0.99 & 1.42 & 0.65 & 1.18 & 1.82 & 1.20 & 2.47 & 2.05 \\
\hline 39 & Environ Studies Geog \& Dev & 1.17 & 1.03 & 0.88 & 0.64 & 0.70 & 1.09 & 0.54 & 0.78 & 1.45 & 0.73 & 1.22 & 1.66 \\
\hline 40 & Environment/Ecology & 0.82 & 1.63 & 1.98 & 0.72 & 1.46 & 2.02 & 0.74 & 2.03 & 2.76 & 0.85 & 2.86 & 3.36 \\
\hline 41 & Environmt Engineering/Energy & 0.78 & 0.86 & 1.10 & 0.62 & 0.82 & 1.32 & 0.25 & 0.50 & 1.98 & 0.60 & 1.61 & 2.67 \\
\hline 42 & Environmt Med \& Public Hlth & 0.82 & 1.81 & 2.22 & 0.62 & 1.66 & 2.66 & 0.81 & 2.75 & 3.41 & 0.76 & 3.03 & 3.98 \\
\hline 43 & Experimental Biology & 0.78 & 1.84 & 2.35 & 0.52 & 1.88 & 3.59 & 0.57 & 3.15 & 5.55 & 0.88 & 5.58 & 6.36 \\
\hline 44 & Food Science/Nutrition & 1.01 & 1.36 & 1.35 & 0.97 & 1.51 & 1.56 & 0.99 & 2.04 & 2.07 & 0.66 & 1.73 & 2.63 \\
\hline 45 & Gastroenterol and Hepatology & 1.37 & 4.71 & 3.43 & 0.61 & 2.10 & 3.42 & 1.17 & 5.64 & 4.83 & 0.74 & 4.18 & 5.68 \\
\hline
\end{tabular}




\begin{tabular}{|c|c|c|c|c|c|c|c|c|c|c|c|c|c|}
\hline \multirow[b]{2}{*}{ Rank } & \multirow[b]{2}{*}{ Discipline } & \multicolumn{3}{|c|}{ 81-85 } & \multicolumn{3}{|c|}{ 90-94 } & \multicolumn{3}{|c|}{ 95-99 } & \multicolumn{3}{|c|}{ 00-04 } \\
\hline & & $\begin{array}{c}\text { Relative } \\
\text { imp }\end{array}$ & Impact & $\begin{array}{c}\text { Imp } \\
\text { base }\end{array}$ & $\begin{array}{c}\text { Relative } \\
\text { imp }\end{array}$ & Impact & $\begin{array}{l}\text { Imp } \\
\text { base }\end{array}$ & $\begin{array}{l}\text { Relative } \\
\text { imp }\end{array}$ & Impact & $\begin{array}{l}\text { Imp } \\
\text { base }\end{array}$ & $\begin{array}{c}\text { Relative } \\
\text { imp }\end{array}$ & Impact & $\begin{array}{l}\text { Imp } \\
\text { base }\end{array}$ \\
\hline 46 & General & 0.91 & 0.29 & 0.32 & 0.00 & 0.00 & 0.23 & 0.77 & 0.20 & 0.26 & 1.65 & 0.38 & 0.23 \\
\hline 47 & General \& Internal Medicine & 0.50 & 1.24 & 2.49 & 0.50 & 1.82 & 3.64 & 0.44 & 2.51 & 5.66 & 0.66 & 4.60 & 7.02 \\
\hline 48 & Geol/Petrol/Mining Engn & 0.88 & 0.45 & 0.51 & 1.03 & 0.62 & 0.60 & 1.05 & 0.62 & 0.59 & 0.55 & 0.46 & 0.83 \\
\hline 49 & Health Care Sci \& Services & 0.00 & 0.00 & 1.42 & 0.48 & 0.80 & 1.68 & 0.48 & 1.05 & 2.18 & 0.69 & 1.73 & 2.52 \\
\hline 50 & Haematology & 1.49 & 7.22 & 4.85 & 0.27 & 1.54 & 5.72 & 0.38 & 2.69 & 7.14 & 0.89 & 6.40 & 7.20 \\
\hline 51 & History & 1.17 & 0.49 & 0.42 & 0.48 & 0.16 & 0.33 & 0.38 & 0.14 & 0.37 & 0.66 & 0.23 & 0.35 \\
\hline 52 & Immunology & 0.44 & 3.48 & 8.00 & 0.66 & 5.95 & 8.98 & 0.48 & 4.71 & 9.76 & 0.78 & 8.03 & 10.34 \\
\hline 53 & Info Technol \& Commun Syst & 0.66 & 0.75 & 1.13 & 0.72 & 0.66 & 0.92 & 0.64 & 0.78 & 1.21 & 0.94 & 1.34 & 1.42 \\
\hline 54 & Inorganic \& Nucl Chemistry & 0.75 & 2.00 & 2.65 & 1.18 & 3.00 & 2.55 & 1.03 & 2.92 & 2.83 & 0.83 & 2.83 & 3.40 \\
\hline 55 & Instrumentation/Measurement & 0.40 & 0.41 & 1.03 & 0.89 & 1.62 & 1.82 & 0.98 & 1.91 & 1.95 & 0.81 & 1.77 & 2.19 \\
\hline 56 & Language \& Linguistics & 1.40 & 0.67 & 0.48 & 0.48 & 0.20 & 0.42 & 1.11 & 0.39 & 0.35 & 1.63 & 0.67 & 0.41 \\
\hline 57 & Law & 0.00 & 0.00 & 0.30 & 0.15 & 0.29 & 1.93 & 0.28 & 0.71 & 2.52 & 0.00 & 0.00 & 2.31 \\
\hline 58 & Library \& Information Sci & 0.13 & 0.09 & 0.72 & 0.49 & 0.36 & 0.73 & 0.37 & 0.37 & 1.01 & 0.48 & 0.65 & 1.35 \\
\hline 59 & Literature & 0.46 & 0.11 & 0.24 & 0.69 & 0.11 & 0.16 & 0.21 & 0.03 & 0.14 & 1.00 & 0.12 & 0.12 \\
\hline 60 & Management & 0.59 & 0.57 & 0.96 & 0.35 & 0.45 & 1.30 & 0.42 & 0.67 & 1.61 & 0.26 & 0.50 & 1.95 \\
\hline 61 & Materials Sci and Engn & 0.84 & 1.31 & 1.56 & 0.94 & 1.61 & 1.72 & 0.86 & 1.62 & 1.89 & 0.70 & 1.71 & 2.46 \\
\hline 62 & Mathematics & 0.76 & 0.88 & 1.16 & 0.94 & 1.00 & 1.06 & 0.86 & 1.01 & 1.18 & 1.04 & 1.34 & 1.29 \\
\hline 63 & Mechanical Engineering & 0.27 & 0.25 & 0.93 & 0.94 & 1.01 & 1.08 & 0.71 & 0.85 & 1.19 & 0.60 & 0.91 & 1.51 \\
\hline 64 & Medical Res Diag \& Treatmt & 0.67 & 2.56 & 3.83 & 0.77 & 2.72 & 3.54 & 0.68 & 2.86 & 4.20 & 0.80 & 3.70 & 4.61 \\
\hline 65 & Medical Res General Topics & 0.84 & 4.58 & 5.43 & 0.72 & 4.20 & 5.83 & 0.73 & 5.60 & 7.72 & 0.94 & 8.56 & 9.06 \\
\hline 66 & Medical Res Organs \& Syst & 0.74 & 2.46 & 3.34 & 0.76 & 2.69 & 3.56 & 0.97 & 4.69 & 4.82 & 0.84 & 4.76 & 5.68 \\
\hline 67 & Metallurgy & 1.57 & 1.46 & 0.93 & 1.33 & 1.64 & 1.23 & 1.00 & 1.23 & 1.23 & 1.45 & 1.59 & 1.10 \\
\hline 68 & Microbiology & 0.75 & 3.17 & 4.20 & 0.68 & 3.66 & 5.39 & 0.78 & 4.70 & 6.02 & 0.96 & 6.32 & 6.60 \\
\hline 69 & Molecular Biology \& Genetics & 0.43 & 2.56 & 5.93 & 0.63 & 5.43 & 8.56 & 1.04 & 10.32 & 9.88 & 1.06 & 11.58 & 10.92 \\
\hline 70 & Multidisciplinary & 0.75 & 1.46 & 1.95 & 0.61 & 1.08 & 1.78 & 0.46 & 1.13 & 2.47 & 0.55 & 2.23 & 4.02 \\
\hline 71 & Neurology & 0.57 & 1.54 & 2.71 & 0.69 & 2.21 & 3.22 & 0.33 & 1.48 & 4.48 & 0.78 & 3.93 & 5.01 \\
\hline 72 & Neurosciences \& Behavior & 0.51 & 2.47 & 4.85 & 0.46 & 2.66 & 5.82 & 0.47 & 3.26 & 6.90 & 0.62 & 4.77 & 7.75 \\
\hline 73 & Nuclear Engineering & 1.01 & 1.67 & 1.66 & 0.36 & 0.39 & 1.07 & 0.81 & 1.00 & 1.24 & 0.34 & 0.47 & 1.37 \\
\hline 74 & Oncogenesis \& Cancer Res & 0.56 & 3.36 & 5.99 & 1.00 & 6.44 & 6.45 & 0.92 & 7.07 & 7.72 & 1.65 & 14.93 & 9.03 \\
\hline 75 & Oncology & 0.73 & 3.64 & 5.01 & 0.76 & 4.55 & 6.01 & 1.04 & 7.31 & 7.06 & 2.17 & 19.00 & 8.74 \\
\hline 76 & Ophthalmology & 0.82 & 1.40 & 1.70 & 0.59 & 0.92 & 1.55 & 1.44 & 3.33 & 2.31 & 1.63 & 4.60 & 2.82 \\
\hline 77 & Optics \& Acoustics & 0.85 & 1.84 & 2.16 & 0.38 & 0.76 & 2.02 & 0.62 & 1.34 & 2.16 & 0.73 & 1.56 & 2.13 \\
\hline 78 & Organic Chem/Polymer Sci & 1.20 & 3.03 & 2.52 & 0.78 & 2.32 & 2.99 & 0.77 & 2.71 & 3.52 & 0.67 & 2.74 & 4.08 \\
\hline 79 & Orthopedics \& Sports Med & 0.80 & 0.83 & 1.04 & 1.49 & 1.22 & 0.82 & 0.89 & 1.68 & 1.89 & 1.45 & 3.34 & 2.30 \\
\hline 80 & Otolaryngology & 0.48 & 0.57 & 1.18 & 0.36 & 0.44 & 1.23 & 0.74 & 1.18 & 1.59 & 0.88 & 1.72 & 1.96 \\
\hline 81 & Pediatrics & 0.95 & 2.22 & 2.34 & 0.59 & 1.17 & 2.00 & 0.69 & 1.62 & 2.36 & 0.88 & 2.55 & 2.90 \\
\hline 82 & Performing Arts & 4.76 & 1.00 & 0.21 & 0.00 & 0.00 & 0.25 & 0.61 & 0.14 & 0.23 & 0.24 & 0.07 & 0.29 \\
\hline 83 & Pharmacology \& Toxicology & 0.83 & 2.67 & 3.21 & 0.38 & 1.33 & 3.49 & 0.63 & 2.39 & 3.82 & 0.59 & 2.81 & 4.76 \\
\hline 84 & Pharmacology/Toxicology & 1.10 & 3.31 & 3.00 & 0.62 & 1.44 & 2.31 & 0.95 & 3.29 & 3.47 & 1.36 & 6.13 & 4.52 \\
\hline 85 & Philosophy & 0.49 & 0.19 & 0.39 & 0.54 & 0.20 & 0.37 & 0.54 & 0.22 & 0.41 & 0.44 & 0.21 & 0.48 \\
\hline 86 & Physical Chem/Chemical Physics & 0.64 & 2.03 & 3.17 & 0.58 & 1.90 & 3.29 & 0.57 & 2.03 & 3.57 & 0.56 & 2.19 & 3.89 \\
\hline 87 & Physics & 0.48 & 1.81 & 3.75 & 0.66 & 2.56 & 3.85 & 0.67 & 2.79 & 4.14 & 0.69 & 3.24 & 4.67 \\
\hline 88 & Physiology & 0.27 & 1.38 & 5.05 & 0.55 & 2.91 & 5.31 & 0.66 & 3.29 & 4.99 & 0.62 & 3.66 & 5.90 \\
\hline 89 & Plant Sciences & 0.61 & 1.23 & 2.02 & 0.37 & 1.00 & 2.71 & 0.50 & 1.74 & 3.51 & 0.46 & 1.86 & 4.02 \\
\hline 90 & Political Sci \& Public Admin & 0.70 & 0.40 & 0.57 & 0.70 & 0.51 & 0.73 & 0.58 & 0.59 & 1.01 & 0.61 & 0.68 & 1.12 \\
\hline 91 & Psychiatry & 0.26 & 0.82 & 3.16 & 0.51 & 1.85 & 3.66 & 0.80 & 3.32 & 4.17 & 1.16 & 5.98 & 5.14 \\
\hline
\end{tabular}




\begin{tabular}{|c|c|c|c|c|c|c|c|c|c|c|c|c|c|}
\hline \multirow[b]{2}{*}{ Rank } & \multirow[b]{2}{*}{ Discipline } & \multicolumn{3}{|c|}{ 81-85 } & \multicolumn{3}{|c|}{ 90-94 } & \multicolumn{3}{|c|}{ 95-99 } & \multicolumn{3}{|c|}{ 00-04 } \\
\hline & & $\begin{array}{c}\text { Relative } \\
\text { imp }\end{array}$ & Impact & $\begin{array}{l}\text { Imp } \\
\text { base }\end{array}$ & $\begin{array}{l}\text { Relative } \\
\text { imp }\end{array}$ & Impact & $\begin{array}{l}\text { Imp } \\
\text { base }\end{array}$ & $\begin{array}{c}\text { Relative } \\
\text { imp }\end{array}$ & Impact & $\begin{array}{l}\text { Imp } \\
\text { base }\end{array}$ & $\begin{array}{c}\text { Relative } \\
\text { imp }\end{array}$ & Impact & $\begin{array}{l}\text { Imp } \\
\text { base }\end{array}$ \\
\hline 92 & Psychology & 0.48 & 0.87 & 1.81 & 0.36 & 0.76 & 2.10 & 0.29 & 0.71 & 2.44 & 0.42 & 1.21 & 2.90 \\
\hline 93 & Public HIth \& Hlth Care Sci & 0.66 & 0.87 & 1.32 & 0.56 & 0.98 & 1.74 & 0.86 & 1.84 & 2.13 & 0.96 & 2.49 & 2.59 \\
\hline 94 & Radiol Nucl Med \& Imaging & 0.64 & 1.88 & 2.96 & 0.48 & 1.31 & 2.74 & 0.47 & 1.62 & 3.42 & 0.70 & 2.85 & 4.08 \\
\hline 95 & Rehabilitation & 0.00 & 0.00 & 1.03 & 0.24 & 0.33 & 1.36 & 0.38 & 0.59 & 1.56 & 0.46 & 0.78 & 1.69 \\
\hline 96 & Religion \& Theology & 0.19 & 0.05 & 0.27 & 0.60 & 0.18 & 0.30 & 0.90 & 0.27 & 0.30 & 0.57 & 0.16 & 0.28 \\
\hline 97 & Reproductive Medicine & 0.63 & 1.57 & 2.48 & 1.17 & 2.76 & 2.36 & 1.01 & 3.24 & 3.20 & 1.01 & 3.43 & 3.39 \\
\hline 98 & Resrch/Lab Med \& Med Technology & 0.53 & 1.40 & 2.63 & 0.83 & 2.99 & 3.62 & 0.59 & 3.38 & 5.73 & 0.97 & 6.19 & 6.35 \\
\hline 99 & Rheumatology & 0.66 & 1.81 & 2.74 & 1.80 & 6.19 & 3.44 & 1.58 & 6.55 & 4.14 & 1.66 & 8.88 & 5.36 \\
\hline 100 & Social Work \& Social Policy & 0.86 & 0.50 & 0.58 & 0.23 & 0.24 & 1.04 & 0.63 & 0.78 & 1.23 & 0.41 & 0.56 & 1.37 \\
\hline 101 & Sociology \& Social Sciences & 0.35 & 0.39 & 1.12 & 0.47 & 0.56 & 1.20 & 0.35 & 0.46 & 1.30 & 0.58 & 0.72 & 1.24 \\
\hline 102 & Space Science & 0.76 & 3.84 & 5.02 & 1.05 & 4.88 & 4.65 & 0.92 & 5.47 & 5.95 & 0.76 & 5.35 & 7.05 \\
\hline 103 & Spectrosc/Instrum/Analyt Sci & 0.79 & 2.00 & 2.52 & 0.85 & 2.14 & 2.52 & 0.77 & 2.27 & 2.96 & 0.78 & 2.69 & 3.45 \\
\hline 104 & Surgery & 0.57 & 1.08 & 1.89 & 0.71 & 1.26 & 1.77 & 0.48 & 1.13 & 2.35 & 0.62 & 1.65 & 2.65 \\
\hline 105 & Urology & 0.70 & 1.46 & 2.10 & 0.71 & 1.83 & 2.58 & 0.93 & 3.37 & 3.64 & 0.63 & 2.88 & 4.55 \\
\hline 106 & Veterinary Med/Animal Health & 0.54 & 0.69 & 1.27 & 0.89 & 0.97 & 1.09 & 0.73 & 1.11 & 1.53 & 0.80 & 1.58 & 1.97 \\
\hline
\end{tabular}

Table 6 aggregates the citation statistics of 21 broad natural science disciplines. The caveat that groups with small number of articles can have higher relative impacts than larger groups becomes evident; only one discipline had a relative impact of one or higher i.e. mathematics. Tables 7 and 8 show the impact factors of the social sciences, and arts and humanities disciplines, respectively; attention is again drawn in the biases introduced by small number of articles in these disciplines.

Table 6: Relative impact to world of 20 science disciplines: South Africa

\begin{tabular}{|c|c|c|c|c|c|c|c|c|c|c|c|c|c|}
\hline \multirow[b]{2}{*}{ Rank } & \multirow[b]{2}{*}{ Discipline } & \multicolumn{3}{|c|}{$81-85$} & \multicolumn{3}{|c|}{$90-94$} & \multicolumn{3}{|c|}{$95-99$} & \multicolumn{3}{|c|}{ 00-04 } \\
\hline & & $\begin{array}{l}\text { Relative } \\
\text { imp }\end{array}$ & Impact & $\begin{array}{c}\text { Imp } \\
\text { base }\end{array}$ & $\begin{array}{l}\text { Relative } \\
\text { imp }\end{array}$ & Impact & $\begin{array}{l}\text { Imp } \\
\text { base }\end{array}$ & $\begin{array}{l}\text { Relative } \\
\text { imp }\end{array}$ & Impact & $\underset{\text { base }}{\text { Imp }}$ & $\begin{array}{l}\text { Relative } \\
\text { imp }\end{array}$ & Impact & $\begin{array}{c}\text { Imp } \\
\text { base }\end{array}$ \\
\hline 1 & Mathematics & 0.76 & 0.88 & 1.16 & 0.94 & 1.00 & 1.06 & 0.86 & 1.01 & 1.18 & 1.04 & 1.34 & 1.29 \\
\hline 2 & Microbiology & 0.75 & 3.17 & 4.20 & 0.68 & 3.66 & 5.39 & 0.78 & 4.7 & 6.02 & 0.96 & 6.32 & 6.60 \\
\hline 3 & Computer Science & 0.65 & 0.88 & 1.35 & 0.69 & 0.68 & 0.99 & 0.53 & 0.59 & 1.12 & 0.94 & 1.29 & 1.37 \\
\hline 4 & Clinical Medicine & 0.58 & 1.70 & 2.91 & 0.68 & 2.21 & 3.27 & 0.68 & 2.93 & 4.33 & 0.91 & 4.66 & 5.10 \\
\hline 5 & Ecology/Environment & 0.82 & 1.63 & 1.98 & 0.72 & 1.46 & 2.02 & 0.74 & 2.03 & 2.76 & 0.85 & 2.86 & 3.36 \\
\hline 6 & Agricultural Sciences & 1.38 & 1.74 & 1.26 & 1.37 & 2.00 & 1.46 & 1.03 & 1.94 & 1.89 & 0.78 & 1.88 & 2.40 \\
\hline 7 & Immunology & 0.44 & 3.48 & 8.00 & 0.66 & 5.95 & 8.98 & 0.48 & 4.71 & 9.76 & 0.78 & 8.03 & 10.34 \\
\hline 8 & Space Science & 0.76 & 3.84 & 5.02 & 1.05 & 4.88 & 4.65 & 0.92 & 5.47 & 5.95 & 0.76 & 5.35 & 7.05 \\
\hline 9 & Geosciences & 0.74 & 1.92 & 2.58 & 0.80 & 2.21 & 2.77 & 0.86 & 2.75 & 3.21 & 0.75 & 2.52 & 3.38 \\
\hline 10 & Materials Science & 1.01 & 1.34 & 1.33 & 1.01 & 1.62 & 1.61 & 0.86 & 1.55 & 1.8 & 0.73 & 1.69 & 2.30 \\
\hline 11 & Molecular Biology \& Genetics & 0.38 & 2.79 & 7.40 & 0.43 & 4.53 & 10.52 & 0.7 & 8.38 & 11.99 & 0.73 & 9.17 & 12.64 \\
\hline 12 & Physics & 0.58 & 1.81 & 3.14 & 0.69 & 2.22 & 3.21 & 0.71 & 2.33 & 3.26 & 0.71 & 2.57 & 3.64 \\
\hline 13 & Engineering & 0.61 & 0.71 & 1.17 & 0.74 & 0.90 & 1.22 & 0.72 & 0.99 & 1.37 & 0.70 & 1.14 & 1.62 \\
\hline 14 & Plant \& Animal Science & 0.70 & 1.21 & 1.73 & 0.56 & 1.10 & 1.96 & 0.62 & 1.56 & 2.5 & 0.69 & 1.99 & 2.87 \\
\hline 15 & Chemistry & 0.76 & 2.07 & 2.71 & 0.82 & 2.43 & 2.95 & 0.66 & 2.25 & 3.4 & 0.65 & 2.60 & 4.00 \\
\hline 16 & Psychology/Psychiatry & 0.41 & 0.86 & 2.10 & 0.35 & 0.85 & 2.45 & 0.38 & 1.08 & 2.84 & 0.65 & 2.23 & 3.43 \\
\hline 17 & Neurosciences \& Behaviour & 0.51 & 2.47 & 4.85 & 0.46 & 2.66 & 5.82 & 0.47 & 3.26 & 6.9 & 0.62 & 4.77 & 7.75 \\
\hline 18 & Biology \& Biochemistry & 0.58 & 2.92 & 5.01 & 0.44 & 2.70 & 6.11 & 0.48 & 3.36 & 6.95 & 0.60 & 4.40 & 7.39 \\
\hline 19 & Pharmacology & 0.83 & 2.67 & 3.21 & 0.38 & 1.33 & 3.49 & 0.63 & 2.39 & 3.82 & 0.59 & 2.81 & 4.76 \\
\hline 20 & Multidisciplinary & 0.75 & 1.46 & 1.95 & 0.61 & 1.08 & 1.78 & 0.46 & 1.13 & 2.47 & 0.55 & 2.23 & 4.02 \\
\hline
\end{tabular}


Table 7: Relative impact to world of Social Science disciplines: South Africa

\begin{tabular}{|c|c|c|c|c|c|c|c|c|c|c|c|c|c|}
\hline \multirow[b]{2}{*}{ Rank } & \multirow[b]{2}{*}{ Discipline } & \multicolumn{3}{|c|}{ 81-85 } & \multicolumn{3}{|c|}{ 90-94 } & \multicolumn{3}{|c|}{ 95-99 } & \multicolumn{3}{|c|}{ 00-04 } \\
\hline & & $\begin{array}{l}\text { Relative } \\
\text { imp }\end{array}$ & Impact & $\begin{array}{l}\text { Imp } \\
\text { base }\end{array}$ & $\begin{array}{l}\text { Relative } \\
\text { imp }\end{array}$ & Impact & $\begin{array}{l}\text { Imp } \\
\text { base }\end{array}$ & $\begin{array}{c}\text { Relative } \\
\text { imp }\end{array}$ & Impact & $\begin{array}{l}\text { Imp } \\
\text { base }\end{array}$ & $\begin{array}{c}\text { Relative } \\
\text { imp }\end{array}$ & Impact & $\underset{\text { base }}{\operatorname{Imp}}$ \\
\hline 1 & Social Sciences, General & 0.72 & 0.66 & 0.92 & 0.64 & 0.76 & 1.19 & 0.66 & 0.99 & 1.51 & 0.81 & 1.43 & 1.76 \\
\hline 2 & Economics \& Business & 0.24 & 0.26 & 1.09 & 0.24 & 0.33 & 1.37 & 0.29 & 0.46 & 1.58 & 0.36 & 0.63 & 1.76 \\
\hline 3 & Education & 1.01 & 0.72 & 0.71 & 1.46 & 1.49 & 1.02 & 0.6 & 0.61 & 1.02 & 0.46 & 0.46 & 0.99 \\
\hline 4 & Law & 0.00 & 0.00 & 0.30 & 0.15 & 0.29 & 1.93 & 0.28 & 0.71 & 2.52 & 0.00 & 0.00 & 2.31 \\
\hline
\end{tabular}

Table 8: Relative impact to world of Arts \& Humanities disciplines: South Africa

\begin{tabular}{|c|c|c|c|c|c|c|c|c|c|c|c|c|c|}
\hline \multirow[b]{2}{*}{ Rank } & \multirow[b]{2}{*}{ Discipline } & \multicolumn{3}{|c|}{$81-85$} & \multicolumn{3}{|c|}{$90-94$} & \multicolumn{3}{|c|}{$95-99$} & \multicolumn{3}{|c|}{$00-04$} \\
\hline & & $\begin{array}{c}\text { Relative } \\
\text { imp }\end{array}$ & Impact & $\begin{array}{l}\text { Imp } \\
\text { base }\end{array}$ & $\begin{array}{c}\text { Relative } \\
\text { imp }\end{array}$ & Impact & $\begin{array}{l}\text { Imp } \\
\text { base }\end{array}$ & $\begin{array}{c}\text { Relative } \\
\text { imp }\end{array}$ & Impact & $\begin{array}{l}\text { Imp } \\
\text { base }\end{array}$ & $\begin{array}{c}\text { Relative } \\
\text { imp }\end{array}$ & Impact & $\begin{array}{l}\text { Imp } \\
\text { base }\end{array}$ \\
\hline 1 & Archaeology & 0.79 & 0.63 & 0.80 & 1.46 & 1.45 & 0.99 & 1.34 & 1.27 & 0.95 & 1.37 & 1.55 & 1.13 \\
\hline 2 & Art \& Architecture & 0.00 & 0.00 & 0.11 & 2.00 & 0.20 & 0.10 & 0.00 & 0.00 & 0.09 & 0.00 & 0.00 & 0.10 \\
\hline 3 & Classical Studies & 0.93 & 0.25 & 0.27 & 0.34 & 0.11 & 0.32 & 0.12 & 0.03 & 0.25 & 1.80 & 0.36 & 0.20 \\
\hline 4 & General & 0.91 & 0.29 & 0.32 & 0.00 & 0.00 & 0.23 & 0.77 & 0.20 & 0.26 & 1.65 & 0.38 & 0.23 \\
\hline 5 & History & 1.17 & 0.49 & 0.42 & 0.48 & 0.16 & 0.33 & 0.38 & 0.14 & 0.37 & 0.66 & 0.23 & 0.35 \\
\hline 6 & Language \& Linguistics & 1.40 & 0.67 & 0.48 & 0.48 & 0.20 & 0.42 & 1.11 & 0.39 & 0.35 & 1.63 & 0.67 & 0.41 \\
\hline 7 & Literature & 0.46 & 0.11 & 0.24 & 0.69 & 0.11 & 0.16 & 0.21 & 0.03 & 0.14 & 1.00 & 0.12 & 0.12 \\
\hline 8 & Performing Arts & 4.76 & 1.00 & 0.21 & 0.00 & 0.00 & 0.25 & 0.61 & 0.14 & 0.23 & 0.24 & 0.07 & 0.29 \\
\hline 9 & Philosophy & 0.49 & 0.19 & 0.39 & 0.54 & 0.20 & 0.37 & 0.54 & 0.22 & 0.41 & 0.44 & 0.21 & 0.48 \\
\hline 10 & Religion \& Theology & 0.19 & 0.05 & 0.27 & 0.60 & 0.18 & 0.30 & 0.90 & 0.27 & 0.30 & 0.57 & 0.16 & 0.28 \\
\hline
\end{tabular}

\section{CHARACTERISTICS OF SA JOURNALS INDEXED IN ISI}

In this section information is provided related to the international journals which are included in each field in the Science Citation Index and the Social Sciences Citation Index, and the relative position of the South African journals included in the two indexes.

Tables 9 and 10 show the statistical characteristics of all the journals indexed in the SCI and SSCI, respectively, according to disciplinary field. The tables show the number of total cites, median and aggregate impact factors of the journals, the aggregate immediacy index, the aggregate cited half life, number of journals in the category and number of articles published:

- The number of total cites refers to the total number of citations to the journals in the particular JCR year.

- The aggregate impact factor for a subject category is calculated the same way as the impact factor for a particular journal (average number of times articles from the journal published in the past two years have been cited in the Journal Citation Report (JCR) year), but it takes into account the number of citations to all journals in the category and the number of articles from all journals in the category. For example, an aggregate impact factor of 1.0 means that the articles in the subject category published one or two years ago have been cited on average once.

- The median impact factor is the median value of all journal impact factors in the subject category.

- The immediacy index is the average number of times an article is cited in the year it is published. The journal immediacy index indicates how quickly articles in a journal are cited. The aggregate immediacy index indicates how quickly articles in a subject category are cited.

- Journal cited half-life is the median age of the articles that were cited in the JCR year. The aggregate cited half-life is calculated the same way as the journal cited half life and is an indication of the turnover rate of the body of work on a subject.

The tables show also the number of journals indexed in the various subject categories. The subject of andrology is represented by the smallest number of journals (5) while the subject of biochemistry and molecular biology is covered by 261 journals (the largest group). It becomes 
apparent that the SCI distinguishes 170 subject categories and the SSCI 54 categories. (Note: The table is useful in providing a rule-of-thumb guide to the assessment of an article in a particular subject for which the number of (recent) citations is known.)

Table 9: Characteristics of journals in various science subject categories-sci

\begin{tabular}{|c|c|c|c|c|c|c|c|c|}
\hline No. & Category & Total Cites & $\begin{array}{l}\text { Median } \\
\text { Impact } \\
\text { Factor }\end{array}$ & $\begin{array}{c}\text { Aggregate } \\
\text { Impact } \\
\text { Factor }\end{array}$ & $\begin{array}{c}\text { Aggregate } \\
\text { Immediacy } \\
\text { Index }\end{array}$ & $\begin{array}{l}\text { Aggregate } \\
\text { Cited } \\
\text { Half-Life }\end{array}$ & Journals & Articles \\
\hline 1 & Acoustics & 52847 & 0.714 & 1.125 & 0.180 & 8.40 & 26 & 3203 \\
\hline 2 & Agricultural Economics \& Policy & 3866 & 0.484 & 0.513 & 0.137 & 8.00 & 8 & 263 \\
\hline 3 & Agricultural Engineering & 11706 & 0.733 & 0.888 & 0.119 & 7.80 & 9 & 1017 \\
\hline 4 & Agriculture, Dairy \& Animal Science & 72642 & 0.676 & 0.972 & 0.188 & 8.70 & 41 & 4170 \\
\hline 5 & Agriculture, Multidisciplinary & 52735 & 0.438 & 1.320 & 0.190 & 7.40 & 29 & 2813 \\
\hline 6 & Agriculture, Soil Science & 64420 & 0.960 & 1.078 & 0.141 & 9.50 & 27 & 2593 \\
\hline 7 & Agronomy & 81572 & 0.770 & 1.086 & 0.161 & 7.90 & 50 & 4989 \\
\hline 8 & Allergy & 48516 & 1.716 & 2.867 & 0.526 & 5.60 & 15 & 1733 \\
\hline 9 & Anatomy \& Morphology & 25926 & 1.204 & 1.726 & 0.336 & 6.80 & 16 & 1381 \\
\hline 10 & Andrology & 5557 & 1.096 & 1.563 & 0.233 & 6.60 & 5 & 322 \\
\hline 11 & Anaesthesiology & 82207 & 1.185 & 2.012 & 0.408 & 6.80 & 22 & 3466 \\
\hline 12 & Astronomy \& Astrophysics & 354515 & 1.158 & 3.701 & 0.987 & 6.20 & 45 & 10669 \\
\hline 13 & Automation \& Control Systems & 47552 & 0.496 & 0.781 & 0.127 & 7.90 & 46 & 3471 \\
\hline 14 & Behavioural Sciences & 124880 & 2.059 & 2.466 & 0.359 & 8.30 & 41 & 3530 \\
\hline 15 & Biochemical Research Methods & 242676 & 2.098 & 2.646 & 0.454 & 6.70 & 51 & 9862 \\
\hline 16 & Biochemistry \& Molecular Biology & 2142579 & 2.292 & 4.404 & 0.852 & 6.10 & 261 & 48319 \\
\hline 17 & Biodiversity Conservation & 52157 & 0.987 & 1.717 & 0.325 & 8.80 & 24 & 2013 \\
\hline 18 & Biology & 164037 & 1.105 & 2.254 & 0.607 & 7.60 & 64 & 5577 \\
\hline 19 & Biophysics & 331899 & 2.050 & 2.945 & 0.517 & 6.20 & 64 & 10491 \\
\hline 20 & Biotechnology \& Applied Microbiology & 331869 & 1.376 & 2.558 & 0.420 & 5.40 & 133 & 14944 \\
\hline 21 & Cardiac \& Cardiovascular Systems & 435073 & 1.488 & 3.557 & 0.609 & 5.80 & 71 & 13131 \\
\hline 22 & Cell Biology & 1008056 & 2.545 & 5.728 & 1.056 & 5.60 & 155 & 19007 \\
\hline 23 & Chemistry, Analytical & 328992 & 1.264 & 2.133 & 0.342 & 6.70 & 70 & 15067 \\
\hline 24 & Chemistry, Applied & 123321 & 0.743 & 1.460 & 0.205 & 6.30 & 58 & 8287 \\
\hline 25 & Chemistry, Inorganic \& Nuclear & 237316 & 1.385 & 1.880 & 0.363 & 7.10 & 45 & 11159 \\
\hline 26 & Chemistry, Medicinal & 127644 & 1.485 & 2.177 & 0.440 & 6.00 & 36 & 6993 \\
\hline 27 & Chemistry, Multidisciplinary & 684778 & 0.854 & 2.775 & 0.582 & 7.00 & 125 & 24166 \\
\hline 28 & Chemistry, Organic & 406645 & 1.390 & 2.297 & 0.496 & 6.70 & 58 & 17660 \\
\hline 29 & Chemistry, Physical & 505843 & 1.554 & 2.173 & 0.381 & 5.50 & 106 & 28081 \\
\hline 30 & Clinical Neurology & 467616 & 1.436 & 2.483 & 0.389 & 6.80 & 140 & 16082 \\
\hline 31 & Computer Science, Artificial Intelligence & 89270 & 0.784 & 1.010 & 0.170 & 6.60 & 78 & 6352 \\
\hline 32 & Computer Science, Cybernetics & 9734 & 0.546 & 0.735 & 0.227 & 6.70 & 18 & 1029 \\
\hline 33 & Computer Science, Hardware \& Architecture & 48930 & 0.721 & 1.060 & 0.141 & 8.30 & 44 & 2899 \\
\hline 34 & Computer Science, Information Systems & 60412 & 0.788 & 1.039 & 0.173 & 6.70 & 78 & 4894 \\
\hline 35 & Computer Science, Interdisciplinary Applications & 89486 & 0.690 & 1.379 & 0.220 & 6.10 & 83 & 6427 \\
\hline 36 & Computer Science, Software Engineering & 53424 & 0.623 & 0.838 & 0.122 & 8.10 & 76 & 4303 \\
\hline 37 & Computer Science, Theory \& Methods & 97773 & 0.732 & 0.660 & 0.074 & 6.70 & 70 & 20186 \\
\hline 38 & Construction \& Building Technology & 16874 & 0.370 & 0.533 & 0.109 & 7.40 & 31 & 2220 \\
\hline 39 & Critical Care Medicine & 88144 & 1.376 & 3.046 & 0.735 & 5.40 & 17 & 2948 \\
\hline 40 & Crystallography & 100827 & 0.889 & 1.219 & 0.306 & 8.30 & 24 & 7116 \\
\hline 41 & Dentistry, Oral Surgery \& Medicine & 107503 & 1.156 & 1.290 & 0.179 & 8.70 & 48 & 4828 \\
\hline
\end{tabular}




\begin{tabular}{|c|c|c|c|c|c|c|c|c|}
\hline No. & Category & Total Cites & $\begin{array}{l}\text { Median } \\
\text { Impact } \\
\text { Factor }\end{array}$ & $\begin{array}{l}\text { Aggregate } \\
\text { Impact } \\
\text { Factor }\end{array}$ & $\begin{array}{c}\text { Aggregate } \\
\text { Immediacy } \\
\text { Index }\end{array}$ & $\begin{array}{l}\text { Aggregate } \\
\text { Cited } \\
\text { Half-Life }\end{array}$ & Journals & Articles \\
\hline 42 & Dermatology & 97,174 & 1.075 & 1.630 & 0.269 & 7.30 & 38 & 4260 \\
\hline 43 & Developmental Biology & 182,352 & 2.181 & 4.766 & 0.991 & 5.70 & 33 & 3640 \\
\hline 44 & Ecology & 317,061 & 1.207 & 2.041 & 0.372 & 8.30 & 107 & 10099 \\
\hline 45 & Education, Scientific Disciplines & 17,952 & 0.520 & 0.923 & 0.241 & 7.00 & 20 & 1599 \\
\hline 46 & Electrochemistry & 105,057 & 2.146 & 2.031 & 0.301 & 6.60 & 20 & 5131 \\
\hline 47 & Emergency Medicine & 19,578 & 0.990 & 1.190 & 0.192 & 6.60 & 11 & 1585 \\
\hline 48 & Endocrinology \& Metabolism & 421,709 & 2.337 & 3.665 & 0.605 & 6.00 & 87 & 11583 \\
\hline 49 & Energy \& Fuels & 60,947 & 0.596 & 0.826 & 0.133 & 6.50 & 61 & 6552 \\
\hline 50 & Engineering, Aerospace & 23,284 & 0.380 & 0.526 & 0.163 & 8.70 & 25 & 2778 \\
\hline 51 & Engineering, Biomedical & 95,053 & 1.240 & 1.916 & 0.295 & 6.20 & 42 & 4747 \\
\hline 52 & Engineering, Chemical & 190,562 & 0.646 & 1.039 & 0.171 & 7.30 & 116 & 14903 \\
\hline 53 & Engineering, Civil & 48,149 & 0.383 & 0.534 & 0.135 & 7.90 & 79 & 5165 \\
\hline 54 & Engineering, Electrical \& Electronic & 360,065 & 0.607 & 1.110 & 0.165 & 6.80 & 209 & 27275 \\
\hline 55 & Engineering, Environmental & 86,937 & 0.789 & 1.627 & 0.275 & 6.30 & 35 & 4630 \\
\hline 56 & Engineering, Geological & 12,809 & 0.549 & 0.588 & 0.118 & 8.80 & 20 & 1211 \\
\hline 57 & Engineering, Industrial & 26,113 & 0.531 & 0.540 & 0.065 & 7.50 & 33 & 2972 \\
\hline 58 & Engineering, Manufacturing & 24,122 & 0.558 & 0.569 & 0.055 & 5.90 & 37 & 3439 \\
\hline 59 & Engineering, Marine & 652 & 0.377 & 0.135 & 0.015 & 7.40 & 6 & 474 \\
\hline 60 & Engineering, Mechanical & 89,033 & 0.523 & 0.669 & 0.112 & 7.60 & 103 & 8788 \\
\hline 61 & Engineering, Multidisciplinary & 47,670 & 0.421 & 0.757 & 0.171 & 7.40 & 61 & 4955 \\
\hline 62 & Engineering, Ocean & 6,983 & 0.321 & 0.693 & 0.322 & 6.60 & 16 & 849 \\
\hline 63 & Engineering, Petroleum & 9,932 & 0.242 & 0.234 & 0.052 & $>10.0$ & 22 & 1810 \\
\hline 64 & Entomology & 70,829 & 0.632 & 0.992 & 0.209 & 9.50 & 66 & 4187 \\
\hline 65 & Environmental Sciences & 314,596 & 1.064 & 1.578 & 0.287 & 6.50 & 134 & 16946 \\
\hline 66 & Evolutionary Biology & 114,550 & 2.381 & 3.313 & 0.636 & 7.20 & 33 & 3064 \\
\hline 67 & Fisheries & 70,558 & 0.845 & 1.054 & 0.215 & 8.40 & 40 & 3512 \\
\hline 68 & Food Science \& Technology & 169,623 & 0.635 & 1.257 & 0.192 & 7.40 & 94 & 9936 \\
\hline 69 & Forestry & 47,096 & 0.720 & 1.191 & 0.196 & 7.60 & 34 & 2671 \\
\hline 70 & Gastroenterology \& Hepatology & 232,915 & 1.780 & 3.299 & 0.613 & 5.70 & 46 & 7430 \\
\hline 71 & Genetics \& Heredity & 571,218 & 2.439 & 4.365 & 0.782 & 5.50 & 120 & 14200 \\
\hline 72 & Geochemistry \& Geophysics & 169,366 & 1.431 & 1.855 & 0.400 & 9.50 & 50 & 5379 \\
\hline 73 & Geography, Physical & 43,838 & 1.204 & 1.622 & 0.262 & 7.40 & 29 & 1944 \\
\hline 74 & Geology & 45,296 & 0.817 & 1.466 & 0.336 & 8.60 & 35 & 1747 \\
\hline 75 & Geosciences, Multidisciplinary & 305,637 & 0.909 & 1.614 & 0.349 & 7.80 & 128 & 13210 \\
\hline 76 & Geriatrics \& Gerontology & 51,374 & 1.529 & 2.401 & 0.432 & 5.70 & 29 & 2258 \\
\hline 77 & Health Care Sciences \& Services & 56,886 & 1.155 & 1.563 & 0.356 & 6.10 & 52 & 3332 \\
\hline 78 & Haematology & 418,877 & 1.835 & 4.998 & 0.888 & 5.40 & 62 & 9590 \\
\hline 79 & History \& Philosophy Of Science & 7,334 & 0.309 & 0.432 & 0.158 & $>10.0$ & 32 & 740 \\
\hline 80 & Horticulture & 39,965 & 0.564 & 1.143 & 0.148 & 7.90 & 22 & 2190 \\
\hline 81 & Imaging Science \& Photographic Technology & 24,662 & 0.615 & 1.721 & 0.229 & 7.00 & 13 & 1117 \\
\hline 82 & Immunology & 643,166 & 2.101 & 4.064 & 0.710 & 5.50 & 111 & 17038 \\
\hline 83 & Infectious Diseases & 207,545 & 2.066 & 3.294 & 0.654 & 5.20 & 41 & 7253 \\
\hline 84 & Instruments \& Instrumentation & 94,867 & 0.739 & 1.074 & 0.198 & 6.30 & 48 & 8548 \\
\hline 85 & Integrative \& Complementary Medicine & 7,396 & 0.786 & 1.068 & 0.156 & 5.70 & 9 & 770 \\
\hline 86 & Limnology & 40,159 & 0.717 & 1.362 & 0.429 & 9.90 & 14 & 1124 \\
\hline
\end{tabular}




\begin{tabular}{|c|c|c|c|c|c|c|c|c|}
\hline No. & Category & Total Cites & $\begin{array}{l}\text { Median } \\
\text { Impact } \\
\text { Factor }\end{array}$ & $\begin{array}{l}\text { Aggregate } \\
\text { Impact } \\
\text { Factor }\end{array}$ & $\begin{array}{l}\text { Aggregate } \\
\text { Immediacy } \\
\text { Index }\end{array}$ & $\begin{array}{l}\text { Aggregate } \\
\text { Cited } \\
\text { Half-Life }\end{array}$ & Journals & Articles \\
\hline 87 & Marine \& Freshwater Biology & 169,079 & 0.983 & 1.330 & 0.279 & 8.80 & 75 & 6847 \\
\hline 88 & Materials Science, Biomaterials & 40,702 & 1.229 & 2.345 & 0.348 & 5.60 & 15 & 2090 \\
\hline 89 & Materials Science, Ceramics & 57,276 & 0.330 & 0.782 & 0.091 & 8.00 & 25 & 5785 \\
\hline 90 & Materials Science, Characterization \& Testing & 7,293 & 0.531 & 0.505 & 0.091 & 6.60 & 23 & 1167 \\
\hline 91 & Materials Science, Coatings \& Films & 87,519 & 0.691 & 1.562 & 0.240 & 6.70 & 19 & 5269 \\
\hline 92 & Materials Science, Composites & 16,711 & 0.441 & 0.567 & 0.061 & 6.20 & 23 & 3279 \\
\hline 93 & Materials Science, Multidisciplinary & 420,407 & 0.732 & 1.496 & 0.236 & 5.60 & 177 & 33319 \\
\hline 94 & Materials Science, Paper \& Wood & 12,892 & 0.471 & 0.461 & 0.070 & $>10.0$ & 19 & 1280 \\
\hline 95 & Materials Science, Textiles & 6,660 & 0.508 & 0.533 & 0.110 & 7.20 & 15 & 1090 \\
\hline 96 & Mathematics & 162,677 & 0.425 & 0.477 & 0.093 & $>10.0$ & 181 & 12899 \\
\hline 97 & Mathematics, Applied & 153,581 & 0.568 & 0.665 & 0.118 & 8.90 & 162 & 12918 \\
\hline 98 & Mathematics, Interdisciplinary Applications & 86,335 & 0.948 & 1.716 & 0.347 & 9.30 & 52 & 4006 \\
\hline 99 & Mechanics & 159,000 & 0.692 & 0.987 & 0.173 & 9.70 & 107 & 9780 \\
\hline 100 & Medical Ethics & 2,988 & 0.908 & 0.933 & 0.276 & 6.00 & 6 & 330 \\
\hline 101 & Medical Informatics & 19,455 & 1.201 & 1.318 & 0.290 & 6.50 & 18 & 1216 \\
\hline 102 & Medical Laboratory Technology & 64,928 & 1.161 & 2.153 & 0.394 & 7.60 & 24 & 2390 \\
\hline 103 & Medicine, General \& Internal & 658,118 & 0.835 & 4.276 & 1.154 & 7.00 & 103 & 12695 \\
\hline 104 & Medicine, Legal & 11,031 & 0.929 & 1.140 & 0.190 & 5.70 & 9 & 1012 \\
\hline 105 & Medicine, Research \& Experimental & 346,793 & 1.712 & 3.452 & 0.615 & 6.20 & 71 & 9089 \\
\hline 106 & Metallurgy \& Metallurgical Engineering & 97,900 & 0.371 & 0.915 & 0.161 & 6.80 & 71 & 9626 \\
\hline 107 & Meteorology \& Atmospheric Sciences & 127,984 & 1.472 & 1.675 & 0.373 & 7.40 & 45 & 5841 \\
\hline 108 & Microbiology & 389,519 & 1.938 & 3.012 & 0.534 & 5.80 & 84 & 13344 \\
\hline 109 & Microscopy & 16,954 & 1.739 & 1.943 & 0.370 & 5.80 & 9 & 883 \\
\hline 110 & Mineralogy & 41,854 & 0.950 & 1.271 & 0.302 & $>10.0$ & 23 & 1701 \\
\hline 111 & Mining \& Mineral Processing & 14,645 & 0.285 & 0.755 & 0.076 & 7.20 & 17 & 1704 \\
\hline 112 & Multidisciplinary Sciences & $1,119,119$ & 0.484 & 8.989 & 1.989 & 7.00 & 45 & 9422 \\
\hline 113 & Mycology & 19,660 & 0.734 & 1.129 & 0.228 & 6.70 & 17 & 1145 \\
\hline 114 & Neuroimaging & 35,300 & 1.015 & 2.385 & 0.311 & 5.00 & 14 & 1719 \\
\hline 115 & Neurosciences & 973,220 & 2.303 & 3.496 & 0.578 & 6.30 & 198 & 25133 \\
\hline 116 & Nuclear Science \& Technology & 74,954 & 0.597 & 0.960 & 0.181 & 6.40 & 31 & 7584 \\
\hline 117 & Nursing & 21,007 & 0.689 & 0.741 & 0.136 & 7.10 & 33 & 1959 \\
\hline 118 & Nutrition \& Dietetics & 134,638 & 1.431 & 2.240 & 0.398 & 6.20 & 53 & 5170 \\
\hline 119 & Obstetrics \& Gynecology & 149,411 & 1.184 & 1.815 & 0.324 & 6.80 & 55 & 6878 \\
\hline 120 & Oceanography & 77,389 & 1.058 & 1.411 & 0.387 & 8.20 & 41 & 2985 \\
\hline 121 & Oncology & 670,434 & 2.225 & 3.986 & 0.647 & 5.50 & 123 & 19831 \\
\hline 122 & Operations Research \& Management Science & 55,385 & 0.548 & 0.659 & 0.115 & 9.30 & 56 & 3786 \\
\hline 123 & Ophthalmology & 137,180 & 1.152 & 1.850 & 0.250 & 7.30 & 42 & 6053 \\
\hline 124 & Optics & 225,917 & 0.976 & 1.840 & 0.398 & 6.70 & 54 & 13158 \\
\hline 125 & Ornithology & 18,600 & 0.722 & 0.900 & 0.387 & $>10.0$ & 15 & 808 \\
\hline 126 & Orthopedics & 130,241 & 0.944 & 1.266 & 0.137 & 9.30 & 42 & 5132 \\
\hline 127 & Otorhinolaryngology & 60,676 & 0.792 & 1.067 & 0.109 & 8.30 & 29 & 3585 \\
\hline 128 & Paleontology & 34,114 & 0.758 & 1.119 & 0.261 & 9.40 & 32 & 1633 \\
\hline 129 & Parasitology & 44,048 & 1.162 & 1.605 & 0.283 & 6.90 & 21 & 2270 \\
\hline 130 & Pathology & 176,764 & 1.500 & 2.312 & 0.354 & 6.80 & 65 & 6097 \\
\hline 131 & Pediatrics & 184,833 & 1.099 & 1.498 & 0.293 & 7.00 & 70 & 9132 \\
\hline
\end{tabular}




\begin{tabular}{|c|c|c|c|c|c|c|c|c|}
\hline No. & Category & Total Cites & $\begin{array}{l}\text { Median } \\
\text { Impact } \\
\text { Factor }\end{array}$ & $\begin{array}{c}\text { Aggregate } \\
\text { Impact } \\
\text { Factor }\end{array}$ & $\begin{array}{c}\text { Aggregate } \\
\text { Immediacy } \\
\text { Index }\end{array}$ & $\begin{array}{l}\text { Aggregate } \\
\text { Cited } \\
\text { Half-Life }\end{array}$ & Journals & Articles \\
\hline 132 & Peripheral Vascular Disease & 349,990 & 1.779 & 4.580 & 0.838 & 5.60 & 51 & 7712 \\
\hline 133 & Pharmacology \& Pharmacy & 598,561 & 1.827 & 2.528 & 0.410 & 6.20 & 187 & 23830 \\
\hline 134 & Physics, Applied & 459,303 & 1.128 & 1.792 & 0.285 & 6.00 & 79 & 28924 \\
\hline 135 & Physics, Atomic, Molecular \& Chemical & 346,245 & 1.424 & 2.187 & 0.503 & 8.70 & 34 & 12212 \\
\hline 136 & Physics, Condensed Matter & 425,190 & 1.010 & 1.696 & 0.317 & 6.90 & 60 & 22403 \\
\hline 137 & Physics, Fluids \& Plasmas & 110,594 & 1.042 & 1.932 & 0.374 & 6.50 & 21 & 5415 \\
\hline 138 & Physics, Mathematical & 130,176 & 1.091 & 1.560 & 0.370 & 6.80 & 34 & 7208 \\
\hline 139 & Physics, Multidisciplinary & 492,626 & 0.902 & 2.506 & 0.662 & 7.10 & 67 & 19396 \\
\hline 140 & Physics, Nuclear & 88,095 & 1.533 & 1.576 & 0.468 & 6.50 & 21 & 5549 \\
\hline 141 & Physics, Particles \& Fields & 188,456 & 1.589 & 3.137 & 1.035 & 4.90 & 21 & 8751 \\
\hline 142 & Physiology & 342,615 & 1.635 & 2.946 & 0.615 & 7.20 & 73 & 8553 \\
\hline 143 & Plant Sciences & 373,984 & 0.976 & 2.100 & 0.358 & 7.50 & 138 & 13683 \\
\hline 144 & Polymer Science & 240,823 & 0.806 & 1.634 & 0.266 & 6.80 & 75 & 12789 \\
\hline 145 & Psychiatry & 309,039 & 1.869 & 2.831 & 0.481 & 6.90 & 90 & 8625 \\
\hline 146 & Psychology & 140,500 & 1.431 & 2.030 & 0.335 & 9.50 & 60 & 3219 \\
\hline 147 & Public, Environmental \& Occupational Health & 231,431 & 1.377 & 1.961 & 0.431 & 6.90 & 93 & 8905 \\
\hline 148 & Radiology, Nuclear Medicine \& Medical Imaging & 278,886 & 1.507 & 2.249 & 0.325 & 6.30 & 84 & 11924 \\
\hline 149 & Rehabilitation & 26299 & 0.948 & 1.165 & 0.201 & 7.10 & 25 & 1789 \\
\hline 150 & Remote Sensing & 26,966 & 1.206 & 1.509 & 0.288 & 7.50 & 10 & 1292 \\
\hline 151 & Reproductive Biology & 88,823 & 1.695 & 2.413 & 0.471 & 5.90 & 24 & 3492 \\
\hline 152 & Respiratory System & 177,619 & 1.662 & 2.823 & 0.557 & 5.70 & 33 & 6017 \\
\hline 153 & Rheumatology & 84,236 & 1.595 & 3.365 & 0.553 & 5.70 & 22 & 3004 \\
\hline 154 & Robotics & 8,658 & 0.468 & 0.765 & 0.097 & 7.50 & 11 & 636 \\
\hline 155 & Spectroscopy & 107,417 & 1.351 & 1.709 & 0.321 & 6.20 & 42 & 7058 \\
\hline 156 & Sport Sciences & 110,966 & 0.861 & 1.373 & 0.257 & 8.20 & 71 & 5067 \\
\hline 157 & Statistics \& Probability & 119,157 & 0.635 & 1.238 & 0.213 & $>10.0$ & 77 & 5034 \\
\hline 158 & Substance Abuse & 27,685 & 2.104 & 2.281 & 0.502 & 6.30 & 8 & 866 \\
\hline 159 & Surgery & 513,447 & 1.013 & 1.681 & 0.235 & 7.60 & 139 & 22014 \\
\hline 160 & Telecommunications & 47,988 & 0.403 & 0.763 & 0.123 & 6.60 & 57 & 5260 \\
\hline 161 & Thermodynamics & 45,113 & 0.632 & 0.803 & 0.132 & 8.30 & 39 & 3746 \\
\hline 162 & Toxicology & 151,499 & 1.651 & 2.056 & 0.339 & 6.20 & 75 & 6905 \\
\hline 163 & Transplantation & 76,797 & 2.101 & 2.117 & 0.386 & 5.30 & 19 & 4251 \\
\hline 164 & Transportation Science \& Technology & 9,878 & 0.266 & 0.293 & 0.081 & 7.80 & 21 & 881 \\
\hline 165 & Tropical Medicine & 26,131 & 0.810 & 1.366 & 0.274 & 7.90 & 11 & 1268 \\
\hline 166 & Urology \& Nephrology & 194,163 & 1.340 & 2.614 & 0.404 & 5.70 & 52 & 8165 \\
\hline 167 & Veterinary Sciences & 131,870 & 0.566 & 0.863 & 0.160 & 7.70 & 123 & 10504 \\
\hline 168 & Virology & 168,115 & 2.644 & 3.814 & 0.652 & 5.80 & 22 & 4682 \\
\hline 169 & Water Resources & 91,434 & 0.733 & 1.020 & 0.177 & 7.60 & 55 & 5655 \\
\hline 170 & Zoology & 171,598 & 0.788 & 1.251 & 0.266 & $>10.0$ & 112 & 6755 \\
\hline
\end{tabular}

Table 10: Characteristics of journals in various social science subject categories-ssci

\begin{tabular}{|l|l|c|c|c|c|c|c|c|}
\hline No. & \multicolumn{1}{|c|}{ Category } & Total Cites & $\begin{array}{c}\text { Median } \\
\text { Impact } \\
\text { Factor }\end{array}$ & $\begin{array}{c}\text { Aggregate } \\
\text { Impact } \\
\text { Factor }\end{array}$ & $\begin{array}{c}\text { Aggregate } \\
\text { Immediacy } \\
\text { Index }\end{array}$ & $\begin{array}{c}\text { Aggregate } \\
\text { Cited } \\
\text { Half-Life }\end{array}$ & Journals & Articles \\
\hline 1 & Anthropology & 26,178 & 0.454 & 0.903 & 0.172 & 9.80 & 50 & 1,479 \\
\hline 2 & Applied Linguistics & 22,167 & 0.741 & 0.976 & 0.272 & 9.00 & 38 & 1,004 \\
\hline 3 & Area Studies & 5,358 & 0.373 & 0.394 & 0.058 & 7.90 & 33 & 864 \\
\hline
\end{tabular}




\begin{tabular}{|c|c|c|c|c|c|c|c|c|}
\hline No. & Category & Total Cites & $\begin{array}{l}\text { Median } \\
\text { Impact } \\
\text { Factor }\end{array}$ & $\begin{array}{l}\text { Aggregate } \\
\text { Impact } \\
\text { Factor }\end{array}$ & $\begin{array}{c}\text { Aggregate } \\
\text { Immediacy } \\
\text { Index }\end{array}$ & $\begin{array}{l}\text { Aggregate } \\
\text { Cited } \\
\text { Half-Life }\end{array}$ & Journals & Articles \\
\hline 4 & Business & 68,320 & 0.673 & 0.836 & 0.187 & $>10.0$ & 57 & 2,685 \\
\hline 5 & Business, Finance & 31,718 & 0.759 & 0.726 & 0.122 & 9.20 & 37 & 2,039 \\
\hline 6 & Communication & 13,861 & 0.705 & 0.737 & 0.104 & 8.20 & 40 & 1,054 \\
\hline 7 & Criminology \& Penology & 11,466 & 0.682 & 0.730 & 0.174 & 7.90 & 26 & 869 \\
\hline 8 & Demography & 7,925 & 0.927 & 0.935 & 0.292 & 8.90 & 17 & 425 \\
\hline 9 & Economics & 148,130 & 0.546 & 0.782 & 0.139 & $>10.0$ & 172 & 7,490 \\
\hline 10 & Education \& Educational Research & 32,078 & 0.462 & 0.525 & 0.114 & 8.40 & 91 & 3,137 \\
\hline 11 & Education, Special & 10,153 & 0.697 & 0.713 & 0.145 & 8.70 & 26 & 608 \\
\hline 12 & Environmental Studies & 25,264 & 0.644 & 0.811 & 0.218 & 7.20 & 50 & 2,012 \\
\hline 13 & Ergonomics & 10,089 & 0.741 & 0.838 & 0.151 & 8.50 & 13 & 723 \\
\hline 14 & Ethics & 8,778 & 0.460 & 0.653 & 0.226 & 7.40 & 28 & 1,018 \\
\hline 15 & Ethnic Studies & 1,362 & 0.445 & 0.445 & 0.038 & 6.90 & 6 & 157 \\
\hline 16 & Family Studies & 18,823 & 0.742 & 0.830 & 0.317 & 8.30 & 29 & 1,019 \\
\hline 17 & Geography & 17,160 & 0.947 & 1.253 & 0.237 & 6.90 & 35 & 1,074 \\
\hline 18 & Gerontology & 35,550 & 0.701 & 1.907 & 0.364 & 6.60 & 24 & 1,489 \\
\hline 19 & Health Policy \& Services & 38,110 & 1.036 & 1.571 & 0.369 & 6.20 & 38 & 2,060 \\
\hline 20 & History & 4,279 & 0.353 & 0.429 & 0.089 & $>10.0$ & 15 & 325 \\
\hline 21 & History \& Philosophy Of Science & 6,718 & 0.298 & 0.434 & 0.156 & $>10.0$ & 27 & 570 \\
\hline 22 & History Of Social Sciences & 3,367 & 0.378 & 0.410 & 0.068 & $>10.0$ & 16 & 353 \\
\hline 23 & Industrial Relations \& Labor & 7,877 & 0.790 & 0.753 & 0.175 & 8.50 & 16 & 417 \\
\hline 24 & Information Science \& Library Science & 18,025 & 0.527 & 0.806 & 0.181 & 6.10 & 54 & 2,049 \\
\hline 25 & International Relations & 14,588 & 0.560 & 0.743 & 0.221 & 6.70 & 54 & 1,665 \\
\hline 26 & Law & 60,027 & 0.890 & 1.381 & 0.450 & 8.80 & 101 & 2,760 \\
\hline 27 & Management & 75,386 & 0.828 & 0.978 & 0.184 & 9.40 & 67 & 2,842 \\
\hline 28 & Nursing & 19,801 & 0.632 & 0.735 & 0.128 & 7.00 & 32 & 1,846 \\
\hline 29 & Planning \& Development & 15,362 & 0.578 & 0.730 & 0.147 & 7.00 & 38 & 1,365 \\
\hline 30 & Political Science & 29,531 & 0.435 & 0.553 & 0.138 & 8.40 & 79 & 3,257 \\
\hline 31 & Psychiatry & 209,305 & 1.247 & 2.601 & 0.399 & 7.70 & 76 & 5,323 \\
\hline 32 & Psychology, Applied & 40,774 & 0.810 & 1.052 & 0.224 & 9.30 & 50 & 1,689 \\
\hline 33 & Psychology, Biological & 33,902 & 1.518 & 1.815 & 0.338 & 9.50 & 16 & 843 \\
\hline 34 & Psychology, Clinical & 116,119 & 1.077 & 1.687 & 0.358 & 8.10 & 84 & 3,820 \\
\hline 35 & Psychology, Developmental & 81,768 & 1.086 & 1.724 & 0.331 & 8.90 & 49 & 2,287 \\
\hline 36 & Psychology, Educational & 34,223 & 0.707 & 1.118 & 0.362 & $>10.0$ & 38 & 1,079 \\
\hline 37 & Psychology, Experimental & 121,401 & 1.417 & 1.853 & 0.351 & 9.10 & 68 & 3,465 \\
\hline 38 & Psychology, Mathematical & 12,652 & 0.715 & 1.107 & 0.341 & $>10.0$ & 10 & 393 \\
\hline 39 & Psychology, Multidisciplinary & 112,246 & 0.704 & 1.321 & 0.257 & 9.50 & 100 & 3,945 \\
\hline 40 & Psychology, Psychoanalysis & 6,471 & 0.623 & 0.950 & 0.269 & 9.40 & 12 & 428 \\
\hline 41 & Psychology, Social & 76,131 & 0.963 & 1.323 & 0.219 & $>10.0$ & 46 & 1,995 \\
\hline 42 & Public Administration & 7,103 & 0.545 & 0.593 & 0.136 & 7.30 & 26 & 701 \\
\hline 43 & Public, Environmental \& Occupational Health & 77,844 & 0.992 & 1.371 & 0.272 & 7.00 & 60 & 3,802 \\
\hline 44 & Rehabilitation & 19,641 & 0.682 & 0.768 & 0.164 & 7.20 & 45 & 1,442 \\
\hline 45 & Social Issues & 8,990 & 0.463 & 0.640 & 0.164 & 7.20 & 31 & 1,004 \\
\hline 46 & Social Sciences, Biomedical & 24,182 & 0.899 & 1.358 & 0.339 & 7.10 & 26 & 1,295 \\
\hline
\end{tabular}




\begin{tabular}{|l|l|c|c|c|c|c|c|c|}
\hline No. Category & \multicolumn{1}{|c|}{ Total Cites } & $\begin{array}{c}\text { Median } \\
\text { Impact } \\
\text { Factor }\end{array}$ & $\begin{array}{c}\text { Aggregate } \\
\text { Impact } \\
\text { Factor }\end{array}$ & $\begin{array}{c}\text { Aggregate } \\
\text { Immediacy } \\
\text { Index }\end{array}$ & $\begin{array}{c}\text { Aggregate } \\
\text { Cited } \\
\text { Half-Life }\end{array}$ & Journals & Articles \\
\hline 47 & Social Sciences, Interdisciplinary & 22,679 & 0.413 & 0.576 & 0.141 & 8.60 & 56 & 2,104 \\
\hline 48 & Social Sciences, Mathematical Methods & 37,682 & 0.673 & 0.927 & 0.168 & $>10.0$ & 31 & 1,194 \\
\hline 49 & Social Work & 12128 & 0.388 & 0.537 & 0.152 & 8.40 & 28 & 862 \\
\hline 50 & Sociology & 50415 & 0.480 & 0.627 & 0.128 & $>10.0$ & 90 & 2470 \\
\hline 51 & Substance Abuse & 21460 & 1.010 & 1.533 & 0.335 & 6.30 & 18 & 1021 \\
\hline 52 & Transportation & 6155 & 0.493 & 0.803 & 0.126 & 8.20 & 12 & 470 \\
\hline 53 & Urban Studies & 10558 & 0.613 & 0.701 & 0.129 & 6.70 & 28 & 1003 \\
\hline 54 & Women's Studies & 8900 & 0.351 & 0.552 & 0.124 & 7.40 & 25 & 808 \\
\hline
\end{tabular}

Table 11 provides information on South African journals covered in the SCI and SSCI and their characteristics; there are 18 journals in the table. (The South African Journal of Marine Science has changed its name to Journal of Marine Science and hence both names appear in the list for a period of few years) The shown characteristics are impact factor, immediacy index and cited half life.

Table 12 shows the impact factors of the South African journals in the 2004 issues of the SCI and SSCI. The table shows the name of the journal, the subject categories in which the journal belongs, the impact factors of the journals for the most recent five years (2000 to 2004) and the median impact factor of the journals in the subject category(ies). From the 19 journals in the list, 17 are indexed by the SCI and 2 by the SSCI. Veterinary sciences and zoology are the only subject categories which appear twice in the list of journals. Comparisons of the local journals' impact factors with the relevant world median impact factors for 2004 show that only four South African journals had impact factors higher than the world median in their category during this year - Social Dynamics, SAJ of Geology, SAJ of Science and SA Medical Journal.

this year - Social

Dynamics, SAJ of Geology, SAJ of Science and $S A$ Medical Journal

Table 11: Characteristics of South African Journals in ISI

\begin{tabular}{|c|c|c|c|c|c|}
\hline No. & Abbreviated Journal Title & $\begin{array}{l}\text { Impact } \\
\text { Factor }\end{array}$ & $\begin{array}{l}\text { Immediacy } \\
\text { Index }\end{array}$ & Articles & $\begin{array}{c}\text { Cited } \\
\text { Half-Life }\end{array}$ \\
\hline 1 & Afr Entomol & 0.408 & 0.095 & 42 & 5.6 \\
\hline 2 & Afr J Mar Sci & 0.204 & 2.500 & 18 & 0 \\
\hline 3 & Afr Zool & 0.386 & 0.139 & 36 & 0 \\
\hline 4 & Bothalia & 0.405 & 0.000 & 13 & $>10.0$ \\
\hline 5 & J S Afr I Min Metall & 0.113 & 0.030 & 66 & $>10.0$ \\
\hline 6 & J S Afr Vet Assoc & 0.316 & 0.000 & 28 & $>10.0$ \\
\hline 7 & Onderstepoort J Vet & 0.487 & 0.044 & 45 & $>10.0$ \\
\hline 8 & Ostrich & 0.617 & 0.020 & 49 & $>10.0$ \\
\hline 9 & S Afr J Anim Sci & 0.380 & 0.036 & 28 & 8.6 \\
\hline 10 & S Afr J Chem-S-afr T & 0.370 & 0.083 & 12 & 9.9 \\
\hline 11 & S Afr J Geol & 1.111 & 1.200 & 30 & 7.0 \\
\hline 12 & S Afr J Marine Sci & 0.643 & $\mathrm{n} / \mathrm{a}$ & $\mathrm{n} / \mathrm{a}$ & $>10.0$ \\
\hline 13 & SAfr J Sci & 0.549 & 1.059 & 85 & 8.7 \\
\hline 14 & S Afr J Surg & 0.206 & 0.050 & 20 & 9.2 \\
\hline 15 & S Afr J Wildl Res & 0.244 & 0.091 & 11 & $>10.0$ \\
\hline 16 & Samj S Afr Med & 1.107 & 1.123 & 65 & $>10.0$ \\
\hline 17 & Water SA & 0.464 & 0.137 & 95 & 6.9 \\
\hline 18 & Soc Dynamics & 0.448 & $\mathrm{~N} / \mathrm{A}$ & $\mathrm{N} / \mathrm{A}$ & 7.9 \\
\hline 19 & S Afr J Econ & 0.337 & 0.038 & 26 & 5.7 \\
\hline
\end{tabular}


Table 12: Impact Factors of South African Journals and Median of Subject Category

\begin{tabular}{|c|c|c|c|c|c|c|c|}
\hline Journal Title & Subject Categories & 2000 & 2001 & 2002 & 2003 & 2004 & $\begin{array}{c}\text { Median IF } \\
2004\end{array}$ \\
\hline Afr Entomol & Entomology & 0.225 & 0.170 & 0.455 & 0.577 & 0.408 & 0.632 \\
\hline Afr J Mar Sci & Marine and Freshwater Biology & 0.000 & 0.000 & 0.000 & 0.000 & 0.204 & 0.983 \\
\hline Afr Zool & Zoology & 0.000 & 0.294 & 0.516 & 0.393 & 0.386 & 0.788 \\
\hline Bothalia & Plant Sciences & 0.219 & 0.176 & 0.358 & 0.281 & 0.405 & 0.976 \\
\hline J S Afr I Min Metall & Metallurgy \& Metallurgical Engineering * Mining \& Mineral Processing & 0.058 & 0.097 & 0.052 & 0.061 & 0.113 & $\begin{array}{l}0.371 \text { * } \\
0.285\end{array}$ \\
\hline J S Afr Vet Assoc & Veterinary Sciences & 0.324 & 0.267 & 0.366 & 0.265 & 0.316 & 0.566 \\
\hline Onderstepoort J Vet & Veterinary Sciences & 0.691 & 0.410 & 0.506 & 0.548 & 0.487 & 0.566 \\
\hline Ostrich & Ornithology & 0.548 & 0.370 & 0.149 & 0.187 & 0.617 & 0.722 \\
\hline S Afr J Anim Sci & Agriculture, Dairy and Animal Science & 0.302 & 0.455 & 0.381 & 0.143 & 0.380 & 0.676 \\
\hline S Afr J Chem-S-afr T & Chemistry, Multidisciplinary & 0.220 & 0.321 & 0.265 & 0.240 & 0.370 & 0.854 \\
\hline S Afr J Geol & Geology & 0.540 & 0.380 & 0.659 & 1.021 & 1.111 & 0.817 \\
\hline S Afr J Marine Sci & Marine and Freshwater Biology & 0.000 & 1.364 & 0.754 & 0.892 & 0.643 & 0.983 \\
\hline S Afr J Sci & Multidisciplinary Sciences & 0.414 & 0.540 & 0.700 & 0.930 & 0.549 & 0.484 \\
\hline S Afr J Surg & Surgery & 0.159 & 0.128 & 0.250 & 0.119 & 0.206 & 1.013 \\
\hline S Afr J Wildl Res & Ecology * Zoology & 0.293 & 0.479 & 0.224 & 0.341 & 0.244 & $\begin{array}{l}1.207 \text { * } \\
0.788\end{array}$ \\
\hline Samj S Afr Med J & Medicine, General and Internal & 0.461 & 0.566 & 1.019 & 0.989 & 1.107 & 0.835 \\
\hline Water Sa & Water Resources & 0.263 & 0.427 & 0.481 & 0.600 & 0.464 & 0.733 \\
\hline Soc Dynamics & Area Studies & 0.000 & 0.200 & 0.435 & 0.000 & 0.448 & 0.373 \\
\hline S Afr J Econ & Economics & 0.104 & 0.213 & 0.375 & 0.295 & 0.337 & 0.546 \\
\hline
\end{tabular}

Table 13 shows the number of national journals covered in the two editions of the Journal Citations Reports (Science and Social Sciences in parentheses). With 17 journals in the list, South Africa shares the 26th position with Sweden (out of the 71 countries in the list). We have reported elsewhere (Pouris, 2005) that South Africa has higher representation in the JCR than Finland and Belgium, both research-intensive countries. (It should be noted that some countries host large multi-national publishing companies which actually publish journals otherwise "belonging" to other countries, e.g. the Netherlands.)

Table 13: Number of journals per country covered in Science edition JCR 2004 (and SSCI 2004)

\begin{tabular}{|l|c|}
\hline Argentina & 1 \\
\hline Armenia & 1 \\
\hline Australia & $60(16)$ \\
\hline Austria & $23(3)$ \\
\hline Bangladesh & 2 \\
\hline Belgium & $12(2)$ \\
\hline Brazil & $16(2)$ \\
\hline Bulgaria & 2 \\
\hline Canada & $75(28)$ \\
\hline Chile & $8(1)$ \\
\hline Colombia & $-(1)$ \\
\hline Costa Rica & 1 \\
\hline Croatia & $11(2)$ \\
\hline Cuba & 1 \\
\hline Czech Republic & $23(4)$ \\
\hline Denmark & $63(2)$ \\
\hline
\end{tabular}




\begin{tabular}{|c|c|}
\hline Ecuador & 1 \\
\hline Egypt & 1 \\
\hline England & $1235(413)$ \\
\hline Estonia & 1 \\
\hline Ethiopia & 2 \\
\hline Finland & $11(1)$ \\
\hline France & $143(12)$ \\
\hline Germany & $427(52)$ \\
\hline Greece & 4 \\
\hline Hong Kong & 1 \\
\hline Hungary & 15 \\
\hline Iraq & $47(3)$ \\
\hline Iran & 3 \\
\hline Ireland & $21(3)$ \\
\hline Israel & $10(1)$ \\
\hline Italy & $65(1)$ \\
\hline Jamaica & 1 \\
\hline Japan & $160(7)$ \\
\hline Kenya & 1 \\
\hline Kuwait & 1 \\
\hline Latvia & 1 \\
\hline Lithuania & 1 \\
\hline Mexico & $7(4)$ \\
\hline Netherlands & $571(102)$ \\
\hline New Zealand & $21(3)$ \\
\hline Norway & $37(6)$ \\
\hline Pakistan & 2 \\
\hline Peoples Republic of China & $71(3)$ \\
\hline Philippines & 1 \\
\hline Poland & 49 \\
\hline Portugal & $-(1)$ \\
\hline Romania & 7 \\
\hline Russia & $104(8)$ \\
\hline Saudi Arabia & 3 \\
\hline Scotland & $26(6)$ \\
\hline Singapore & $30(1)$ \\
\hline Slovakia & $12(3)$ \\
\hline Slovenia & $3(1)$ \\
\hline South Africa & $17(2)$ \\
\hline South Korea & $27(2)$ \\
\hline Spain & $29(2)$ \\
\hline Sweden & $17(3)$ \\
\hline Switzerland & $149(21)$ \\
\hline Taiwan & $16(1)$ \\
\hline Thailand & 1 \\
\hline Tobago Trinidad & 1 \\
\hline Turkey & $3(1)$ \\
\hline UAE & 2 \\
\hline
\end{tabular}




\begin{tabular}{|l|c|}
\hline Ukraine & 6 \\
\hline Uruguay & 1 \\
\hline USA & 2288 (982) \\
\hline Uzbekistan & 1 \\
\hline Venezuela & 3 \\
\hline Wales & 6 \\
\hline Yugoslavia & 2 \\
\hline
\end{tabular}

\section{DISCUSSION}

In this chapter, analytical information related to South African publications and journals indexed by the Institute for Scientific Information (ISI) has been reported and analysed. Such information can be of particular assistance in the development of appropriate strategic approaches to the promotion of South African based research journals, as ISI covers the most influential and highly selected body of reputable research journals internationally (see Jacso, 2005).

The scientific disciplines in which indexed South African publications are produced have been linked with the existence or lack of local journals in the fields concerned. Furthermore, information has been presented on the performance of the local journals in their international context. The argument is that recommendations aimed at supporting the local research publishing domain can only be made if the country's publishing profile and the relative performance of its local journals is well understood.

By setting a particular reasonable threshold for articles published in a particular field, one can deduce that local publishing activity could in principle support a limited number of new international-level journals (those at the top of Table 1). The underlying assumption ${ }^{2}$ has been that a local journal will in fact be supported by local researchers and that their "worthwhile" papers, published currently in international journals covered by ISI indices, would be transferred to the (proposed) new journals in the respective fields. In addition, it would be reasonable to expect a significant number of international articles also to come to a vigorous and increasingly well-recognised local newcomer.

Local journals included in the ISI indices have also been analysed in respect of their relative performance (Tables 11 and 12). Comparing the identified fields in which significant research outputs are produced by South African authors with the fields in which journals are published in South Africa, it becomes evident that in most of the fields of strength there is already some journal representation. For example, in animal sciences there are two journals (African Zoology and the South African Journal of Wildlife Research); in plant sciences, one (Bothalia), while environmental sciences /ecology is covered by one (the South African Journal of Wildlife Research). It can be debated, of course, whether an adequate number of articles is published in local journals in the country's fields of strength. (e.g. in animal and plant sciences, and in ecology and environmental sciences, South Africa has been contributing approximately 400 articles per year of which only a small percentage appear in local journals.)

The fields in which South Africa is producing an appreciable number of publications and there are no local journals indexed in ISI, are those of space sciences, physics and microbiology; as the fields of physics and microbiology are covered in any case by a large number of journals in ISI, the only possible opportunity for a successful local journal may exist in the field of space sciences.

In summary, the bibliometric analysis described in this chapter of South African publications in the ISI system points to a clear need for support of selected local journals to improve and entrench their position in the ISI system, and the existence of opportunities for locally published journals in a number of areas which must, however, be carefully contextualized in terms of their potential appeal to international authors as well as the likelihood or otherwise that South

2 Our analysis considers journals as a supporting mechanism for the dissemination of scientific research. It should be emphasised, however, that scientific publishing could be seen as an industrial activity (the Netherlands phenomenon). In such a case the number of local publications will not be relevant. The country may decide to develop a scientific publishing industry aiming to attract clients (authors) from the rest of the world. 
African scholars may be willing to transfer their papers to high-quality local journals. The circumstances in which this might happen is examined in later chapters.

\section{REFERENCES}

Cronin, B. (2005) A hundred million acts of whimsy? Current Science 89: 1505-1509

Garfield, E. (1955) Citation indexes for science: a new dimension in documentation through association of ideas. Science 122: 108-111

Jacso, P. (2005) As we may search - comparison of major features of the Web of Science, Scopus, and Google Scholar citation-based and citation-enhanced databases. Current Science 89:1537-1547.

Lewison,G. (2005) Beyond SCI citations -- new ways to evaluate research. Current Science 89: 1524-1530

Moed, H F. (2005) Citation analysis of scientific journals and journal citation measures. Current Science 90: 1990-1996

Nature, Editorial (1970) Is your lab well cited? Nature 227: 219

Pouris A. (2005) An assessment of the impact and visibility of South African Journals. Scientometrics 62(2):213-222

Roth,D. (2005) The emergence of competitors to the Science Citation Index and the Web of Science. Current Science 89: 1531-1536 


\section{A comprehensive analysis of South African Research Journals}

By Johann Mouton ${ }^{1}$, Nelius Boshoff ${ }^{2}$ and Robert Tijssen ${ }^{3}$

\section{BACKGROUND}

There are currently at least 255 South African scientific or scholarly journals recognized by the Department of Education (DoE) as meeting the minimum requirements for state subsidy under the policy of supply-side support for authors (and their institutions) who publish in these journals. Twenty-three of these journals appear in one of the ISI Citation Indexes, 14 are indexed in the International Bibliography of the Social Sciences (2 journals appear in both), while the remaining 220 journals are "accredited" separately by the Department (2003 list and 2004 supplementary list).

The criteria that these journals had to meet in order to be accredited by the DoE were the following:

- The required purpose of the journal is to disseminate research results, and the content has to support high-level learning, teaching and research in the subject area concerned;

- The journal requires an ISSN (International Standard Serial Number);

- The journal has to be published regularly (frequency of publication);

- The journal requires an editorial board that was reflective of expertise in the subject area covered;

- The members of the editorial board are required have standing in their respective subject areas in terms of their own peer-reviewed research, through their publications and citations;

- Articles accepted for publication in the journal require to be peer-reviewed;

- The journal requires to be distributed beyond a single institution (holdings of South African and/or international Libraries were taken as the standard against which this criterion was measured).

It is perhaps very appropriate that an analysis of the state of South Africa's scientific journals is conducted exactly 20 years after this rather unique incentive/reward scheme was introduced by the then National Department of Education in 1985. A few studies have been conducted over the years to review the effectiveness and appropriateness of the scheme. Despite these studies, many perceptions about the quality or lack thereof of South African journals remain, and include the questions:

- Are the SA journals in the ISI-indexes automatically superior compared to those who are not? If this is the case, would it imply that the vast majority of SA journals in the humanities and social sciences - which are not indexed in the ISI -- are to be regarded as being of inferior quality? Does it also mean that those SA journals that at some point in time were included in the ISI lists but were subsequently removed from them (e.g. the South African Statistical Journal), should now be regarded as inferior?

- Are all journals not included in the ISI-indexes of similar (accreditable) quality? Technically, they are viewed as such, since the DoE retained most of them on their revised list dated September 2003. To our knowledge, however, no rigorous and systematic review of these journals has recently been undertaken, and even a cursory investigation of some of them reveals very irregular appearance of issues, small numbers of articles and a high incidence of authors writing from the same institution (see Chapters 1 and 4). So how
It is perhaps very

appropriate that an

analysis of the state

of South Africa's

scientific journals is

conducted exactly 20

years after this rather

unique incentive/

reward scheme

was introduced by

the then National

Department of

Education in 1985

Jm6@sun.ac.za; Centre for Research on Science and Technology, Stellenbosch University

scb@sun.ac.za; Centre for Research on Science and Technology, Stellenbosch University

tijssen@cwts.leidenuniv.nl; University of Leiden and Visiting Professor, Stellenbosch University 
do we establish whether the 220 non-ISI and non-IBSS South African journals are all of "adequate" quality?

- But has the DoE scheme not led to a compromise in quality anyway? Any article - irrespective of length or content - which appears in any of these lists, qualifies for subsidy. Many commentators have viewed this as a recipe for lowering the standards of these journals. In fact, there are many cases (e.g. the South African Journal of Higher Education) where the number of articles per issue has escalated over the past few years - seemingly to meet the increasing demand for publication outlets. And since we do not have any reliable, audited data on the "success rates" (exemplified, by their frequent citation in more recent articles) of submitted articles to South African journals, it is impossible to establish whether the increase (in some cases) in the number of articles per issue has coincided with a decline in rejection rates.

The aim of this chapter is to provide an in-depth and systematic analysis of a large set of South African research journals ${ }^{4}$. All of the issues raised above will not necessarily be addressed, but an attempt will be made to provide a comprehensive analysis of key questions that revolve around the scope, profile, historical trends and criterion-based quality of locally published journals. The following are the key issues addressed in this chapter:

- The ISI versus non-ISI profile of South African journals

- Publication data by main scientific field over time (for both ISI-listed and non-ISI South African journals)

- An analysis of article numbers by journals and scientific field - which gives an indication of which journals attract the largest numbers of local articles

- Institutional patterns in journal publication

- Basic demographic analyses of South African authors: race, gender and age, by scientific field.

- Introducing novel comparative measures to assess the impact factors and citation profiles of South African journals.

Before addressing these issues, we will first provide a brief history overview of the official policies and procedures with regard to South African journals, as well as presenting a brief discussion of the databases (CREST's SA Knowledgebase and CWTS's ISI Citation Indexes) on which our analyses in the remainder of this chapter are based.

\section{THE HISTORY OF JOURNAL ACCREDITATION IN SOUTH AFRICA}

In 1985, the then Department of National Education launched a programme to incentivise scientific publishing in South Africa. This programme basically entailed that articles published by South African academics (with an address at a university or technikon) in any of the accredited journals as stipulated by the Department would qualify for a subsidy to be determined each year as part of the "block subsidy" granted to each of the public higher education institutions. The original list of accredited journals was compiled by including all ISI-journals, and adding South African journals to an "Accreditation List".

Due to regular submissions of successful proposals for additions of new journals, the List of accredited South African journals grew to 210 by the end of 1997. Between 1998 and 2003, however, the Department of Education did not augment the list; its "freezing" was justified in anticipation of a planned review of the whole programme. In addition to a comprehensive study of the national journals that was done for the Department of Arts, Culture, Science and Technology in $1999^{5}$, the Department commissioned its own study of this programme in 2001. The "freezing" of the list has had the very negative effect that no new journal titles (including South African titles) were added to the list for a period of 5 years; and no systematic review of existing titles was undertaken. Not surprisingly, this situation led to much dissatisfaction within the academic community. New journals appear regularly and are more often than not

4 Our focus here is predominantly on the non-ISI South African journals, given that Chapter 2 addresses South Africa's journals listed in the ISI. However, in some cases, where we need to compare ISI versus non-ISI journals, the boundaries between that and this chapter inevitably get blurred.

5 Pouris, A. \& Richter, L. (2000). 
an indication of where the real innovation and discovery in a research field takes place. New journals also tend to appear in the "inter-disciplinary" space that emerges when old boundaries become redundant and signify new potential breakthroughs.

Towards the end of 2001, the Department of Education circulated a letter to all higher education institutions, informing them that a new Accreditation List had been compiled; the new List appended to this letter contained 173 South African journal titles. Universities and technikons were invited to submit motivations to add other titles to this list. A first inspection of the new list - and a comparison with the previous list - revealed a number of discrepancies/anomalies.

- A large number (67) of SA titles, which had previously been accredited, had simply disappeared and were not included in the new List.

- A significant number (41) of new titles, which had not been previously accredited, were now listed.

These statistics immediately raised concerns and led to two kinds of questions:

- Firstly, on what grounds were previously accredited journals now dis-accredited? The criteria that were now being applied did not seem to be fundamentally different from those that these titles had met at some time in the past. It was conceivable that some of the formerly accredited journals could have been dropped because they did not appear at regular intervals, or because their status had changed (for example, becoming mainly a "house journal" for a particular profession or disciplinary community). It would have been surprising, however, if this were true of all 67 journals omitted from the new List.

- Secondly, on what grounds were journals, that had not been accredited before, now being accredited? Presumably, some of the newly listed journals were either brand-new journals and/or had not been submitted for accreditation before. Again, it was unlikely that this would apply to the majority of the 41 newly listed journals.

These "anomalies" have been further aggravated when a "journal" such as "Woord en Daad", which is basically a popular scientific magazine, appeared on the list, whereas a respected (and formerly accredited) learned journal in the same field, e.g. the Nederduits Gereformeerde Teologiese Tydskrif disappeared from the list. Other anomalous examples also arise in the debate.

In response to various questions and criticisms, the 2001 List was never implemented. In September 2003, the Department of Education published its latest official policy on SA research output - "Policy and Procedures for the Measurement of Research Output for Public Higher Education Institutions", which came into effect on the 1 January, 2005 for the 2004 research outputs. The policy listed the following journal categories as qualifying for subsidy purposes. Journals listed in the following:

a) The Sciences Citation Index of the Institute of Scientific Information (ISI)

b) The Social Sciences Citation Index of the ISI

c) The Arts and Humanities Citation Index of the ISI

d) The International Bibliography of Social Sciences (IBSS)

e) The Department of Education (DoE) List of Approved South African Journals

The List of approved South African journals (excluding the ISI-listed titles) was appended to this new policy, numbered 197. A supplementary List, containing the names of a further 23 South African journal titles, was added in 2004. This brought the total of South African journals titles (still excluding those on the ISI-list) accredited by the Department to 220 journal titles. At the time, 23 South African journals were listed in one of the ISI indexes ${ }^{6}$. In addition there were 14 social science journals included in the International Bibliograhy of the Social Sciences of which 2 were also included in the ISI (South African Archaeological Bulletin and the South African Journal of Economics), which means that the total number of SA journals which are recognized in one way or the other as being of acceptable quality by the DoE, numbers 255 . One way to illustrate this rather complex and fluid picture is as follows:

6 In 200418 South African Journals (if one includes the SA Journal of Botany now published by NISC) were included in the Science Citation Index), 2 SA journals were included in the Social Sciences Citation Index (SA Journal of Economics and Social Dynamics) and 3 SA Journals were listed in the Arts and Humanities Index (SA Archaelogical Bulletin, SA Historical Journal and the SA Journal of Philosophy). 


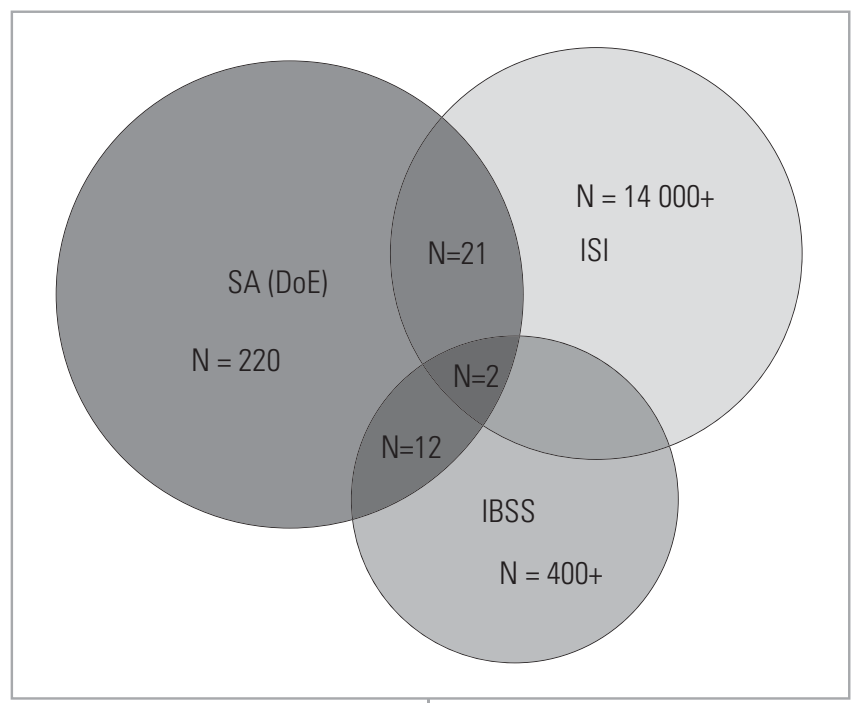

Figure 1: SA Journals by index
This number of 255 cannot be viewed as being fixed, however, as any changes to either one of the international indexes (ISI or IBSS) will mean the addition or reduction in the overall list of accredited journals ${ }^{7}$. It is not clear whether under the new policy, or by other means, the Department of Education will add or remove journals from the 220 titles that it accredited for the 2004 list, although provision for this was made in the gazetted policy.

\section{DATABASES}

\section{CREST's S A Knowledgebase (SAK)}

SA Knowledgebase is a dynamic database of public science in South Africa, developed by the Centre for Research on Science and Technology (CREST) at the University of Stellenbosch. The Centre's work on the database commenced in 1998, with the aim of mapping the following aspects of the country's public science base:

- Scientific output, measured as peer-reviewed journal articles

- Human resources for Science and Technology

Research and Development-performing institutions

- Publicly funded research projects and programmes

As far as scientific output is concerned, SA Knowledgebase collects bibliographic information (excluding citations) on articles, with any South African author addresses, which have appeared in journals accredited by the South African Department of Education (including those included in the ISI and IBSS indexes). It should be emphasized that SAK collects information on articles that appear in South African journals which - at any given date and time - have been accredited by the DoE. As should be evident from the discussion above, however, given the changing nature of the DoE list, it cannot be claimed that all 253 currently accredited South African journals are equally well covered in SA Knowledgebase. Every time there is a shift in policy with a concomitant change in the list of SA accredited journals, there has to be an adjustment in the SAK data-importing procedures.

SA Knowledgebase captures information on every article title, full authorship, journal name, publishing details, and keywords. Data are captured from a variety of sources, including the ISI Web of Science, the Index of South African Periodicals, institution-specific information on DoE submissions, institutional and other websites, as well as from individual curriculi vitae. At present, almost 100000 articles are included in SA Knowledgebase.

As implied, SA Knowledgebase not only covers articles produced by the South African higher education sector, but also articles by the science councils, national research facilities and government research organizations located in South Africa. The database also provides authorspecific information by disaggregating the article output by selected demographic variables (gender, race, year of birth, highest qualification, areas of specialisation and institutional affiliation). The linking of these demographic data to the article authors is an on-going task. Since 1998 CREST has utilised a variety of sources, including its own national surveys, requests for demographic information from South African universities, technikons and science councils, as well as web searches, to add the demographic information of the authors of these articles. The almost 100000 articles have been produced by more than 50000 unique individual South African authors.

\section{CWTSs ISI citation indexes}

The journal citation analyses were conducted with CWTS's bibliometric version of Thomson Scientific's Citation Index-database (CI-database). Thomson Scientific was formerly known as

7 In fact, at least two other journals which had been previously included in the ISI-indexes (Sa Journal of Psychology and Transactions of the Royal Society of South Africa should be added to this number as they do not appear on the new DoE lists, thus bringing the total of South African "accredited" journals to 257. 
the Institute for Scientific Information (ISI); the acronym ISI will be used from now on when referring to Thomson Scientific. The current version of the CWTS/CI-database is an integrated information system comprising the CD/ROM-editions of the ISI's Science Citation Index, Social Sciences Citation Index, Arts and Humanities Citation Index, and six Specialty Citation Indices. The CI-database covers the years 1980-2004/5.

The CWTS/CI database consists of some 10,000 peer-reviewed journals, including conference proceedings published in journals; this is the set of 'source' journals. These sources are either fully indexed ('cover-to-cover') or partially indexed by ISI for inclusion in the CI. Most of the research publications in these source journals include the reference list with relevant 'citations' to related scientific literature. The large majority of these 'citations' relates to CI-indexed 'source items', that is cited publications in journals that were ISI-indexed during the entire time interval 1980-2004/5. Most of the remainder consists of citations to items in ISI--listed journals which are not peer-reviewed original articles (and therefore not indexed in the sense of being included in the denominator function in calculating impact factor), 'non-ISI' citations to 'non source' items such as books and reports, or publications in 'non source' journals that were never ISI-indexed. These two categories are not mutually exclusive; in between we find the 'ISI/nonISI' citations to source items in journals that were only indexed for a limited number of years during in the past.

Hence, the CWTS/CI database enables us to find out if, how heavily, and by whom, research publications in SA journals (both ISI-indexed, non-indexed, or partially indexed journals), are cited in the international scientific literature. This information allows us to develop quantitative measures to characterize and compare SA journals according to their international scientific impact. Most importantly, it allows us, for the first time, to compare ISI-indexed SA journals and non-indexed journals in terms of citation impact. In doing this we build on CWTS's unique database and relatively new data-mining techniques developed at CWTS (e.g. Butler and Visser, 2006).

\section{PROFILES OF SOUTH AFRICAN RESEARCH JOURNALS IN TERMS OF ISI VERSUS NON-ISI, AND FOREIGN VS. LOCAL}

For the purposes of this chapter, the high-level analyses of SA Knowledgebase has been confined to the period 1990 to 2003, and for more detailed analyses (e.g. by scientific field) to the period $1990-2002$. One of the consequences of this decision is that it does not bring into play the IBSS as an index which contains information on SA journals. In the analyses presented below, there is a concentration- where appropriate - on comparing ISI to non-ISI South African journals. This in effect means that one can "categorize" South African journal articles in one of two different ways, viz. ISI versus non-ISI and foreign versus local:

- If articles in ISI versus non-ISI journals are compared, it turns out that 56176 (or 57\%) of all articles appeared in ISI journals and the remaining 43\% in non-ISI journals.

- If South African (local) versus non-South African (foreign) journals are compared, 55157 (or $57 \%$ ) appeared in local journals and $43 \%$ in foreign journals.

These two ways provide very different perspectives on SA scientific output between 1990 and 2003. Within the first perspective (ISI versus nonISI), one is comparing two systems of "accreditation" or "quality assurance". But neither system is purely based on considerations of quality. The ISI-Thompson system - as has been well documented - is equally interested in commercial concerns (Van Raan, 2005; Weingart, 2005). Although journal impact factors (and the underlying citation patterns) are the main criterion for inclusion in ISI Citations Indexes, it is common knowledge that journals with large subscription bases and published by big commercial publishers are more likely to be included. There is also doubt that criteria for inclusion operate equitably, certainly at the margins of the system where regional and/or developing country journals have been concerned. As far as the DoE (or non-ISI) system goes, there is also sufficient evidence to suggest that a
The CWTS/CI

database enables

us to find out if,

how heavily, and

by whom, research

publications in SA

journals (both ISI-

indexed, non-indexed,

or partially indexed

journals), are cited

in the international

scientific literature

Figure 2: SA Articles by index

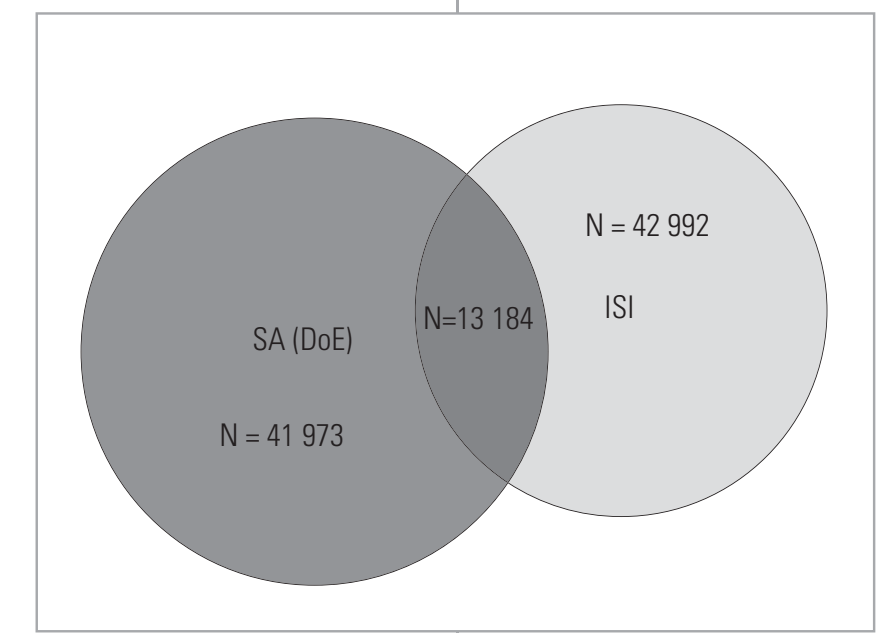




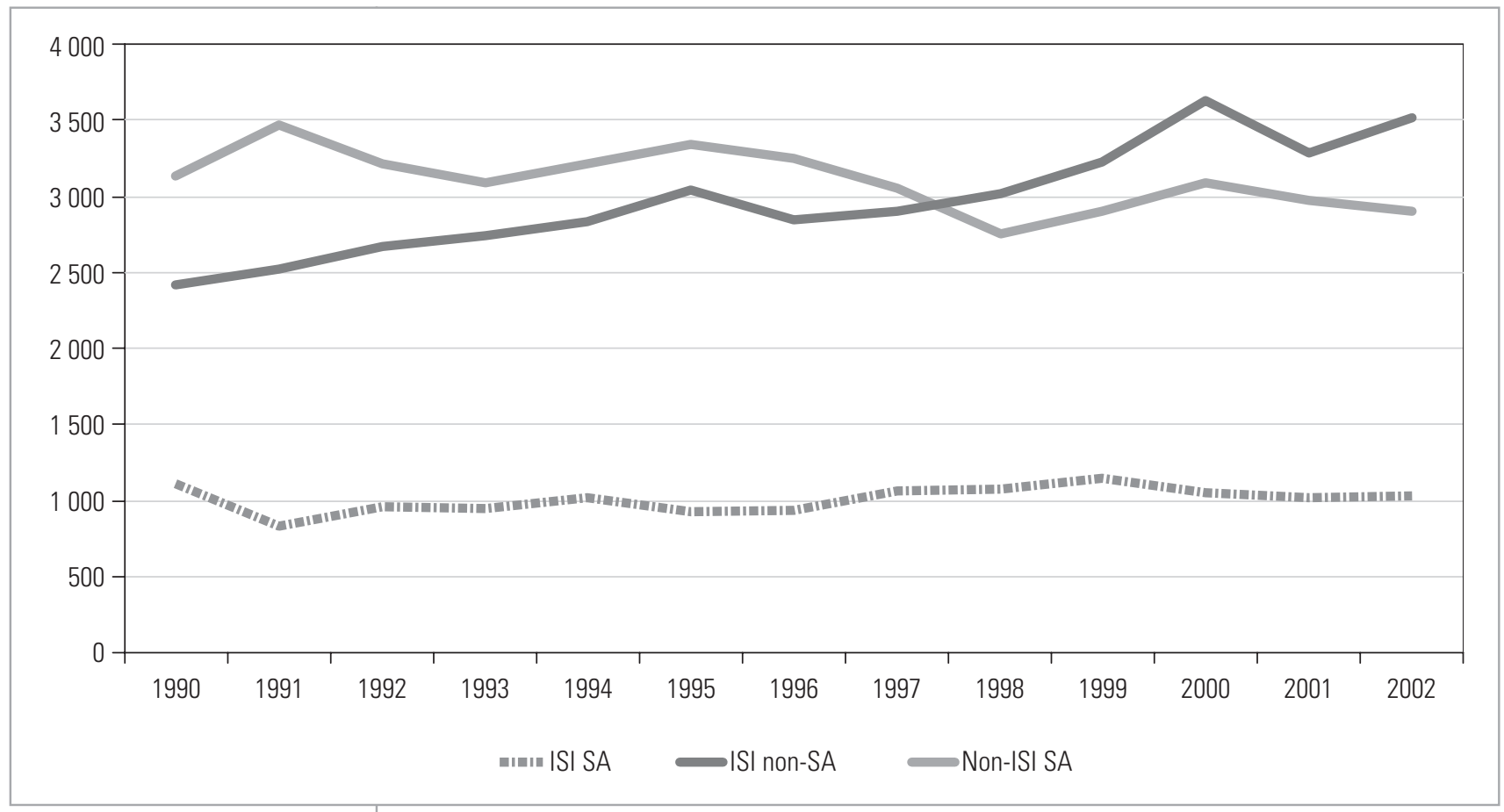

Figure 3: Journal articles by index type by year (1990-2002)

If one looks at the situation in 1990 - the heyday of apartheid academic isolation - where only $36 \%$ of all articles were published in foreign journals with the situation in 2002 where nearly half (47\%) were published in foreign journals, great strides have been made in breaking out of the isolation mould rigorous concern for quality has not always been applied; there certainly seems to be too many inconsistencies that have surfaced over the past years in the inclusion and exclusion of SA journal titles, to warrant a strong belief in quality as the sole criterion. (As far as is known, the Department of Education has not clearly indicated how it intends monitoring the quality of journals currently listed in the future so as to ensure that a decline in journal quality is identified in good time: see chapter 6).

The second way of looking at the journal output, viz. as local versus foreign brings other factors into play. It is fair to say that one of the consequences, if not explicit objectives, of the original DoE policy, was both to protect and encourage the expansion of local journals. There are very good reasons why a relatively small science system such as South Africa should take special measures to protect viable and high-quality small journals. This is especially the case in very small niche areas (see Chapter 2). The obvious concern is that this form of "protectionism", as is often the case, might go hand in hand with a loss in quality.

It is probably fair to say, that most science policy makers in South Africa would prefer the "intersection" of the two Venn diagrammes to have been larger, i.e. more journals and more journals articles that are BOTH South African and ISI. The fact of the matter is that the inclusion of journals in the ISI indexes is neither predictable nor reliable and - as some people have suggested - not immune to political manipulation (Weingart, 2005).

In Figures 3 and 4, the focus is on these distributions over time. Figure 3 shows three quite different trends for each of the "index type" journals. The number of articles in South African ISI-journals has remained reasonably stable over the 13-year period (red line). The number of South African authored articles in South African journals not indexed in ISI has declined steadily (green line), whereas (conversely) the number of articles in ISI-journals has increased quite dramatically.

If the trends are compared for the same articles in terms of local versus foreign journals (Figure 4), the numbers of articles appear to have nearly converged by 2002. There may soon be a situation, if it has not already happened, where South African scientists and scholars publish in equal numbers in local and overseas journals. If one looks at the situation in 1990 - the heyday of apartheid academic isolation - where only $36 \%$ of all articles were published in foreign journals with the situation in 2002 where nearly half (47\%) were published in foreign journals, great strides have been made in breaking out of the isolation mould.

Two salient points emerged from the analysis in this section:

- As far as the ISI versus non-ISI journals are concerned, one has witnessed a significant increase in the number of South African articles published in ISI-journals. Unfortunately, the number of South African journals included in ISI has remained rather constant (in fact 


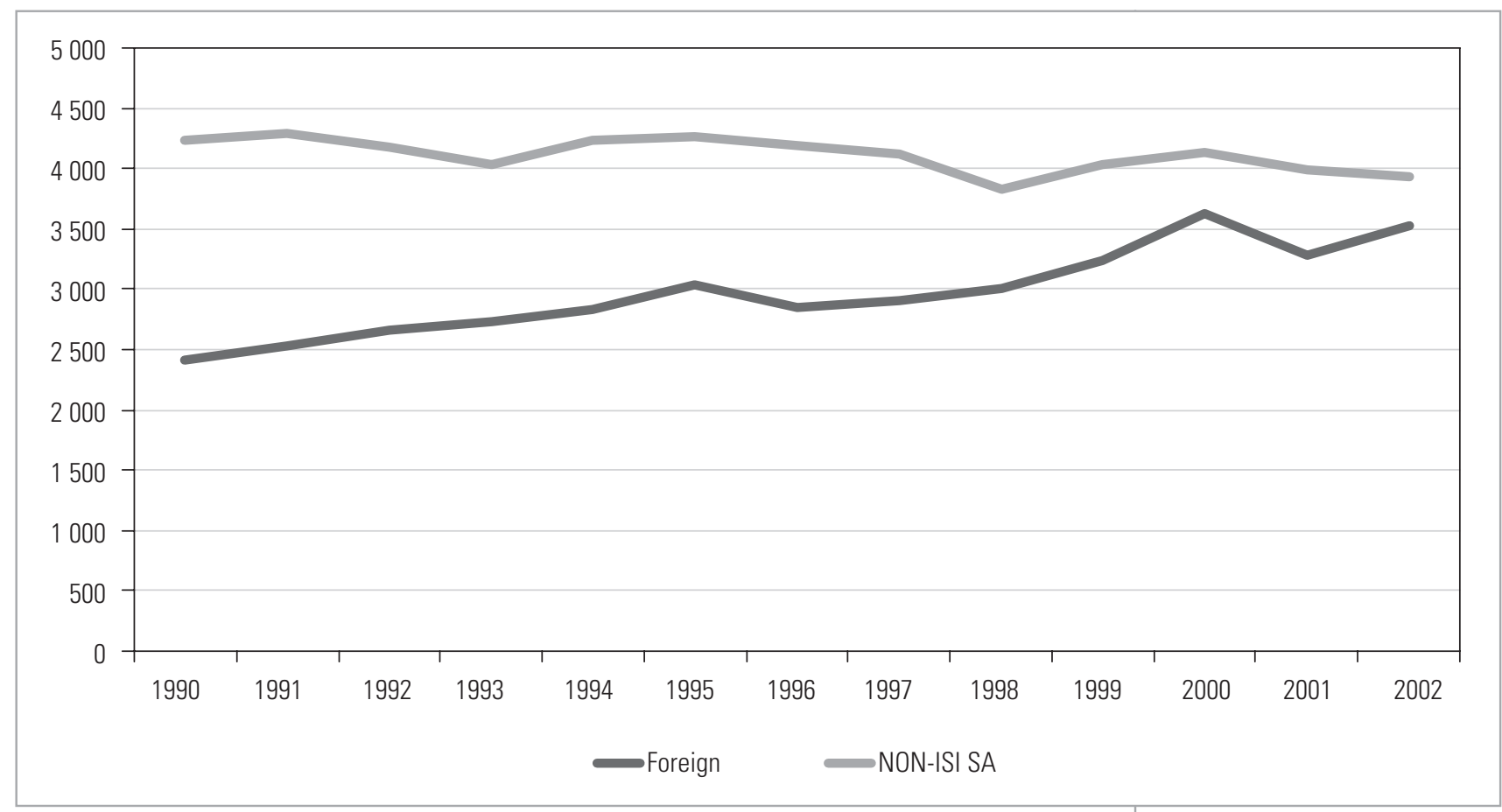

there has been a small decline), which explains why the number of articles in this category has remained fairly stable.

- As far as the distinction between local and foreign journals is concerned, the proportion of articles in foreign journals has increased from just over one third in 1990 to nearly half in 2002.

These two trends (increased production in ISI-journals and in foreign journals) are of course interdependent, although the actual numbers are in themselves worth noting.

\section{PUBLICATION DATA BY MAIN SCIENTIFIC FIELD, AND OVER TIME}

It is a well-established fact that scientists in different fields adhere to different publication patterns. Besides the obvious distinction between book publications and peer-reviewed articles (which is not addressed in this report), scientists in different fields conform to different patterns as far as foreign versus local journals are concerned. Many studies have shown and argued that scholars in the social sciences and humanities tend to publish more in local journals because of the contextuality, historicity and localness of their materials. Studies on indigenous languages, ethnic practices, social forces and artistic trends, are often peculiar to local cultures and societies and scholars prefer to write for local audiences. Although this is very different for scientists in the "pure" disciplines such as mathematics, chemistry, physics, astronomy and so on, which are often viewed as a-contextual or even "universal", there are of course topics in some of the natural and health sciences which are more contextually embedded (the study of tropical diseases in Africa or of biodiversity in the Western Cape). All of this means that one should expect a wide range of publication patterns between and even within scientific fields.

The analysis in this section commences with a breakdown of all articles for the period by main field (Figure 5) followed by a breakdown by year (Table 1).

Following the analyses of ISI versus ISI and foreign versus local in Section 4, these factors are combined in field-specific profiles.

In the Engineering Sciences (Figure 6), the majority (58\%) of articles during this period appeared in foreign ISI-journals. If one adds the additional 604 articles

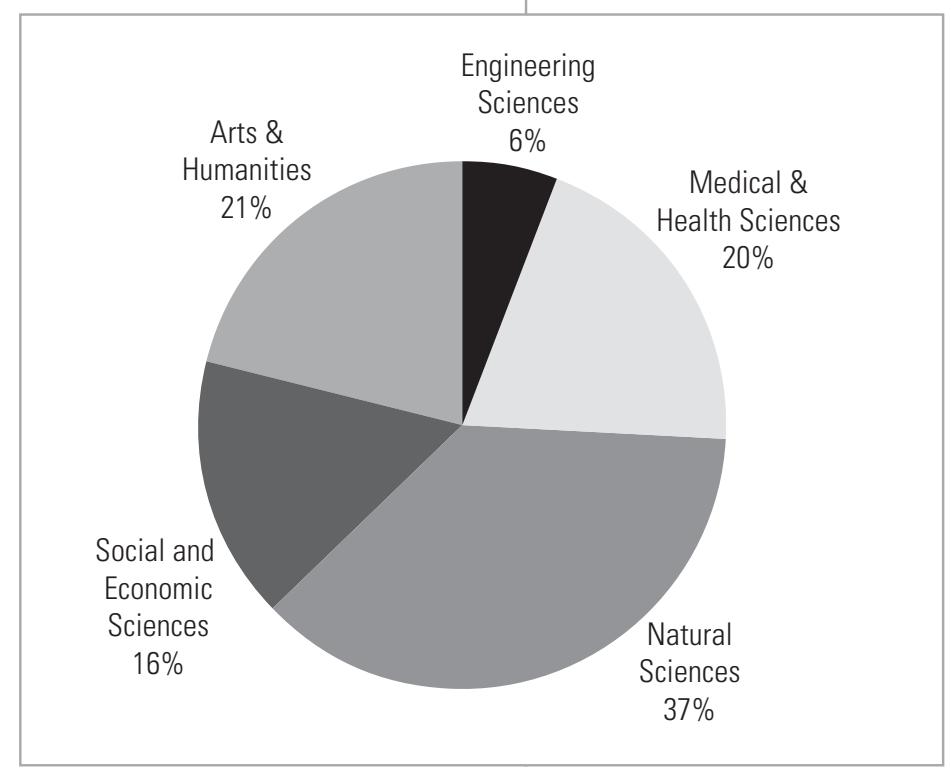

Figure 4: Journal articles by local/foreign by year (1990-2002)

Figure 5: SA articles by main scientific field (1990-2003) 
Table 1: Articles published by main scientific field by year.

\begin{tabular}{|c|c|c|c|c|c|c|c|c|c|c|}
\hline \multirow{3}{*}{$\begin{array}{c}\text { Year of } \\
\text { publication }\end{array}$} & \multicolumn{10}{|c|}{ Main scientific field } \\
\hline & \multicolumn{2}{|c|}{ Arts \& Humanities } & \multicolumn{2}{|c|}{ Engineering Sciences } & \multicolumn{2}{|c|}{$\begin{array}{l}\text { Medical \& Health } \\
\text { Sciences }\end{array}$} & \multicolumn{2}{|c|}{ Natural Sciences } & \multicolumn{2}{|c|}{$\begin{array}{l}\text { Social \& Economic } \\
\text { Sciences }\end{array}$} \\
\hline & Count & Row \% & Count & Row \% & Count & Row \% & Count & Row \% & Count & Row $\%$ \\
\hline 1990 & 1,365 & $20.5 \%$ & 277 & $4.2 \%$ & 1,484 & $22.3 \%$ & 2517 & $37.8 \%$ & 1012 & $15.2 \%$ \\
\hline 1991 & 1,652 & $24.2 \%$ & 340 & $5.0 \%$ & 1,333 & $19.5 \%$ & 2500 & $36.6 \%$ & 1005 & $14.7 \%$ \\
\hline 1992 & 1,607 & $23.4 \%$ & 401 & $5.8 \%$ & 1,299 & $18.9 \%$ & 2422 & $35.3 \%$ & 1126 & $16.4 \%$ \\
\hline 1993 & 1,565 & $23.1 \%$ & 425 & $6.3 \%$ & 1,283 & $18.9 \%$ & 2470 & $36.5 \%$ & 1028 & $15.2 \%$ \\
\hline 1994 & 1,738 & $24.6 \%$ & 462 & $6.5 \%$ & 1,341 & $19.0 \%$ & 2425 & $34.3 \%$ & 1107 & $15.7 \%$ \\
\hline 1995 & 1,644 & $22.5 \%$ & 546 & $7.5 \%$ & 1,356 & $18.6 \%$ & 2550 & $34.9 \%$ & 1209 & $16.6 \%$ \\
\hline 1996 & 1,693 & $24.1 \%$ & 479 & $6.8 \%$ & 1,281 & $18.2 \%$ & 2379 & $33.8 \%$ & 1200 & $17.1 \%$ \\
\hline 1997 & 1,611 & $22.9 \%$ & 454 & $6.5 \%$ & 1,445 & $20.6 \%$ & 2457 & $35.0 \%$ & 1058 & $15.1 \%$ \\
\hline 1998 & 1,307 & $19.1 \%$ & 535 & $7.8 \%$ & 1,430 & $20.9 \%$ & 2471 & $36.1 \%$ & 1103 & $16.1 \%$ \\
\hline 1999 & 1,442 & $19.8 \%$ & 515 & $7.1 \%$ & 1,550 & $21.3 \%$ & 2720 & $37.4 \%$ & 1041 & $14.3 \%$ \\
\hline 2000 & 1,501 & $19.3 \%$ & 497 & $6.4 \%$ & 1,811 & $23.3 \%$ & 2789 & $35.9 \%$ & 1171 & $15.1 \%$ \\
\hline 2001 & 1,527 & $21.0 \%$ & 460 & $6.3 \%$ & 1,573 & $21.6 \%$ & 2621 & $36.0 \%$ & 1106 & $15.2 \%$ \\
\hline 2002 & 1,458 & $19.6 \%$ & 465 & $6.2 \%$ & 1,524 & $20.5 \%$ & 2774 & $37.2 \%$ & 1228 & $16.5 \%$ \\
\hline
\end{tabular}
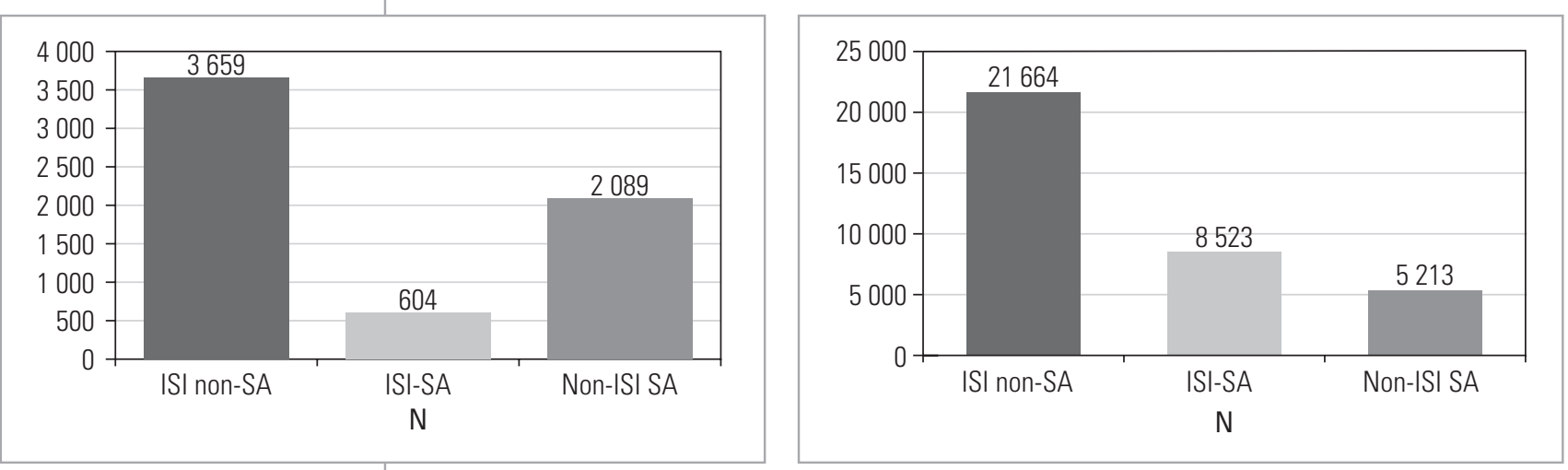

Left: Figure 6: Engineering Sciences (1990-2003)

Right: Figure 7: Natural Sciences (1990-2003)

Left: Figure 8: Medical \& Health Sciences (1990-2003)

Right: Figure 9: Social \& Economic Sciences (1990-2003) that appeared in the South African articles, an overall total of $67 \%$ or two-thirds appeared in ISI-indexed journals.

The profile for publications in the Natural Sciences (Figure 7) is not dissimilar. Again, the vast majority (21664 or $61 \%$ of all articles appeared in foreign ISI-indexed journals. To this should be added the South African ISI-journals (8523) that add another 24\% to an overall total of $85 \%$ of articles appearing in ISI-journals.

Again, a very similar profile emerges when one look at the Medical and Health Sciences (Figure 8) where 12749 articles or 64\% appeared in foreign or overseas journals. Articles in SA ISI-journals add another 3112 or $16 \%$ to bring the total proportion of articles in ISI-journals to nearly $80 \%$
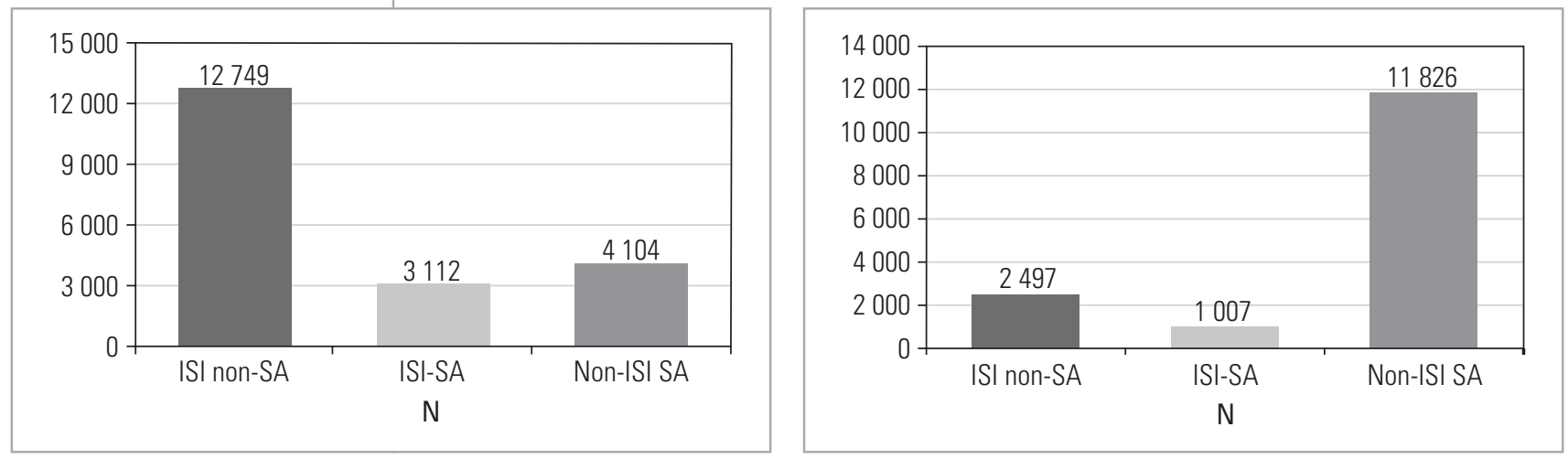
Not surprisingly, the profiles for the human sciences are quite different. As far as the social and economic sciences (Figure 9) are concerned, the vast majority of articles (11826 or $77 \%$ ) appeared in local, non-ISI journals.

A similar situation applies to the Arts and Humanities (Figure 10) where an even higher proportion (90\% or 18642) articles were published in local journals during this periods. Two sets of distributions have been presented for each scientific field: the proportion of ISI versus non-ISI, and the proportion of foreign vs. local journal articles. The overall patterns, as far as the ISI/non-ISI profiles are concerned, are as one might expect, given the fact that the vast majority of

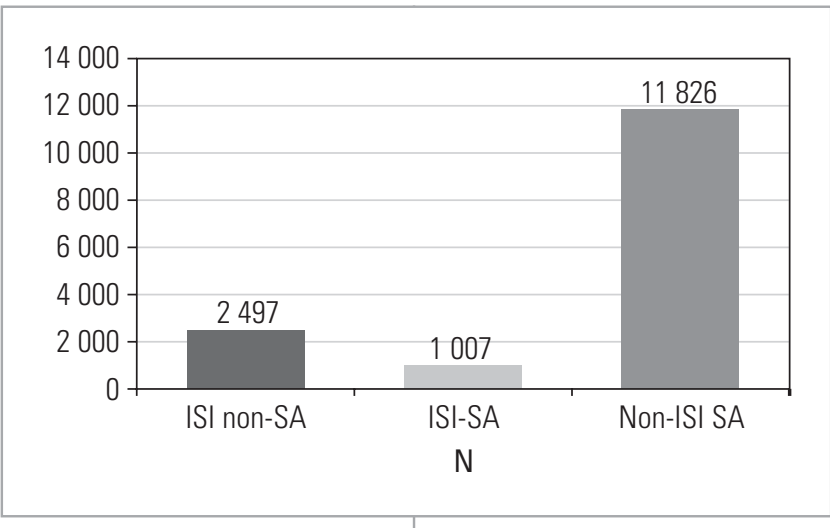

Table 2: summarises the ISI versus non-ISI and foreign vs. local proportions of articles by scientific field:

\begin{tabular}{|l|c|c|c|c|}
\hline \multirow{2}{*}{\multicolumn{1}{|c|}{ Main field }} & \multicolumn{2}{|c|}{ Classification by index } & \multicolumn{2}{c|}{ Classification by region } \\
\cline { 2 - 5 } & ISI & Non-ISI & Foreign & Local \\
\hline Engineering Sciences & $67.1 \%$ & $32.9 \%$ & $57.6 \%$ & $42.4 \%$ \\
\hline Medical \& Health Sciences & $79.4 \%$ & $20.5 \%$ & $63.9 \%$ & $36.1 \%$ \\
\hline Natural Sciences & $85.0 \%$ & $15.0 \%$ & $61.0 \%$ & $39.0 \%$ \\
\hline Social \& Economic Sciences & $22.9 \%$ & $77.1 \%$ & $16.3 \%$ & $83.7 \%$ \\
\hline Arts \& Humanities & $9.7 \%$ & $90.3 \%$ & $6.9 \%$ & $93.1 \%$ \\
\hline
\end{tabular}

South African journals indexed in ISI are from the natural, engineering and health sciences. It comes as no surprise that more than two thirds of articles in these fields are published in ISI-journals.

The foreign vs. local distributions of journal articles by scientific field have also been presented, to "correct' for the "bias" that the serious under-representation of South African social science journals are subject to in the ISI system. It also provides another perspective on where South African scientists publish. These results revealed some interesting "differences" in the profiles with large proportions of articles in the engineering sciences (42\%), natural science articles (nearly 40\%) and medical and health sciences (36\%) appearing in local journals. The high proportion of articles in the human sciences appearing in local journals is not surprising, especially if one takes into account that the arts and humanities would include work in the field of indigenous languages, theology, law, music, theatre - all fields that are locally embedded. A separate study has shown (Mouton, 2005) that higher proportions of articles in these fields are still published in Afrikaans, which makes it inevitable that they would appear in local journals.

\section{AN ANALYSIS OF ARTICLE NUMBERS BY JOURNALS AND SCIENTIFIC FIELD}

In this section, the focus is shifted to take a closer look at the journals in which South African scientists tend to publish most frequently. The analysis is by main scientific field, and in each case the interest is in the following:

- The spread of journals is assessed where scholars in that field published their papers; as a measure of "spread" (not unlike "variance" in statistical terms), the number of journals was counted in which $50 \%$ of the articles over this period appeared.

- Whether there is a small number of journals that predominates in a specific field, established by looking at which journals "attract" a disproportionate number of articles in the field or clusters of sub-fields.

- And finally, the ISI/non-ISI, and the Foreign/Local proportions of journals containing the top $50 \%$ of articles in each field are examined. 


\section{ARTS AND HUMANITIES}

A total of 20383 articles appeared in 611 journals that were classified as "arts and humanities" journals over the period 1990 - 2003. 50\% of these articles appeared in 25 journals only $(\text { Table } 3)^{8}$.

Table 3: Arts and humanities ( $n=20383$ ARTICLES)

\begin{tabular}{|c|c|c|c|}
\hline Journal title & Index & Nr of articles & $\begin{array}{c}\% \text { Of total } \\
\text { articles }\end{array}$ \\
\hline Tydskrif vir Hedendaagse Romeins-Hollandse Reg & Non-ISI \& SA & 845 & 4.15 \\
\hline Tydskrif vir die Suid-Afrikaanse Reg & Non-ISI \& SA & 816 & 4.00 \\
\hline South African Law Journal & Non-ISI \& SA & 668 & 3.28 \\
\hline Hervormde Teologiese Studies & Non-ISI \& SA & 646 & 3.17 \\
\hline Nederduitse Gereformeerde Teologiese Tydskrif & Non-ISI \& SA & 596 & 2.92 \\
\hline Annual Survey of South African Law & Non-ISI \& SA & 505 & 2.48 \\
\hline De jute & Non-ISI \& SA & 475 & 2.33 \\
\hline South African Journal of Criminal Justice & Non-ISI \& SA & 468 & 2.30 \\
\hline South African Journal on Human Rights & Non-ISI \& SA & 402 & 1.97 \\
\hline Scriptura & Non-ISI \& SA & 369 & 1.81 \\
\hline Acta Academica & Non-ISI \& SA & 364 & 1.79 \\
\hline Old Testament Essays & Non-ISI \& SA & 363 & 1.78 \\
\hline Literator & Non-ISI \& SA & 354 & 1.74 \\
\hline South African Journal of African Languages & Non-ISI \& SA & 353 & 1.73 \\
\hline In die Skriflig & Non-ISI \& SA & 349 & 1.71 \\
\hline Journal for Language Teaching & Non-ISI \& SA & 325 & 1.59 \\
\hline Tydskrif vir Geesteswetenskappe & Non-ISI \& SA & 324 & 1.59 \\
\hline Comparative and International Law Journal of Southern Africa & Non-ISI \& SA & 306 & 1.50 \\
\hline Journal of Theology for Southern Africa & Non-ISI \& SA & 299 & 1.47 \\
\hline South African Journal of Linguistics & Non-ISI \& SA & 292 & 1.43 \\
\hline Koers & Non-ISI \& SA & 287 & 1.41 \\
\hline SA Mercantile Law Journal & Non-ISI \& SA & 282 & 1.38 \\
\hline Obiter & Non-ISI \& SA & 275 & 1.35 \\
\hline Stellenbosch Law Review & Non-ISI \& SA & 268 & 1.32 \\
\hline SA Public Law & Non-ISI \& SA & 266 & 1.31 \\
\hline Total & & & 51.50 \\
\hline
\end{tabular}

As far as spread is concerned, a small number of journals (25) accounts for $50 \%$ or more than 10000 of the articles published in this field; one would characterise this as a field that is highly concentrated. Although there is no clear domination by a single journal, it is nevertheless striking that the first three journals on the list - all Law journals - account for $11 \%$ of all the articles in the field. It is also relatively easy to identify the main clusters of sub-fields:

- LAW (12 journals) - 27.35\%

- Theology/Religious studies (6) - $12.86 \%$

- Language and literary studies (4) $-6.49 \%$

- General humanities journals (TGW/Koers/Acta Academica) - 4.78\%

What is remarkable is that none of the other fields in the Arts and Humanities, such as Philosophy, History and the Performing Arts, feature prominently in this list. And, not surprisingly, none of these 25 journals are ISI-listed journals and all are locally published.

8 In the tables that follow, journals indexed in one of the three ISI citation-indexes have been indicated in capital letters. 


\section{HEALTH AND MEDICAL SCIENCES}

A total of 19983 articles appeared in 1677 journals that were classified as "medical and health sciences" journals over the period 1990 - 2003. 50\% of these articles appeared in 63 journals only (Table 4).

Table 4: Health and Medical Sciences ( $n=19983$ ARTICLES)

\begin{tabular}{|c|c|c|c|}
\hline Journal title & Index & $\begin{array}{c}\text { No. of } \\
\text { articles }\end{array}$ & $\begin{array}{c}\% \text { of total } \\
\text { articles }\end{array}$ \\
\hline South African Medical Journal & $I S I \& S A$ & 2331 & 11.66 \\
\hline South African Dental Journal & Non-ISI \& SA & 728 & 3.64 \\
\hline South African Journal of Continuing Medical Education & Non-ISI \& SA & 666 & 3.33 \\
\hline Geneeskunde & Non-ISI \& SA & 518 & 2.59 \\
\hline South African Family Practice & Non-ISI \& SA & 435 & 2.18 \\
\hline South African Journal of Surgery & $I S I \& S A$ & 422 & 2.11 \\
\hline Central African Journal of Medicine & ISI \& non-SA & 356 & 1.78 \\
\hline South African Journal of Chemistry & $I S I \& S A$ & 299 & 1.50 \\
\hline South African Journal of Physiotherapy & Non-ISI \& SA & 223 & 1.12 \\
\hline SA Bone \& Joint Surgery & Non-ISI \& SA & 212 & 1.06 \\
\hline Cardiovascular Journal of Southern Africa & Non-ISI \& SA & 188 & 0.94 \\
\hline Southern African Journal of Epidemiology \& Infection & Non-ISI \& SA & 185 & 0.93 \\
\hline Phytochemistry & ISI \& non-SA & 164 & 0.82 \\
\hline Southern African Journal of Child and Adolescent Mental Health & Non-ISI \& SA & 143 & 0.77 \\
\hline British Journal of Anaesthesia: South African edition & Non-ISI \& SA & 132 & 0.84 \\
\hline South African Journal of Clinical Nutrition & Non-ISI \& SA & 103 & 0.52 \\
\hline Journal of Organometallic Chemistry & ISI \& non-SA & 92 & 0.46 \\
\hline LANCET & ISI \& non-SA & 89 & 0.45 \\
\hline Journal of Clinical Microbiology & ISI \& non-SA & 86 & 0.43 \\
\hline Annals of Tropical Paediatrics & ISI \& non-SA & 83 & 0.42 \\
\hline International Journal of Tuberculosis and Lung Disease & ISI \& non-SA & 81 & 0.41 \\
\hline British Journal of Surgery & ISI \& non-SA & 79 & 0.40 \\
\hline AIDS & ISI \& non-SA & 73 & 0.37 \\
\hline Pediatric Surgery International & ISI \& non-SA & 70 & 0.35 \\
\hline Pediatric Infectious Disease Journal & ISI \& non-SA & 70 & 0.35 \\
\hline The South African Optometrist & Non-ISI \& SA & 67 & 0.34 \\
\hline Journal Of Ethnopharmacology & ISI \& non-SA & 67 & 0.34 \\
\hline East African Medical Journal & ISI \& non-SA & 64 & 0.32 \\
\hline Journal of Tropical Pediatrics & ISI \& non-SA & 64 & 0.32 \\
\hline Medical Science Research & ISI \& non-SA & 63 & 0.32 \\
\hline Inorganic Chemistry & ISI \& non-SA & 63 & 0.32 \\
\hline Injury-International Journal of the Care of the Injured & ISI \& non-SA & 61 & 0.31 \\
\hline Military Medicine & Non-ISI \& SA & 61 & 0.31 \\
\hline Journal of Infectious Diseases & ISI \& non-SA & 60 & 0.30 \\
\hline Journal of General Virology & ISI \& non-SA & 60 & 0.30 \\
\hline Transactions of the Royal Society of Tropical Medicine And Hygiene & ISI \& non-SA & 60 & 0.30 \\
\hline Antimicrobial Agents and Chemotherapy & ISI \& non-SA & 60 & 0.30 \\
\hline Transplantation Proceedings & ISI \& non-SA & 58 & 0.29 \\
\hline American Journal of Medical Genetics & ISI \& non-SA & 58 & 0.29 \\
\hline British Journal of Obstetrics and Gynaecology & ISI \& non-SA & 57 & 0.28 \\
\hline Journal of Medical Virology & ISI \& non-SA & 57 & 0.29 \\
\hline
\end{tabular}




\begin{tabular}{|l|c|c|c|}
\hline \multicolumn{1}{|c|}{ Journal title } & Index & $\begin{array}{c}\text { No. of } \\
\text { articles }\end{array}$ & $\begin{array}{c}\% \text { of total } \\
\text { articles }\end{array}$ \\
\hline British Medical Journal & ISI \& non-SA & 56 & 0.28 \\
\hline Journal of Biological Chemistry & ISI \& non-SA & 55 & 0.28 \\
\hline Prostaglandins Leukotrienes And Essential Fatty Acids & ISI \& non-SA & 53 & 0.27 \\
\hline Journal of Laryngology And Otology & ISI \& non-SA & 53 & 0.27 \\
\hline International Journal of Gynecology \& Obstetrics & ISI \& non-SA & 51 & 0.26 \\
\hline Anticancer Research & ISI \& non-SA & 51 & 0.26 \\
\hline Comparative Biochemistry and Physiology B-Biochemistry \& & ISI \& non-SA & 50 & 0.25 \\
\hline Molecular Biology & ISI \& non-SA & 49 & 0.25 \\
\hline Journal of Antimicrobial Chemotherapy & ISI \& non-SA & 49 & 0.25 \\
\hline Andrologia & ISI \& non-SA & 49 & 0.25 \\
\hline International Journal of Pharmaceutics & ISI \& non-SA & 48 & 0.24 \\
\hline Bulletin of the World Health Organization & ISI \& non-SA & 46 & 0.23 \\
\hline Drug Development and Industrial Pharmacy & ISI \& non-SA & 46 & 0.23 \\
\hline Annals of Thoracic Surgery & ISI \& non-SA & 46 & 0.23 \\
\hline Infection and Immunity & ISI \& non-SA & 45 & 0.23 \\
\hline Cardiovascular Drugs and Therapy & ISI \& non-SA & 45 & 0.23 \\
\hline Medical Hypotheses & Non-ISI \& SA & 44 & 0.22 \\
\hline The South African Journal of Communication Disorders & ISI \& non-SA & 44 & 0.22 \\
\hline Medicine and Science in Sports and Exercise & ISI \& non-SA & 42 & 0.21 \\
\hline Optometry and Vision Science & ISI \& non-SA & 42 & 0.21 \\
\hline Forensic Science International & ISI \& non-SA & 41 & 0.21 \\
\hline Journal of Coordination Chemistry & ISI \& non-SA & 41 & 0.21 \\
\hline British Journal Of Anaesthesia & & & 50.19 \\
\hline Total & & \\
\hline
\end{tabular}

As far as journals spread is concerned, the most striking feature of this listing is the obvious dominance of the South African Medical Journal in the field, accounting for $11.67 \%$ of all articles published in this period. Another 5 South African journals (South African Dental Journal, South African Journal of Continuing Medical Education,. Geneeskunde, South African Family Practice and South African Journal of Surgery) account for a further $13.85 \%$ of all articles in this period. This means that a quarter of all articles published in this field over the period 1990 - 2003 appeared in 6 local journals only. (It is worth emphasizing, though, that two of these journals are also ISI-listed journals.). Although the first six journals on the list are all local journals, local journals only constitute 17 out of the total of 63 journals in this listing, and the vast majority (49) are ISI-listed journals.

\section{NATURAL SCIENCES}

A total of 135499 articles appeared in 2357 journals that were classified as "natural sciences" journals over the period 1990 - 2003. 50\% of these articles appeared in 90 journals only (Table 5).

Table 5: Natural Sciences $(n=35499$ ARTICLES)

\begin{tabular}{|c|c|c|c|}
\hline Journal title & Index & Nr of articles & $\%$ Of total articles \\
\hline South African Journal of Science & ISI \& SA & 1,910 & 5.38 \\
\hline South African Journal of Botany & ISI \& SA & 876 & 2.47 \\
\hline Water SA & ISI \& SA & 728 & 2.05 \\
\hline Agrekon & Non-ISI \& SA & 572 & 1.61 \\
\hline South African Journal of Marine Science & ISI \& SA & 561 & 1.58 \\
\hline South African Journal of Plant and Soil & Non-ISI \& SA & 538 & 1.51 \\
\hline
\end{tabular}




\begin{tabular}{|c|c|c|c|}
\hline Journal title & Index & Nr of articles & $\%$ Of total articles \\
\hline Ostrich & $|S| \& S A$ & 506 & 1.43 \\
\hline Journal of the South African Veterinary Association & $|S| \& S A$ & 500 & 1.41 \\
\hline Bothalia & $I S I \& S A$ & 495 & 1.39 \\
\hline Monthly Notices of the Royal Astronomical Society & ISI \& non-SA & 436 & 1.23 \\
\hline South African Forestry Journal & Non-ISI \& SA & 421 & 1.19 \\
\hline South African Journal of Animal Science & $|S| \& S A$ & 417 & 1.17 \\
\hline The Onderstepoort Journal of Veterinary Research & $I S I \& S A$ & 380 & 1.07 \\
\hline African Entomology & $I S I \& S A$ & 376 & 1.06 \\
\hline South African Journal of Wildlife Research & $|S| \& S A$ & 329 & 0.93 \\
\hline South African Computer Journal & Non-ISI \& SA & 313 & 0.88 \\
\hline South African Journal of Zoology & $I S I \& S A$ & 304 & 0.86 \\
\hline Phytophylactica & Non-ISI \& SA & 266 & 0.75 \\
\hline South African Journal of Geology & Non-ISI \& SA & 264 & 0.74 \\
\hline Nuclear Instruments \& Methods in Physics Research Section B- Beam Interactions with Materials and Atoms & ISI \& non-SA & 250 & 0.70 \\
\hline Koedoe & Non-ISI \& SA & 244 & 0.69 \\
\hline South African Journal of Geology & ISI \& SA & 226 & 0.64 \\
\hline Transactions of the Royal Society of South Africa & Non-ISI \& SA & 213 & 0.60 \\
\hline Onderstepoort Journal of Veterinary Research & ISI \& SA & 196 & 0.55 \\
\hline South African Geographical Journal & Non-ISI \& SA & 193 & 0.54 \\
\hline African Journal of Range and Forage Science & Non-ISI \& SA & 183 & 0.52 \\
\hline Journal of African Earth Sciences & ISI \& non-SA & 181 & 0.51 \\
\hline Agricultural Engineering in South Africa = Landbou-Ingenieurswese in Suid Afrika & Non-ISI \& SA & 179 & 0.50 \\
\hline Astrophysical Journal & ISI \& non-SA & 178 & 0.50 \\
\hline The SA Journal of Food Science \& Nutrition & Non-ISI \& SA & 175 & 0.49 \\
\hline Journal of Zoology & ISI \& non-SA & 162 & 0.47 \\
\hline Annals of the Natal Museum & Non-ISI \& SA & 153 & 0.43 \\
\hline African Zoology & $|S| \& S A$ & 138 & 0.39 \\
\hline South African Statistical Journal & Non-ISI \& SA & 137 & 0.39 \\
\hline African Journal of Ecology & ISI \& non-SA & 129 & 0.36 \\
\hline Journal of Applied Polymer Science & ISI \& non-SA & 129 & 0.36 \\
\hline Physical Review C-nuclear Physics & ISI \& non-SA & 126 & 0.35 \\
\hline Journal Of arid Environments & ISI \& non-SA & 125 & 0.35 \\
\hline African Plant Protection & Non-ISI \& SA & 121 & 0.34 \\
\hline South African Journal for Enology And Viticulture & Non-ISI \& SA & 119 & 0.34 \\
\hline Die Suid-Afrikaanse Tydskrif vir Natuurwetenskap en Tegnologie & Non-ISI \& SA & 117 & 0.33 \\
\hline Physics Letters B & ISI \& non-SA & 112 & 0.32 \\
\hline Journal of the Chemical Society-Dalton Transactions & ISI \& non-SA & 108 & 0.32 \\
\hline South African Journal of Agricultural Extension & Non-ISI \& SA & 108 & 0.32 \\
\hline Astrophysics and Space Science & ISI \& non-SA & 108 & 0.32 \\
\hline Physical Review B-condensed Matter & ISI \& non-SA & 105 & 0.30 \\
\hline Astronomy and Astrophysics & ISI \& non-SA & 103 & 0.29 \\
\hline Biological Conservation & ISI \& non-SA & 102 & 0.29 \\
\hline Mycological Research & ISI \& non-SA & 101 & 0.28 \\
\hline Marine Ecology-Progress Series & ISI \& non-SA & 101 & 0.28 \\
\hline Precambrian Research & $|S| \&$ non-SA & 96 & 0.27 \\
\hline Plant Growth Regulation & ISI \& non-SA & 94 & 0.26 \\
\hline Marine Ornithology & Non-ISI \& SA & 94 & 0.26 \\
\hline
\end{tabular}




\begin{tabular}{|c|c|c|c|}
\hline Journal title & Index & Nr of articles & $\%$ Of total articles \\
\hline Hydrobiologia & $|S| \&$ non-SA & 93 & 0.26 \\
\hline Discrete Mathematics & $|S| \&$ non-SA & 92 & 0.26 \\
\hline South African Journal of Physics & Non-ISI \& SA & 92 & 0.26 \\
\hline Southern African Journal of Aquatic Sciences & Non-ISI \& SA & 89 & 0.25 \\
\hline Plant Disease & ISI \& non-SA & 89 & 0.25 \\
\hline Physical Review D & ISI \& non-SA & 87 & 0.25 \\
\hline Palaeontologia Africana & Non-ISI \& SA & 87 & 0.25 \\
\hline Nuclear Physics A & ISI \& non-SA & 87 & 0.25 \\
\hline Environmental Biology of Fishes & $|S| \&$ non-SA & 86 & 0.24 \\
\hline Journal of the South African Veterinary Association - Tydskrif van die Suid-afrikaanse Veterinere Vereniging & $I S I \& S A$ & 85 & 0.24 \\
\hline Tetrahedron & $|S| \&$ non-SA & 84 & 0.24 \\
\hline Polyhedron & $|S| \&$ non-SA & 83 & 0.23 \\
\hline Journal of the Grassland Society of Southern Africa & Non-ISI \& SA & 79 & 0.22 \\
\hline Acta Crystallographica Section C-Crystal Structure Communications & ISI \& non-SA & 79 & 0.22 \\
\hline Tetrahedron Letters & $|S| \&$ non-SA & 78 & 0.22 \\
\hline African Journal of Aquatic Science & Non-ISI \& SA & 77 & 0.22 \\
\hline Oecologia & ISI \& non-SA & 76 & 0.21 \\
\hline Synthetic Communications & ISI \& non-SA & 76 & 0.21 \\
\hline Economic Geology and the Bulletin of the Society of Economic Geologists & $|S| \&$ non-SA & 76 & 0.21 \\
\hline Journal Of Physics-condensed Matter & ISI \& non-SA & 76 & 0.21 \\
\hline Applied And Environmental Microbiology & $|S| \&$ non-SA & 72 & 0.20 \\
\hline Durban Museum Novitates & Non-ISI \& SA & 72 & 0.20 \\
\hline Biochemical Systematics and Ecology & ISI \& non-SA & 71 & 0.20 \\
\hline Biodiversity and Conservation & ISI \& non-SA & 71 & 0.20 \\
\hline Thermochimica Acta & ISI \& non-SA & 70 & 0.20 \\
\hline Polar Biology & ISI \& non-SA & 70 & 0.20 \\
\hline Journal of the Chemical Society-perkin Transactions 1 & ISI \& non-SA & 70 & 0.20 \\
\hline Journal of Applied Physics & ISI \& non-SA & 69 & 0.19 \\
\hline Applied Surface Science & ISI \& non-SA & 69 & 0.19 \\
\hline Analytica Chimica Acta & $|S| \&$ non-SA & 67 & 0.19 \\
\hline South African Journal of Antarctic Research & Non-ISI \& SA & 66 & 0.19 \\
\hline Journal of Geophysical Research-Space Physics & ISI \& non-SA & 66 & 0.19 \\
\hline American Journal of Human Genetics & ISI \& non-SA & 64 & 0.18 \\
\hline Classical and Quantum Gravity & ISI \& non-SA & 63 & 0.18 \\
\hline Inorganica Chimica Acta & ISI \& non-SA & 63 & 0.18 \\
\hline Nature & $|S| \&$ non-SA & 63 & 0.18 \\
\hline Total & & & 50.12 \\
\hline
\end{tabular}

With the exception of the South African Journal of Science (which accounts for $5.38 \%$ of articles published) and which is probably best characterized as a "general science" journal, no single journal dominates this table. What is striking is that of the first 34 journals listed, no fewer than 29 are local journals of which 17 are included in the ISI (although the SA Statistical Journal has recently been removed from the ISI)

\section{ENGINEERING SCIENCES}

A total of 6352 articles appeared in 576 journals that were classified as "engineering sciences" journals over the period 1990 - 2003. 50\% of these articles appeared in 16 journals only (Table 6). 
Table 6: Engineering Sciences ( $n=6352$ ARTICLES)

\begin{tabular}{|c|c|c|c|}
\hline Journal title & Index & Nr of articles & $\%$ Of total articles \\
\hline The South African Mechanical Engineer & Non-ISI \& SA & 952 & 14.98 \\
\hline Journal of the South African Institute of Mining and Metallurgy & ISI \& SA & 575 & 9.05 \\
\hline Water Science and Technology & ISI \& non-SA & 269 & 4.23 \\
\hline Journal of the Mine Ventilation Society of South Africa & Non-ISI \& SA & 259 & 4.08 \\
\hline Minerals Engineering & ISI \& non-SA & 218 & 3.43 \\
\hline Journal of Energy in Southern Africa & Non-ISI \& SA & 207 & 3.25 \\
\hline Transactions of the South African Institute of Electrical Engineers & Non-ISI \& SA & 146 & 2.30 \\
\hline Journal of the South African Institution of Civil Engineers & Non-ISI \& SA & 135 & 2.12 \\
\hline Concrete & Non-ISI \& SA & 94 & 1.48 \\
\hline Electronics Letters & ISI \& non-SA & 69 & 1.09 \\
\hline Hyperfine Interactions & ISI \& non-SA & 66 & 1.04 \\
\hline The Transactions of the South African Institute of Electrical Engineers & Non-ISI \& SA & 64 & 1.01 \\
\hline International Journal of Pressure Vessels and Piping & ISI \& non-SA & 62 & 1.00 \\
\hline Composite Structures & ISI \& non-SA & 58 & 0.91 \\
\hline Hydrometallurgy & ISI \& non-SA & 58 & 0.91 \\
\hline Applied Catalysis A-General & ISI \& non-SA & 44 & 0.69 \\
\hline Total & & & 50.88 \\
\hline
\end{tabular}

Sixteen journals account for $50 \%$ of production in this field with an equal split of 8 South African and 8 foreign journals. Nine of the journals are ISI-indexed. As in the case of the Medical and Health Sciences, a few journals dominated production in this field, most notably in the fact that two journals: The South African Mechanical Engineer (15\%) and The Journal of the SA Institute of Mining and Metallurgy (9\%) accounted for nearly one quarter of all articles published by South Africans in this field.

\section{SOCIAL SCIENCES}

A total of 15339 articles appeared in 734 journals that were classified as "social and economic sciences" journals over the period 1990 - 2003. 50\% of these articles appeared in 21 journals only (Table 7).

Table 7: Social Sciences $(n=15339$ ARTICLES)

\begin{tabular}{|c|c|c|c|}
\hline Journal title & Index & Nr of articles & $\%$ Of total articles \\
\hline South African Journal of Education & Non-ISI \& SA & 736 & 4.86 \\
\hline South African Journal of Higher Education & Non-ISI \& SA & 716 & 4.73 \\
\hline Development Southern Africa & Non-ISI \& SA & 630 & 4.16 \\
\hline Agenda & Non-ISI \& SA & 629 & 4.16 \\
\hline Social Work & Non-ISI \& SA & 555 & 3.67 \\
\hline Africa Insight & Non-ISI \& SA & 458 & 3.03 \\
\hline Acta Criminologica & Non-ISI \& SA & 455 & 3.01 \\
\hline South African Journal of Economics & ISI \& SA & 442 & 2.92 \\
\hline South African Journal of Economic And Management Sciences & Non-ISI \& SA & 370 & 2.44 \\
\hline South African Journal of Psychology & Non-ISI \& SA & 325 & 2.15 \\
\hline South African Journal of Business Management & Non-ISI \& SA & 253 & 1.67 \\
\hline Journal of Dietetics and Home Economics & Non-ISI \& SA & 231 & 1.53 \\
\hline Politeia & Non-ISI \& SA & 229 & 1.51 \\
\hline Ecquid Novi & Non-ISI \& SA & 229 & 1.51 \\
\hline Transformation & Non-ISI \& SA & 225 & 1.49 \\
\hline
\end{tabular}




\begin{tabular}{|l|c|c|c|}
\hline \multicolumn{1}{|c|}{ Journal title } & Index & Nr of articles & \% Of total articles \\
\hline Journal of Industrial Psychology & Non-ISI \& SA & 221 & 1.46 \\
\hline Perspectives in Education & Isi \& Sa & 217 & 1.43 \\
\hline Communicatio & Non-ISI \& SA & 216 & 1.43 \\
\hline Journal for Studies in Economics and Econometrics & Non-ISI \& SA & 215 & 1.42 \\
\hline Curationis: The South African Journal of Nursing & Non-ISI \& SA & 208 & 1.37 \\
\hline South African Journal of Ethnology & Non-ISI \& SA & 206 & 1.36 \\
\hline Total & & & 51.30 \\
\hline
\end{tabular}

Twenty-one journals in the social and economic sciences account for 50\% of all articles produced in the field. All 21 are South African journals with (the South African Journal of Economics and the South African Journal of Psychology) included in the ISI.

\section{INSTITUTIONAL PATTERNS IN JOURNAL PUBLICATION}

Are there systematic trends (even biases) in publication patterns across institutions as far as journals used for publication of peer-reviewed articles are concerned? This question touches on a range of related issues referring to WHERE scholars publish. More specifically, two questions are addressed:

- Where do scholars from the most research-active universities publish, in relation to the distinction between ISI/non-ISI and foreign/local journals?

- Is there a clear pattern (correlation) between institutional affiliation and publication in certain South African journals? Stated differently, do academics from University X or Institution Y tend to publish more in journals that are produced and edited at their institutions?

As far as the first question is concerned, nine universities were selected with the highest research output over the past 13 years. In each case, we looked at four indicators:

- How many article equivalents did the institution produce over this period and what proportion appeared in local South African journals?

- In how many journals in total did the institution publish its article output for the period $1990-2003$ ?

What proportion of these articles appeared in the 50 journals in which the most articles were published?

What is the proportion of ISI-journals in these last-mentioned 50 journals?

- What is the proportion of foreign journals in the same 50 journals?

The results of these analyses are summarized in Table 8 .

The results in column 1 show a clear correlation - as one would expect - between the "size" of an institution's research activity, measured in terms of total article equivalents, and the number of journals in which staff at that university published their papers (column 4). The Universities of Cape Town, the Witwatersrand and Stellenbosch each published their articles in more than 2000

Table 8: Institutional profiles by journal indicators

\begin{tabular}{|c|c|c|c|c|c|c|c|c|}
\hline University & $\begin{array}{c}\text { Total sum } \\
\text { of article } \\
\text { equivalents } \\
\text { (1) }\end{array}$ & $\begin{array}{c}\text { Total sum } \\
\text { of article } \\
\text { equivalents in SA } \\
\text { journals (2) }\end{array}$ & $\begin{array}{c}\text { \% of article } \\
\text { equivalents in SA } \\
\text { journals } \\
(3=1 / 2)\end{array}$ & $\begin{array}{l}\text { Total Nr of } \\
\text { Journals } \\
\text { Published (4) }\end{array}$ & $\begin{array}{c}\text { Ratio of articles } \\
\text { to journals ( } 5 \\
=1 / 3)\end{array}$ & $\begin{array}{c}\% \text { of articles in } \\
\text { Top } 50 \text { Journals } \\
\text { (6) }\end{array}$ & $\begin{array}{c}\text { ISI-journals (Top } \\
50) \\
(7)\end{array}$ & $\begin{array}{c}\text { Foreign journals } \\
\text { (Top 50) } \\
\text { (8) }\end{array}$ \\
\hline Cape Town & 9309 & 3399 & $36.5 \%$ & 2438 & 3.82 & $23 \%$ & $96 \%$ & $74 \%$ \\
\hline Witwatersrand & 9179 & 3738 & $40.7 \%$ & 2294 & 4.00 & $23 \%$ & $72 \%$ & $52 \%$ \\
\hline Stellenbosch & 8639 & 5199 & $60.2 \%$ & 2096 & 4.12 & $24 \%$ & $42 \%$ & $30 \%$ \\
\hline Pretoria & 8314 & 4988 & $60.0 \%$ & 1691 & 4.92 & $28 \%$ & $60 \%$ & $36 \%$ \\
\hline Natal & 5902 & 2691 & $45.6 \%$ & 1610 & 3.67 & $26 \%$ & $74 \%$ & $54 \%$ \\
\hline Free State & 3532 & 2199 & $62.2 \%$ & 798 & 4.43 & $33 \%$ & $72 \%$ & $56 \%$ \\
\hline Rand Afrikaans & 2791 & 1824 & $65.4 \%$ & 544 & 5.13 & $34 \%$ & $56 \%$ & $42 \%$ \\
\hline Potchefstroom & 2664 & 1939 & $72.7 \%$ & 712 & 3.74 & $33 \%$ & $40 \%$ & $32 \%$ \\
\hline Rhodes & 2153 & 978 & $45.4 \%$ & 694 & 3.10 & $30 \%$ & $80 \%$ & $60 \%$ \\
\hline
\end{tabular}


Table 9: Rankings of institutions i.r.o. degree of internationalisation

\begin{tabular}{|l|c|c|}
\hline \multicolumn{1}{|c|}{ University } & $\begin{array}{c}\text { Ranking i.t.o. article equivalents in SA } \\
\text { journals (lowest to highest) }\end{array}$ & $\begin{array}{c}\text { Ranking i.t.o. \% foreign journals in top } \\
\mathbf{5 0} \text { journals (highest to lowest) }\end{array}$ \\
\hline Cape Town & 1 & 1 \\
\hline Witwatersrand & 2 & 5 \\
\hline Rhodes & 3 & 4 \\
\hline Natal & 4 & 7 \\
\hline Pretoria & 5 & 9 \\
\hline Stellenbosch & 6 & 3 \\
\hline Free State & 7 & 6 \\
\hline Rand Afrikaans & 8 & 8 \\
\hline Potchefstroom & 9 & \\
\hline
\end{tabular}

journals. At the same time, it is interesting to look at the ratio of article equivalents to journals (Column 5). Here a smaller number (3.10 for Rhodes University) means that academics at this institution published about 3 articles per journal title. At the other extreme, academics at the Rand Afrikaans University published, on average, 5 articles per journal title. In the latter case, there is a suggestion of one of two forces at work: (a) either there exists a greater tendency at this institution always to select particular journals when submitting articles for publication; or (b) there was a greater concentration effect as far as scientific fields were concerned, which would translate into smaller number of academics publishing in the same cluster of journals all or most of the time.

Two other indicators in this column (Column 3 and Column 8) measure the degree of "internationalisation" of academic output at each university. Indicator 3 refers to the proportion of total article output that appeared in South African journals. Indicator 8 refers to the number of foreign journals that appears in the list of the 50 most published in journals at that institution; these two indicators are to some extent mirror images of each other. "Ranking" the institutions in terms of degree of internationalisation on these indicators, we get the following:

The historically English-medium universities (Cape Town, Rhodes, Witwatersrand and Natal) rank highest on Indicator 7 - the proportion of ISI-journals in the top 50. Conversely, the historically Afrikaans-medium universities ranked much lower on this indicator with the exception of the University of the Free State where $72 \%$ of the journals in the top 50 are ISI-journals.

The second main research question refers to institutional patterns of publication by Journal. South African journals that have published 300 or more articles over the past 13 years were selected, in order to make the dataset manageable. This produced a list of 60 South African journals. In each case (Table 11), the top 3 - 5 South African institutions were then listed, each with the number of authorships in that journal. So, for example, in the first row of Table 11, there is the journal, "In die Skriflig", in which a total of 349 articles and 391 authorships appeared between 1990 and 2003; the five institutions that contributed most to articles in this journal are listed in descending order of authorship. The proportion of authorships contributed by the highest institution as calculated - in this case, is Potchefstroom University. Over this period, academics from this institution generated 235 authorships out of the total of 391, which means that they produced $60 \%$ of the content of this journal. Journals are listed in Table 11 in descending order according to the proportion of the highest "contributing institution" in relation to the overall article content in that journal.

Table 11: SA Journals and institutional publication patterns

\begin{tabular}{|c|c|c|c|c|c|c|c|c|c|}
\hline \multirow{2}{*}{$\begin{array}{l}\text { Journal (>300 articles) } \\
\text { In die Skriflig }\end{array}$} & \multirow{2}{*}{$\begin{array}{l}\text { Place of publication/ Publisher } \\
\text { Reformed Theological Society of South } \\
\text { Africa, Potchefstroom }\end{array}$} & \multicolumn{6}{|c|}{ Institutional affiliation } & \multirow{2}{*}{$\begin{array}{l}\text { Articles } \\
349\end{array}$} & \multirow{2}{*}{$\begin{array}{l}\text { Authorships } \\
391\end{array}$} \\
\hline & & PU (235) & $60 \%$ & SU (45) & UFS (19) & UP (18) & $\begin{array}{l}\text { UNISA } \\
\text { (14) }\end{array}$ & & \\
\hline $\begin{array}{l}\text { Annual Survey of South } \\
\text { African Law }\end{array}$ & $\begin{array}{l}\text { Published for the School of Law of the } \\
\text { Univ of the Witwatersrand by Juta Law }\end{array}$ & Wits (303 & $58 \%$ & SU (58) & $\begin{array}{l}\text { UNISA } \\
(35)\end{array}$ & UCT (33) & & 506 & 520 \\
\hline $\begin{array}{l}\text { SA Mercantile Law Journal } \\
\text { / SA Tydskrif vir Handelsreg }\end{array}$ & Juta Law & $\begin{array}{l}\text { UNISA } \\
(210)\end{array}$ & $53 \%$ & UN (23) & SU (20) & $\mathrm{RAU}(17)$ & PU (12) & 366 & 399 \\
\hline
\end{tabular}




\begin{tabular}{|c|c|c|c|c|c|c|c|c|c|}
\hline \multirow{2}{*}{$\begin{array}{l}\text { Journal (>300 articles) } \\
\text { De Jure }\end{array}$} & \multirow{2}{*}{\begin{tabular}{|l} 
Place of publication/ Publisher \\
Butterworth Publishers
\end{tabular}} & \multicolumn{6}{|c|}{ Institutional affiliation } & \multirow{2}{*}{\begin{tabular}{|l|} 
Articles \\
475
\end{tabular}} & \multirow{2}{*}{$\begin{array}{l}\text { Authorships } \\
513\end{array}$} \\
\hline & & UP (252) & $49 \%$ & $\begin{array}{l}\text { UNISA } \\
(57)\end{array}$ & PU (43) & $\operatorname{RAU}(26)$ & & & \\
\hline Bothalia & National Botanical Institute, Pretoria & NBI (411) & $47 \%$ & UP(71) & UFS (70) & $\operatorname{RAU}(36)$ & $\begin{array}{l}\text { UN (31)/ } \\
\text { SU (31) }\end{array}$ & 495 & 880 \\
\hline $\begin{array}{l}\text { Koers: Bulletin for Christian } \\
\text { Scholarship / Bulletin vir } \\
\text { Christelike Wetenskap }\end{array}$ & $\begin{array}{l}\text { Bureau for Scholarly Publications, } \\
\text { Potchefstroom }\end{array}$ & PU (185) & $47 \%$ & UFS (40) & $\begin{array}{l}\text { UNISA } \\
(28)\end{array}$ & $\operatorname{RAU}(23)$ & SU (21) & 339 & 397 \\
\hline $\begin{array}{l}\text { Hervormde Teologiese } \\
\text { Studies }\end{array}$ & Faculty of Theology, UP & UP (297) & $45 \%$ & $\begin{array}{l}\text { UNISA } \\
(66)\end{array}$ & UFS (26) & SU (21) & & 646 & 663 \\
\hline Acta Criminologica & Criminological Society of South Africa & $\begin{array}{l}\text { UNISA } \\
(307)\end{array}$ & $44 \%$ & UP (84) & UNIN (29) & TSA (21) & & 455 & 705 \\
\hline $\begin{array}{l}\text { Comparative and } \\
\text { International Law Journal of } \\
\text { Southern Africa }\end{array}$ & $\begin{array}{l}\text { Institute of Foreign and Comparative } \\
\text { Law, UNISA }\end{array}$ & $\begin{array}{l}\text { UNISA } \\
(140)\end{array}$ & $43 \%$ & UP (21) & Vista (13) & Wits (12) & & 306 & 329 \\
\hline $\begin{array}{l}\text { Tydskrif vir die Suid- } \\
\text { Afrikaanse Reg }\end{array}$ & Faculty of Law, RAU & RAU (382) & $43 \%$ & $\begin{array}{l}\text { UNISA } \\
\text { (70) }\end{array}$ & SU (55) & $\mathrm{PU}(50)$ & UP (39) & 821 & 887 \\
\hline $\begin{array}{l}\text { Journal of the South African } \\
\text { Veterinary Association } \\
\text { / Tydskrif van die Suid- } \\
\text { Afrikaanse Veterinêre } \\
\text { Vereeniging }\end{array}$ & SA Veterinary Association, Pretoria & UP (664) & $41 \%$ & $\begin{array}{l}\text { Medunsa } \\
\text { (197) }\end{array}$ & $\operatorname{ARC}(195)$ & $\begin{array}{l}\text { Foreign } \\
(60)\end{array}$ & SU (54) & 599 & 1632 \\
\hline $\begin{array}{l}\text { Nederduitse Gereformeerde } \\
\text { Teologiese Tydskrif }\end{array}$ & Faculty of Theology, SU & SU (270) & $41 \%$ & UFS (89) & UP (65) & UWC (37) & UNIN (27) & 600 & 666 \\
\hline Scriptura & Department of Religion, SU & SU (151) & $39 \%$ & UWC (48) & $\begin{array}{l}\text { UNISA } \\
(31)\end{array}$ & UN (18) & & 369 & 386 \\
\hline $\begin{array}{l}\text { Journal of Contemporary } \\
\text { Roman Dutch Law / Tydskrif } \\
\text { vir Hedendaagse Romein- } \\
\text { Hollandse Reg }\end{array}$ & Butterworths & $\begin{array}{l}\text { UNISA } \\
(330)\end{array}$ & $34 \%$ & UP(193) & PU (113) & SU (51) & $\operatorname{RAU}(27)$ & 870 & 978 \\
\hline $\begin{array}{l}\text { South African Journal of } \\
\text { Criminal Justice }\end{array}$ & Juta Law & UN (168) & $33 \%$ & $\begin{array}{l}\text { UNISA } \\
(62)\end{array}$ & $\begin{array}{l}\text { Rhodes } \\
\text { (50) }\end{array}$ & UP (31) & UDW (25) & 486 & 504 \\
\hline $\begin{array}{l}\text { South African Journal of } \\
\text { Surgery }\end{array}$ & SA Medical Association & $\begin{array}{l}\text { Wits } \\
(396)\end{array}$ & $33 \%$ & UCT (212) & UN (206) & UFS (95) & SU (73) & 422 & 1191 \\
\hline Acta Academica & University of the Free State & UFS (153) & $32 \%$ & SU (60) & $\operatorname{RAU}(44)$ & $\begin{array}{l}\text { UNISA } \\
(27)\end{array}$ & PU (23) & 374 & 472 \\
\hline Geneeskunde & Medharm Publications, Pretoria & UP (244) & $32 \%$ & UFS (134) & SU (51) & $\begin{array}{l}\text { Medunsa } \\
\text { (24) }\end{array}$ & & 518 & 762 \\
\hline $\begin{array}{l}\text { Onderstepoort Journal of } \\
\text { Veterinary Research }\end{array}$ & $\begin{array}{l}\text { Onderstepoort Veterinary Research, } \\
\text { ARC }\end{array}$ & ARC (535) & $32 \%$ & UP (428) & $\begin{array}{l}\text { Foreign } \\
(125)\end{array}$ & $\begin{array}{l}\text { Medunsa } \\
\text { (97) }\end{array}$ & UFS (65) & 581 & 1697 \\
\hline $\begin{array}{l}\text { South African Journal of } \\
\text { Marine Science }\end{array}$ & $\begin{array}{l}\text { Marine \& Coastal Management, Cape } \\
\text { Town }\end{array}$ & SFRI (437) & $31 \%$ & UCT (330) & $\begin{array}{l}\text { Rhodes } \\
\text { (71) }\end{array}$ & $\begin{array}{l}\text { Foreign } \\
(48)\end{array}$ & UPE (48) & 575 & 1417 \\
\hline $\begin{array}{l}\text { South African Journal on } \\
\text { Human Rights }\end{array}$ & Juta Law & $\begin{array}{l}\text { Wits } \\
\text { (129) }\end{array}$ & $30 \%$ & UCT (40) & UWC (25) & SU (21) & & 403 & 430 \\
\hline $\begin{array}{l}\text { SA Publiekereg/SA Public } \\
\text { Law }\end{array}$ & UNISA & PU (138) & $29 \%$ & $\begin{array}{l}\text { UNISA } \\
\text { (53) }\end{array}$ & UP (30) & SU (28) & & 372 & 484 \\
\hline Agrekon & & UP (283) & $27 \%$ & SU(103) & UN (96) & UFS (55) & $\begin{array}{l}\text { Foreign } \\
\text { (33) }\end{array}$ & 589 & 1061 \\
\hline $\begin{array}{l}\text { South African Dental } \\
\text { Journal SADJ }\end{array}$ & & SU (177) & $27 \%$ & $\begin{array}{l}\text { Wits } \\
(108)\end{array}$ & UP (71) & & & 365 & 648 \\
\hline $\begin{array}{l}\text { South African Journal of } \\
\text { Plant and Soil }\end{array}$ & & ARC (308) & $27 \%$ & SU (150) & UP (139) & UFS (129) & UN (48) & 538 & 1152 \\
\hline $\begin{array}{l}\text { South African Journal of } \\
\text { Economic and Management } \\
\text { Sciences }\end{array}$ & & UP (149) & $26 \%$ & PU (40 & SU (37) & UFS (22) & UN (21) & 376 & 568 \\
\hline $\begin{array}{l}\text { South African Journal of } \\
\text { Philosophy }\end{array}$ & & SU 183 & $26 \%$ & $\begin{array}{l}\text { UNISA } \\
(33)\end{array}$ & UN (29) & UPE (24) & $\operatorname{RAU}(23)$ & 301 & 325 \\
\hline Literator & & PU (98) & $25 \%$ & $\operatorname{RAU}(31)$ & SU (30) & UFS (20) & $\begin{array}{l}\text { UNISA } \\
(18)\end{array}$ & 357 & 395 \\
\hline
\end{tabular}




\begin{tabular}{|c|c|c|c|c|c|c|c|c|c|}
\hline \multirow{2}{*}{$\begin{array}{l}\text { Journal (>300 articles) } \\
\text { Ostrich }\end{array}$} & \multirow[t]{2}{*}{ Place of publication/ Publisher } & \multicolumn{6}{|c|}{ Institutional affiliation } & \multirow{2}{*}{$\begin{array}{l}\text { Articles } \\
506\end{array}$} & \multirow{2}{*}{\begin{tabular}{|l} 
Authorships \\
956
\end{tabular}} \\
\hline & & UCT (236) & $25 \%$ & $\begin{array}{l}\text { Foreign } \\
(109)\end{array}$ & UN (66) & Wits (45) & $\begin{array}{l}\text { Rhodes } \\
\text { (42) }\end{array}$ & & \\
\hline $\begin{array}{l}\text { South African Journal of } \\
\text { African Languages }\end{array}$ & & $\begin{array}{l}\text { UNISA } \\
(96)\end{array}$ & $24 \%$ & SU (35) & UP (30) & RAU (22) & & 353 & 394 \\
\hline $\begin{array}{l}\text { South African Medical } \\
\text { Journal }\end{array}$ & & $\begin{array}{l}\text { UCT } \\
\text { (1646) }\end{array}$ & $23 \%$ & $\begin{array}{l}\text { Wits } \\
\text { (1112) }\end{array}$ & SU (1009) & UN (616) & $\begin{array}{l}\text { MRC } \\
(561)\end{array}$ & 2349 & 7218 \\
\hline Old Testament Essays & & $\begin{array}{l}\text { UNISA } \\
\text { (82) }\end{array}$ & $22 \%$ & SU (76) & UP (48) & UFS (18) & & 379 & 380 \\
\hline $\begin{array}{l}\text { Journal of the Dental } \\
\text { Association of South Africa }\end{array}$ & & SU (155) & $21 \%$ & $\begin{array}{l}\text { Wits } \\
\text { (144) }\end{array}$ & UP (106) & $\begin{array}{l}\text { Medunsa } \\
(45)\end{array}$ & & 414 & 747 \\
\hline $\begin{array}{l}\text { South African Journal of } \\
\text { Wildlife Research }\end{array}$ & & UP (168) & $21 \%$ & UN (78) & UCT (70) & US (51) & $\begin{array}{l}\text { Foreign } \\
\text { (47) }\end{array}$ & 329 & 786 \\
\hline $\begin{array}{l}\text { South African Journal of } \\
\text { Animal Science }\end{array}$ & & ARC (260) & $20 \%$ & UP (190) & UFS (163) & SU (146) & $\begin{array}{l}\text { Elsenburg } \\
\text { (127) }\end{array}$ & 442 & 1292 \\
\hline $\begin{array}{l}\text { South African Journal of } \\
\text { Botany }\end{array}$ & & UN (406) & $20 \%$ & UP (396) & SU (173) & UFS (157) & NBI (136) & 880 & 2073 \\
\hline $\begin{array}{l}\text { Southern African Journal of } \\
\text { Epidemiology and Infection }\end{array}$ & & $\begin{array}{l}\text { Wits } \\
\text { (143) }\end{array}$ & $20 \%$ & SU (83) & UN (48) & $\begin{array}{l}\text { SAIMR } \\
\text { (45) }\end{array}$ & UP (44) & 341 & 707 \\
\hline $\begin{array}{l}\text { Tydskrif vir } \\
\text { Geesteswetenskappe }\end{array}$ & & SU (76) & $20 \%$ & UFS (68) & UP (46) & PU (30) & $\operatorname{RAU}(19)$ & 324 & 386 \\
\hline $\begin{array}{l}\text { South African Historical } \\
\text { Journal:SAHJ / Suid- } \\
\text { Afrikaanse Historiese } \\
\text { Joernaal }\end{array}$ & & UCT (73) & $18 \%$ & $\begin{array}{l}\text { UNISA } \\
\text { (65) }\end{array}$ & Wits (50) & UWC (34) & UN (30) & 359 & 400 \\
\hline African Entomology & & ARC (133) & $17 \%$ & UP (76) & $\begin{array}{l}\text { Rhodes } \\
\text { (64) }\end{array}$ & UCT (61) & SU (53) & 393 & 782 \\
\hline $\begin{array}{l}\text { Journal of Theology for } \\
\text { Southern Africa }\end{array}$ & & UN (54) & $17 \%$ & $\begin{array}{l}\text { UNISA } \\
\text { (32) }\end{array}$ & UCT (32) & SU (30) & UWC (22) & 305 & 322 \\
\hline $\begin{array}{l}\text { South African Journal of } \\
\text { Linguistics }\end{array}$ & & PU (72) & $17 \%$ & $\begin{array}{l}\text { UNISA } \\
(55)\end{array}$ & SU (49) & UFS (38) & $\begin{array}{l}\text { Rhodes } \\
\text { (32) }\end{array}$ & 355 & 432 \\
\hline $\begin{array}{l}\text { South African Journal of } \\
\text { Zoology }\end{array}$ & & UCT (105) & $17 \%$ & UP (56) & $\operatorname{RAU}(42)$ & SU (42) & Wits (37) & 304 & 607 \\
\hline $\begin{array}{l}\text { South African Journal of } \\
\text { Psychology }\end{array}$ & & UCT (130) & $16 \%$ & $\begin{array}{l}\text { Wits } \\
\text { (111) }\end{array}$ & $\begin{array}{l}\text { UNISA } \\
(90)\end{array}$ & UN (88) & UWC (44) & 439 & 799 \\
\hline South African Law Journal & & $\begin{array}{l}\text { Wits } \\
\text { (115) }\end{array}$ & $16 \%$ & UN (71) & $\begin{array}{l}\text { Rhodes } \\
\text { (61) }\end{array}$ & UCT (48) & UP (42) & 670 & 717 \\
\hline $\begin{array}{l}\text { Social work / Maatskaplike } \\
\text { Werk }\end{array}$ & & SU (113) & $15 \%$ & UN (88) & UP (63) & Wits (48) & PU (44) & 559 & 766 \\
\hline $\begin{array}{l}\text { South African Family } \\
\text { Practice }\end{array}$ & & $\begin{array}{l}\text { Medunsa } \\
\text { (79) }\end{array}$ & $15 \%$ & SU (61) & UP (61) & Wits (29) & UCT (20) & 368 & 517 \\
\hline $\begin{array}{l}\text { South African Journal of } \\
\text { Geology }\end{array}$ & & $\begin{array}{l}\text { Wits } \\
\text { (161) }\end{array}$ & $15 \%$ & $\begin{array}{l}\text { Foreign } \\
(119)\end{array}$ & UCT (101) & UP (84) & CGS (84) & 490 & 1091 \\
\hline $\begin{array}{l}\text { South African Journal of } \\
\text { Education }\end{array}$ & & $\begin{array}{l}\text { UNISA } \\
\text { (157) }\end{array}$ & $14 \%$ & PU (137) & SU (129) & UP (118) & RAU (112) & 736 & 1153 \\
\hline $\begin{array}{l}\text { South African Journal of } \\
\text { Science }\end{array}$ & & UCT (621) & $14 \%$ & $\begin{array}{l}\text { Wits } \\
\text { (609) }\end{array}$ & $\begin{array}{l}\text { Foreign } \\
(326)\end{array}$ & UN (299) & UP (262) & 1910 & 4460 \\
\hline $\begin{array}{l}\text { Journal of the South African } \\
\text { Institute for Mining and } \\
\text { Metallurgy }\end{array}$ & & $\begin{array}{l}\text { Wits } \\
\text { (144) }\end{array}$ & $12 \%$ & $\begin{array}{l}\text { CSIR } \\
(131)\end{array}$ & $\begin{array}{l}\text { Mintek } \\
\text { (91) }\end{array}$ & UP (90) & UCT (47) & 604 & 1179 \\
\hline Water SA & & UCT (245) & $12 \%$ & UP (191) & RAU (137) & UFS (128) & UN (112) & 765 & 1963 \\
\hline Africa Insight & & WITS (57) & $11 \%$ & SU (42) & AISA (39) & $\begin{array}{l}\text { Foreign } \\
\text { (31) }\end{array}$ & $\begin{array}{l}\text { VISTA } \\
\text { (26) }\end{array}$ & 458 & 533 \\
\hline $\begin{array}{l}\text { South African Journal of } \\
\text { Economics }\end{array}$ & & UP (67) & $11 \%$ & UCT (60) & Wits (57) & UN (43) & SA (41) & 442 & 601 \\
\hline $\begin{array}{l}\text { Development Southern } \\
\text { Africa }\end{array}$ & & UN (96) & $10 \%$ & Wits (71) & SU (69) & UP (64) & UCT (45) & 631 & 954 \\
\hline
\end{tabular}




\begin{tabular}{|l|l|l|l|l|l|l|l|l|l|}
\hline \multicolumn{1}{|c|}{ Journal (>300 articles) } & \multicolumn{3}{|c|}{ Place of publication/ Publisher } & \multicolumn{3}{|c|}{ Institutional affiliation } & Articles & Authorships \\
\hline $\begin{array}{l}\text { Journal for Language } \\
\text { Teaching/Tydskrif vir } \\
\text { Taalonderrig }\end{array}$ & & $\begin{array}{l}\text { UNISA } \\
(37)\end{array}$ & $9 \%$ & PU (37) & RAU (36) & UFS (27) & $\begin{array}{l}\text { VISTA } \\
\text { (27) }\end{array}$ & 340 & 408 \\
\hline Agenda & & UN (61) & $8 \%$ & UCT (42) & Wits (39) & UDW (29) & UWC (21) & 629 & 738 \\
\hline $\begin{array}{l}\text { South African Computer } \\
\text { Journal }\end{array}$ & & UP (41) & $8 \%$ & $\begin{array}{l}\text { UNISA } \\
(39)\end{array}$ & UCT (39) & SU (39) & Wits (35) & 316 & 537 \\
\hline $\begin{array}{l}\text { South African Journal of } \\
\text { Higher Education }\end{array}$ & & $\begin{array}{l}\text { UNISA } \\
\text { (89) }\end{array}$ & $8 \%$ & SU (69) & UFS (61) & Wits (65) & PU (55) & 753 & 1091 \\
\hline $\begin{array}{l}\text { South African Mechanical } \\
\text { Engineer }\end{array}$ & UP (38) & $3 \%$ & Wits (23) & SU (22) & UCT (20) & & 952 & 1136 \\
\hline
\end{tabular}

Acronyms: UCT, University of Cape Town; UP, University of Pretoria; US, University of Stellenbosch; Wits, University of the Witwatersrand; UNISA, University of South Africa; UFS, University of the Free State; UN, University of Natal; RAU, Rand Afrikaans University;UWC, University of the Western Cape; PU, University of Potchefstroom; SAIMR, South African Institute for Medical Research; UNIN, University of the North; UDW, Univesity of DurbanWestville;ARC, Agricultural Research Council; CSIR, Council for Scientific and Industrial Research; NBI, National Botanical Institute.

In the sample of 60 journals, a SINGLE institution contributed $30 \%$ or more of the article content to 21 of these journals; of these journals, a SINGLE institution contributed $40 \%$ or more of the article contents in 12 of these journals
The results of this analysis of institutional contributions to particular South African journals reveal some disturbing trends. In the sample of 60 journals, a SINGLE institution contributed $30 \%$ or more of the article content to 21 of these journals; of these journals, a SINGLE institution contributed $40 \%$ or more of the article contents in 12 of these journals. It is also pertinent to point out that of the 10 journals with the highest single institutional contribution, nine are in the arts and humanities (only Bothalia excluded) and 4 are in the field of Law. In fact, it is fair to say that journals in the fields of Law and Theology are particularly prominent in this listing. If one looks at the 20 journals with the highest contribution by one institution (all above 30\%), it is hardly coincidence that in 11 of these cases, the journal is published by the same institution/unit that produces the majority of articles. Further research should be undertaken into this issue, and specifically relating the number of outputs to the size of the specific scientific or scholarly community. There are strong indications that some South African journals currently may be published for the benefit of certain institutions only, rather than for that of a research field or a national scholarly association.

Incidentally, it is also useful to look closely at this table where there are significant proportions of contributions from foreign authors as an indication of an inverse pattern. In this respect, the following journals stand out:

- Ostrich (11.4\% foreign)

- SA Journal of Geology (10.9\% foreign)

Onderstepoort Journal of Veterinary Research (7.4\% foreign)

- SA Journal of Science (7.3\% foreign)

- SA Journal of Wildlife Research (6\% foreign)

\section{BASIC DEMOGRAPHIC ANALYSES OF SOUTH AFRICAN AUTHORS: RACE, GENDER AND AGE BY SCIENTIFIC FIELD}

It is now generally known that there is a significant ageing cohort of actively publishing scientists in the South African science system. CREST first published its results on this trend in 2001 and has been monitoring it regularly since. Figure 11 presents a breakdown of this trend by main scientific field ${ }^{9}$. In each case, the age interval distribution for a scientific field is compared for two years: 1990 and 2002. So, for example, as far as the Arts and Humanities are concerned, one can see that in 1990 there were $18.2 \%$ of authors over the age of 50 producing scientific articles, whereas by 2002 , this proportion had increased to $46.1 \%$. Similarly, for the Health Sciences, there was an increase from 26\% in the over 50 age bracket in 1990 to $48.9 \%$ in 2002 .

The interest in this chapter is more specifically whether there are different ageing trends with regard to different clusters of South African journals. For this purpose, similar age interval distributions were calculated for the three journal categories: South African ISI-journals; foreign

$9 \mathrm{AH}=$ Arts and Humanities; $\mathrm{SH}=$ Social and Economic Sciences; $\mathrm{HS}=$ Medical and Health Sciences; NS = Natura Sciences; ES = Engineering Sciences. 


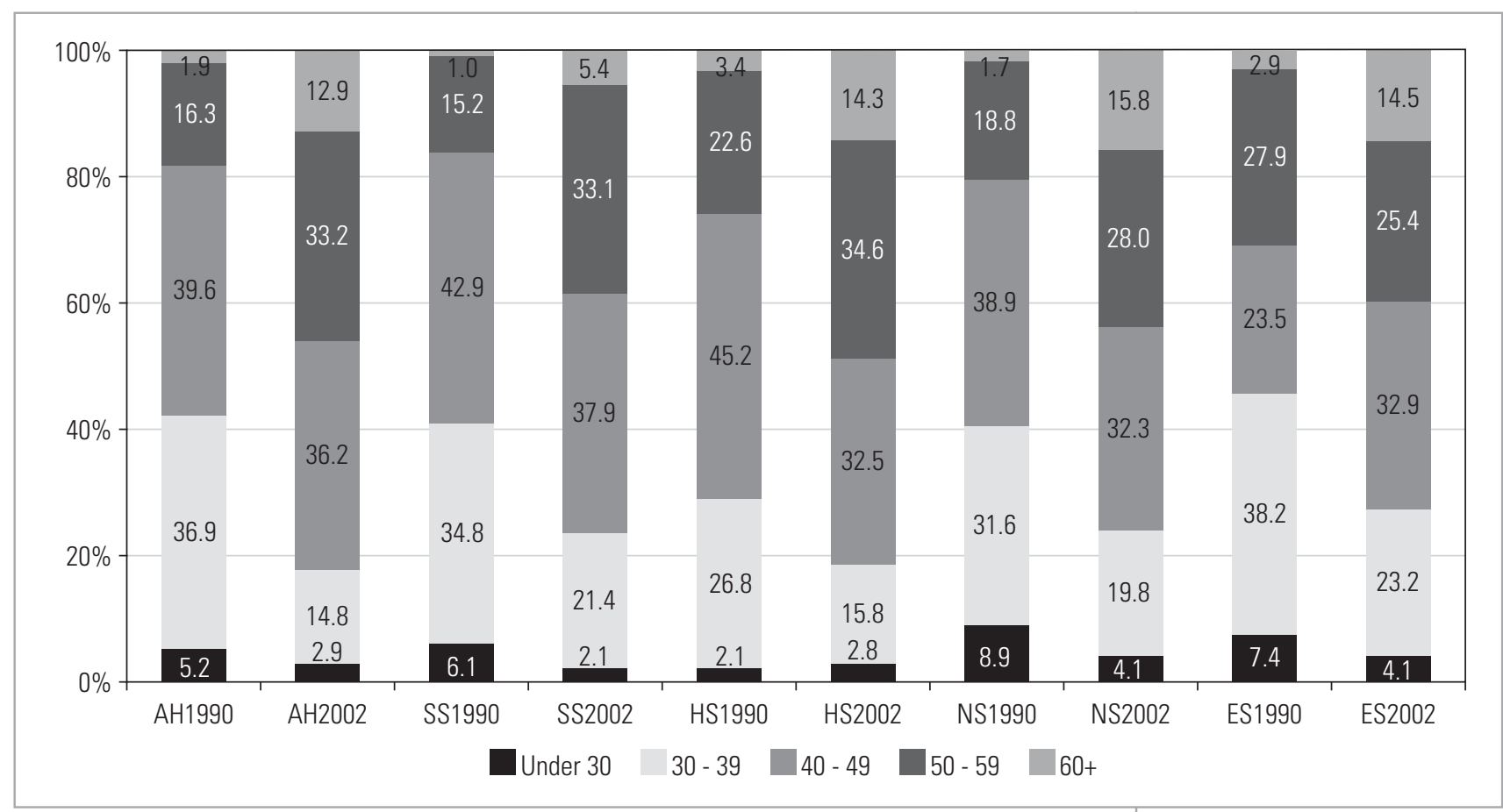

ISI journals and local non-ISI journals. In each case, one wishes to see whether the age profiles of South African authored articles were significantly different.

The analysis by Journal Index Category reveals only small differences. If the focus is on the highest age intervals ( $>50$ ), the age profile of articles in South African ISI-journals (predominantly natural sciences) shifts from 22.4\% of authors above the age of 50 in 1990 to $47.4 \%$ in 2002. For the foreign ISI-journals, South African authored articles show a similar, if not as substantial a shift: from $23.8 \%$ of authors over the age of 50 in 1990 to $41.6 \%$ of authors over the age of 50 in 2002. For local, non-ISI journals (predominantly social sciences and humanities), there is a similar shift from $18.8 \%$ of authors over 50 in 1990 to $45.4 \%$ of authors over 50 in 2002.

Four journals (or journal categories) were selected to see whether there are large differences between them. They were selected because they were journals with substantive outputs, three of them ISI-listed, and representing different scientific fields. In each case, the percentage shift was highlighted in the above-50 years of age category between 1990 and 2002.

Figure 11: The ageing of publishing scientists: Scientific field (1990 vs. 2002)

Figure 12: The ageing of publishing scientists: Journal Index Category (1990 vs. 2002)

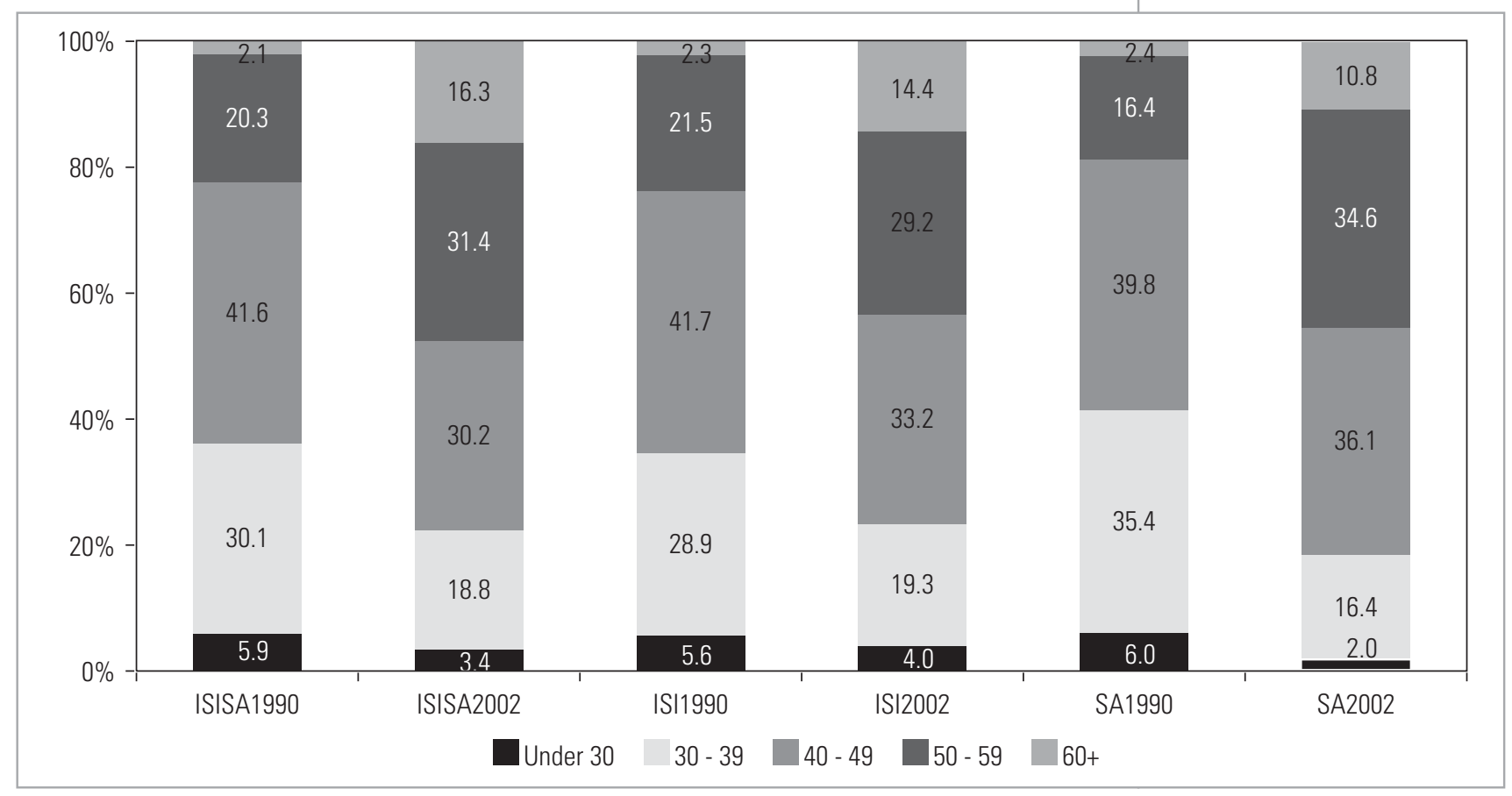


Table 14: Age profiles for selected journals (1990 vs. 2002)

\begin{tabular}{|l|c|c|c|}
\hline \multicolumn{1}{|c|}{ Journal } & \% authors above $\mathbf{5 0}$ in $\mathbf{1 9 9 0}$ & \% authors above $\mathbf{5 0}$ in $\mathbf{2 0 0 2}$ & \% increase \\
\hline SA Medical Journal & 26.8 & 47.8 & $+21.0 \%$ \\
\hline SA Journal of Science & 16.4 & 45.5 & $+29.1 \%$ \\
\hline SA Journal of Botany & 31.4 & 60.3 & $+28.9 \%$ \\
\hline Three Top Law Journals & 14.5 & 30.5 & $+16.0 \%$ \\
\hline
\end{tabular}

This comparison reveals large differences between the selected journals, which undoubtedly reflects field-specific differences. The smaller increase in the higher-age category for LAW journals could possibly be explained by the fact that most of these journals also cater for professional practising lawyers, rather than just for academics in law faculties, which means, in theory at least, a broader pool of younger authors.

The final demographic analysis is devoted to the gender profiles of South African authored articles. The overall gender distribution for all articles in SA Knowledgebase is presented in Figure 13 below; it shows a steady increase in female authorship from a low base of approximately $16 \%$ in 1990 to about $22 \%$ in 2002.

A comparison between Journal Index Categories in Figure 14 reveals no significant differences in gender trends between the two ISI categories (South African ISI and Foreign ISI). In both cases, we observe a substantive increase from around $13 \%$ to $24 \%$ and $13 \%$ to $23 \%$, respectively. The increase in female-authored articles in local South African journals was more substantive, however, with an increase from 19\% in 1990 to $20 \%$ in 2002 . It is not obvious why this is the case. It might be linked with other variables such as age, viz. that younger women tend to publish in South African journals first. It could certainly be correlated with scientific field, where women are better represented in the social sciences and humanities, and these journals are more dominant in this Index category.

The demographic analyses (age and gender) of journal profiles have not revealed major deviations from the population norms. This indicates that the general ageing trend and the general increase in female-authored articles are both fairly pervasive across the science system.

Figure 13: Gender by year of There are, however, some journal-specific trends which are most likely correlated with field publication (1990 - 2002) differences rather than any other factor.

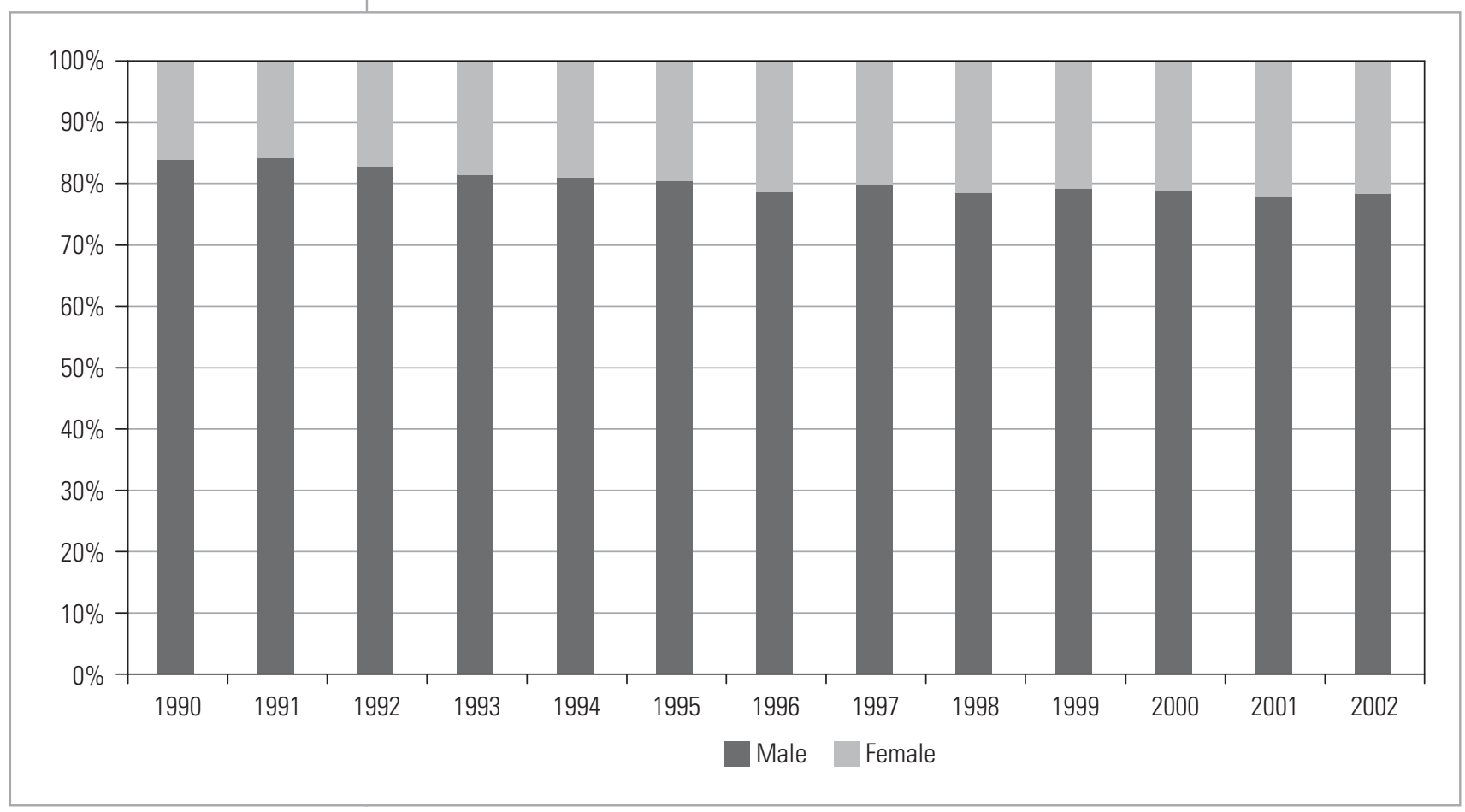




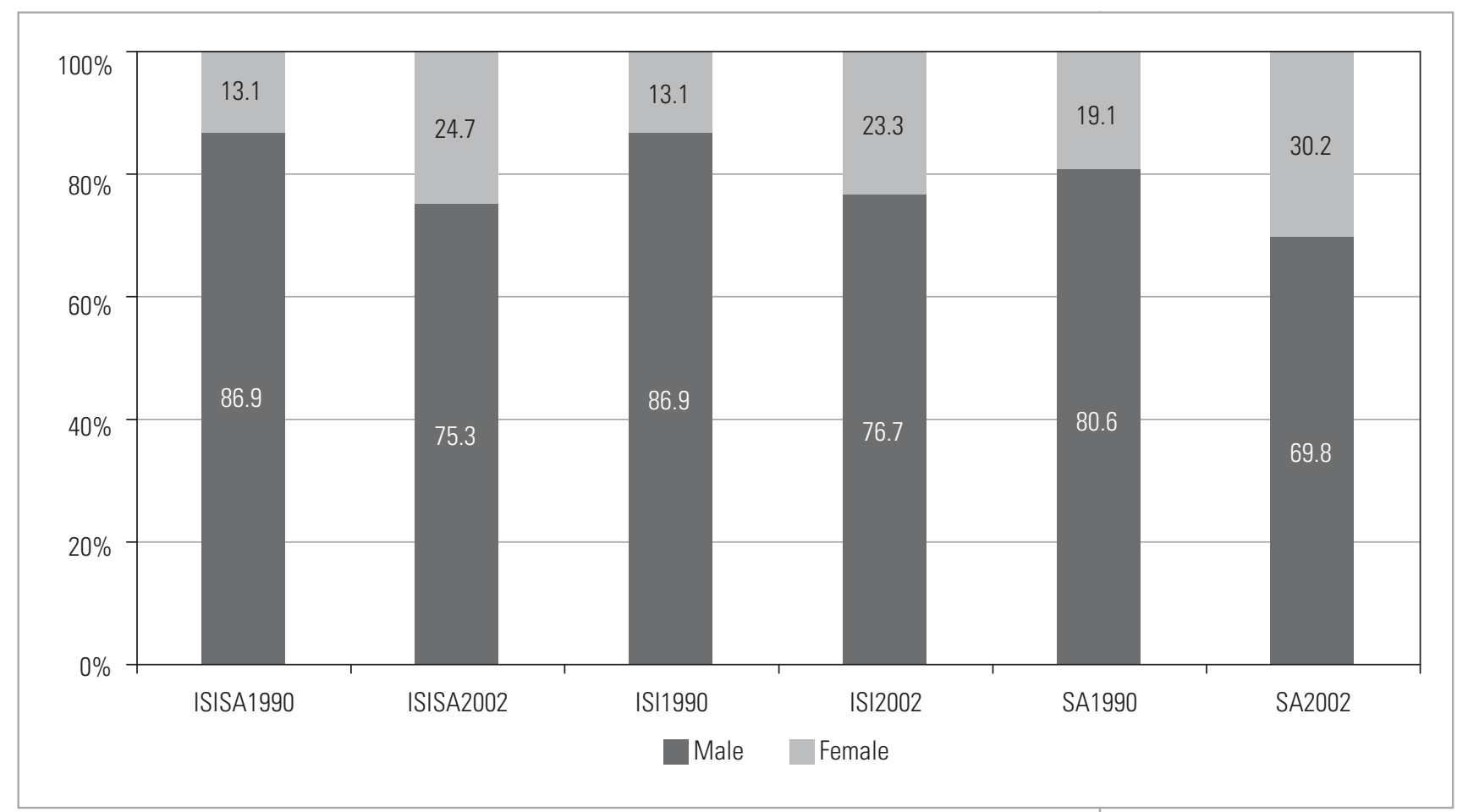

\section{NOVEL COMPARATIVE MEASURES TO ASSESS THE IMPACT FACTORS AND CITATION PROFILES OF SOUTH AFRICAN JOURNALS}

Citations used in research publications in peer-reviewed international scholarly journals of research articles produced by South African scientists and scholars enable analysts to gauge the impact of SA research publication within the international scientific community, defined for this purpose as those scientists and scholars who publish papers in ISI-listed and -indexed, peer-reviewed, research journals. This approach can also be used to assess the impact and international visibility, if not utility, of the corresponding South African journals in which some of these articles were published. The titles of 225 SA journals were entered into the CWTS/CI-database (see section 3.2) to gather the citation frequencies of publications in these journals during recent years. ${ }^{10}$ Firstly, these citations were analysed by the country of origin, i.e. the affiliate countr(y)(ies) of the author(s) as listed in the byline of the citing research articles in ISI-indexed journals. By calculating the shares of citations coming from research papers with at least one South African author address (author self-citations included), one can develop an empirical measure of a journal's geographical impact. This analysis was done for the subset of 45 'highly cited' journals that managed to attract at least 25 citations during the years 1994-2002. The key issue was to ascertain the degree to which South African journals cater for a local audience of South African citing authors or, in contrast, appeal predominantly to foreign 'citers'. The findings are summarized in Table 15 by broad field of science. Only 5 journals are found in which the South African authors represent the majority of the citers: The South African Archaeological Bulletin, Koedoe, The Southern African Journal of Aquatic Sciences, The Southern African Journal of Epidemiology and Infection, and the South African Journal of Higher Education. South African citations are only a small minority (less than 20\% of all citations) in 17 journals. Interestingly, all five journals attributed to the Arts and Humanities belong to this category. In other words, the very few SA Arts and Humanities journals that manage to attract citations within the international scientific literature appear to have an international citation impact rather than a domestic one.

Secondly, attention was focused on the citation frequencies, as such. It is well known that epistemological differences between fields of science tend to affect these citation rates. Publications in fields of the natural and life sciences, with their large international research

10 The entire list consisted of 225 journals, 59 of which were not cited in recent years. That is, based on the titles of the journals (incl. name variations, acronyms or truncations) we were unable to identify any citations to these journals for the citing years 2001-2004 and the cited years 1980-2004. 
Table 15: Distribution of journals by share of SA citations and broad fields*

One cannot simply

rates of journals from difference fields of scholarship without taking into account fielddependent citation characteristics

\begin{tabular}{|l|c|c|c|c|}
\hline \multicolumn{1}{|c|}{ Main field } & $\begin{array}{c}\text { International } \\
\text { orientation } \\
\text { (share SA<20\%) }\end{array}$ & $\begin{array}{c}\text { Intermediate } \\
(\mathbf{2 0 \%}<\text { share SA<50\%) }\end{array}$ & $\begin{array}{c}\text { Domestic orientation } \\
\text { (share SA>50\%) }\end{array}$ \\
\hline Natural Sciences & 6 & 15 & 4 & $56 \%$ \\
\hline Health and Medical Sciences & 3 & 1 & 0 & $9 \%$ \\
\hline Engineering & 1 & 1 & 1 & $20 \%$ \\
\hline Social Sciences & 2 & 6 & 0 & $11 \%$ \\
\hline Arts \& Humanities & 5 & 0 & $11 \%$ & \\
\hline
\end{tabular}

* Citing years: 2001- 2004; cited years: 1980-2004.

communities, often based on a clearly defined, common research paradigm, tend to exhibit more dense citation traffic, as opposed to other fields where research is of a more applied nature and focused on local or regional problems or themes. Hence one would expect that the South African journals in the Natural Sciences would collect the largest quantities of citations, and those in the Art and Humanities the lowest. Table 16 displays the results for all 166 cited South African journals in our data set. Note that the citation data refer to the citing years 20022003 and the cited years 1994-2002, rather than the extended citation window stretching back to 1980. As a result, some journals that received citations to publications published before 1994, but none thereafter, appear in this table as being 'non cited'. The results clearly support the notion that structural differences between fields of science affected citation rates. Although the 39 journals attributed to the Natural Sciences showed a wide range in citation frequencies, this field accounted for no less than 7 out of the 8 most highly cited journals. The Arts and Humanities on the other hand accounted for 12 of the 18 less-cited journals. It is also interesting to see that the large majority of the South African medical journals are among the less-cited journals, suggesting that local medical researchers are publishing their more highly cited research articles in non-SA journals.

The main conclusion to be drawn from these results is that one cannot simply compare the citation rates of journals from difference fields of scholarship without taking into account field-dependent citation characteristics (Moed, 2005) Normalisation of the citation frequencies is clearly in order, to arrive at more fair comparisons of journal citation impacts. A second determining factor of citation frequency levels is the size of the cited journal itself; those with many articles are more likely to draw more citations. Hence, one should also normalize for the publication output of each journal. The Impact Factor (IF), issued by Thomson Scientific (ISI) and applied worldwide as a measure to compare journal impact performances (see Chapter 2) , is probably the prime example of such a size-corrected measure of citation impact. The IF is defined as follows: all citations received in year t, referring to publications from the years $\mathrm{t}-1$ and $\mathrm{t}-2$, divided by the number of research publications published in those two years. The IF's two-year 'citation window' was originally designed to measure the short term impact of

Table 16: Distribution of journals by citation frequency and broad fields *

\begin{tabular}{|c|c|c|c|c|c|c|}
\hline Main field & No citations & $1<$ Very Low $<25$ & $25<$ Low $<100$ & $100<$ Medium $<250$ & High $(>250)$ & \\
\hline Natural Sciences & 2 & 12 & 11 & 7 & 7 & $24 \%$ \\
\hline Health and Medical Sciences & 1 & 14 & 2 & 1 & 1 & $12 \%$ \\
\hline Engineering & & 5 & 2 & & & $4 \%$ \\
\hline Social Sciences & 3 & 30 & 7 & 2 & & $25 \%$ \\
\hline \multirow[t]{2}{*}{ Arts \& Humanities } & 12 & 42 & 5 & & & $35 \%$ \\
\hline & $11 \%$ & $62 \%$ & $16 \%$ & $6 \%$ & $5 \%$ & \\
\hline
\end{tabular}

* Citing years: 2002 and 2003; cited years: 1994-2002. 
Table 17: Distribution of journals by Journal Impact Factor (CE-JIF 2002/2003) and broad fields * **

\begin{tabular}{|l|c|c|c|c|c|}
\hline \multicolumn{1}{|c|}{ Scientific field } & $\mathbf{0}<\mathbf{C E}-\mathbf{J F}<\mathbf{0 . 1}$ & $\mathbf{0 . 1}<\mathbf{C E}-\mathbf{J I F}<\mathbf{0 . 2 5}$ & $\mathbf{0 . 2 5}<\mathbf{C E}-\mathbf{J I F}<\mathbf{0 . 5}$ & $\mathbf{C E}-\mathbf{J I F}>\mathbf{0 . 5}$ & \\
\hline Natural Sciences & $8(1)$ & $7(1)$ & $8(6)$ & $6(6)$ & $27 \%$ \\
\hline Health and Medical Sciences & 8 & $3(1)$ & $2(2)$ & & $12 \%$ \\
\hline Engineering Sciences & 2 & $2(1)$ & 1 & & $5 \%$ \\
\hline Social Sciences & $21(1)$ & $1(1)$ & 2 & & $22 \%$ \\
\hline Arts and Humanities & 31 & 5 & & & $20 \%$ \\
\hline & $66 \%$ & $17 \%$ & $11 \%$ & $6 \%$ & \\
\hline
\end{tabular}

* Citing years: 2002 and 2003; cited years: 1994-2002.

** The number of ISI-indexed SA journals in 2004 indicated between brackets.

"leading" journals, that those originating from the advanced countries (especially the USA) that gather significant quantities of citations in such a short period of time.

Most SA journals play a modest role in worldwide science and fail to meet these criteria; articles in these take (much) more time to attract sufficient numbers of citations from the international scientific literature (if any). Hence, in order to account for these differences, the citation window was extended to eight years. Moreover, two consecutive citing years (in this case, 2002 and 2003) were merged in order to reduce the possibility of large yearly fluctuations. The resulting Composite Extended Journal Impact Factor (denoted as 'CE-JIF 2002/2003') enables one to obtain a more reliable measure of the citation impact of SA journals than the use of the standard Impact Factor used throughout chapter 2. The impact factor analysis using CE-JIF 2002/2003 was restricted to the subset of 107 journals that received at least 1 citation during the interval 1994-2002 and where the frequency data on the annual number of publications during the same time-interval was available. ${ }^{11}$ What is the effect of this size-corrected measure on the distribution of SA journals across the broad fields? And are the 20 SA journals indexed by ISI in 2004 also amongst the most highly cited, or do non-ISI journals also manage to achieve a comparable level of impact? The answers are in Table 17 which provides aggregate level information by field of science.

The first noticeable outcome is that only 6 out of the 105 journals surpass the CE-JIF score of 0.50 , in other words a relative citation frequency of $50 \%$. These are:

- South African Journal of Marine Science (0.73)

- South African Journal of Geology (0.64)

- Onderstepoort Journal of Veterinary Research (0.56)

- Water SA (0.56)

- African Zoology (South African Journal of Zoology) (0.56)

- South African Archaeological Bulletin (0.51)

All of the above journals belong to the Natural sciences and all are indexed by ISI (indicated by the brackets). Overall, a distribution is found that resembles Table 16: the more highly cited journals tend to cluster in the Natural Sciences and in the Health and Medical Sciences. There are, however, several journals from other fields with CE-JIF scores ranging from 0.25 to 0.50, including 5 non-ISI journals which attracted relatively high quantities of citations in the ISIindexed journal literature:

- Concrete

- African Journal of Range and Forage Science

- South African Journal for Enology and Viticulture

- Social Dynamics

- South African Journal of Psychology (previously ISI-indexed)

Although most of the ISI-indexed SA journals are amongst the more highly cited, 6 journals were cited at a rather low level, given their elevated status of ISI-covered journals (Bothalia,

11 The data on the numbers of publications in each journal were retrieved from SAK, Index to South African Periodicals and from SA Studies. The some cases data on the annual publication output was missing in these information sources. In those cases the output was estimated by using the average output during the years 19942004. Journals with more than 4 more missing entries were excluded from the analysis 
Table 18: Journals categorised according to $0.25<C E-J I F<0.5$ (ISI-indexed journals in bold and italics; ISI journals indexed for one or more years during the time-interval 1993-2004)

\begin{tabular}{|l|l|l|l|}
\hline \multicolumn{1}{|c|}{ Journal Title } & \multicolumn{1}{|c|}{$\begin{array}{c}\text { E-JIF } \\
\mathbf{2 0 0 2}\end{array}$} & \multicolumn{1}{|c|}{ E-JIF } & \multicolumn{1}{c|}{$\begin{array}{c}\text { CE-JIF } \\
\mathbf{2 0 0 2 / 2 0 0 3}\end{array}$} \\
\hline African Entomology & 0.35 & 0.40 & 0.38 \\
\hline Concrete & 0.56 & 0.38 & 0.47 \\
\hline African Journal of Range and Forage Science & 0.26 & 0.23 & 0.25 \\
\hline $\begin{array}{l}\text { Journal of the South African Veterinary Association / Tydskrif van die Suid- } \\
\text { Afrikaanse Veterinêre Vereeniging }\end{array}$ & 0.32 & 0.35 & 0.34 \\
\hline Ostrich & 0.32 & 0.24 & 0.28 \\
\hline Social Dynamics & 0.22 & 0.30 & 0.26 \\
\hline South African Journal of Wildlife Research & 0.46 & 0.43 & 0.44 \\
\hline South African Journal of Science & 0.43 & 0.54 & 0.49 \\
\hline South African Journal for Enology and Viticulture & 0.40 & 0.54 & 0.47 \\
\hline South African Journal of Botany & 0.28 & 0.27 & 0.27 \\
\hline South African Journal of Chemistry & 0.35 & 0.34 & 0.34 \\
\hline South African Medical Journal & 0.46 & 0.43 & 0.44 \\
\hline South African Journal of Psychology & 0.38 & 0.32 & 0.35 \\
\hline
\end{tabular}

Perspectives in Education, Journal of the South African Institute for Mining and Metallurgy, South African Journal of Animal Science, South African Journal of Surgery, and South African Journal of Economics). The journal-specific data are presented in Tables 18 - 21 below.

Table 19: Journals categorised according to $0.1<C E-J I F<0.25$

\begin{tabular}{|c|c|c|c|}
\hline Journal Title & E-JIF 2002 & E-JIF 2003 & CE-JIF 2002/2003 \\
\hline Annals of the Transvaal Museum & 0.18 & 0.05 & 0.11 \\
\hline Durban Museum Novitates & 0.14 & 0.10 & 0.12 \\
\hline Historia & 0.19 & 0.07 & 0.13 \\
\hline Industrial Law Journal & 0.19 & 0.15 & 0.17 \\
\hline Journal of the South African Institute for Mining and Metallurgy & 0.13 & 0.10 & 0.11 \\
\hline Koedoe & 0.25 & 0.22 & 0.24 \\
\hline Kronos & 0.03 & 0.17 & 0.10 \\
\hline Philosophical Papers & 0.14 & 0.10 & 0.12 \\
\hline South African Journal of Philosophy & 0.10 & 0.09 & 0.10 \\
\hline South African Journal of Surgery & 0.13 & 0.18 & 0.16 \\
\hline South African Journal of Plant and Soil & 0.12 & 0.10 & 0.11 \\
\hline South African Journal of Animal Science & 0.24 & 0.29 & 0.26 \\
\hline South African Forestry Journal & 0.13 & 0.13 & 0.13 \\
\hline South African Journal of Economics & 0.21 & 0.26 & 0.24 \\
\hline Southern African Journal of Aquatic Sciences & 0.16 & 0.16 & 0.16 \\
\hline South African Journal of Clinical Nutrition & 0.12 & 0.15 & 0.14 \\
\hline South African Journal of Sports Medicine & 0.18 & 0.14 & 0.16 \\
\hline
\end{tabular}

Table 20: Journals categorised according to $2(0<C E-J I F<0.1)$

\begin{tabular}{|l|l|l|l|}
\hline \multicolumn{1}{|c|}{ Journal Title } & \multicolumn{1}{|c|}{ E-JIF 2002 } & E-JIF 2003 & CE-JIF 2002/2003 \\
\hline African Plant Protection & 0.10 & 0.03 & 0.06 \\
\hline African Sociological Review & 0.09 & 0.07 & 0.08 \\
\hline Agrekon & 0.01 & 0.01 & 0.01 \\
\hline Bothalia & 0.05 & 0.06 & 0.06 \\
\hline
\end{tabular}




\begin{tabular}{|c|c|c|c|}
\hline Journal Title & E-JIF 2002 & E-JIF 2003 & CE-JIF 2002/2003 \\
\hline Cardiovascular Journal of Southern Africa & 0.05 & 0.09 & 0.07 \\
\hline Critical Arts: A Journal of South-North Cultural and Media Studies & 0.00 & 0.08 & 0.04 \\
\hline Journal for Contemporary History / Joernaal vir die Eietydse Geskiedenis & 0.07 & 0.06 & 0.06 \\
\hline Journal of Energy in Southern Africa & 0.03 & 0.01 & 0.02 \\
\hline Journal of South African Dental Association SADJ & 0.04 & 0.05 & 0.05 \\
\hline Journal of the Mine Ventilation Society of South Africa & 0.00 & 0.06 & 0.03 \\
\hline Navorsinge van die Nasionale Museum Bloemfontein & 0.05 & 0.07 & 0.06 \\
\hline Politeia & 0.12 & 0.06 & 0.09 \\
\hline South African Bone and Joint Surgery & 0.01 & 0.03 & 0.02 \\
\hline South African Journal on Human Rights & 0.01 & 0.04 & 0.03 \\
\hline $\begin{array}{l}\text { South African Historical Journal:SAHJ / Suid-Afrikaanse Historiese } \\
\text { Joernaal }\end{array}$ & 0.03 & 0.04 & 0.03 \\
\hline South African Journal of Libraries and Information Science & 0.08 & 0.10 & 0.09 \\
\hline Verbum et Ecclesia (Skrif en Kerk) & 0.06 & 0.01 & 0.03 \\
\hline South African Family Practice & 0.03 & 0.01 & 0.02 \\
\hline South African Law Journal & 0.00 & 0.02 & 0.01 \\
\hline $\begin{array}{l}\text { South African Journal of Education / Suid-Afrikaanse Tydskrif vir } \\
\text { Opvoedkunde }\end{array}$ & 0.02 & 0.02 & 0.02 \\
\hline South African Computer Journal & 0.01 & 0.06 & 0.04 \\
\hline South African Statistical Journal & 0.04 & 0.12 & 0.08 \\
\hline Southern African journal of child and adolescent mental health & 0.09 & 0.07 & 0.08 \\
\hline Southern African Journal of Epidemiology and Infection & 0.10 & 0.05 & 0.07 \\
\hline South African Journal of Communication Disorders & 0.01 & 0.07 & 0.04 \\
\hline South African Journal of Higher Education & 0.03 & 0.02 & 0.02 \\
\hline Society in Transition & 0.12 & 0.04 & 0.08 \\
\hline
\end{tabular}

Table 21: Journals categorised according to share of citations from SA research publications in ISIindexed journals (journals that were ISI-indexed in 2004 are highlighted in bold and italics)

\begin{tabular}{|c|c|c|}
\hline Journal Title & $\%$ SA citations* & $\begin{array}{c}\text { Citation frequency } \\
\text { category** }^{* *}\end{array}$ \\
\hline African Entomology & $27.3 \%$ & $100<$ Medium $<250$ \\
\hline African Journal of Herpetology & $28.2 \%$ & $25<$ Low $<100$ \\
\hline African Journal of Range and Forage Science & $40.6 \%$ & $25<$ Low $<100$ \\
\hline African Plant Protection & $13.9 \%$ & 10<Very Low <25 \\
\hline African Sociological Review & $35.4 \%$ & 10<Very Low <25 \\
\hline African Studies & $29.4 \%$ & $25<$ Low $<100$ \\
\hline African Zoology & $27.5 \%$ & high $(>250)$ \\
\hline Annals of the South African Museum & $20.5 \%$ & $10<$ Very Low <25 \\
\hline Bothalia & $36.7 \%$ & $25<$ Low $<100$ \\
\hline Cardiovascular Journal of Southern Africa & $28.7 \%$ & $10<$ Very Low $<25$ \\
\hline Concrete & $1.5 \%$ & $25<$ Low $<100$ \\
\hline Curationis & $26.7 \%$ & $25<$ Low $<100$ \\
\hline Durban Museum Novitates & $61.4 \%$ & $10<$ Very Low <25 \\
\hline Historia & $12.8 \%$ & $25<$ Low $<100$ \\
\hline Industrial Law Journal & $0.0 \%$ & $25<$ Low $<100$ \\
\hline Journal for Contemporary History & $0.0 \%$ & $10<$ Very Low <25 \\
\hline Journal for Studies in Economics and Econometrics & $84.6 \%$ & $10<$ Very Low <25 \\
\hline Journal of Education & $4.5 \%$ & 10<Very Low <25 \\
\hline
\end{tabular}




\begin{tabular}{|c|c|c|}
\hline Journal Title & $\%$ SA citations* & $\begin{array}{c}\text { Citation frequency } \\
\text { category** }^{* *}\end{array}$ \\
\hline Journal of Endocrinology, Metabolism and Diabetes of South Africa & $18.9 \%$ & $10<$ Very Low $<25$ \\
\hline Journal of South African Dental Association & $7.8 \%$ & $25<$ Low $<100$ \\
\hline Journal of the South African Institute for Mining and Metallurgy & $31.6 \%$ & $25<$ Low $<100$ \\
\hline Journal of the South African Veterinary Association & $12.8 \%$ & $100<$ Medium $<250$ \\
\hline Koedoe & $51.2 \%$ & $25<$ Low $<100$ \\
\hline Kronos & $49.1 \%$ & $10<$ Very Low $<25$ \\
\hline Marine Ornithology & $4.9 \%$ & $100<$ Medium $<250$ \\
\hline Occupational Health Southern Africa & $9.3 \%$ & $25<$ Low $<100$ \\
\hline Onderstepoort Journal of Veterinary Research & $16.0 \%$ & high $(>250)$ \\
\hline Orion & $6.5 \%$ & $10<$ Very Low $<25$ \\
\hline Ostrich & $14.3 \%$ & $100<$ Medium $<250$ \\
\hline Palaeontologia Africana & $31.5 \%$ & $25<$ Low $<100$ \\
\hline Philosophical Papers & $1.7 \%$ & $25<$ Low $<100$ \\
\hline Pins & $33.3 \%$ & $25<$ Low $<100$ \\
\hline Politeia & $6.8 \%$ & $25<$ Low $<100$ \\
\hline Quaestiones Mathematicae & $13.8 \%$ & $25<$ Low $<100$ \\
\hline Social Dynamics & $24.2 \%$ & $25<$ Low $<100$ \\
\hline Society in Transition & $40.7 \%$ & $10<$ Very Low $<25$ \\
\hline South African Archaeological Bulletin & $62.9 \%$ & $100<$ Medium $<250$ \\
\hline South African Computer Journal & $25.5 \%$ & $10<$ Very Low $<25$ \\
\hline South African Family Practice & $34.0 \%$ & $10<$ Very Low $<25$ \\
\hline South African Forestry Journal & $34.8 \%$ & $25<$ Low $<100$ \\
\hline South African Historical Journal & $40.5 \%$ & $10<$ Very Low $<25$ \\
\hline South African Journal for Enology and Viticulture & $9.1 \%$ & $25<$ Low $<100$ \\
\hline South African Journal of Animal Science & $21.9 \%$ & $100<$ Medium $<250$ \\
\hline South African Journal of Botany & $36.9 \%$ & high (>250) \\
\hline South African Journal of Business Management & $40.9 \%$ & $10<$ Very Low $<25$ \\
\hline South African Journal of Chemistry & $0.0 \%$ & $100<$ Medium $<250$ \\
\hline South African Journal of Clinical Nutrition & $63.9 \%$ & $10<$ Very Low $<25$ \\
\hline South African Journal of Economics & $43.4 \%$ & $100<$ Medium $<250$ \\
\hline South African Journal of Education & $76.3 \%$ & $10<$ Very Low $<25$ \\
\hline South African Journal of Geology & $28.1 \%$ & high (>250) \\
\hline South African Journal of Higher Education & $73.7 \%$ & $25<$ Low $<100$ \\
\hline South African Journal of Libraries and Information Science & $50.8 \%$ & $10<$ Very Low $<25$ \\
\hline South African journal of Marine science & $26.5 \%$ & high (>250) \\
\hline South African Journal of Philosophy & $0.0 \%$ & $25<$ Low $<100$ \\
\hline South African Journal of Plant and Soil & $29.3 \%$ & $25<$ Low $<100$ \\
\hline South African Journal of Psychology & $41.9 \%$ & $100<$ Medium $<250$ \\
\hline South African Journal of Science & $37.1 \%$ & high (>250) \\
\hline South African Journal of Sports Medicine & $48.8 \%$ & $10<$ Very Low $<25$ \\
\hline South African Journal of Surgery & $10.5 \%$ & $25<$ Low $<100$ \\
\hline South African Journal of Wildlife Research & $38.1 \%$ & $100<$ Medium $<250$ \\
\hline South African Journal on Human Rights & $42.0 \%$ & $10<$ Very Low <25 \\
\hline South African Law Journal & $32.4 \%$ & $10<$ Very Low $<25$ \\
\hline South African Medical Journal & $21.6 \%$ & high (>250) \\
\hline South African Statistical Journal & $7.0 \%$ & $10<$ Very Low $<25$ \\
\hline
\end{tabular}




\begin{tabular}{|c|c|c|}
\hline Journal Title & $\%$ SA citations* & $\begin{array}{l}\text { Citation frequency } \\
\text { category** }\end{array}$ \\
\hline Southern African Journal of Aquatic Sciences & $60.1 \%$ & $25<$ Low $<100$ \\
\hline Southern African journal of Child and Adolescent Mental Health & $57.4 \%$ & $10<$ Very Low $<25$ \\
\hline Southern African Journal of Epidemiology and Infection & $72.8 \%$ & $25<$ Low $<100$ \\
\hline Speculum Juris & $0.0 \%$ & $10<$ Very Low <25 \\
\hline Theoria & $13.4 \%$ & $25<$ Low $<100$ \\
\hline Verbum et Ecclesia & $2.0 \%$ & $10<$ Very Low $<25$ \\
\hline Water SA & $23.4 \%$ & high (>250) \\
\hline \multicolumn{3}{|c|}{$\begin{array}{l}\text { Share of citation from South African (co-lauthored research papers (including author self-citations). Citing years: } \\
\text { 2001-2004, Cited years 1980-2004. } \\
\text { * Number of citations received during the citing years } 2002 \text { and } 2003 \text { to publications published in the cited years }\end{array}$} \\
\hline
\end{tabular}

\section{SUMMARY COMMENTS AND CONCLUSIONS}

\section{Increasing internationalisation of SA journals: Breaking the isolationist mould?}

Some of the evidence presented in this chapter shows that South African scientists and scholars are gradually overcoming the isolationist effects of the apartheid era. As far as the ISI versus non-ISI journals are concerned, there has been a significant increase in the number of South African articles published in ISI-journals. Unfortunately, the number of South African journals included in the ISI system has remained rather constant (in fact there has been a small decline), which explains why the number of articles in this category has remained fairly stable. As far as the distinction between local and foreign journals is concerned, the proportion of articles in foreign journals has increased from just over one third in 1990 to nearly half in 2002.

\section{Substantive local scientific production across all scientific fields}

A closer look at scientific publication patterns by main scientific field reveals that the increase in publications in overseas and ISI-journals is not equally pervasive across all fields, and does not mean that substantial proportions of articles do not still appear in local journals. As far as the distribution by scientific field is concerned, the profiles for the natural, engineering and health sciences are as expected. Given that the majority of South Africa's ISI-indexed journals are in these fields, it is not surprising that more than two thirds of articles in these fields are published in ISI-journals.

In order to "correct' for the "bias" associated with the under-representation of South African social science journals in the ISI system, and to provide another perspective on where South African scientists publish their articles, a comparison is made between the foreign vs. local distributions of journal articles by scientific field. These results reveal some interesting "differences" in the profiles, with large proportions of articles in the engineering sciences (42\%), natural science articles (nearly 40\%) and medical and health sciences (36\%) appearing in local journals. The high proportions of articles in the human sciences appearing in local journals are not surprising, especially if one takes into account that the arts and humanities would include work in the field of indigenous languages, theology, law and performing arts - all fields that are especially locally embedded.

These results show unequivocally that simplistic generalisations about the publication profiles of different scientific fields need to be avoided. The field-specific distributions reveal a much more differentiated picture.

\section{Institutional differences in scientific production - A case of protectionist publishing?}

The results of our analysis of institutional contributions to particular South African journals point to some worrying trends. Sixty SA journals published more than 300 articles over the period 1990 - 2002. In our analysis of these journals, we find that 30\% of the articles of 21 of these journals originate from a SINGLE institution. It is even more striking that $40 \%$ of the articles of 12 of these journals arise from one institution only. If one looks at the 20 journals with the highest contribution by one institution (all above 30\%), it is unlikely to be a coincidence 


\section{Of the nearly 225 \\ South African journals \\ submitted to the \\ CWTS-database, \\ only 107 journals \\ received 1 or more \\ citations during the \\ interval 1994-2002, \\ while only 45 of these \\ journals received \\ 25 or more citations \\ over this period}

We find a substantive

cluster (our estimate

is that this might

pertain to about

half of all South

African journals)

that does not have

any international

visibility: articles in

these journals are

not cited outside of

South Africa and the

production of content

in many of them is

dominated by one or

two institutions and

in some cases by

the same institution

(or department) that

publishes the journal that in 11 of these cases, the journal is published by the same institution/unit that produces the majority of articles! Is this a case of "protectionist" publishing, where the institution which publishes the journal in question acts as an (intentional) gatekeeper to external articles? Or is this a case where insufficient external supply for publication in these journals leads to the de facto over-representation of "in-house" publications? Nine of the 10 journals with the highest single institutional contribution are in the arts and humanities, with a clear over-representation from the fields of theology and law.

\section{New bibliometric measures of journal impact and citation rates relevant to developing countries}

Most SA journals play a modest role in worldwide science. Publications from the more marginal scientific countries in the world generally take (much) more time to attract sufficient numbers of citations from the international scientific literature (if any). Hence, in order to account for these differences, a new measure of journal impact was adopted, based on an extended citation window of eight years (compared to more common IF-measures based on 2-year and 5-year citation windows) and the use of two consecutive citing years (in this case, 2002 and 2003), in order to reduce the possibility of large yearly fluctuations. The new measure is referred to as the Composite Extended Journal Impact Factor, and may be useful in countries, like South Africa which have relatively large research journal systems with limited penetration of the "Bradford barrier" (see Chapter 2) to international databases, such as the ISI.

Of the nearly 225 South African journals submitted to the CWTS-database, only 107 journals received 1 or more citations during the interval 1994-2002, while only 45 of these journals received 25 or more citations over this period. This in itself raises a large question mark about the international visibility (or lack thereof) of the majority of South African journals.

Two significant findings were recorded regarding the first subset of journals (107) First, only 6 out of those 107 journals (all ISI-journals) recorded an impact factor of higher than 0.5. Overall, the results are disappointing, with the vast majority of these journals generating impact factor scores of lower than 0.35 . Second, if one ignores the 6 ISI-journals in the highest impact factor interval, the remaining journals produce a very "confusing" picture. Many of the SA ISIjournals fall in the low impact factor categories, with some - such as Bothalia, SA Historical Journal - generating extremely low scores. Conversely, a number of non-ISI journals recorded moderate scores (between 0.4 and 0.5). These journals - for example Concrete, African Journal of Range and Forage Science, South African Journal for Enology and Viticulture, and Social Dynamics - could make a strong claim (and certainly a stronger claim than some existing SA ISI-journals) for inclusion in the ISI.

If one focusses on the $45 \mathrm{SA}$ journals that recorded 25 citations or more over this period, a relatively more positive picture emerges, with a large proportion (38\%) of journals exhibiting what can be referred to as an "international" profile. And, perhaps somewhat surprisingly, the five South African arts and humanities journals that generated significant citations all fall in the high international category.

\section{Conclusion}

In the final analysis, this bibliometric analysis reinforces the general picture that emerges from the other components of this Report. South African journals present a very differentiated and hugely disjuncted picture. There is a small cluster of South African journals (both ISI and non-ISI, mostly natural and health sciences but also some social science and humanities) that have "acceptable" impact factors, recorded moderate to high citations from non-South African authors and generally present an "international" profile. At the other extreme, we find a substantive cluster (our estimate is that this might pertain to about half of all South African journals) that does not have any international visibility: articles in these journals are not cited outside of South Africa and the production of content in many of them is dominated by one or two institutions and in some cases by the same institution (or department) that publishes the journal.

There is a strong case to be made that this study be expanded into a detailed case-by-case analysis of each South African journal. In depth analysis - which combines bibliometric, survey and qualitative methods - of all currently accredited South African journals is required. The 
current accreditation process clearly does not distinguish sufficiently between South African journals which have succeeded in reaching international standards and those which effectively cater for a small, parochial audience. Until a proper journal-specific analysis is done, looking at a wide range of quality criteria (international visibility, spread of local and overseas authors, frequency of issues, rejection rates of submitted articles, composition of editorial boards, and so on), one will not be able to state unequivocally that the currently accredited list of 253 South African research journals should in fact be regarded as of acceptable quality and uniform standard.

\section{ACKNOWLEDGEMENTS}

We would like to thank Thed van Leeuwen, Erik van Wijk (CWTS), and Derick van Niekerk, Lynn Lorenzen, Ricci Louw and Charline Mouton (CREST) for their contributions to the data collection and statistical analyses.

\section{REFERENCES}

Butler, L. and M. Visser, (2006) Extending citation analysis to non-source items. To be published in Scientometrics, 2006.

Moed, H.F. (2005) Citation analysis in research evaluation. Springer.

Mouton, J. (2002) Research (with Ahmed Bawa) In Transformation in higher education: Global pressures and local realities in South Africa, edited by Nico Cloete, R. Fehnel, P. Maassen, T. Moja, H. Perold and T. Gibbon. Juta and Company.

Mouton, J. (2005) Afrikaans as wetenskapstaal. Tydskrif vir Geesteswetenskappe 45(3): 317-326.

Pouris, A. \& Richter, L. (2000) Investigation into state-funded research journals in South Africa. South African Journal of Science 96(3): 98-104.

Van Raan, A.F.J. (2005) Fatal attraction: Conceptual and methodological problems in the ranking of universities by bibliometric methods. Scientometrics Vol. 62(1): 133-143.

Weingart, P. (2005) Impact of bibliometrics upon the science system: inadvertent consequences. Scientometrics Vol 62(1): 117-131 



\section{Survey of Editors' opinions and related information}

by Xola Mati ${ }^{1}$

As a significant process of targeted consultation with a constituency that has a large stake in the future of research publishing in South Africa, a questionnaire (as attached to this Chapter as appendix A), was sent by email in February 2005 to the editors of all journals accredited by the Department of Education, DoE (see Chapter 3). The intention was to obtain relevant opinions and related information from this sector, focusing on the draft criteria for the accreditation of South African research journals drawn up by the Steering Committee for this Project (see Chapter 1) All of the editors returned the questionnaire by April 2005 and the data were captured and consolidated using standard techniques. Of the 213 journals captured in the database, five journals were listed in the International Bibliography of the Social Sciences (IBSS), and 15 in the Thomson Scientific (Thomson ISI) databases (see Chapters 2 and 3), while the other 193 South African journals were accredited only with DoE.

The following analysis of the survey data provides some indication of where the editors of South African research journals stand in relation to the draft accreditation criteria mentioned above, and examines whether their collective views provide empirical support for these criteria.

\section{THE CRITERION OF HAVING A WELL-FUNCTIONING}

\section{EDITORIAL BOARD IN PLACE}

Of the 213 journals, only four editors did not answer this question. All the IBSS- and ISI-listed journals had editorial boards in place and only two of the other DoE-accredited journals did not, indicating that there was virtually universal compliance with this criterion.

Figure 1: Rating of the editorial board chairperson's

1 Academy of Science of South Africa, Didacta Building, 211 Skinner Street, Pretoria, 0001 performance or effectiveness

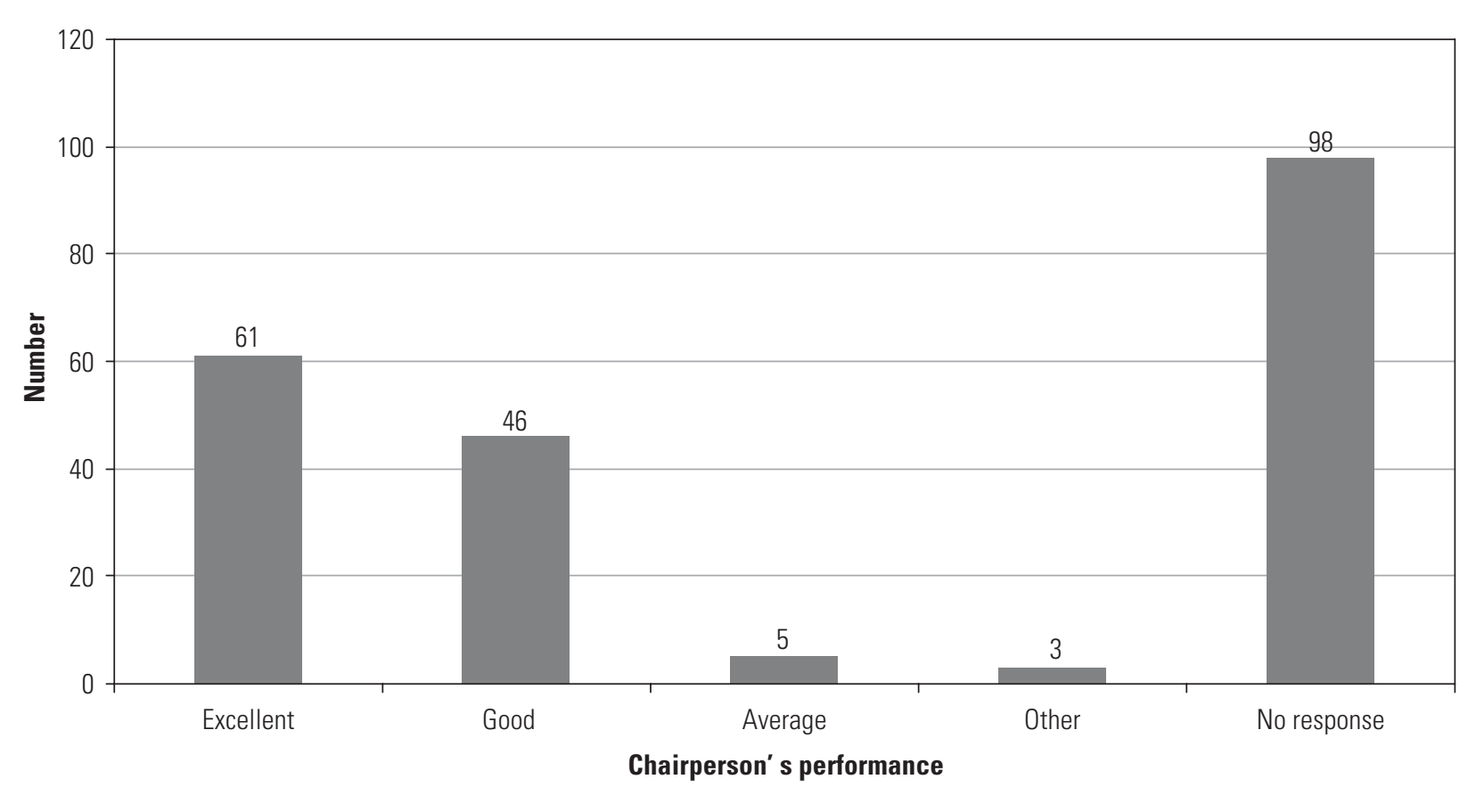


One can conclude that editorial boards are universally perceived by journal editors as being necessary and useful, and that there is also a widely held view that such an editorial board needs to have a chairperson to hold it together, independently of the editor him- or herself

Figure 2: Number of members of the editorial board
Table 1: Rating of the chairperson's performance or effectiveness by category

\begin{tabular}{|c|l|c|c|c|c|c|}
\hline \multirow{2}{*}{ Category } & \multicolumn{4}{|c|}{ Rating of chairperson's effectiveness } & \multirow{2}{*}{ Total } \\
\cline { 3 - 7 } & ISI & Excellent & Good & Average & Bad & 4 \\
\hline \multirow{3}{*}{ Number } & DoE & 3 & 1 & 0 & 0 & 111 \\
\cline { 2 - 7 } & Total & 58 & 45 & 5 & 3 & 115 \\
\hline \multirow{2}{*}{$\%$} & ISI & $75.0 \%$ & $25.0 \%$ & $0 \%$ & 3 & $100.0 \%$ \\
\cline { 2 - 7 } & DoE & $52.3 \%$ & $40.5 \%$ & $4.5 \%$ & $2.7 \%$ & $100.0 \%$ \\
\cline { 2 - 7 } & Total & $53.0 \%$ & $40.0 \%$ & $4.3 \%$ & $2.6 \%$ & $100.0 \%$ \\
\hline
\end{tabular}

The editors rated the performance of the chairpersons of the relevant editorial boards in each case (Table 1). A very large number of respondents (98) chose not to respond, but of those who responded, the majority rated their chairpersons as either excellent or good. The information is broken down by category for those who did respond, the number in each category being presented at the top and the percentage below.

None of the editors of the 5 IBSS-listed journals responded to this question, and only 4 of the 15 editors of ISI listed journals did so. With so few responses, it was not possible to say anything definite about this aspect in respect of these (in terms of policy, automatically accredited) journals. The majority of the chairpersons of DoE-listed journals were rated as excellent or good.

One can conclude that editorial boards are universally perceived by journal editors as being necessary and useful, and that there is also a widely held view that such an editorial board needs to have a chairperson to hold it together, independently of the editor him- or herself. It is not known whether the silence on this issue of nearly half of all respondent editors was an indication that they might espouse a model in which an editorial board is effectively chaired or organized in its functions by the editor; certainly, no-one expressed this preference in writing. It may well be that many simply refrained from answering, as this would imply evaluating themselves, as some of the journal editors also play a chairperson's role.

The number of editorial board members per journal is summarized in Figure 2, and more detail is given in Table 2 .

The percentage of journals in the above categories was much the same in the case of both ISIand DoE-listed journals, with the majority having editorial boards of fewer than 20 members.

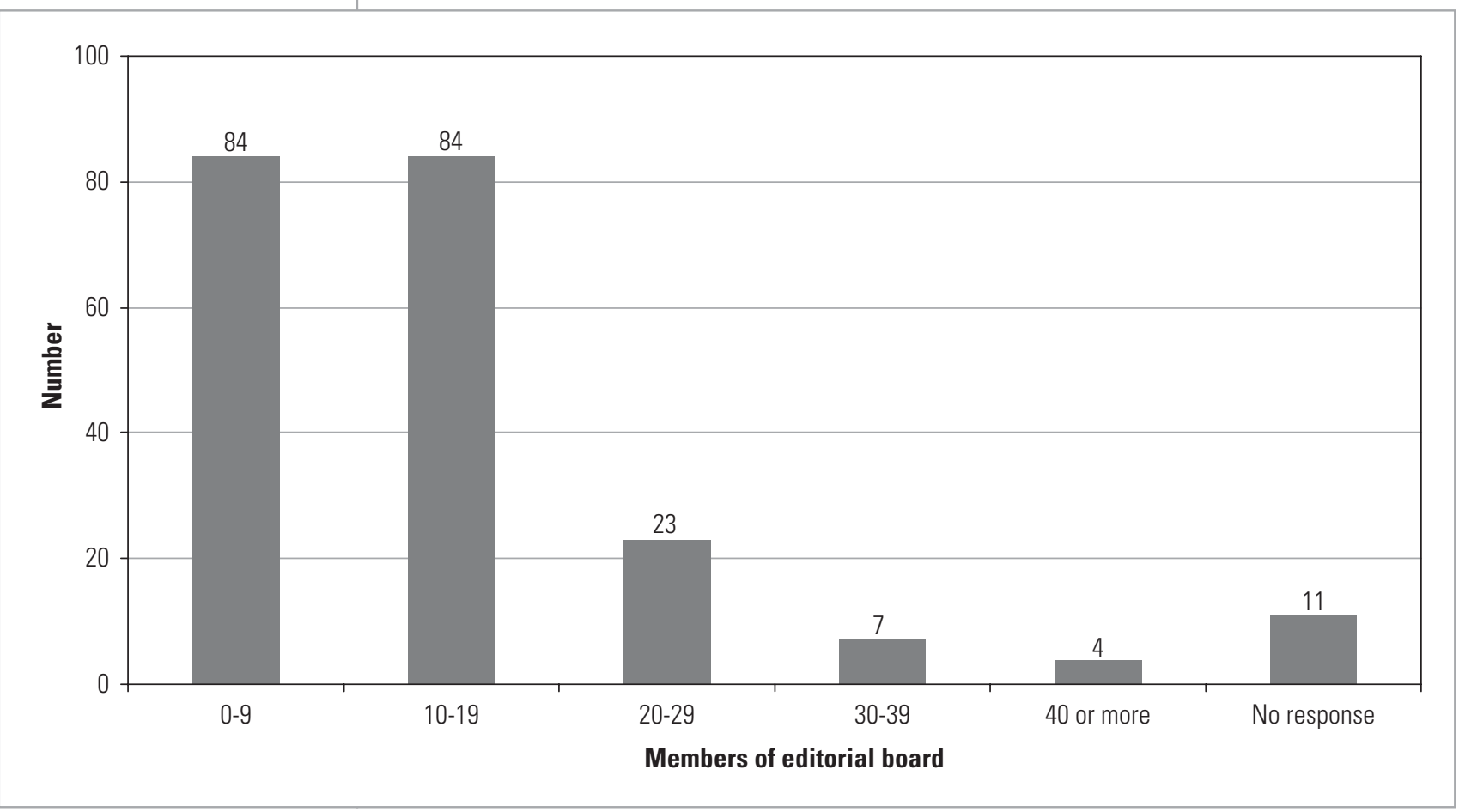


Table 2: Number of members of the editorial board

\begin{tabular}{|c|c|c|c|c|c|c|c|}
\hline & \multirow{2}{*}{ Category } & \multicolumn{5}{|c|}{ Number of members of the editorial board } & \multirow{2}{*}{ Total } \\
\hline & & 0-9 & 10-19 & 20-29 & 30-39 & 40 or more & \\
\hline \multirow{4}{*}{ Number } & IBSS & 1 & 2 & 2 & 0 & 0 & 5 \\
\hline & $|S|$ & 9 & 4 & 1 & 0 & 0 & 14 \\
\hline & DoE & 74 & 78 & 20 & 7 & 4 & 183 \\
\hline & Total & 84 & 84 & 23 & 7 & 4 & 202 \\
\hline \multirow{4}{*}{$\%$} & IBSS & $20.0 \%$ & $40.0 \%$ & $40.0 \%$ & $0 \%$ & $0 \%$ & $100.0 \%$ \\
\hline & ISI & $64.3 \%$ & $28.6 \%$ & $7.1 \%$ & $0 \%$ & $0 \%$ & $100.0 \%$ \\
\hline & DoE & $40.4 \%$ & $42.6 \%$ & $10.9 \%$ & $3.8 \%$ & $2.2 \%$ & $100.0 \%$ \\
\hline & Total & $41.6 \%$ & $41.6 \%$ & $11.4 \%$ & $3.5 \%$ & $2.0 \%$ & $100.0 \%$ \\
\hline
\end{tabular}

Thirty one of the DoE-listed journals exceeded this number, rising up to figures of 40 or more members. It is possible that journals with large editorial boards are associated with a different model of functioning, where board members are either used as a core panel of referees or to contain many "sleeping" members who have agreed to serve in response to invitations aimed at artificially enhancing the prestige of a journal, rather than directly affecting the quality of its contents. Having 6-12 members is more compatible with a Board's direct role in the strategic

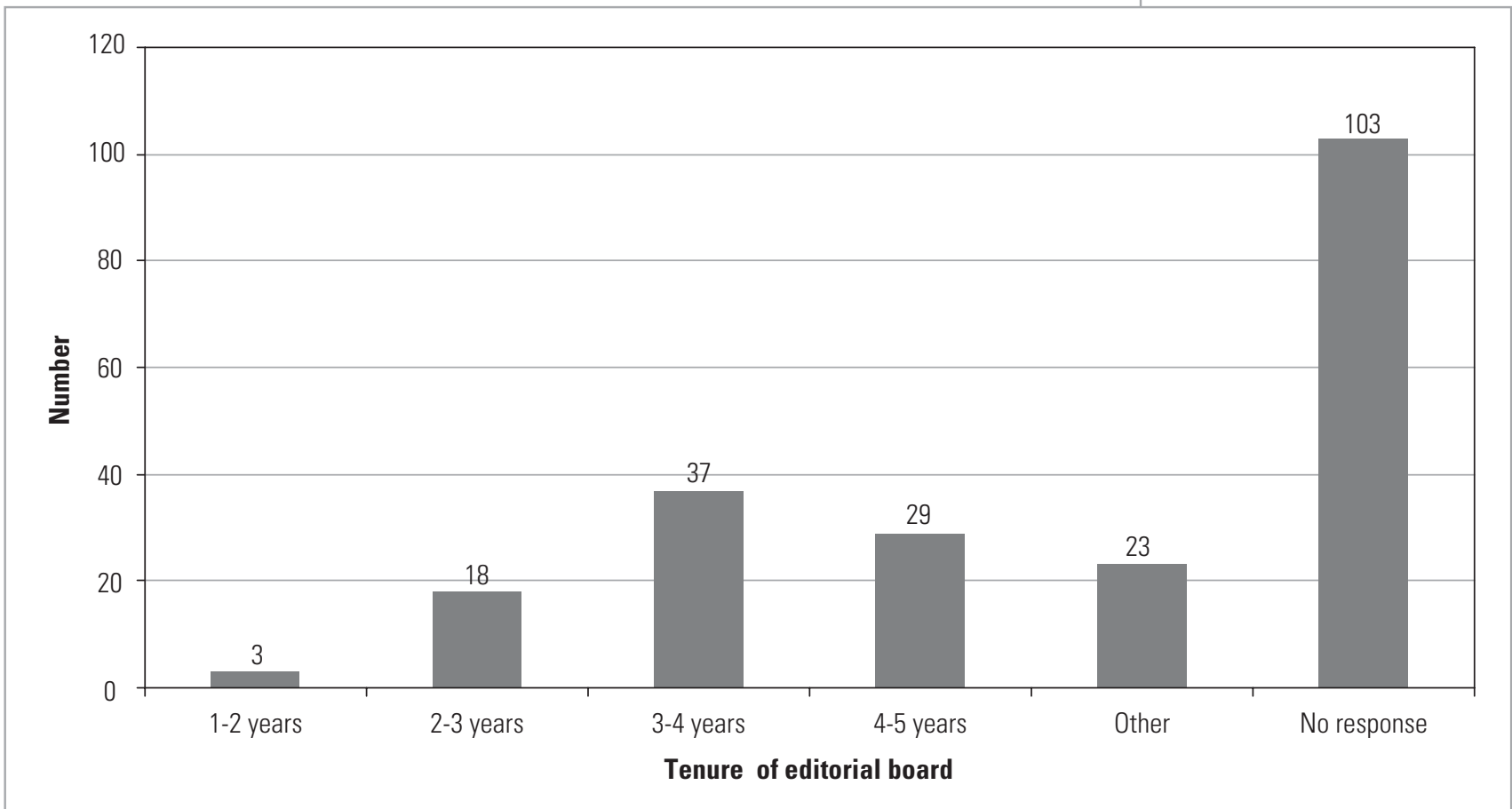

Table 3: Tenure of members of the editorial board

\begin{tabular}{|c|l|c|c|c|c|c|c|}
\hline \multirow{2}{*}{ Category } & \multicolumn{5}{|c|}{ Turnover period of members of the editorial board } & \multirow{2}{*}{ Total } \\
\cline { 2 - 8 } & $\mathbf{1 - 2}$ years & $\mathbf{2 - 3}$ years & $\mathbf{3 - 4}$ years & $\mathbf{4 - 5}$ years & 0ther & \\
\hline \multirow{3}{*}{ Number } & IBSS & 0 & 1 & 0 & 1 & 1 & 3 \\
\cline { 2 - 8 } & ISI & 0 & 0 & 2 & 2 & 3 & 7 \\
\cline { 2 - 8 } & DoE & 3 & 17 & 35 & 26 & 19 & 100 \\
\cline { 2 - 8 } & Total & 3 & 18 & 37 & 29 & 23 & 110 \\
\hline \multirow{3}{*}{$\%$} & IBSS & $0 \%$ & $33.3 \%$ & $0 \%$ & $33.3 \%$ & $33.3 \%$ & $100.0 \%$ \\
\cline { 2 - 8 } & ISI & $0 \%$ & $0 \%$ & $28.6 \%$ & $28.6 \%$ & $42.9 \%$ & $100.0 \%$ \\
\cline { 2 - 7 } & DoE & $3.0 \%$ & $17.0 \%$ & $35.0 \%$ & $26.0 \%$ & $19.0 \%$ & $100.0 \%$ \\
\cline { 2 - 7 } & Total & $2.7 \%$ & $16.4 \%$ & $33.6 \%$ & $26.4 \%$ & $20.9 \%$ & $100.0 \%$ \\
\hline
\end{tabular}

Figure 3: Tenure of members of the editorial board 


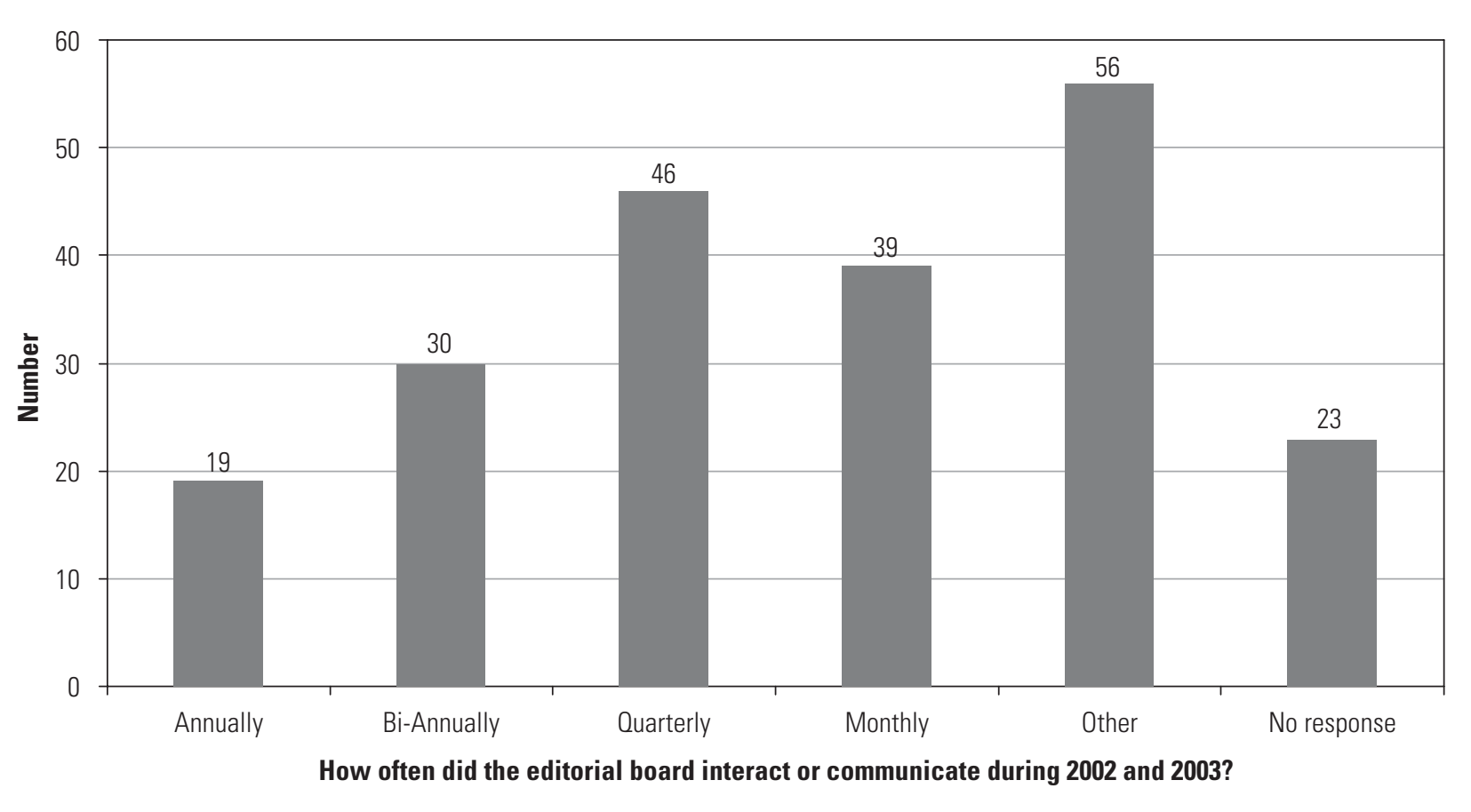

Figure 4: How often editorial board members interacted during 2002 and 2003 management of a journal's direction and supporting the editor in ways that go beyond acting as a referee on occasion, or making the journal look more authoritative than it is.

As seen in Figure 3, in most cases the editorial board members' tenure period was reported as being between 2 and 5 years. Only half of the editors responded to this question and the reason for the low response rate is not immediately obvious. A breakdown by category is presented in Table 3.

For the majority of both ISI- and DoE-listed journals the tenure was 2 to 5 years.

While the data shown here do not reveal cases where tenure of board members was very long, and we do not know why turnover took place (i.e. did board members usually ask to be relieved, or did editors or the boards themselves regulate this) it was evident that the principle of reasonable rates of turnover was well-accepted, as a balance between continuity and fresh ideas.

The frequency of interaction between editorial board members is presented as a histogram in Figure 4, and further detail is presented in Table 4.

Interaction of some kind usually occurred at least monthly, as indicated by half of the respondents to this question. Such interaction is indicative of a regulatory, rather than perfunctory role of board members. The pattern of interaction was fairly similar for ISI- and DoE-listed journals, yet the board members of 18 of the DoE journals and one IBSS journal interacted only annually.

Table 4: How often editorial board members interacted during 2002 and 2003

\begin{tabular}{|c|c|c|c|c|c|c|c|}
\hline & \multirow{2}{*}{ Category } & \multicolumn{5}{|c|}{ How often editorial board members interact } & \multirow{2}{*}{ Total } \\
\hline & & Annually & Bi-Annually & Quarterly & Monthly & Other & \\
\hline \multirow{4}{*}{ Number } & IBSS & 1 & 2 & 1 & 0 & 1 & 5 \\
\hline & $|S|$ & 0 & 2 & 3 & 1 & 4 & 10 \\
\hline & DoE & 18 & 26 & 42 & 38 & 51 & 175 \\
\hline & Total & 19 & 30 & 46 & 39 & 56 & 190 \\
\hline \multirow{4}{*}{$\%$} & IBSS & $20.0 \%$ & $40.0 \%$ & $20.0 \%$ & $0 \%$ & $20.0 \%$ & $100.0 \%$ \\
\hline & $|S|$ & $0 \%$ & $20.0 \%$ & $30.0 \%$ & $10.0 \%$ & $40.0 \%$ & $100.0 \%$ \\
\hline & $\mathrm{DoE}$ & $10.3 \%$ & $14.9 \%$ & $24.0 \%$ & $21.7 \%$ & $29.1 \%$ & $100.0 \%$ \\
\hline & Total & $10.0 \%$ & $15.8 \%$ & $24.2 \%$ & $20.5 \%$ & $29.5 \%$ & $100.0 \%$ \\
\hline
\end{tabular}




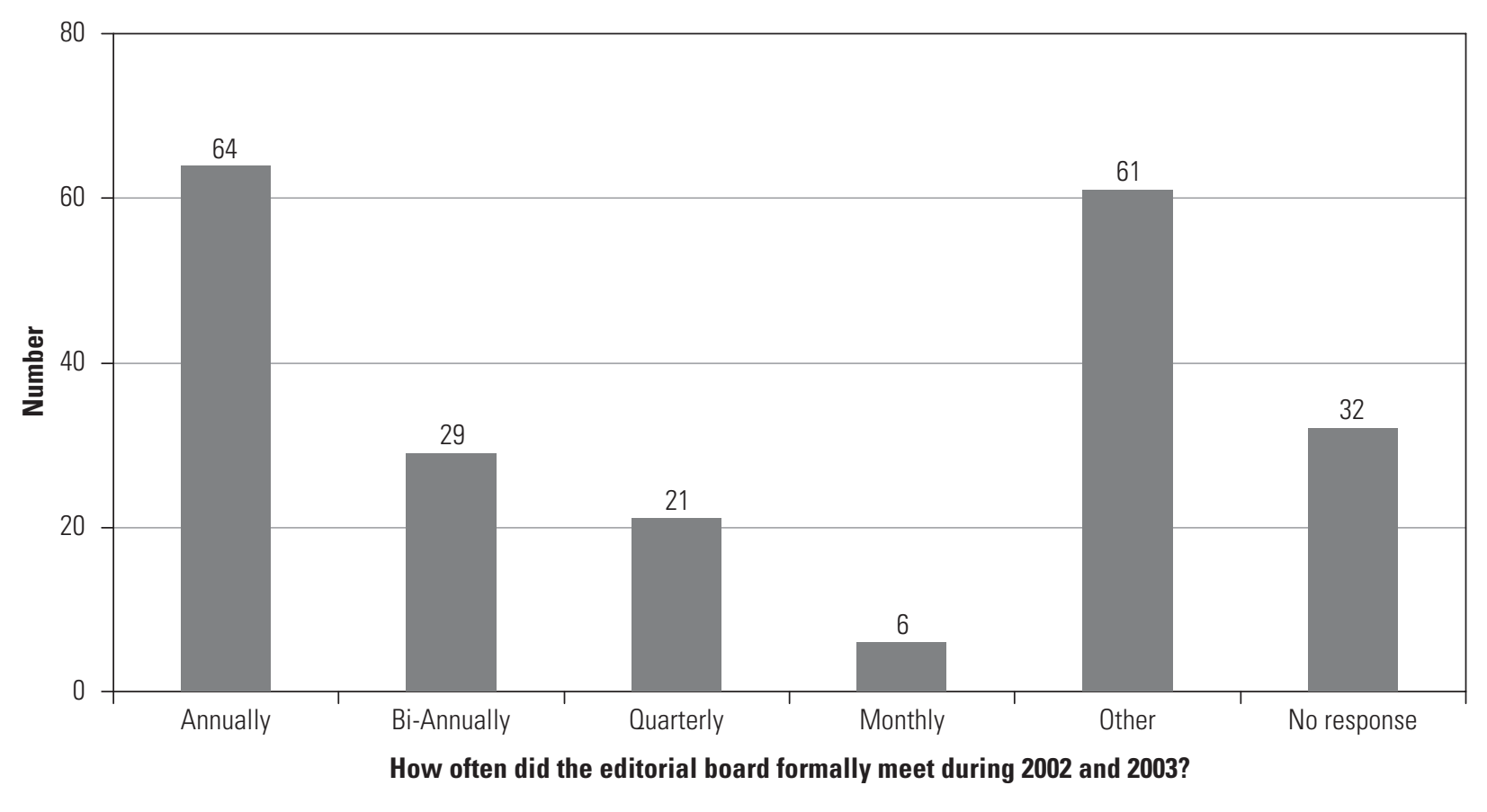

Table 5: How often editorial board members formally met during 2002 and 2003

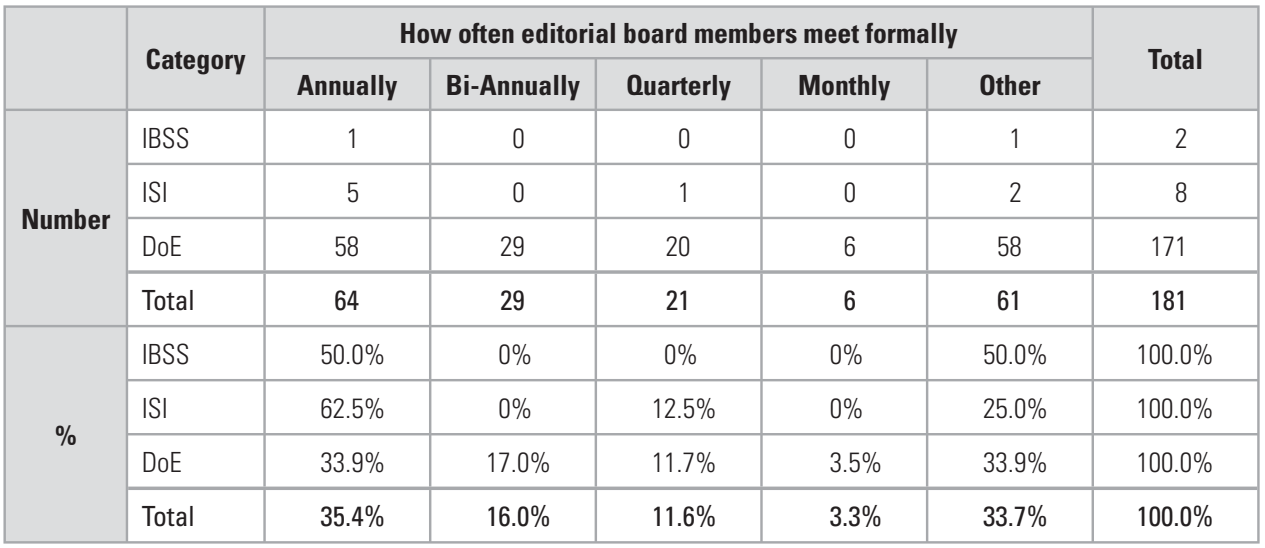

Figure 5: How often editorial board members formally met during 2002 and 2003

The frequency of editorial board meetings is presented in Figure 5 and more detail is given in Table 5 .

While a large number of boards met only annually and 61 never met, the fact is that twothirds of the boards DID meet at least once a year, which indicated that such meetings were thought to be of some value and reflected some kind of regulatory role of the board in respect of the journal. Only half of the editors of ISI-listed journals responded to this question, but

Table 6: Rating of the board's performance?

\begin{tabular}{|c|c|c|c|c|c|c|c|}
\hline & \multirow[b]{2}{*}{ Category } & \multicolumn{5}{|c|}{ Rating of the board's performance } & \multirow{2}{*}{ Total } \\
\hline & & Excellent & Good & Average & Bad & Other & \\
\hline \multirow{4}{*}{ Number } & IBSS & 2 & 2 & 1 & 0 & 0 & 5 \\
\hline & $|S|$ & 9 & 3 & 1 & 0 & 0 & 13 \\
\hline & DoE & 68 & 91 & 25 & 1 & 2 & 187 \\
\hline & Total & 79 & 96 & 27 & 1 & 2 & 205 \\
\hline \multirow{4}{*}{$\%$} & IBSS & $40.0 \%$ & $40.0 \%$ & $20.0 \%$ & $0 \%$ & $0 \%$ & $100.0 \%$ \\
\hline & $|S|$ & $69.2 \%$ & $23.1 \%$ & $7.7 \%$ & $0 \%$ & $0 \%$ & $100.0 \%$ \\
\hline & DoE & $36.4 \%$ & $48.7 \%$ & $13.4 \%$ & $0.5 \%$ & $1.1 \%$ & $100.0 \%$ \\
\hline & Total & $38.5 \%$ & $46.8 \%$ & $13.2 \%$ & $0.5 \%$ & $1.0 \%$ & $100.0 \%$ \\
\hline
\end{tabular}




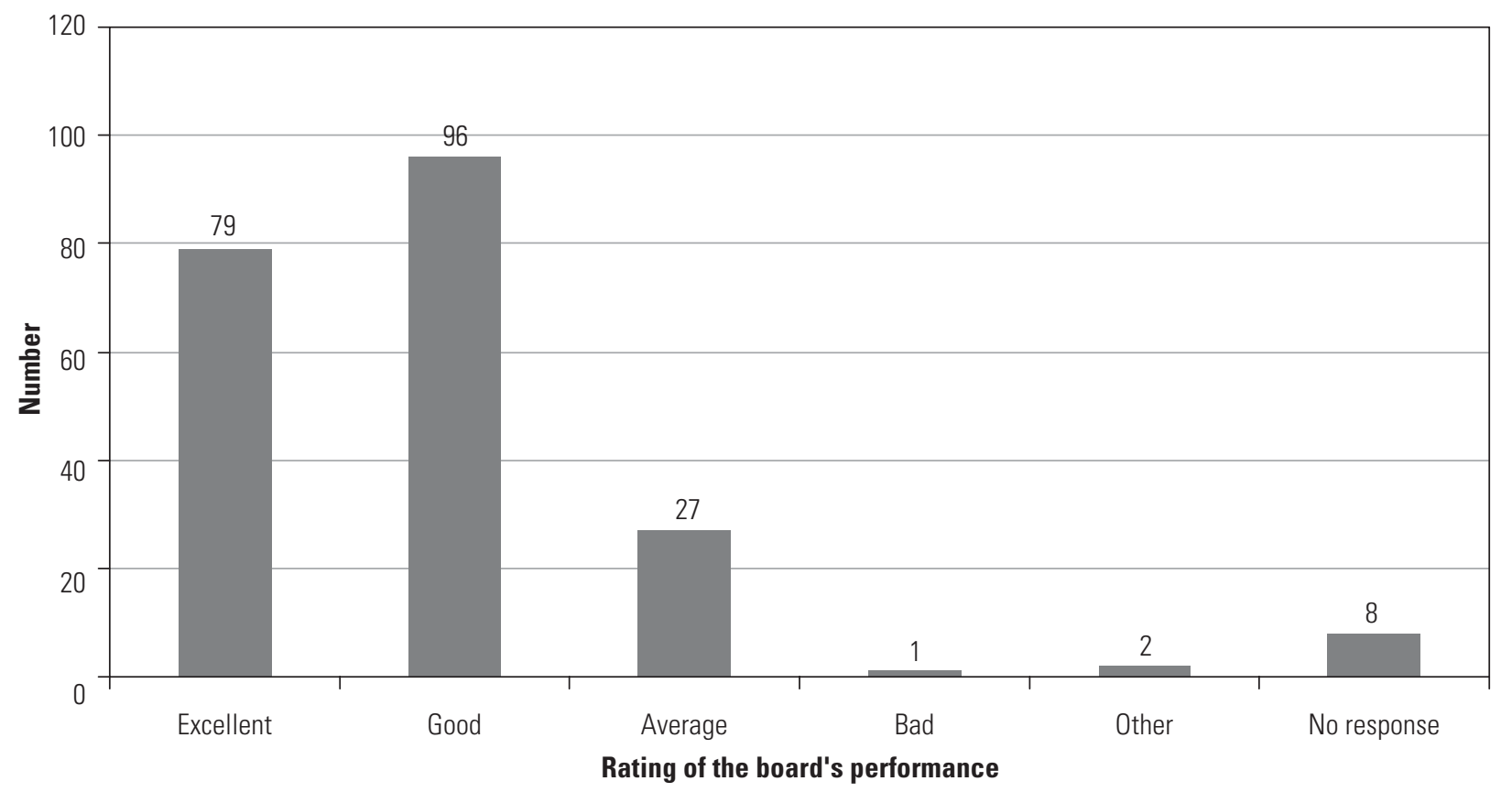

Figure 6: Rating of the board's performance?

Figure 7: Number of peer reviewers per original submitted research article broadly speaking the meeting patterns of their boards appeared to be similar to those of DoElisted journals.

The editors rated the performance of the respective editorial boards; the outcome appears in Figure 6 and the available values are broken down according to journal category in Table 6.

The performance of the overwhelming majority of the editorial boards was rated as either good or excellent by the editors. It can be assumed that this confirmed the widespread acceptance of an editorial board as being essential to the quality of a research journal, even if expectations may vary. The boards of ISI-listed journals received a higher percentage of excellent ratings than did those of DoE-listed journals, and only one of 13 ISI-listed journals received an average rating.

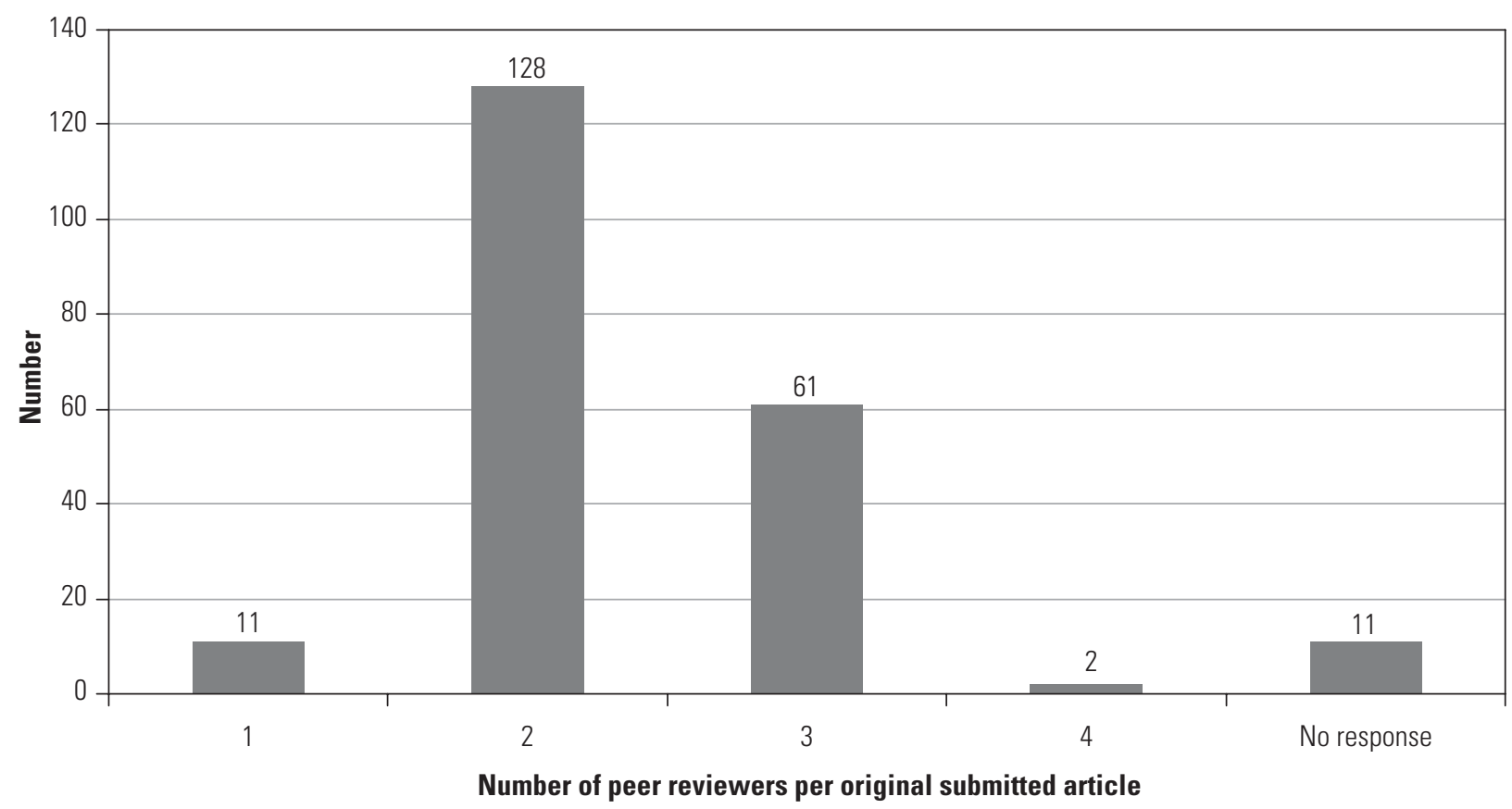


Table 7: Number of peer reviewers per original submitted research article

\begin{tabular}{|c|c|c|c|c|c|c|}
\hline & \multirow[b]{2}{*}{ Category } & \multicolumn{4}{|c|}{ Number of peer reviewers per original submitted research article } & \multirow{2}{*}{ Total } \\
\hline & & 1 & 2 & 3 & 4 & \\
\hline \multirow{4}{*}{ Number } & IBSS & 0 & 5 & 0 & 0 & 5 \\
\hline & $|S|$ & 1 & 8 & 5 & 0 & 14 \\
\hline & DoE & 10 & 115 & 56 & 2 & 183 \\
\hline & Total & 11 & 128 & 61 & 2 & 202 \\
\hline \multirow{4}{*}{$\%$} & IBSS & $0 \%$ & $100.0 \%$ & $0 \%$ & $0 \%$ & $100.0 \%$ \\
\hline & $|S|$ & $7.1 \%$ & $57.1 \%$ & $35.7 \%$ & $0 \%$ & $100.0 \%$ \\
\hline & DoE & $5.5 \%$ & $62.8 \%$ & $30.6 \%$ & $1.1 \%$ & $100.0 \%$ \\
\hline & Total & $5.4 \%$ & $63.4 \%$ & $30.2 \%$ & $1.0 \%$ & $100.0 \%$ \\
\hline
\end{tabular}

\section{THE CRITERION OF OBLIGATORY, EFFECTIVE PEER REVIEW OF ALL ORIGINAL ARTICLES}

The number of peer reviewers used per article is presented as a histogram below.

In almost all cases, two or three peer reviewers were used per article. While it was disturbing that there were 11 cases where one referee was thought to be sufficient, the very notion of independent peer review requires that more than one referee be employed for each submitted article, apart from the editor's (or associate editor's) more general discretion. Two or three referees is a good compromise between the burdensome use of (voluntary, unpaid) scholars that 4-5 referees would represent, and the minimum requirements of an effective system for recommending yes/no decisions on publication, and improving articles in respect of insightful comment and criticism. Ten of the 11 journals that made use of one peer reviewer were DoE-listed journals. The five IBS-listed journals all made use of two peer reviewers per article.

The average number of pages per peer-review is presented in the histogram below and details are presented in Table 8 .

In most cases, peer reviews were from two to three pages, which in the circumstances of skilled, voluntary work of this kind suggested that considerable care was usually taken in carrying out the review and reporting on it. Four of the 14 ISI-listed journals indicated a length of one page as common.

The very notion of independent peer review requires that more than one referee be employed for each submitted article, apart from the editor's (or associate editor's) more general discretion

Figure 8: Average length in pages of peer review submission or opinion

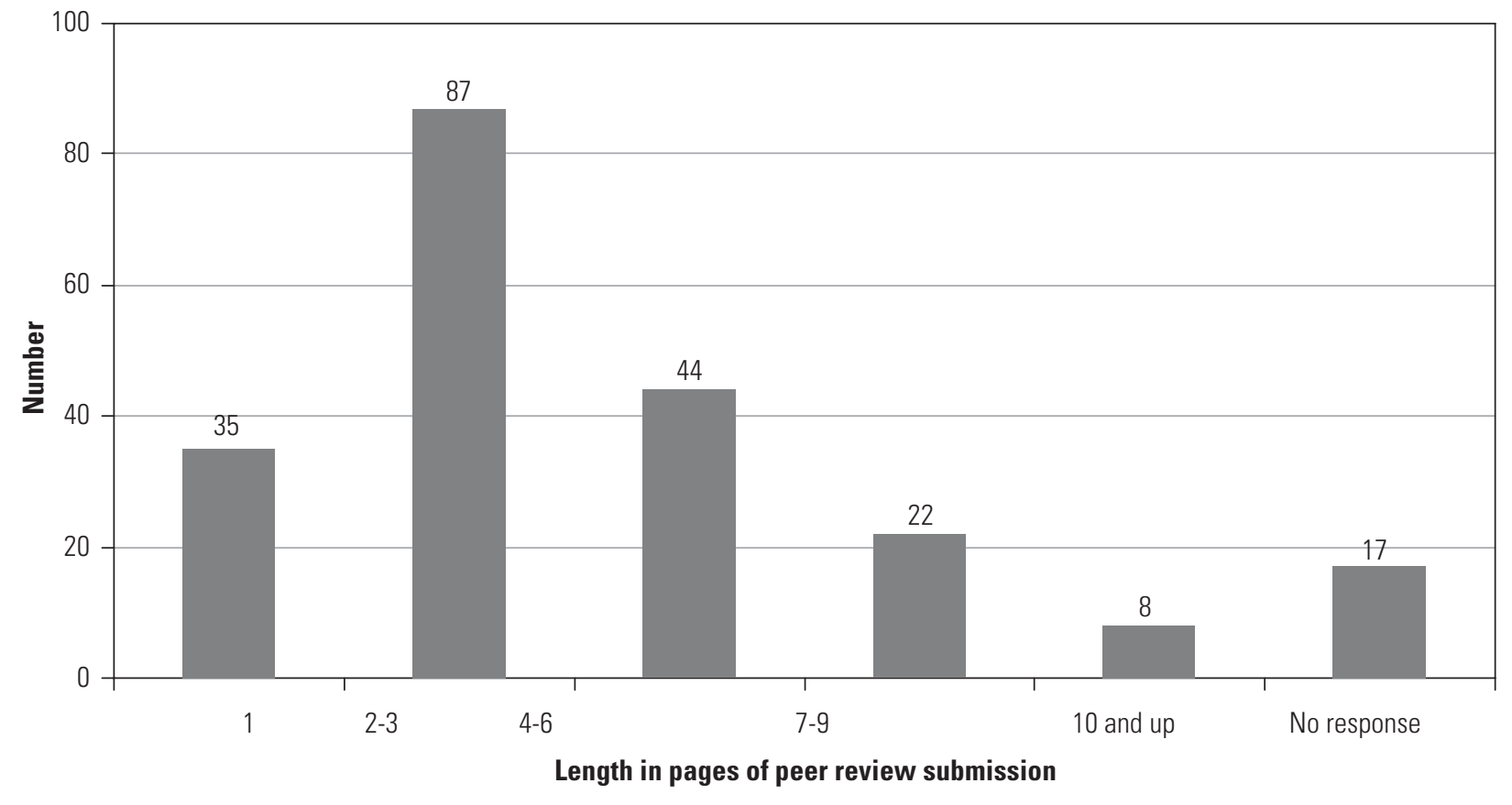


Table 8: Average length in pages of peer review submission or opinion

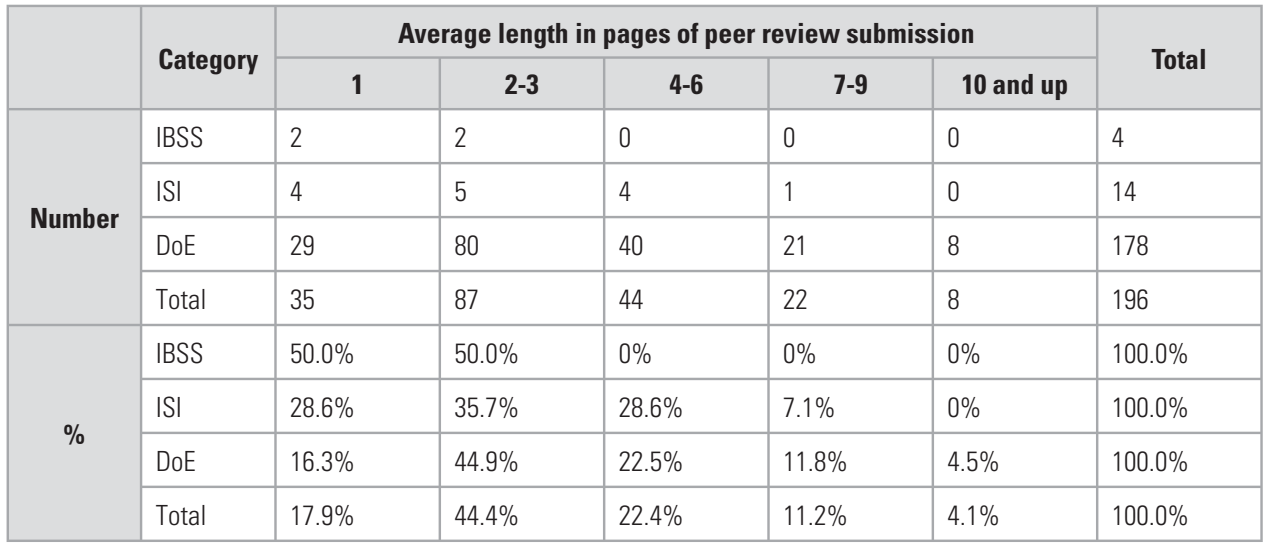

One hundred and forty-one of the 213 journals editors indicated that they have a core panel of peer-reviewers and 57 said they did not; only three of the 15 ISI-listed journals indicated that they had a core panel. Core panels are useful, but obviously not essential in achieving consistency of peer review, but should always be augmented by especially knowledgeable outsiders in cases where this is necessary.

One hundred and seventy one of the journals indicated that they believed that they used a "blind" peer-review system. The questionnaire unfortunately could not distinguish between true "blindness" in which the reviewer(s) were unaware of the author(s)' identity or affiliation(s), and "blindness" in which the identity of the reviewer(s) was kept from the author(s). Twentynine journals did not use "blind" peer review, presumably of either kind, and a small number (13) did not respond to this question for some reason, perhaps not understanding what kind of "blindness" was referred to in the questionnaire. Eighty seven percent of DoE-listed journals indicated that they made use of blind peer review, while only $62 \%$ of ISI journals indicated that this was their approach to review.

"Blindness" in peer review has become a controversial question in the field, arising from abuse of privileged information, hostility and bias, technical inadequacies of reviews, and transfer of the work to less experienced associates. There is gathering support for true "blindness" of

Figure 9: Average acceptance/ rejection rate for 2002 and 2003 the review to address some of these problems, even though it can be unavoidably "leaky", while there remains general agreement that the identity of reviewers should not be revealed to

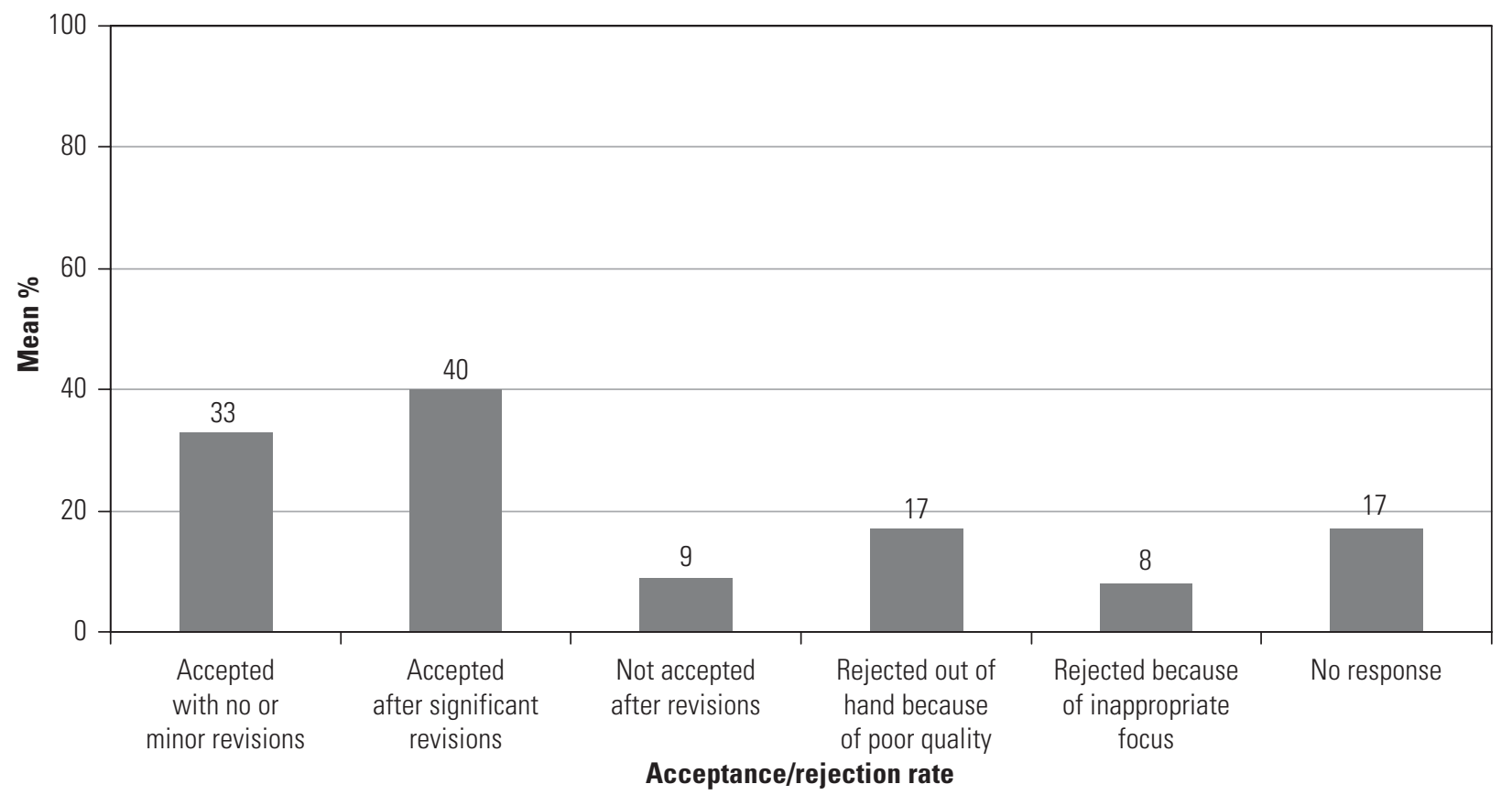


Table 9: Average acceptance/rejection rate for 2002 and 2003 according to category

\begin{tabular}{|l|c|c|c|c|c|}
\hline \multirow{2}{*}{ Category } & \multicolumn{5}{|c|}{ Average acceptance/rejection rate for 2002 and 2003} \\
\cline { 2 - 6 } & $\begin{array}{c}\text { Accepted with } \\
\text { no or minor } \\
\text { revisions }\end{array}$ & $\begin{array}{c}\text { Accepted after } \\
\text { significant } \\
\text { revisions }\end{array}$ & $\begin{array}{c}\text { Not accepted } \\
\text { after revisions }\end{array}$ & $\begin{array}{c}\text { Rejected out of } \\
\text { hand because of } \\
\text { poor quality }\end{array}$ & $\begin{array}{c}\text { Rejected } \\
\text { because of } \\
\text { inappropriate } \\
\text { focus }\end{array}$ \\
\hline IBSS & $40^{*}$ & 35 & 6 & 23 & 8 \\
\hline ISI & 27 & 39 & 13 & 16 & 9 \\
\hline DoE & 34 & 40 & 9 & 17 & 8 \\
\hline Total & 33 & 40 & 9 & 17 & 8 \\
\hline
\end{tabular}

authors, if only to sustain a system that is generally under stress from over-load of a volunteer work force. In this context, it was interesting that seventy journals regularly published a full list of contributing peer reviewers in the relevant journal, and 130 did not; the percentage in the two categories was about the same for ISI- and DoE-listed journals. One hundred and nine journals had an ethical code for peer reviewers, while 86 did not; about $75 \%$ of ISI-listed and $54 \%$ of DoE-listed journals had such a code.

There are good arguments for giving increased public credit for peer review service to good and effective reviewers, whose anonymity remains preserved by inclusion in a list of persons who have contributed over time. There are also very compelling arguments for putting an ethical code for reviewers into place and enforcing it at the level of the editor, or even the editorial board, where necessary. Misconduct as a peer reviewer for a research journal is at least as serious as other forms of scholarly misconduct, and the penalties should be as severe.

The average acceptance/rejection rate for 2002 and 2003 is presented as a histogram in Figure 9 and more detail is presented in Table 9.

The same patterns of acceptance and rejection appeared to be holding for all three categories of journals. The finding that about 33\% of articles received were accepted after no or minor revisions was not as reassuring as the fact that about $40 \%$ were only accepted after significant revisions. The overall acceptance rate of about $73 \%$ was, however, deeply disturbing, as this greatly exceeded the norms in most listed, internationally reputable journals and suggests that the "struggle to publish" in an over-informed world was much easier than it should have been. This may have been due to a surfeit of journal outlets, each prepared and keen to capture material even if it is not of high quality; to lax peer reviewing; to the persistence of the "publish or perish" system of academic promotion; or to other, unidentifiable factors. Peer review of an entire journal (issues published over a period of time) is one approach to this question, and should be done more often than is now the case. While peer-review is one of the most fundamental indicators of the quality of a research journal, the way it is applied is what reflects the journal's standards and indicates the overall quality of the research presented in its pages.

\section{THE CRITERION OF FREQUENT, REGULAR AND ON-TIME PUBLICATION}

The response to the question asking about frequency of publication is presented as a histogram in Figure 10.

Most journals were published bi-annually and this was closely followed by those appearing quarterly or annually. A substantial number of editors selected "other", and there were indications that some of these actually appeared tri-annually. The issue arises whether infrequent publication was caused by financial stringencies or cost considerations in general, lack of sufficient articles of sufficient quality, lack of editorial time, or combinations of these and other factors. The alternative word "periodical", often used by libraries to categorize research journals, implies that a journal appears sufficiently frequently and regularly to be read as a self-educational habit, to become an organ in which articles appear soon enough after being submitted to be current, to acquire a reputation for regular authoritative communications and reports, to be accepted internationally in the important listings of noteworthy journals, and to have a positive effect on a discipline or group of disciplines. It is not clear how journals appearing as infrequently as once or twice a year can have had these good, multi-purpose attributes. ISI-listed journals did considerably better in this respect than did most of the DoE-

\section{The finding that about $33 \%$ of articles received were} accepted after no or minor revisions was not as reassuring as the fact that about $40 \%$ were only accepted after significant revisions 


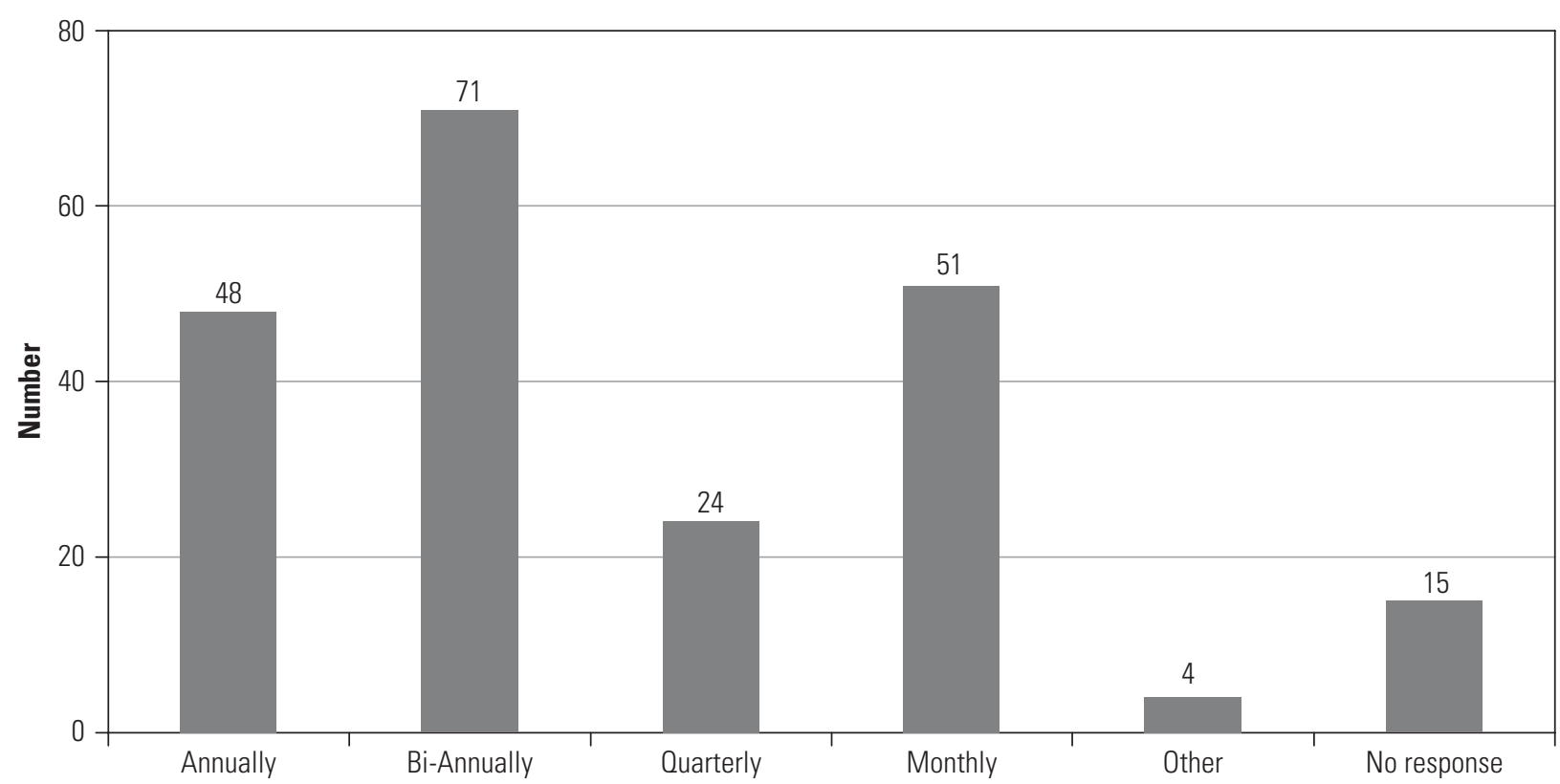

Frequency of publication on average for 2002 and 2003

Figure 10: Frequency of publication on average for 2002 and 2003
Table 10: Frequency of publication on average for 2002 and 2003

\begin{tabular}{|c|c|c|c|c|c|c|c|}
\hline & \multirow{2}{*}{ Category } & \multicolumn{5}{|c|}{ Frequency of publication on average for 2002 and 2003} & \multirow{2}{*}{ Total } \\
\hline & & Annually & Bi-annually & Tri-annually & Quarterly & Monthly & \\
\hline \multirow{4}{*}{ Number } & IBSS & 0 & 2 & 0 & 2 & 1 & 5 \\
\hline & $|S|$ & 1 & 4 & 1 & 6 & 0 & 12 \\
\hline & DoE & 47 & 65 & 23 & 43 & 3 & 181 \\
\hline & Total & 48 & 71 & 24 & 51 & 4 & 198 \\
\hline \multirow{4}{*}{$\%$} & IBSS & $0 \%$ & $40.0 \%$ & $0 \%$ & $40.0 \%$ & $20.0 \%$ & $100.0 \%$ \\
\hline & $|S|$ & $8.3 \%$ & $33.3 \%$ & $8.3 \%$ & $50.0 \%$ & $0 \%$ & $100.0 \%$ \\
\hline & DoE & $26.0 \%$ & $35.9 \%$ & $12.7 \%$ & $23.8 \%$ & $1.7 \%$ & $100.0 \%$ \\
\hline & Total & $24.2 \%$ & $35.9 \%$ & $12.1 \%$ & $12.1 \%$ & $2.0 \%$ & $100.0 \%$ \\
\hline
\end{tabular}

listed journals. The ISI criteria for listing journals include frequency, regularity and on-time publication (which amongst other things implies a healthy reserve of good articles) as amongst the most important considerations. This matter will be examined further below, as it concerns the present study.

Table 11: Number of peer reviewed articles published in each issue

\begin{tabular}{|c|c|c|c|c|c|c|}
\hline & \multirow{2}{*}{ Category } & \multicolumn{4}{|c|}{ Number of peer reviewed articles published in each issue } & \multirow{2}{*}{ Total } \\
\hline & & $1-4$ & $5-8$ & $9-12$ & 13 and up & \\
\hline \multirow{4}{*}{ Number } & IBSS & 2 & 1 & 1 & 1 & 5 \\
\hline & $|S|$ & 0 & 2 & 7 & 5 & 14 \\
\hline & DoE & 28 & 78 & 46 & 26 & 178 \\
\hline & Total & 30 & 81 & 54 & 32 & 197 \\
\hline \multirow{4}{*}{$\%$} & IBSS & $40.0 \%$ & $20.0 \%$ & $20.0 \%$ & $20.0 \%$ & $100.0 \%$ \\
\hline & ISI & $0 \%$ & $14.3 \%$ & $50.0 \%$ & $35.7 \%$ & $100.0 \%$ \\
\hline & DoE & $15.7 \%$ & $43.8 \%$ & $25.8 \%$ & $14.6 \%$ & $100.0 \%$ \\
\hline & Total & $15.2 \%$ & $41.1 \%$ & $27.4 \%$ & $16.2 \%$ & $100.0 \%$ \\
\hline
\end{tabular}




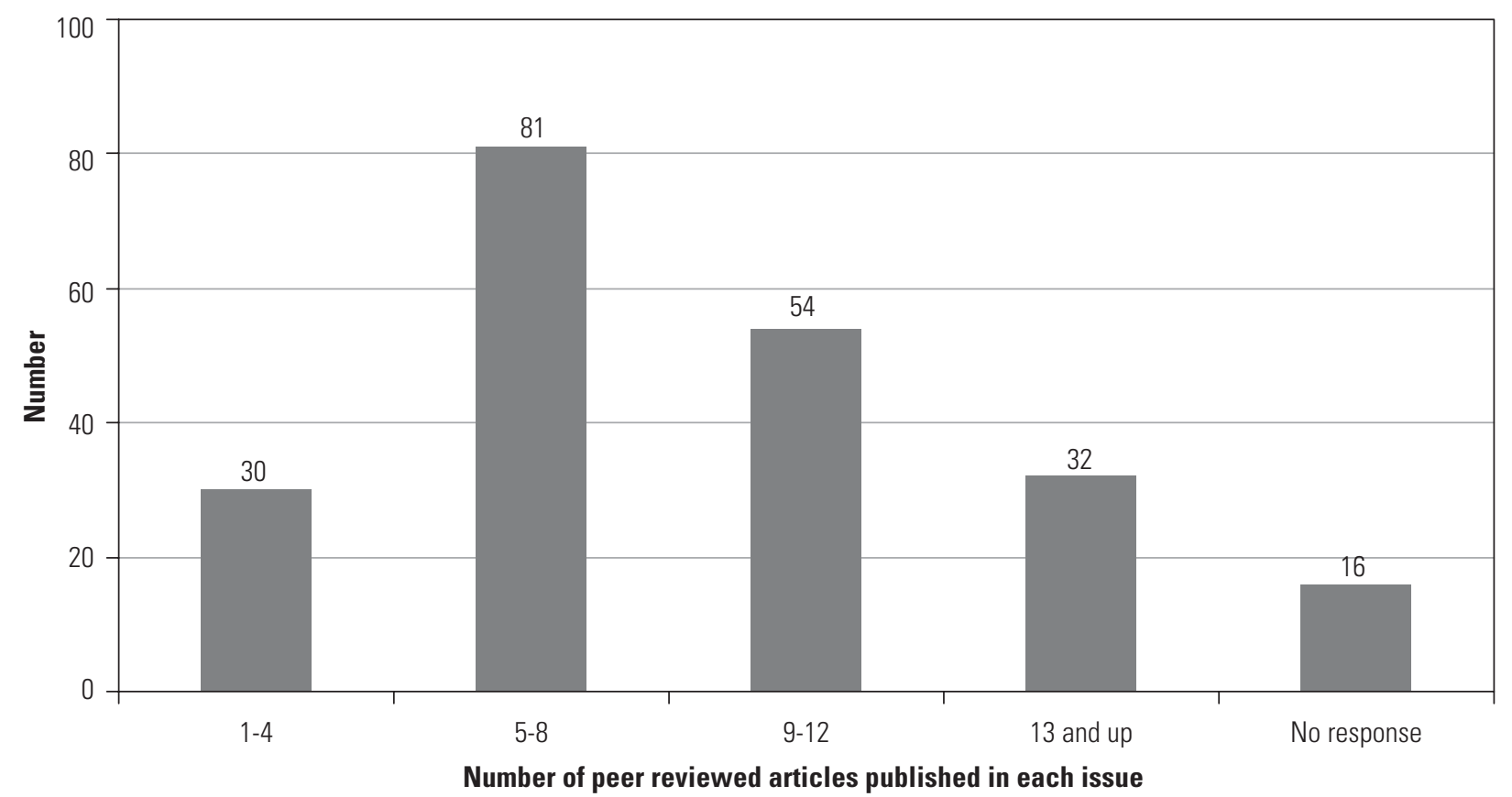

\section{THE CRITERION OF AN ADEQUATE NUMBER OF ARTICLES IN ANY GIVEN ISSUE}

The average number of articles in each issue appears in Figure 11.

The number of articles per issue ranged from 5 to 12 for most of the journals. It was alarming that $80 \%$ of all journals contained fewer than 13 articles, with half having fewer than 9 per issue. From this finding, often combined with that of infrequent publication and low rejection rates, one could conclude that a large number of journals attracted a very small total number of articles per year, suggesting that they were either too specialized in their niche, too "unpopular" with authors, or too insignificant in the larger system, to make a real difference to the dissemination of scholarly work. Why have they survived under these conditions? Are they worth the effort of production? This issue is examined further below.

The journals containing from one to four articles per issue were either IBSS- or DoElisted. Most ISI-listed journals had more than nine articles per issue and 36\% of them actually contained more than 13 articles per issue.

\section{THE CRITERION OF DISCIPLINARY COHERENCE, PROTECTED OR PROMOTED BY THE JOURNAL}

Editors had to indicate a minimum of one and a maximum of three broad fields covered in their journals. The intention of this question was to determine the extent to which various fields were reflected in journal content, from the frequency with which certain fields have been selected by the editors. The number of times a field was mentioned is indicated in the second column of Table 12 below. The frequency is expressed as a percentage in the last column.

Table 12: Extent to which various broad fields are reflected in SA journals

\begin{tabular}{|l|c|c|}
\hline \multicolumn{1}{|c|}{ Broad fields covered in SA journals } & Journal Coverage as selected by editors \\
\cline { 2 - 3 } & Frequency & \%* \\
\hline Social Sciences and Social Studies & 56 & 8.6 \\
\hline Education & 37 & 8.1 \\
\hline Multi-disciplinary & 35 & 7.9 \\
\hline Languages, Linguistics and Literatures & 34 & 6.5 \\
\hline Philosophy, Religion and Theology & 28 & 6.3 \\
\hline Health Care and Health Science & 27 & 27 \\
\hline
\end{tabular}


In this regard, it could provisionally be concluded that consolidation of smaller disciplines into larger ones could assist journals

to become more active, appear more frequently, contain more articles, and have a better chance of being accepted in major international databases

\begin{tabular}{|c|c|c|}
\hline \multirow{2}{*}{ Broad fields covered in SA journals } & \multicolumn{2}{|c|}{ Journal Coverage as selected by editors } \\
\hline & Frequency & $\% *$ \\
\hline Law & 24 & 5.6 \\
\hline Life Sciences and Physical Sciences & 23 & 5.3 \\
\hline Other fields or disciplines & 23 & 5.3 \\
\hline Agriculture and Renewable Natural Resources & 21 & 4.9 \\
\hline Business, Commerce and Management Sciences & 20 & 4.6 \\
\hline Arts, Visual and Performing & 15 & 3.5 \\
\hline Communication & 14 & 3.2 \\
\hline Public Administration and Social Studies & 10 & 2.3 \\
\hline Architecture and Environmental Design & 9 & 2.1 \\
\hline Libraries and Museums & 9 & 2.1 \\
\hline Mathematical Sciences & 9 & 2.1 \\
\hline Psychology & 9 & 2.1 \\
\hline Engineering and Engineering Technology & 8 & 1.9 \\
\hline Military Sciences & 6 & 1.4 \\
\hline Physical Education, Health Education and Leisure & 5 & 1.2 \\
\hline Industrial Arts, Trades and Technology & 4 & 0.9 \\
\hline Computer Science & 3 & 0.7 \\
\hline Home Economics & 2 & 0.5 \\
\hline Total & 431 & 100 \\
\hline
\end{tabular}

* Extent to which various broad fields are covered by journal content, expressed as a percentage of all fields selected by all editors

A majority of journals (about 55-60\%) in this set appear to cater generally for the Social Sciences, Social Studies, Education and Languages, Linguistics and Literatures. In addition, the number of journals varies greatly among disciplines. Smaller fields such as Home Economics and Computer Science do not generate as many articles as do larger fields such as Social Sciences and Social Studies, Education and Languages, Linguistics and Literatures. In this regard, it could provisionally be concluded that consolidation of smaller disciplines into larger ones could assist journals to become more active, appear more frequently, contain more articles, and have a better chance of being accepted in major international databases. Another conclusion may be that the social sciences and humanities were more home-country focussed than, for example, the natural sciences and engineering, either because their quality is not competitive in international terms or because they have been deliberately targeted at a local audience/ readership for reasons such as language (Afrikaans) or relevance. Resolution of this matter is critically important for South Africa's scholarship, and one could perhaps distinguish between negative causes (requiring remediation) and positive causes by a more detailed study of the history of articles submitted to South African journals, i.e. were many of them re-submissions after unsuccessful submissions to internationally listed journals (including South African listed journals) or were they first submissions based on authors' preferences?

The survey has not provided any other useful information on the way in which journals either supported or did not support disciplinary coherence in the general context of teaching, learning and professional practice. This is a function that is very important in a developing country, and needs further detailed study.

\section{THE CRITERION OF SUSTAINABILITY OF A JOURNAL, ON THE BASIS OF A MIX OF REVENUE STREAMS}

Editors were requested to provide an estimate of the proportions of their journal income originating from six sources; the means of the percentages reported for various sources of income is reported in Figure 12. A breakdown for journals into the three categories is provided in Table 13. 


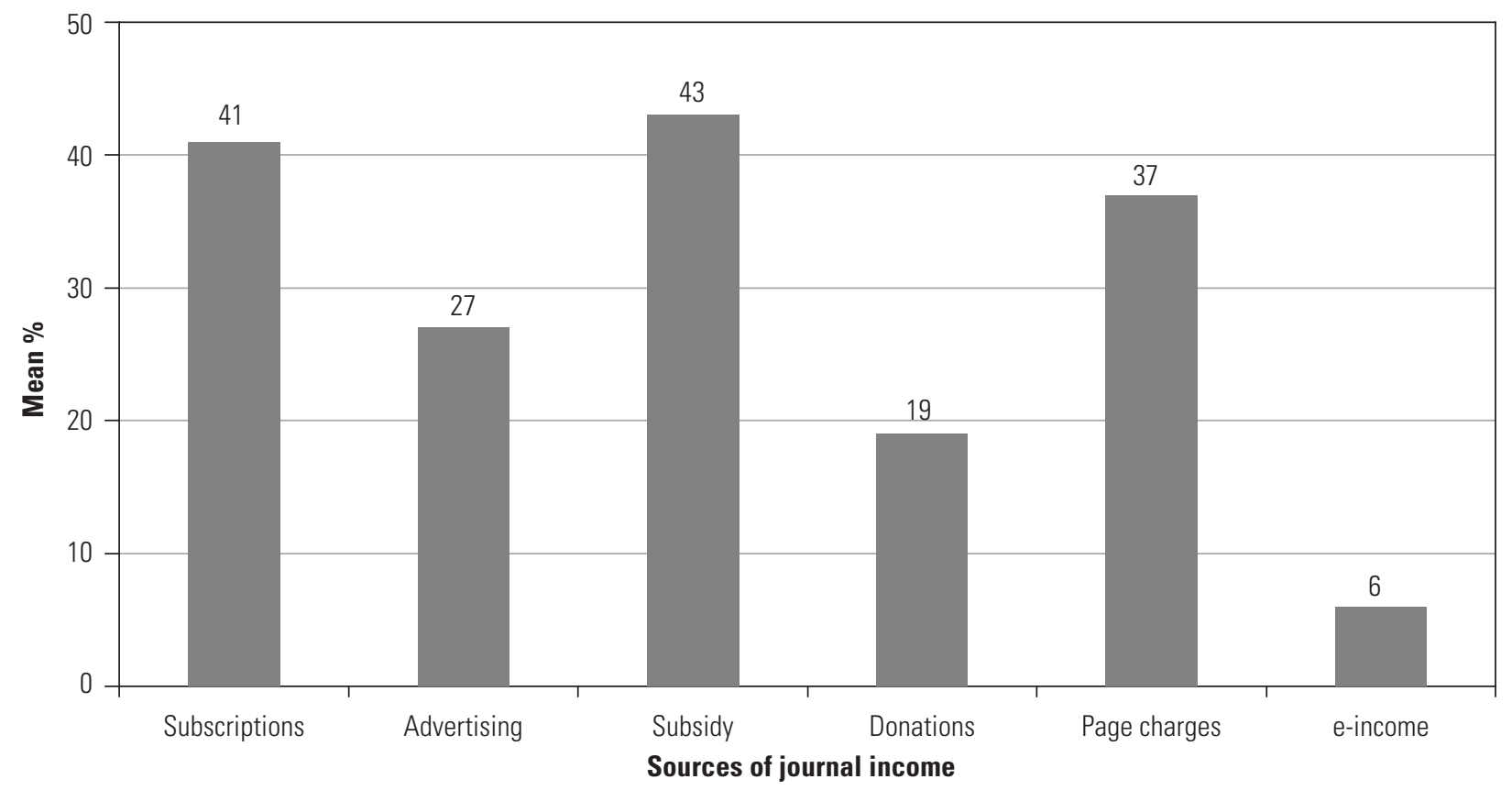

Table 13: Means of the percentages reported for various sources of income

\begin{tabular}{|l|c|c|c|c|c|c|}
\hline & \multicolumn{6}{|c|}{ Sources of income } \\
\cline { 2 - 7 } & Subscriptions & Advertising & Subsidy & Donations & Page charges & E-income \\
\hline IBSS & 90 & & 100 & & & 20 \\
\hline ISI & 57 & 11 & 25 & 4 & 19 & 5 \\
\hline DoE & 39 & 30 & 46 & 21 & 39 & 6 \\
\hline
\end{tabular}

Figure 12: Means of the percentages reported for various sources of income

On average, journals sourced their income from a mix of revenue streams, with the largest income streams coming from subscriptions, subsidy (from various sources) and page charges; such a mix of income sources is healthy in providing incentives for increasing subscriptions (as could for example be achieved by consolidation of titles or by increasing the perceived value to readers and institutions), for implementing page charges, for obtaining advertising, and for providing electronic access. Journals listed with the DoE only, tended to rely more on subsidy, subscriptions, page charges and advertising than did ISI-listed journals, which are more dependent on subscriptions.

Table 14: Average percentage of articles in each of 9 major categories

\begin{tabular}{|l|c|c|c|c|}
\hline \multirow{2}{*}{ Category } & \multicolumn{4}{|c|}{ \% of journal content } \\
\cline { 2 - 5 } & IBSS & ISI & Local & Total \\
\hline Scientific & 80 & 68 & 77 & 5 \\
\hline Reviews & 0 & 4 & 6 & 2 \\
\hline Proceedings & 2 & 2 & 2 & 4 \\
\hline Research Notes & 4 & 10 & 3 & 4 \\
\hline Book Reviews & 4 & 4 & 3 & 3 \\
\hline News Articles & 4 & 2 & 2 & 2 \\
\hline Comments or Letters & 1 & 1 & 1 & 1 \\
\hline Advertorials & 0 & 0 & 1 & 1 \\
\hline Abstracts & 2 & 0 & 1 & 1 \\
\hline Other & 3 & 93 & 99 & 99 \\
\hline Total & 100 & & & 5 \\
\hline
\end{tabular}




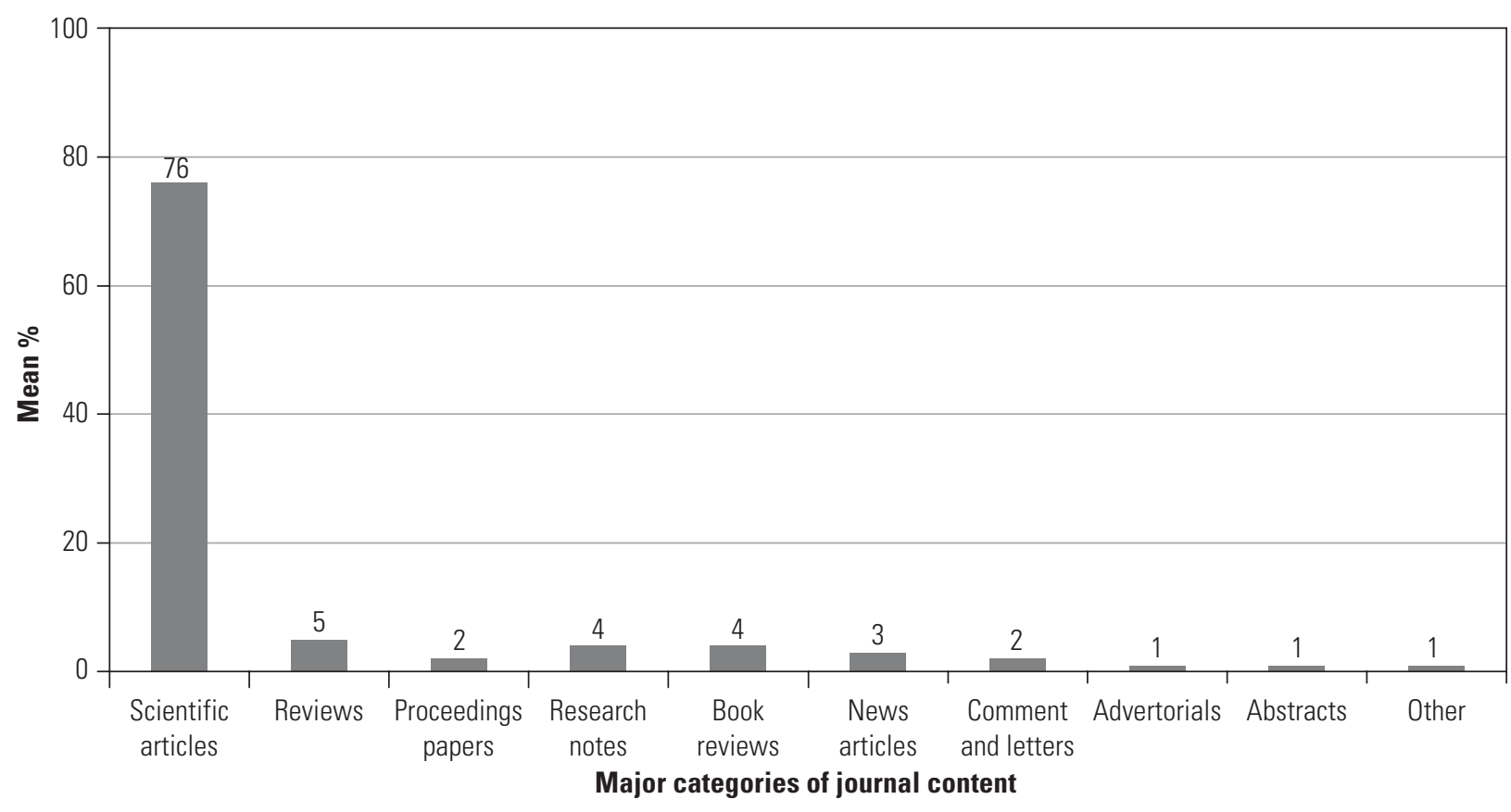

Figure 13: Average percentage of articles in each of 9 major categories

Between 75 and 80\% of journal content on average was devoted to scientific articles, which was indicative of a clear focus on the dissemination of original scholarly work

\section{THE CRITERION OF THE PRIMARY PURPOSE OF THE JOURNAL BEING THE DISSEMINATION OF ORIGINAL, PEER-REVIEWED RESEARCH}

The responding editors estimated the percentage breakdown of the major categories of content of each journal, and the average percentage in each category appears in Figure 13. Detail is provided in Table 14. As stated above, the means were calculated for each of the 10 categories separately. The means for each of the 10 categories did not add up to $100 \%$ as some of the distributions received did not total $100 \%$, but a clear general picture can nevertheless be derived.

Between 75 and $80 \%$ of journal content on average was devoted to scientific articles, which was indicative of a clear focus on the dissemination of original scholarly work, but must be considered in conjunction with other conclusions of this study (see below). The pattern was also fairly similar across the three journal categories: for the ISI-listed journals the percentage of journal articles devoted to scientific articles was slightly lower than for the other two categories, but $10 \%$ of the content of these journals was described as "research notes".

\section{THE CRITERION OF INTERNATIONAL STANDING OF THE JOURNAL}

The following graph represents the distribution of hard copies of the journal to other countries and a further breakdown is provided in Table 15.

Fifty-one of the 213 editors did not respond to this question. In the case of the majority of the other journals, a very limited number of copies was distributed to other countries. 73

Table 15: Number of non-SA institutions to which the journal is distributed

\begin{tabular}{|c|c|c|c|c|c|c|c|c|}
\hline & \multirow{2}{*}{ Category } & \multicolumn{6}{|c|}{ Number of non-SA institutions to which the journal is distributed } & \multirow{2}{*}{ Total } \\
\hline & & $1-24$ & $25-49$ & $50-74$ & $75-124$ & 125-199 & 200 and up & \\
\hline \multirow{4}{*}{ Number } & IBSS & 0 & 1 & 0 & 0 & 1 & 1 & 3 \\
\hline & ISI & 0 & 3 & 2 & 2 & 2 & 1 & 10 \\
\hline & DoE & 73 & 36 & 13 & 12 & 7 & 8 & 149 \\
\hline & Total & 73 & 40 & 15 & 14 & 10 & 10 & 162 \\
\hline \multirow{4}{*}{$\%$} & IBSS & $0 \%$ & $33.3 \%$ & $0 \%$ & $0 \%$ & $33.3 \%$ & $33.3 \%$ & $100.0 \%$ \\
\hline & ISI & $0 \%$ & $30.0 \%$ & $20.0 \%$ & $20.0 \%$ & $20.0 \%$ & $10.0 \%$ & $100.0 \%$ \\
\hline & DoE & $49.0 \%$ & $24.2 \%$ & $8.7 \%$ & $8.1 \%$ & $4.7 \%$ & $5.4 \%$ & $100.0 \%$ \\
\hline & Total & $45.1 \%$ & $24.7 \%$ & $9.3 \%$ & $8.6 \%$ & $6.2 \%$ & $6.2 \%$ & $100.0 \%$ \\
\hline
\end{tabular}




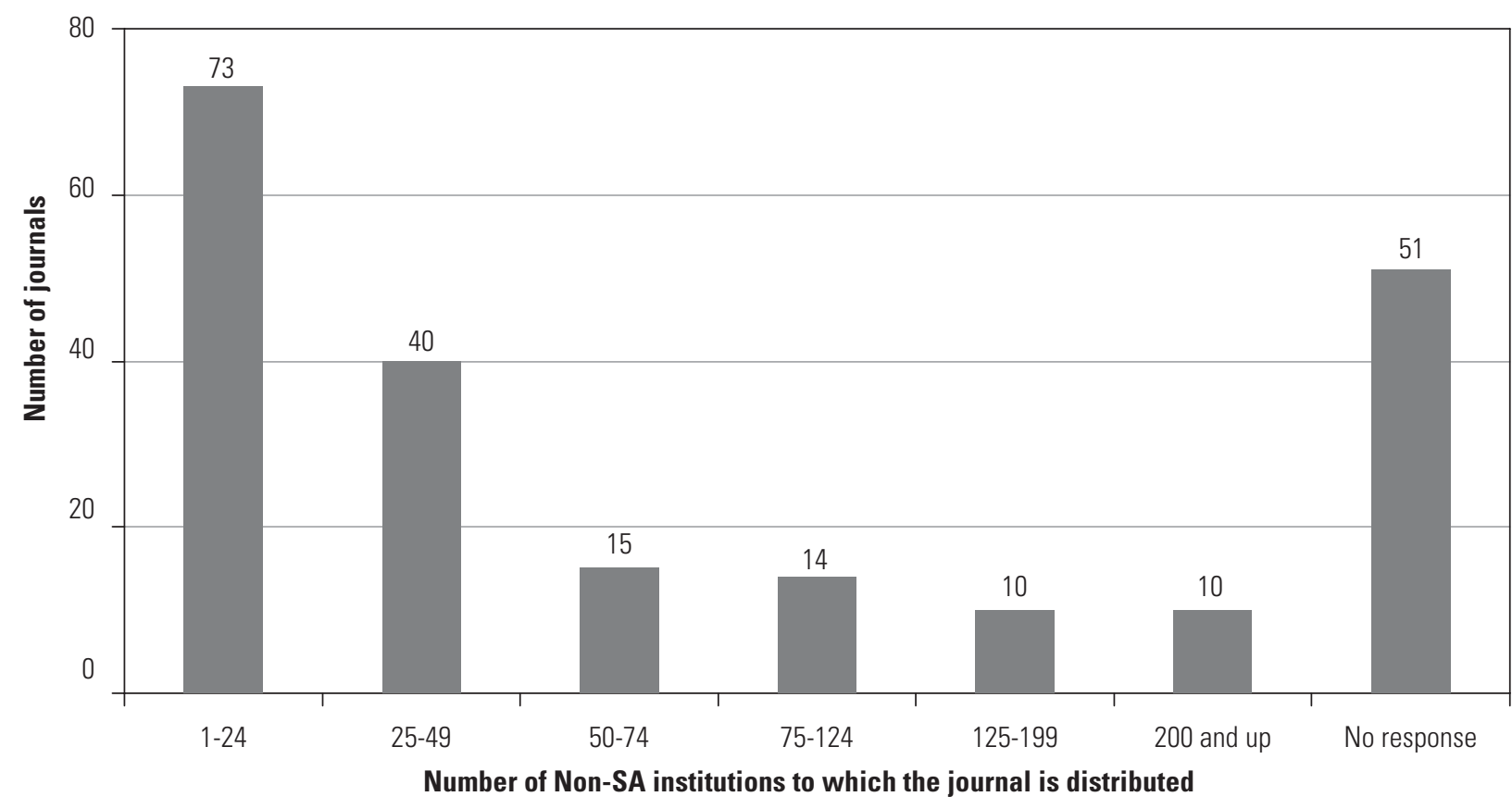

journals (all of them DoE-listed) distributed fewer than 25 copies to other countries. Sixty percent of IBSS- and ISI-listed journals were distributed to more than 75 non-SA institutions.

\section{THE CRITERION OF PEER REVIEW OF A JOURNAL ITSELF}

All journals contributing to the survey had an ISSN number, and could be assumed to be meeting the criteria needed for maintaining their registration in the ISSN system. The fact that all journal editors responded by completing the questionnaire was indicative of their willingness to subject themselves to scrutiny, but that is not the same as peer review conducted with a view to assessing the overall quality and contribution of a journal to its discipline, to training and education, and to South African competence and productivity in the field concerned. No specific question(s) on this aspect of the criterion was included in the questionnaire, but see the section on scientometric measurement below.

\section{BIBLIOMETRIC CRITERIA}

There were two questions relating to the impact factor of the journals, a question about the citing of articles in listed (accessable) or unlisted journals (inaccessible), as well as one on the cites per article (same considerations). Unfortunately, and perhaps surprisingly, the editors reported that this information was not available to them and consequently they did not have the necessary data to respond to these questions.

\section{THE CRITERION OF WIDE CIRCULATION AND \\ DISTRIBUTION, INCLUDING ELECTRONIC ACCESS}

The number of institutional subscriptions was one criterion for determining whether a journal was distributed widely or not. Information on the number of institutional subscriptions appears in Figure 15 and further details in Table 16.

All journals were distributed in hard copy to at least some institutions, mostly in South Africa, and mostly to libraries. Forty of the DoE-listed journals, about 25\% of them, were distributed to fewer than 25 institutions. About $80 \%$ of the IBSS- and ISI-listed journals were distributed to 75 or more institutions. (One journal was sent to a particularly very large number of institutions for a particular reason).

One hundred and forty-seven (about 70\%) of the journals provided electronic access, an impressively large number taking into account the complexities of so doing. It is likely that the activities of a small number of companies or agents specialising in "electronization" of journals was responsible for this (recent) progress. 


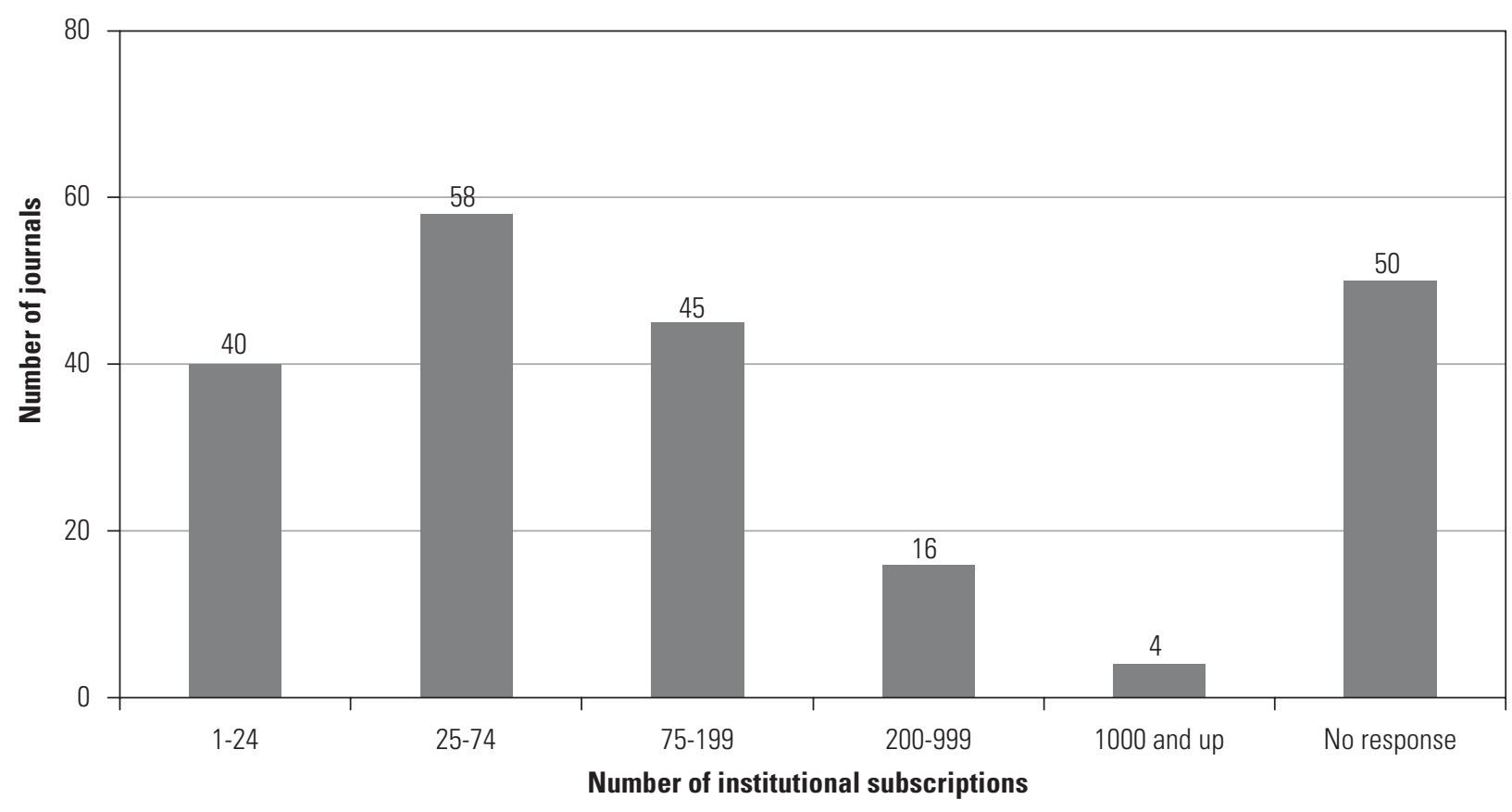

Figure 15: Institutional subscriptions per annum

Figure 16: The print run of the journal

Table 16: Institutional subscriptions per annum

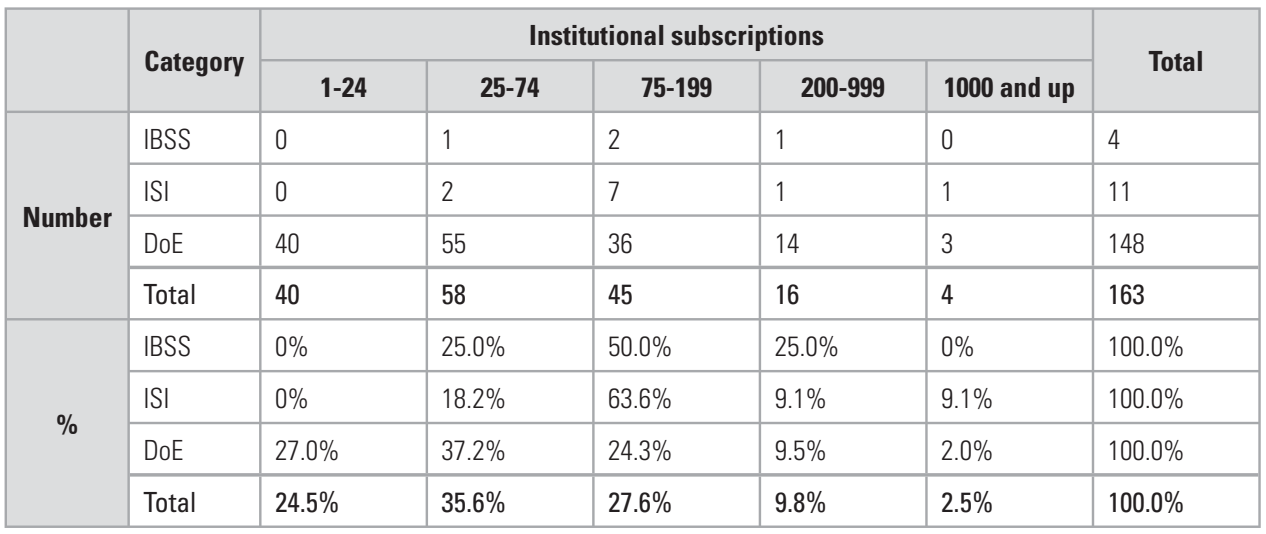

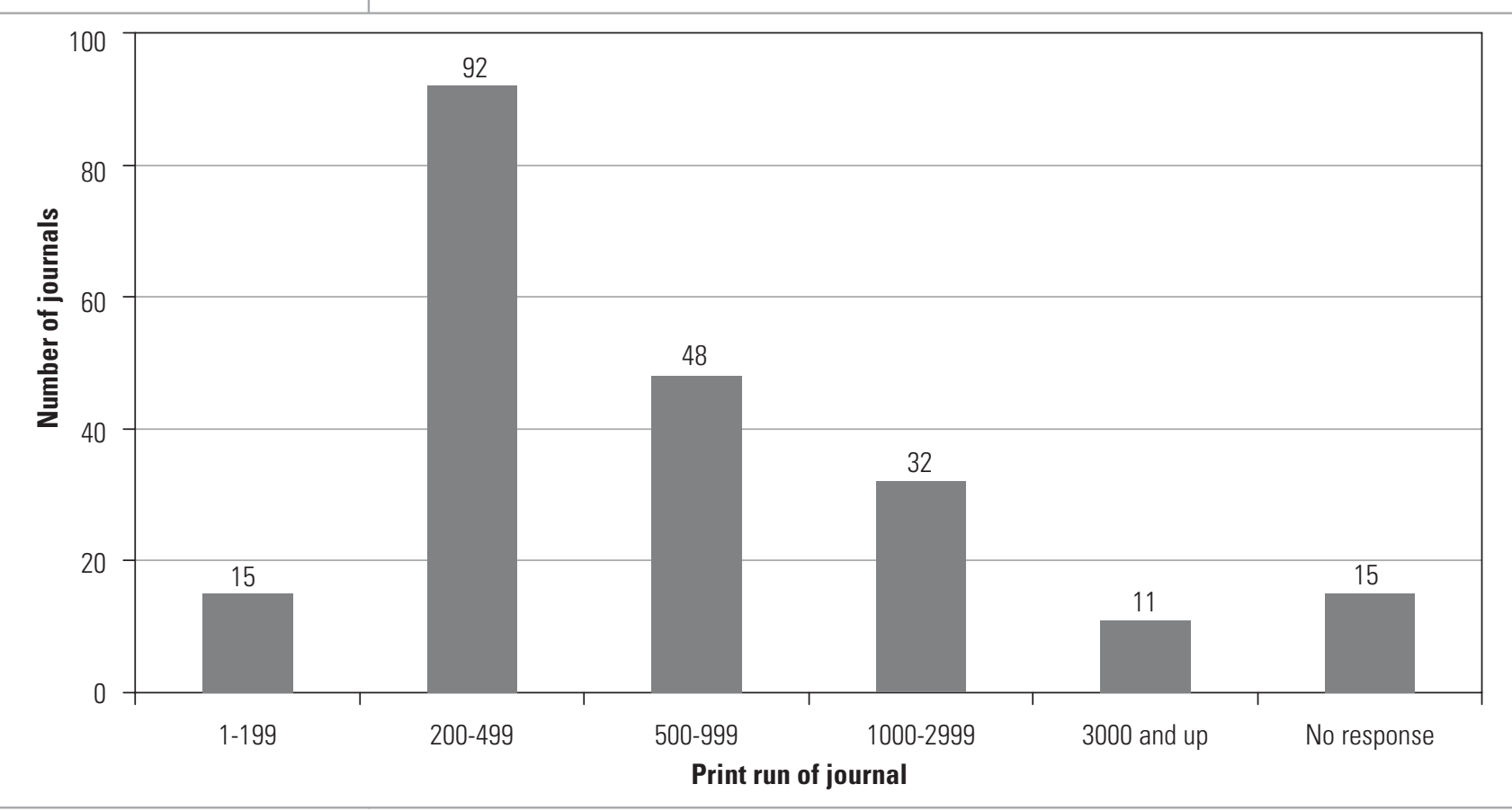


Table 17: The print run of the journal

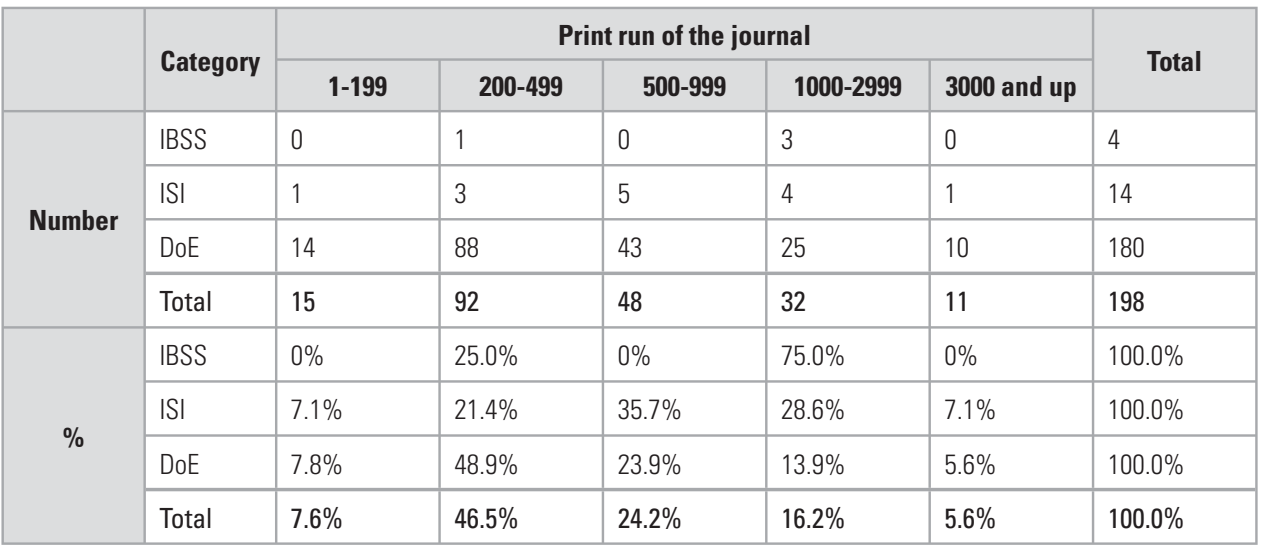

The print runs of journals are depicted in the histogram below and a further breakdown is presented in Table 17.

In the vast majority of cases, the print run was less than 1000; more than 50\% of DoElisted journals had a print run of less than 500. Fifteen of the journals had a print run of less than 200. The one journal that had a very wide distribution had a print run of 15 000. Low print runs reflect low subscription rates and high costs, as high print runs bring substantial economies of scale, including more effective advertising and therefore revenue from this source as well as from the subscriptions themselves. Bearing in mind that there are now only 21 higher education institutions, albeit several with multiple campuses, the numbers circulated to libraries and teaching departments appeared to be adequate, and the journals did appear to be adequately accessible within South Africa.

\section{VERIFICATION OF SOME DATA BY DIRECT INSPECTION OF JOURNALS}

The assumption was made in this survey-type study that the likelihood of incorrect answers, whether deliberate or accidental, was low, despite the possibly in-built "incentive" of editors wishing to portraying high functionality on behalf of their respective journals. The answers to some of the questions in the questionnaire could in fact be verified by consulting copies of journals available in the Pretoria-based National Library. This was done for 142 of the journals in the dataset, in respect of a number of selected objective parameters. These were the verification of some basic data by direct inspection of journals, such as:

Editor's profile;

- Research journal publication profile;

- broad fields of the SA journals accessible in the SA public national libraries (including electronic access);

presence or absence of an editorial board of the journal;

- frequency of publication of the journal;

adequate number of articles in a single issue of the journal; and

- percentage content of original, peer-reviewed articles as opposed to other kinds of features; In each case, there was excellent (less than 5\% difference) correspondence between the surveygenerated information and the observed data. It may therefore be assumed that the larger amount of information obtained from the editors in the mail survey was generally correct. Unfortunately, a number of editors chose not to answer some of the questions. The reason for this was not immediately clear, but in most cases it would appear that the question was perceived as somewhat ambiguous or unclear. In a few cases, the editor concerned might have found it inappropriate to provide a rating that in some way might reflect criticism or self-praise.

\section{EDITORS' GENERAL OPINIONS REGARDING CRITERIA FOR ACCREDITED JOURNALS.}

Editors' opinions were solicited regarding their preferred criteria for accrediting journals. For each criterion stated, they had to indicate whether (1) they agreed with the criterion, (2) whether they were neutral on the issue, or (3) whether they disagreed. The frequencies in each category 
Table 18: Editor's opinion regarding certain criteria for accrediting journals

\begin{tabular}{|c|c|c|c|c|c|}
\hline No. & Question/Criterion & $\begin{array}{c}1 \\
\text { Agree }\end{array}$ & $\stackrel{2}{2}$ & $\begin{array}{c}3 \\
\text { Disagree }\end{array}$ & $\begin{array}{l}\text { No } \\
\text { response }\end{array}$ \\
\hline a) & Journals that can guarantee financial viability after an initial period. & 45 & 30 & 23 & 2 \\
\hline b) & Journals that have a functional Editorial Board & 82 & 13 & 2 & 3 \\
\hline c) & $\begin{array}{l}\text { Journals that conform to the criterion of obligatory peer review performed as an effective mechanism } \\
\text { for improvement of articles, for detection of misconduct and flawed reasoning, including statistical } \\
\text { reasoning as well as reduplication or frequentation of research studies, and overall quality assurance. }\end{array}$ & 92 & 3 & 2 & 3 \\
\hline d) & $\begin{array}{l}\text { Journals that have a frequent publication such as at least quarterly (or } 4 \mathrm{X} \text { per annum) but preferably } \\
\text { at least } 6 \text { times per annum and regular, "on time" publication of a periodical. }\end{array}$ & 26 & 22 & 49 & 3 \\
\hline e) & $\begin{array}{l}\text { Journals that have an adequate number of articles in a single issue of a journal such as at least } 10 \text { or } \\
\text { more original, peer reviewed articles in each issue, plus other materials as desired. }\end{array}$ & 37 & 25 & 35 & 3 \\
\hline f) & $\begin{array}{l}\text { Journals that result from substantial amalgamation amongst currently competing South African } \\
\text { journals in overlapping field or disciplines or the criterion of disciplinary coherence protected or } \\
\text { promoted by the journal. }\end{array}$ & 15 & 47 & 35 & 3 \\
\hline g) & $\begin{array}{l}\text { Journals that have the sustainability of a journal from a mix of revenue streams including } \\
\text { subscriptions, page charges, subsidy and advertising. }\end{array}$ & 39 & 34 & 23 & 4 \\
\hline h) & $\begin{array}{l}\text { Journals that showcase the South African scientific enterprise or have the criterion of being a } \\
\text { "Proudly South African" product. }\end{array}$ & 60 & 24 & 13 & 3 \\
\hline i) & $\begin{array}{l}\text { Journals that have an appropriate primary purpose of a journal as being the dissemination of peer- } \\
\text { reviewed, original research. }\end{array}$ & 93 & 3 & 2 & 2 \\
\hline j) & $\begin{array}{l}\text { Journals that have an international standing of a journal or will attract the interest of national and/or } \\
\text { international scientific publishers. }\end{array}$ & 74 & 20 & 3 & 3 \\
\hline k) & Journals that have a wide circulation and distribution, including electronic access. & 48 & 35 & 15 & 2 \\
\hline 1) & Journals that have constant citation impact and measure related scientometric parameters. & 30 & 48 & 17 & 5 \\
\hline
\end{tabular}

are expressed as percentages in Table 18 in order to facilitate comparisons between questions. Responses were not substantially different for the journals from the three categories.

Editors were virtually unanimous in their support for the publication of appropriately peer-reviewed research in accredited journals (Questions c and i) as well as for the idea that such research should be effectively disseminated. Almost half disagreed with the 6 times-per-

Figure 17: Position regarding journals that result from substantial amalgamation annum publication criterion suggested in Question d. A large percentage had misgivings or reservations about the possibility of amalgamation with journals with a related focus (Question f). This is also depicted in Figure 17 below.

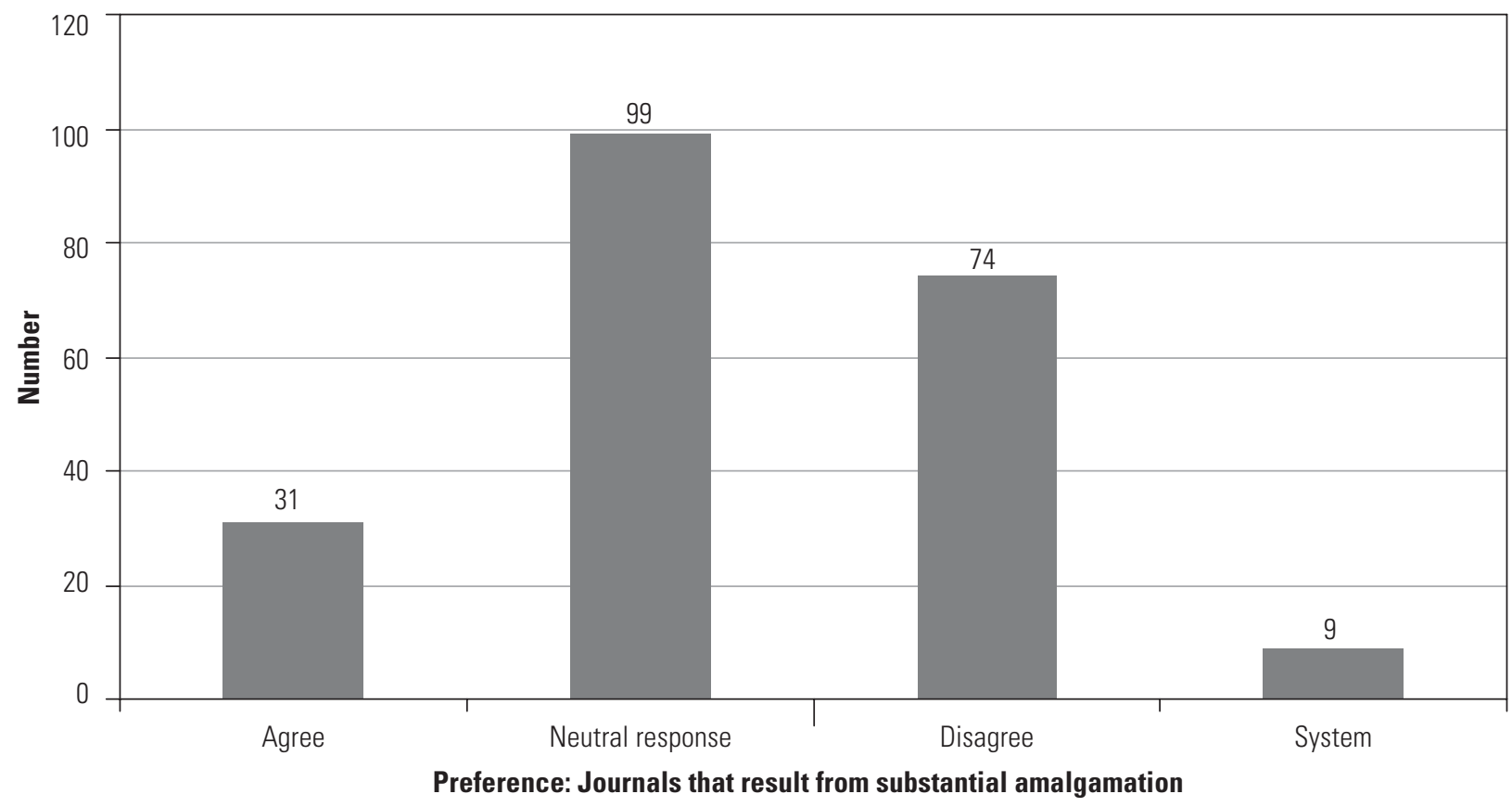


It is evident that the analysis, while confirming many of the conclusions already reached from other answers in the survey, reflected an expected bias in terms of the key issues of consolidation versus atomization of disciplinary areas, frequent and regular publication as against the prevailing phenomenon of infrequent copies with few articles, and a lack of support for scientometric assessment of impact and dissemination.

The question may well be asked how the survey would have worked out in respect of these parameters, if the community of publishing scholars were similarly surveyed, or the leadership of science councils and research administrators, in general. The results of the editors' survey indicate that there must, however, have been some underlying factors at work that made it worthwhile for so many good and well-qualified people to spend a great deal of time and effort on editing many journals, with little apparent impact on the fields of endeavour concerned.
The question may

well be asked how

the survey would

have worked out

in respect of these

parameters, if

the community of

publishing scholars

were similarly

surveyed, or the

leadership of science

councils and research

administrators,

in general 



\section{Global eResearch trends and their implications for South African research publishing in print and online}

Roy Page-Shipp ${ }^{1}$ and Monica Hammes ${ }^{2}$

\section{INTRODUCTION}

Science, or the building of shared objective knowledge about the world, is a collective human endeavour, and the advent of the connected cyberworld has emphasized this more forcefully than ever before. The system relies upon the free circulation of newly documented experimental facts and hypotheses driven by the specific nature of the general publishing system. Research papers, which are now widely available as electronic files, are intended at all times to display the workings of the five ethical principles ruling academic science, defined in Robert Merton's seminal works and recently described by John Ziman (2000) as CUDOS principles: C stands for communality, U for universality, D for disinterestedness, $\mathrm{O}$ for originality and $\mathrm{S}$ for skepticism Everybody should have access to the results of scientific research considered as a public good (C); nobody should be excluded from the process of contributing scientific papers for reasons of race, nationality, age or sex (U); nobody relies upon publishing to get rich (D), and everybody contributing to the scientific archive must have something new to say (O) (Spreading the Word 2004).

Transforming an individual discovery into codified knowledge, thus making it available to others, involves prior approval by the invisible colleges of fellow-scientists, at present through the mediation of a small but critical subset of the college, the 2-4 peer reviewers selected by an editor to function as proxies for the rest. Some recent adaptations of the review system entail the use of a much larger, in principle unlimited, set of reviewers (see below). The role of reviewers, viz to be sceptical (S) and critical, especially about the issue of novelty or originality $(\mathrm{O})$ before recommending any submitted paper for publication, is another duty of any scientist contributing otherwise actively as author to the scientific archive.

This chapter examines the impact of new trends in eResearch and globalised electronic scholarly communication on these core publishing principles, and hence on the progress of science.

\section{BACKGROUND TO ERESEARCH}

The production and dissemination of scholarly output has always been at the heart of the collective research process, but times and modes have changed in response to geographical and technical considerations.

However, it was not only the technical advance provided by the printing press in the late 15th century but the emergence of a reliable postal system and the development of the experimental method in the 16th century that led to the production of the first Scientific Journal in 1665 . Similarly, it may not be simply the technical ability to reproduce and distribute articles electronically (e-publishing), but also the emergence of highly collaborative, large-scale investigations and analyses (e-science) that is likely to lead to significant change in the field of scientific communication and significant changes in the way such communications are produced, curated and disseminated. (Lucier 1990)

1 roy@pageshipp.co.za

2 monica.hammes@up.ac.za; University of Pretoria Academic Information Service 
Broadband connectivity, highperformance grid computing, digital data capture and data mining have created opportunities for hitherto unimaginable global collaborative research projects often with an interdisciplinary, multidisciplinary or transdisciplinary nature

Figure 1: The Components of eResearch
The advent of affordable global connectivity via the Internet could in principle virtually recreate the original mode where communication between groups of scholars in small but intellectually lively regions was inter-personal and near-immediate (1650 to about 1900 AD). The current, century-old, branded print journal-dominated mode has been a response to specific conditions that existed prior to the Internet's recent emergence. Now innovative alternatives are emerging of which "Open Access" on the Internet is perhaps the most important one (see below), with restoration of the inter-personal and immediate mode of collegial communication and collaboration, this time on a global scale.

Broadband connectivity, high-performance grid computing, digital data capture and data mining have created opportunities for hitherto unimaginable global collaborative research projects often with an interdisciplinary, multi-disciplinary or trans-disciplinary nature. Researchers in all disciplines are increasingly able to undertake a variety of research-associated tasks online. These include access to each other's data, models, graphical objects, knowledge tools and applications and computing capacity. To support such communication it has become necessary to manage large databases, either for the sake of transfer to other researchers, or to extract and distribute relevant subsets. Such digital curation can enable better and more protracted use of expensively acquired datasets.

Taken together with changes in the formal publishing of research results, these activities will almost certainly lead to better collation, use and re-use of research results. Scholarly discourse via the World Wide Web (WWW) is thus part of the broad eResearch phenomenon.

\section{Components of eResearch}

eResearch is founded on three broad categories of activity illustrated in Fig 1, but it is obvious that some research activities overlap with activities in more than one category. The factors that integrate the components are the access medium, the digital character of the content and the common need for security - often described as the "3A's", Access, Authentication and Authorization, and the role of marketing and training in ensuring that the support services are user friendly and well-used. (Page-Shipp et al. 2005)

\begin{tabular}{|c|c|c|c|c|c|}
\hline \multicolumn{3}{|c|}{ eScience } & \multirow{2}{*}{$\begin{array}{c}\text { Digital } \\
\text { Curation \& } \\
\text { Preservation }\end{array}$} & \multicolumn{2}{|c|}{ Access to eContent } \\
\hline Data Transfer & $\begin{array}{c}\text { Tools \& } \\
\text { Applications }\end{array}$ & $\begin{array}{c}\text { Primary } \\
\text { Data Sharing }\end{array}$ & & $\begin{array}{l}\text { Commercial } \\
\text { Publishing }\end{array}$ & $\begin{array}{l}\text { Open Access } \\
\text { Publishing }\end{array}$ \\
\hline \multicolumn{6}{|c|}{ by definition this is } \\
\hline $\begin{array}{c}\text { Science employing } \\
\text { transfer and } \\
\text { sharing of large } \\
\text { volumes of data }\end{array}$ & $\begin{array}{l}\text { Software } \\
\text { that allows } \\
\text { manipulation, } \\
\text { modeling and } \\
\text { analysis of data }\end{array}$ & $\begin{array}{l}\text { Making research } \\
\text { data available to } \\
\text { other researchers }\end{array}$ & $\begin{array}{l}\text { Active management } \\
\text { of databases including } \\
\text { promotion of effective } \\
\text { and widespread use } \\
\text { of the datasets for } \\
\text { their scientific \& } \\
\text { scholarly useful life }\end{array}$ & $\begin{array}{l}\text { Contribution } \\
\text { to and use } \\
\text { of published } \\
\text { resources } \\
\text { requiring payment } \\
\text { by readers }\end{array}$ & $\begin{array}{l}\text { Contribution } \\
\text { to and use } \\
\text { of published } \\
\text { resources where } \\
\text { content is } \\
\text { regarded as 'free' }\end{array}$ \\
\hline \multicolumn{6}{|c|}{ which requires } \\
\hline \begin{tabular}{|} 
Access to remotely \\
held large \\
datasets and high \\
performance and \\
grid computing via \\
affordable high \\
bandwidth
\end{tabular} & $\begin{array}{l}\text { Access to models } \\
\text { and results as well } \\
\text { as source code. } \\
\text { Open standards }\end{array}$ & $\begin{array}{l}\text { Accessible } \\
\text { repositories with } \\
\text { easy discovery }\end{array}$ & $\begin{array}{l}\text { Repositories } \\
\text { supported by } \\
\text { access mechanisms } \\
\text { archival skills and } \\
\text { infrastructure }\end{array}$ & $\begin{array}{l}\text { Affordable } \\
\text { licenses for } \\
\text { researcher access } \\
\text { and discovery } \\
\text { mechanisms }\end{array}$ & $\begin{array}{c}\text { Serviceable } \\
\text { infrastructure for } \\
\text { publication and } \\
\text { access }\end{array}$ \\
\hline $\begin{array}{l}\text { Researcher Requ } \\
\text { Supplier must ens }\end{array}$ & $\begin{array}{l}\text { erpetual access, } \\
\text { Security - Access, }\end{array}$ & $\begin{array}{l}\text { n, Training, Mar } \\
\text { rization, Authen }\end{array}$ & & & \\
\hline
\end{tabular}


In broad terms, the components of eResearch are as follows:

The ability to transfer large volumes of data and to share computational capacity between remotely situated researchers is the basis of eScience, 'faster, different, better research'. (Prof Tony Hey, Core Programme Director for UK eScience, pers comm. 22 June 2004). Two good international examples of this are the Human Genome Project and the International Virtual Observatory Alliance (http://www.ivoa.net/), but it also includes regional initiatives such as the creation, across 40 UK Oncology Departments, of a networked archive of annotated mammograms (32Mb each) that can be searched for image matching etc by any oncologist in the system (http://www.ucl.ac.uk/research-computing/research/e-diamond.html). Making primary research data available to other researchers is part of this eScience paradigm, but its preservation and management fall more appropriately within the eResearch component of Digital Curation (see below).

The need to make better use of expensively created databases by "the active management and appraisal of data over the life cycle of scholarly and scientific interest" is the basis of a new field of endeavour called digital curation. (P. Burnhill, Acting Director, Digital Curation Centre, Edinburgh, UK, pers comm, 25 June 2004). Concern is regularly expressed that too many valuable data, often collected at great expense, are lost or rendered inaccessible for lack of such a standard approach and supporting infrastructure. It is of particular importance that, where the data are potentially useful to a wider user group, such permanence should be independent of the life of the project or any other activity that generated it. A good example of a digital curation service is the University of Manchester's MIMAS that not only holds the output of the UK Population Census, but actively promotes the use of extracts from the database - with due protection of individual privacy (www.mimas.ac.uk).

Formal (published) scholarly discourse now takes place on the dual playing field of the well-established but crisis-ridden terrain of commercial publication and the emerging Open Access system, which is the major topic in this Chapter.

\section{eResearch implications for research journals in the future}

- The world of eResearch places new emphasis on increasing speed and scope of communications, with researchers being able to share their findings in near-real time with their colleagues located almost anywhere.

- Similarly, research data, including graphical objects, can be promptly and extensively shared via rapid data transfer networks, as can models and other computer-supported aids.

- This generates a need for capture, quality control, archiving and linking of the research findings as well as the data and models that support them, for their 'scholarly useful life' ie beyond the needs of the immediate project or programme. Data mining and data visualization pose new challenges.

- Open Access has established a role for itself, although still considered to be untested in terms of sustainability, and active participation on a national scale should be carefully considered.

- The ongoing need for the maintenance of quality standards via editorial discretion and peer-review is universally recognised although new modes should be investigated for their applicability and utility.

- All the above apply to South African researchers wishing to achieve or maintain status as participants in the global research discourse. However, current infrastructural support ranges from the second-rate (in global terms) to the non-existent.

\section{THE INTERNET AND RESULTING NEW DYNAMICS IN SCHOLARLY DISCOURSE}

\section{The internet as change agent}

Over the past two decades, the infrastructure provided by the Internet and the applications making up the World Wide Web have provided the means for researchers to make their research results available to almost anyone, anywhere, at any time. The established communication mode of one-to-(privileged) few, is likely to be replaced (or at least significantly augmented) in the near future by one-to-one in real time and one-to-many fairly expeditiously. This applies
Over the past

two decades, the infrastructure provided by the Internet and the applications making up the World Wide Web have provided the means for researchers to make their research results available to almost anyone, anywhere, at any time 
Because libraries' contribution to scholarship has rarely been properly integrated in a holistic model of the scholarship process, researchers have for a long time been largely shielded from the dilemma of journal cost-inflation

These developments have highlighted aspects of scholarly discourse and publishing that must be reviewed and reformed if researchers are to continue to benefit from the core functions of the published literature in the eResearch era to 'journal' articles as well as to other types of research output such as conference papers, theses or research reports. In addition to these 'traditional', results-orientated items, it also applies to datasets, simulations, software, multimedia and dynamic knowledge representations collected and created in the course of the research. In many respects, this returns the research enterprise to something like its original condition, when the numbers of researchers was small and they were mostly in direct communication with each other (ie one-to-one). In a similar vein, collaborating researchers who have access to each other's data and models have little need for research papers as information sources. (Houghton 2005).

The slow pace of progress frustrates pioneers in this revived mode of rapid and liberal communication, however; the current model is little more than an electronic version of the paper world: fundamental change has yet to come. Processes and practices established over the past century are threatened by this new modality - either because of a natural conservative reluctance to change, or because significant role-players have too much to lose if the status quo is disrupted.

Some of these difficulties can be ascribed to the fact that the different functions of formal scholarly communication are not responding evenly to the potential for renewal that the Internet is offering. Roosendaal and Geurts described these functions as

- Registration, which allows claims of precedence for a scholarly finding.

- Certification, which establishes the validity of a registered scholarly claim.

- Awareness, which allows actors in the scholarly system to remain aware of new claims and findings, and also signals their availability for collaborative projects in the modern era (Authors' addition)

- Archiving, which preserves the scholarly record over time.

- Rewarding, which rewards actors for their performance in the communication system based on metrics derived from that system. (Roosendaal \& Geurts 1997).

The first four of these functions are still performed in a more or less linear fashion by the publishers of research journals in spite of the fact that registration could in principle be better served by early sharing and debating of results with colleagues, which will lead to a shorter research cycle. Certification in the form of peer review could be returned to the scientific communities who "own" the research. Dependence on the publishers to create awareness and to archive the scholarly output has been disrupted by the growing Open Access phenomenon.

The growing dissatisfaction with the current system's speed, restrictions on use and lack of flexibility could be overcome if these core functions are unbundled and performed by more role players in novel ways, options that will be further explored in this Chapter. During this same period, a crisis has developed around the affordability of journals and the consequent exclusion of many researchers through diminished access to the best information, severely affecting their ability to keep abreast of their fields (Bosc \& Harnad 2004). Because libraries' contribution to scholarship has rarely been properly integrated in a holistic model of the scholarship process, researchers have for a long time been largely shielded from the dilemma of journal cost-inflation. More recently, they have realised with "shock and awe" that access to the papers which they handed over to commercial publishers was consuming the budgets of their institutions' libraries. From 1986 to 2004 the total spend of the Association of Research Libraries on serials increased by $263 \%$ with the mean cost per serial increasing by $188 \%$. (ARL Statistics 2003-2004). (See also Fig 2). In South Africa, this situation was frequently seriously exacerbated by exchange rate fluctuations.

These developments have highlighted aspects of scholarly discourse and publishing that must be reviewed and reformed if researchers are to continue to benefit from the core functions of the published literature in the eResearch era. Research publishing analysts argue that the process of scholarly publishing is uncoordinated with the emerging eResearch paradigm (Rzepa \& Murray-Rust 2004, Warner 2005). According to Djorgovski (2004), the journal article is "obsolete". Van de Sompel et al. (2004) point out that "scholars deserve an innately digital scholarly communication system that is able to capture the digital scholarly record, make it accessible, and preserve it over time" and propose a total overhaul of the process based on their belief that the" future scholarly communication system should closely resemble —and be intertwined with-the scholarly endeavor itself, rather than being its after-thought or annex." A participant in the National Academies' 2004 symposium on electronic publishing describes 
it as a "subtle shift from our concept of publication as product to the notion of publication as process" (National Academies 2004)

\section{The message and the medium}

More than ever 'content consumers' are 'format agnostic'... whatever container - such as a book, journal, blog or web page the content comes from. (OCLC 2004)

For a variety of reasons, textual description of research results in the open domain is not a complete way to transfer new knowledge to all comers. It clearly suits the traditional journal publishing mode and has been, and is, a powerful tool for increasing human knowledge in an open way. Most authors' and readers' concept of a unit of scholarly communication and its use is accordingly still equal to a learned paper, fundamentally rooted in the concept of the medium being all that matters, as distinct from the message.

The Internet has expanded the possibilities for research communication dramatically; it is now possible to choose the best medium for a specific message. To record and transfer scholarship fully and effectively we must extend our notion of the unit of communication from a text-based journal article to include other formats and media. Bundling rich media (e.g. a video) as an add-on to a publication is clearly not adequate. What may be needed is a more flexible approach that permits the composition of complex documents consisting of different data streams that aggregate and extend other complex documents (Warner 2005). This would complement one of the features of modern research practice, namely the sharing of massive research datasets - not necessarily in the form of numbers and words. It should also make provision for other transmission modes, eg webcasting, virtual networking and blogging.

\section{Peer review - time to revise the process in the light of technological change?}

The search for truth through research depends on the willingness and ability of researchers to expose their new discoveries to peer scrutiny for validity and to participate objectively in the scrutiny of the work of others. In principle, this quality assurance process has stood the test of time as essentially (when working well) the best and most robust system there is of ensuring that the fundamental principles of formal research publishing ("CUDOS, see above) are observed. Participation in the process, though time-consuming, is also an invaluable means of acquiring and maintaining an objective critical faculty.

The mere possibility of out-of-control proliferation of unreliable material via the Web cautions us against abandoning time-tested peer-review principles. Current practices do justifiably attract a number of criticisms (Peek 2003), and the following are a few of those cited in an extensive literature on the subject:

- Should the management of peer review be left with the publishing company's appointed editors? For example, the peer review process could in principle be carried out more effectively, and probably more objectively, by uncoupling it from editing/publishing as part of an unbundling of the scholarly process in which the scientific community takes responsibility for the peer-review process (Van de Sompel et al. 2004). Moreover, should the entire community not be invited to solicit comments as part of the process?

- Are the peer reviewers evaluated and properly credited and awarded for their work?

- Time delays - the review process, through its very nature as volunteer add-on work, is time-consuming and this, compounded by the queuing process for a journal of limited size, may mean that work appears in print months or even years after the project concerned was completed.

- Anonymity - Reviewers of papers usually assert the right to provide their comments anonymously, an aspect of the process which, while apparently necessary for productivity in the volunteer system, is in conflict with the emerging global ethos of transparency and accountability. An advantage of online publishing is that it lends itself to on-going, attributed comment, whether in open or commercial access mode, leading to a healthy dialogue among relevant participants. (Of course, some reviewers might feel constrained in expressing their views by the possibility that an author who has been criticised may be able to influence future

\section{The Internet}

has expanded

the possibilities

for research

communication

dramatically; it is now

possible to choose

the best medium for

a specific message

The search for truth

through research

depends on the

willingness and

ability of researchers

to expose their new

discoveries to peer

scrutiny for validity

and to participate

objectively in the

scrutiny of the

work of others 
Major publishers are starting to think of the online version of their journals as the principal copy and regard print copies as a necessary inconvenience to be endured for another few years research funding decisions!) The BMJ is an example of a prominent journal that has moved to open peer review. This model is exploited in a number of new interactive scientific journals such as Biogeosciences (http://www.copernicus.org/EGU/bg/publication_process.html)

- Bias - Many top researchers who have worked in both developed and developing countries have testified that their work has consistently had poorer access to publication in highimpact journals if submitted from addresses in their native 'developing' country than from one closer to the mainstream of science - regardless of the merits of the papers in question. A study by Peters and Ceci (1982) indicates that authors affiliated to the more prestigious research institutions find readier acceptance of their manuscripts and that the nationality and sex of authors, as well as their research field, have a marked influence on reviewer judgments. Social scientists in South Africa (T. Marcus, Exec Director NRF, personal communication, 2004) find that some key research issues of high relevance in SA are not favoured by global journals.

It has previously been argued in this report that peer review combined with expert editorial discretion is fundamental to the mechanism of the entire knowledge production and growth enterprise. The above critical questions are not catastrophic to this position; they merely raise the issue as to whether the coming cyber-enriched system of research publishing can provide improvements and refinements that make peer review and editorial discretion more effective and less open to critical questions like those cited above.

\section{Publishing in the online environment}

Twenty-first century researchers will likely expect to find their journals online and many young people already subscribe to the idea that if it's not on the internet, it might just as well not exist. In 2002 Odlyzco noted that "readers will settle for inferior forms of papers if those are the ones that can be reached easily", a trend that has become even more pronounced in the Google era where search engines are becoming the de facto interface to information. Libraries all over the world are taking the e-only route. Readers still make printouts of articles but many have become used to reading on screen, highlighting important passages, making notes and forwarding articles to colleagues, all in the same environment. There is broad agreement that online journals are superior to print versions in terms of international reach, speed of publication, additional capabilities, reduced costs, convenience, searchability, linking and archiving (Morris 2002)

Major publishers are starting to think of the online version of their journals as the principal copy and regard print copies as a necessary inconvenience to be endured for another few years. They have made huge infrastructure investments and are in the process of digitizing all their back copies. Learned society publishers have had to follow suit. Open-source publishing software has made it possible for everybody to be a publisher, leading to a flourish of new journals. However, many of these "new" publishers underestimate the publishing process and confuse the technical ability to produce an online journal with the range of skills and resources needed to produce a quality journal on the Web.

Table 1: Components of Journal Publishing and Online Implications

\begin{tabular}{|l|l|}
\hline \multicolumn{1}{|c|}{ Component of Journal Publishing } & \multicolumn{1}{c|}{ Online Implications } \\
\hline $\begin{array}{l}\text { Copy Management and Communication } \\
\text { with Authors }\end{array}$ & $\begin{array}{l}\text { Software available for submission and to manage articles as they move } \\
\text { through the process }\end{array}$ \\
\hline Peer Review & $\begin{array}{l}\text { As important as ever: online communication can speed up the process and } \\
\text { save costs but the principal task is still time-consuming }\end{array}$ \\
\hline Revision and Copy-editing & Online tools available but still needs expensive human inputs \\
\hline Processing of Graphics and Colour Images & Many new possibilities posing new challenges and new costs \\
\hline Rights Management & Online tools available but still time-consuming \\
\hline File Production, Conversion and Tagging & MSWord, PDF, HTML, XML needed depending on the model \\
\hline Linking & Additional, very important feature \\
\hline $\begin{array}{l}\text { Additional Content Management: Data, } \\
\text { Multimedia etc. }\end{array}$ & New possibilities with many challenges, particularly regarding archiving \\
\hline Metadata Creation & Essential for online publication \\
\hline
\end{tabular}




\begin{tabular}{|l|l|}
\hline \multicolumn{1}{|c|}{ Component of Journal Publishing } & \multicolumn{1}{c|}{ Online Implications } \\
\hline Layout & Important for web site, article and journal \\
\hline Online Hosting & Requires additional infrastructure and human resources \\
\hline Archiving & Requires additional infrastructure and ongoing commitment \\
\hline Marketing and Promotion & $\begin{array}{l}\text { As important as ever: ensuring visibility via search engines and secondary } \\
\text { publishing is very important }\end{array}$ \\
\hline Sales & Software available to simplify the process; new skills needed \\
\hline Subscription Management & Software available to simplify the process \\
\hline Customer Service & All communication media need to be employed; new skills needed \\
\hline
\end{tabular}

The following table lists the different components of journal publishing with notes regarding some of the online implications:

It should be obvious by now that online publishing is not simpler than print, and in fact new skills are needed to perform it well enough to create the environments that users are coming to expect. One of the main advantages of online publications, visibility, may also be the downfall of unprofessional publishers: every mistake will be visible for the whole world to see.

\section{Costs of online publishing in context}

There are two major cost issues that must be raised in this connection, viz

- the cost of getting published

- the cost of access to published work (licences/subscriptions).

\section{PUBLISHING COSTS}

Publishing costs in the online environment tend to be underestimated. High first-copy costs remain the same, largely due to the logistics of peer review and the overall editing function. Enhanced possibilities for graphics incur new costs. Saving on printing, packaging and distribution, which contribute significantly to the cost of paper journals, is offset by the necessary [ongoing] investment in information technology infrastructure as well as the need for well-trained technical staff that is more expensive than those required for conventional copyediting and the like. Tenopir and King (2000) have found that overall savings of online publishing are only approximately $4 \%$ for a journal with a circulation of 500 copies; costs are increased about $20 \%$ by parallel print and electronic publishing. Customer support, sales, metadata creation and subject classification are other aspects of online publication requiring additional costly expertise necessary for success. The debate about the archiving of electronic journals and who should be responsible is still wide open but there is consensus that it will be an expensive ongoing process.

\section{ACCESS COSTS}

An extraordinary feature of print research is that the researchers provide the output of their work (including copyright) to publishers at no cost, participate in the review process without payment, and pay - usually via an institutional library, for the right to read about it! Alma Swan, well-known consultant to the publishing industry, aptly describes this illogical situation in an interview as

An imperfect market. An analysis of the exchange of value in the process is instructive. The users of the items purchased, ie journals, are not the purchasers, so the people (usually librarians) who have to make the purchasing decisions are constantly trying to match these decisions with the interests of the ultimate users, which is not an easy task. Ironically the ultimate consumers (researchers) are also the raw material suppliers, and they are extremely unusual in any capitalist market situation in that they happily supply their raw material for free, and almost as happily pay to have it back again to use later. Finally, the same raw material suppliers/consumers also carry out one of the stages of production (peer review). Add to these ingredients the fact that it is a global enterprise, so there is little room for tailoring to local economic conditions, and you have all the ingredients of a mess (Swan 2005).

\section{Publishing costs}

in the online

environment tend to

be underestimated

\section{An extraordinary}

feature of print

research is that

the researchers

provide the output

of their work

(including copyright)

to publishers at no

cost, participate in

the review process

without payment,

and pay - usually

via an institutional

library, for the right

to read about it 
These licenses tend to take over the bulk of library budgets, leaving little money for other journals, such as those from smaller publishers such as scholarly societies, and for books

Figure 2: Monograph and Serial Expenditure 1986-2004
To this should be added that restrictive licensing implies multiple payments: universities and research institutions pay for subscriptions, and additionally for copyright and other permissions to use the articles they need.

\section{THE SERIALS CRISIS}

Libraries' inability to accommodate the runaway costs of journal subscriptions and the pricing models of big commercial publishers are symptomatic of the progressively more problematic scholarly communications process in terms of unsustainable economics; it is generally known as the 'serials crisis'. Association of Research Libraries (ARL) statistics for 1986-2004 reveal that the average price per subscription rose by $185 \%$ during this period compared to the $68 \%$ rise in the US Consumer Price Index for the same period. The average number of subscriptions rose by only $14 \%$.

Particularly, publishing of science, engineering and medicine journals is a very profitable business; in 2003 this market was valued at \$US8.5 billion, and its profitability is fuelled by a lack of competition. The so-called "Big Deal" subscriptions, which bundle a number of offerings under one single user-friendly interface and which tend to make economic sense if you have the means to pay the licence, represent an additional strategy to create an enticing usability comfort zone which makes it unnecessary to search for free articles on the web. It is, however, necessary to understand that the "Big Deals" effectively serve the interests of the publishers by preserving their revenue streams, targeting the market share of other publishers and taking over the valueadded services of downstream secondary and tertiary publishers. Some library consortia have complained that they have been inveigled into taking on more than they wanted or needed as part of "Big Deals". Furthermore, these licenses tend to take over the bulk of library budgets, leaving little money for other journals, such as those from smaller publishers such as scholarly societies, and for books. This feeds an unhealthy cycle where important publishers are pushed to the sidelines, often becoming the victims of unnecessary takeovers.

In a 2001 study by Bergstrom \& Bergstrom, it was found that, for papers in Economics and Ecology, there was a marked difference in 'cost-benefit' of commercial and non-profit journals: eg the average institutional subscription price per page charged by the former was about 5 times that of the latter, whereas the average price per citation, was about 15 times higher. Similar patterns were detected for Mathematics, Neurobiology, Physics and Atmospheric sciences.

A healthy and widespread debate over these issues has brought new stakeholders to the table: university administrators, research funders, governments, and international bodies, who have become aware of publishers' profiteering from public money spent on research, and have begun to throw their weight behind the Open Access movement. The position taken by the Wellcome Trust, one of the first funding bodies to revise its policies, is described by Robert Terry, Senior Policy Advisor, as "Only to fund research and give no thought to its dissemination is a job left unfinished. That is why the organisations which fund research have a vested interest in ensuring that the most

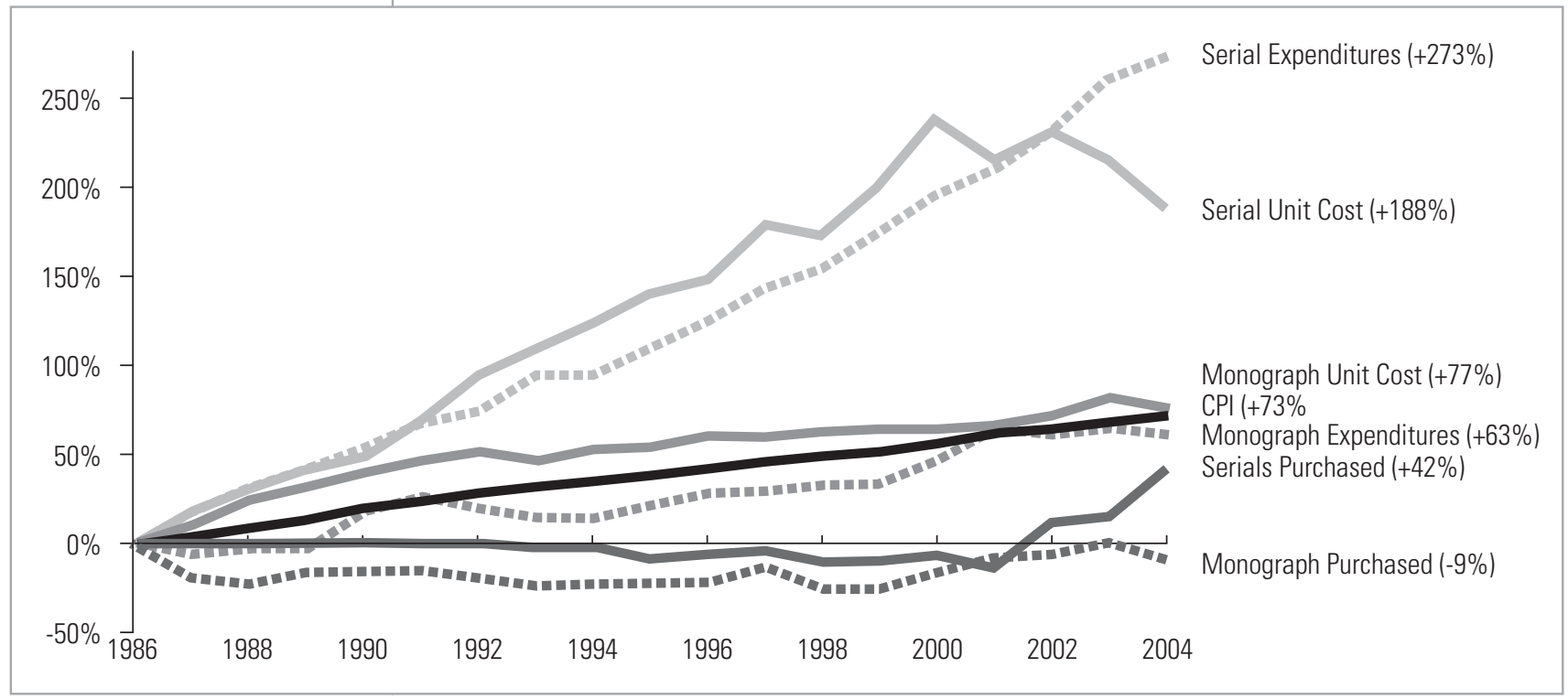


efficient and effective method is used to disseminate that research and should contribute funding to that dissemination." (Terry 2004).

Subscription costs have been combated by energetic negotiation by regional and national consortia, with the SA Site Licensing Initiative (SASLI), operating under the aegis of the Coalition of SA Library Consortia (COSALC) having achieved some success, although it has been argued (Page-Shipp et al. 2005) that better institutional support would improve effectiveness. National subscriptions that allow any registered researcher access to a core set of publications, as is practiced in Scandinavia, should also be contemplated for South Africa, particularly in view of the wide disparity in library funding across the research system.

\section{Implications for the publishing of research journals in South Africa in future}

- Scholarly discourse already effectively takes place via a combination of print and digital publication.

- ePublication is set to become the dominant model for research publishing, and there are signs that within the next five years all journals of consequence will be on the WWW, albeit with print versions for those who cannot yet make use of the new connectivity.

- The cost of e-publishing and particularly emerging costs should be understood: local participants will have to compete with international companies who have the financial means to invest heavily and who will take over successful South African journals as part of their growth strategies.

- The importance of quality maintenance via peer review by active researchers and of editorial discernment remains absolute, despite the opportunity and the need for improved practice. Online publishing, including OA, present additional peer review options such as phasing out of anonymous review; opportunities for open, voluntary peer review in the whole system; and interactive debate and ensuing reform concerning reviewing issues.

- The role of peer review as a developmental skill for researchers must never be underestimated, nor must it be forgotten that peer review and editing are costly activities.

- The library serials crisis is a real crisis, especially for the developing world, and it is a driver for the Open Access movement.

\section{OPEN ACCESS (OA)}

The term Open Access encompasses a specific online publication business model as well as a range of channels for making research literature available to everybody at no cost. It is based on the philosophy that the research literature, which is not written for profit but for the advancement of science and which is largely funded by public money, is a public good and should be accessible to everyone who has a need for the information. Open Access is described in detail in the box. Strictly speaking, only open access journals qualify as "publishing". Archiving on homepages and in repositories is a form of dissemination or secondary publishing.

What Open Access is: The Open Access research literature is composed of free, online copies of peer-reviewed journal articles and conference papers as well as technical reports, theses and working papers. In most cases there are no licensing restrictions on their use by readers. They can therefore be used freely for research, teaching and other purposes.

What Open Access is not: It is not self-publishing, nor a way to bypass peer-review and publication, nor a kind of second-class, cut-price publishing route. It is simply a means to make research results freely available online to the whole research community.

How is Open Access provided? A researcher can place a copy of each article in an Open Access archive or repository (known as the green route), or can publish articles in Open Access journals (known as the gold route). In addition, a researcher may place a copy of each article on a personal or departmental website. Whilst all three routes to Open Access ensure that far more users can access such articles than if they were hidden away in subscription-based journals, the first two constitute much more systematic and organised approaches than the third and maximise the chance of other researchers locating and reading articles.
The term Open

Access encompasses

a specific online

publication business

model as well as a

range of channels

for making research

literature available to

everybody at no cost.

It is based on the

philosophy that the

research literature,

which is not written

for profit but for the

advancement of

science and which

is largely funded

by public money, is

a public good and

should be accessible

to everyone who

has a need for

the information 
Open Access archives or repositories are digital collections of research articles that have been placed there by their authors. In the case of journal articles this may be done either before (preprints) or after publication (postprints, depending on the terms of the publisher (see SHERPA http://wwwsherpa.ac.uk.)). This is known as 'self-archiving'. These repositories expose the metadata of each article (the title, authors, and other bibliographic details) in a format compliant with the Open Archives Initiative Protocol for Metadata Harvesting (OAIPMH). To access the contents of these archives, you can use Google or one of the specialised search engines for a more focused and efficient search.

(JISC 2005)

John Willinsky of the Public Knowledge Process at the University of British Columbia describes different OA business models as the 'nine flavours' (Willinsky 2003).

Table 2: The Nine Flavours of Open Access Business Models (Willinsky 2003).

\begin{tabular}{|l|l|l|}
\hline \multicolumn{1}{|c|}{ Types of OA } & \multicolumn{1}{|c|}{ Description } & \multicolumn{1}{c|}{ Journal Example } \\
\hline ePrint Archive & Authors archive preprints and or postprints in OA archive & arXiv.org, ePrint Service \\
\hline Unqualified & Immediate \& full OA publication of journal & First Monday \\
\hline Dual Mode & Both Subscription-print \& OA journal editions offered & J of Postgraduate Medicine \\
\hline Delayed OA & OA edition available some months after initial publication & New England J of Medicine \\
\hline Author Fee & Authors pay fee to support OA publication & BioMed Central \\
\hline Partial OA & Some articles in issue are OA & New York Review of Books \\
\hline Per Capita & PA made available to country based on per capita income & HINARI (WHO) \\
\hline Abstract & OA to journal table of contents \& abstracts & Science Direct \\
\hline Co-op & Institutional members support OA journals & German Academic Publishers \\
\hline
\end{tabular}

\section{Open Access journals}

Many Open Access journals are now in existence, with numbers growing daily. On 16 Sept 2005 there were 1763 journals listed in the Directory of Open Access Journals (http://www.doaj. org/), of which 439 were searchable at article level. They included 77757 articles. Other OA Journals are listed under free full-text journals on the Japan Science and Technology Information Aggregator, Electronic (J-STAGE) site at Meiji University Library (http://www.lib.meiji.ac.jp/ olj/list/12000.html), and the Scientific Electronic Library Online (SciELO) project created by the FAPESP, BIREME and CNPq agencies in Brazil (http://www.scielo.br/).

One of the first major OA publishing efforts that set out to challenge the big commercial publishers was the Public Library of Science (PLoS) (http://www.plos.org). The business model of PLoS and Biomed Central (BMC) provides for publishing cost to be carried by the author, or his/her institution]. This model, although logical and elegant, does not go uncriticised: it can be unsustainable for institutions who wish to publish many articles in these journals, while giving a 'free ride' to everybody else including commercial companies.

A recent study sponsored by the Association of Learned and Professional Society Publishers, the American Association for the Advancement of Science and the Highwire Press in which 248 OA journals were compared with 375 subscription journals (ALPSP 2005), revealed an industry in its infancy with the following features:

- The majority of OA journals were younger than ten years.

- Content was made up of original research articles with far less additional material such as reviews, editorials, perspectives [but note: these are all citable].

- Peer review was the norm, but often done in-house.

- They received ten times fewer article submissions and had higher acceptance rates, but also fewer articles per issue.

- $74 \%$ had never published in print. 
- Articles were published online as soon as they were approved for publication by peer reviewers and editors (84\%).

- $80 \%$ did their own Internet hosting.

- $40 \%$ used a wide range of discovery services to enhance visibility.

- Author fees were actually not the norm: the business models mostly relied on grants, free labour and classified advertising.

- Copyright was left with the authors (86\%) and readers had generous re-use options as long as authorship was acknowledged.

\section{Open Access archives (OAA) and repositories}

The practice of self-archiving on personal or departmental websites has been widespread since the start of the WWW. The pioneering subject specific repository was Paul Ginsparg's very successful physics archive, arXiv (http://arxiv.org/), which started in 1999; this was created as a response to researchers' need to share information at an early stage of their investigations. Subject specific repositories are generally known as archives. The availability of Open Source software such as Eprints (http://www.eprints.org), made available by the University of Southampton, and DSpace by MIT (http://www.dspace.org), combined with extensive user support, led to a flurry of institutional repositories. These can be set up quite cheaply to archive copies of published peer-reviewed articles as well as electronic theses, conference proceedings, research reports and other local knowledge products. Besides the many institutional repositories, there are now a number of national/regional projects such as the Netherlands DARE (Digital Academic Repositories) (http://www.surf.nl/en/themas/ index2.php?oid=7).

All OAA may be configured to be globally interoperable through the use of the OAI Protocol for Metadata Harvesting (OAIPMH) that has been internationally defined by the Open Archive Initiative (http://www.oai.org). OA repositories are listed on web sites such as the Registry of Institutional Open Access Repositories (http://archives. eprints.org/eprints. php?action=browse) where 434 OAI-compliant archives were listed in Jun 2005, and OpenDOAR (http://www.opedoar.org). All are searchable by specialist search engines such as AOIster as well as the general search engines such as Google. Currently Google's ranking algorithm favours the OA copy.

Publishers have grown used to OAA and the majority allow self-archiving with various restrictions, including strict control of the time of publication in relation to their process. Currently over $90 \%$ of publishers consent to publication in an organisational repository, once a paper has been accepted for publication in their journal, although some demand embargo periods of varying duration. The SHERPA and Project Romeo web sites give full information on publishers' policies (http://www.sherpa.ac.uk, http://romeo.eprints. org/stats.php). Many publishers, acknowledging the sentiments and researcher needs underlying the OA movement, now allow limited OA in their journals in the form of

- providing open access to certain articles of high public interest;

granting open access to older volumes (delayed OA);

- giving authors the option to pay up front if they want to provide open access to their own articles (open choice).Springer Open Choice ${ }^{\mathrm{TM}}$ is a good example of such a programme (http://www.springer.com/sgw/cda/frontpage/0,11855,1-40359-0-0-0,00.html).

The success of Open Access is dependent on harvesting (described in the next paragraph) as well as the willingness of researchers to contribute as a matter of course. This, however, does not seem to be the case at the moment. In a 2004 study by Harnad and Brody it was clearly demonstrated that institutional repositories without any mandate tend to stagnate, whereas a clear mandate from the organisation makes it the logical conclusion to the entire research process. Pressure to mandate OAA is mounting, with funders, universities, and governments taking a hand; this issue will be explored in more detail below.

\section{Harvesting: essential for success}

The need for systematic harvesting of open access content is described by Suleman as follows Open access has changed only the method of access - not the method of scientific discovery. In order to discover research-related documents, one needs to have access to a (ideally
Publishers have grown used to OAA and the majority allow self-archiving with various restrictions, including strict control of the time of publication in relation to their process 
universal) collection of human or discipline-specific knowledge (a subset of which is found in any reasonably well-stocked library), and mechanisms to scan or search through the information (via card catalogues in libraries or search engines online). A great deal of recent research in digital libraries has revolved around the question of how to build universal or union catalogues.

In 2001, the Open Archives Initiative (OAI) developed a sophisticated, yet deceptively simple, Web-based protocol to share metadata and this has achieved wide acceptance internationally. The OAI Protocol for Metadata Harvesting (PMH) allows an institution (known as a data provider) to maintain its own collection of documents using any software technology, but share its metadata with others in any XML-based standard metadata format, with incremental transfers to minimize bandwidth use. The OAI-PMH is the core interoperability technology used within the international Electronic Thesis and Dissertation (ETD) and Institutional Repository (IR) communities. (Dr Hussein Suleman, Senior Lecturer, Dept of Computing Science, University of Cape Town, e-mail correspondence, 4 October 2005)

Metadata which are exposed in this fashion can be harvested into a combined data store, and value-adding services such as searching with one query language, ranking, browsing, and linking of content can be built on top of this by service providers such as OAISTER (http://oaister.umdl.umich.edu/o/oaister/). Citebase (http://citebase.eprints.org) is another promising product built on harvested metadata. It is a discovery service and citation index for OA which will appeal to readers who regard the search engines as the natural interface to information (Brody et al. 2003; Hitchcock 2003).

\section{The cost of Open Access archives}

Information about the cost of OAA is scarce. Setting up a modest archive is not expensive and depends on the availability of hardware and human resources; the software to do so is available as open source. It is, however, not without costs and sustaining an archive should not be underestimated. Provision should be made for a server, storage capacity and adequate bandwidth. The need for information technology expertise will be high at the outset to set up the archive and to customize it to suit the needs of the organization, but should drop in the maintenance phase. Document conversion and submission can be the responsibility of the authors or of the library. Provision must also be made for long-term preservation.

Both development and operating budgets will be largely determined by the practices and intentions of the organization. Resource-intensive activities associated with archives which should not be overlooked, are

development of policy and guidelines;

- development of tutorials and training;

- interaction with authors and publishers regarding permission; and

marketing and lobbying.

A cost saving that is regularly overlooked in the OA debate is that of copyright fees. Articles deposited in institutional repositories or published in OA journals are not subject to the restrictive copyright measures imposed by the (mostly offshore) for-profit publishers. Copyright fees run into millions of Rand for South African higher education institutions and this money is paid out to other countries. Copyright has become a tollgate on the information super-highway: developing countries need the information, developed countries control the information. The knowledge and digital divide between the North and the South will continue to widen until these issues are addressed very directly. (Denise Nicholson, Copyright Librarian, University of the Witwatersrand, pers comm. September 2005).

\section{International support for Open Access}

The history of the Open Access movement, which started out as a spontaneous action by scientists in response to their needs, reveals an escalating sequence of events and declarations as various bodies were enlisted and provided support. A fairly comprehensive listing of these events is reproduced in http://www.earlham.edu/ peters/fos/timeline.htm and some relevant subcategories are given in Table 3. 
Table 3: Declarations of Support for Open Access - Summary

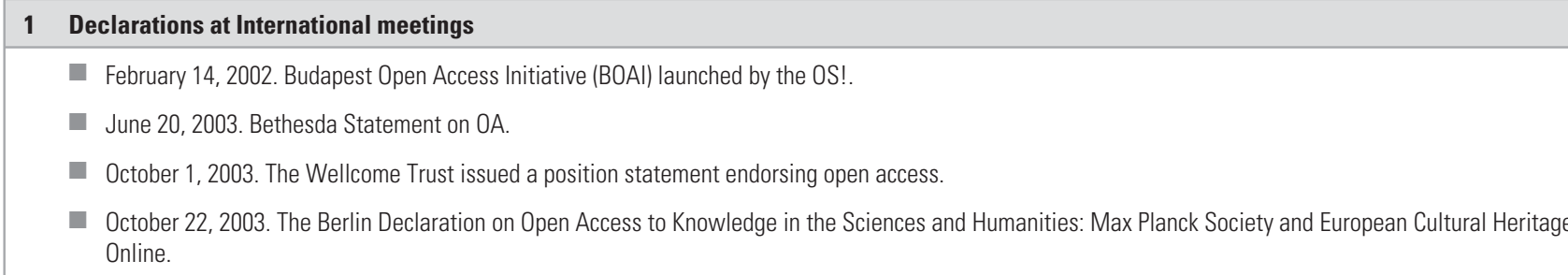

Many others have since followed the BBB (Budapest, Bethesda, Berlin) route

2 Government awareness and action

- December 2003: The UK House of Commons Science and Technology Committee launched an inquiry

- July 20, 2004, The Committee report recommends that public funding agencies require open access to publicly-funded research

July 14, 2004. The U.S. House Appropriations Committee proposes that the National Institutes of Health (NIH) require open access to NIH-funded research through deposit in the NIH's PubMed Central.

In September 3, 2004. The NIH released its open-access plan, Enhanced Public Access to NIH Research Information, for public comment and on n May 2, 2005, the revised version went into effect.

340 articles resulting from this have been submitted, 11 are now available

- SA DST officials predict similar action from the SA Government soon.

- India (no official position but a variety of initiatives underway, www.earlham.edu / peters /writing/wsis2.htm)

- Australia: Australian government has supported the Open Access declaration formulated by the OECD Committee for Scientific and Technological Policy. Open Access Statement by the Australian Research Information Infrastructure Committee (ARIIC), 17 December 2004 http://www.caul.edu.au/ scholcomm/OpenAccessARIICstatement.doc

- March 18, 2005. The Open Access Scientific Publishing Committee of the Finnish Ministry of Education issued a report endorsing open access and making recommendations for nationwide support and adoption.

May 2, 2005. The NIH Public Access Policy came into effect.

- September 23, 2005. Participants at the 9th World Congress on Health Information and Libraries, Commitment to Equity (Salvador, Bahia, Brazil, September 20-23, 2005) issued two declarations on access to knowledge. The first, The Declaration of Salvador - Commitment to Equity, asks governments to promote equitable and open access. The second, The Salvador Declaration on Open Access: The Developing World Perspective, asks governments to require open access to publicly-funded research.

3 International organisations respond

December 12, 2003. The UN World Summit on the Information Society approved a Declaration of Principles and Plan of Action endorsing open access to scientific information.

- January 30, 2004. OECD Declaration on Access to Research Data From Public Funding

- June 15,2004. The EC commences inquiry - inc rapidly rising journal prices and open access to research findings.

- January 2004. 25 journal editors and WHO released the public statement, Galvanising Mental Health Research in Low- and Middle-Income Countries: Role of Scientific Journals, inc recommendations that journals provide open access to their contents.

October 1, 2005. The Wellcome Trust starts implementing its new open-access mandate for Wellcome-funded research.

4 Research Societies \&Academia follow:

- December 17, 2004. The Australian Research Information Infrastructure Committee (ARIIC) issued its Open Access Statement.

- September 8, 2004. The International Committee of Medical Journal Editors (ICMJE) calling for an open-access registry and database of drug trial data; member journals would not publish research articles based on unregistered drug trials.

May 25, 2004. The Australian Group of Eight, the country's eight leading research universities, released a Statement on open access to scholarly information.

March 26, 2004. The Association of Learned and Professional Society Publishers released the ALPSP Principles of Scholarship-Friendly Journal Publishing Practice.

Dec 2004 . ICSU priority area assessment on scientific data and information.

- Research Councils UK draft OA policy currently debated.

- June 28, 2005. The Research Councils UK released its draft open-access policy for a period of public comment to end on August 31,2005 . The policy would mandate open access to virtually all publicly-funded research in the UK.

5 Even the publishers respond

- February 24, 2005. Blackwell Publishing launched its Online Open program

July 1, 2005. Oxford University Press launched its Oxford Open program.

- August 16, 2005. Springer created the position of Director of Open Access and appointed Jan Velterop, former publisher of BioMed Central. Springer became the first major commercial publisher to have such a position. 


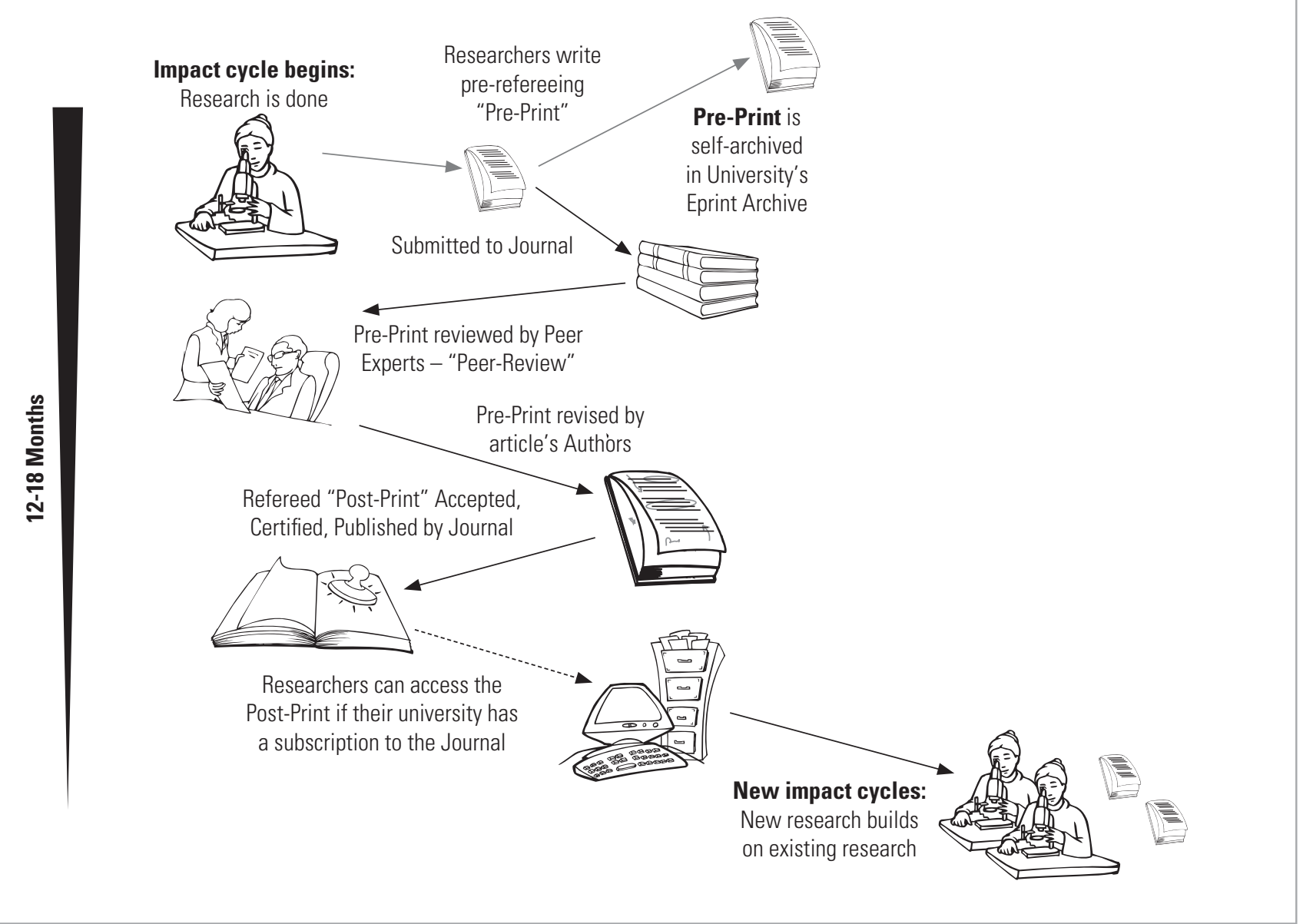

Figure 3: Limited impact without Open Access (Harnad 2005)

Publication leads

to involvement

in joint activities

such as forums

and conferences,

collaborative

research and in the

modern era, virtual

communities

\section{THE VALUE AND IMPACT OF OPEN ACCESS}

The recent move to provide scientific and scholarly materials free through "open access" is one of the most exciting and radical events in publishing in recent years. Electronic publishing changed the way most scholars access literature in their field. Now Open Access is changing the way electronic materials are distributed. (McVeigh 2004)

Researchers publish their work for several operational reasons, beyond those listed in the Roosendaal and Geurts core functions (see above). Apart from the fundamental need to have one's work peer-reviewed and thus accepted in the formal corpus of scientific knowledge, there is the fact that, in addition, publication leads to involvement in joint activities such as forums and conferences, collaborative research and in the modern era, virtual communities. Furthermore, many funders and employers rate applicants for promotion and research funds by their publication record; citation by other researchers is currently the most accepted indicator for research impact. However, an article can only be used and cited if it is visible and accessible. The value of $O A$ lies in the fact that through maximising research access it maximises visibility, usage, uptake, impact and hence research progress.

Stevan Harnad (2005) has refined the advantages of OA by breaking them down into Early, Usage and Selectivity Advantage. Early Advantage mostly applies to preprints and refers to the head start of articles which are accessible before being published (note many publishers now also pre-publish to gain this advantage). Usage Advantage refers to increased downloads and citations, anywhere between 25\%-300\% (http://opcit.eprints.org/oacitation-biblio.html). If all research articles were OA, researchers all over the world would have the Selectivity Advantage to use and cite the best and most relevant work.

Besides these compelling advantages for authors, and the advancement of science in general, OA may also have the following benefits: 


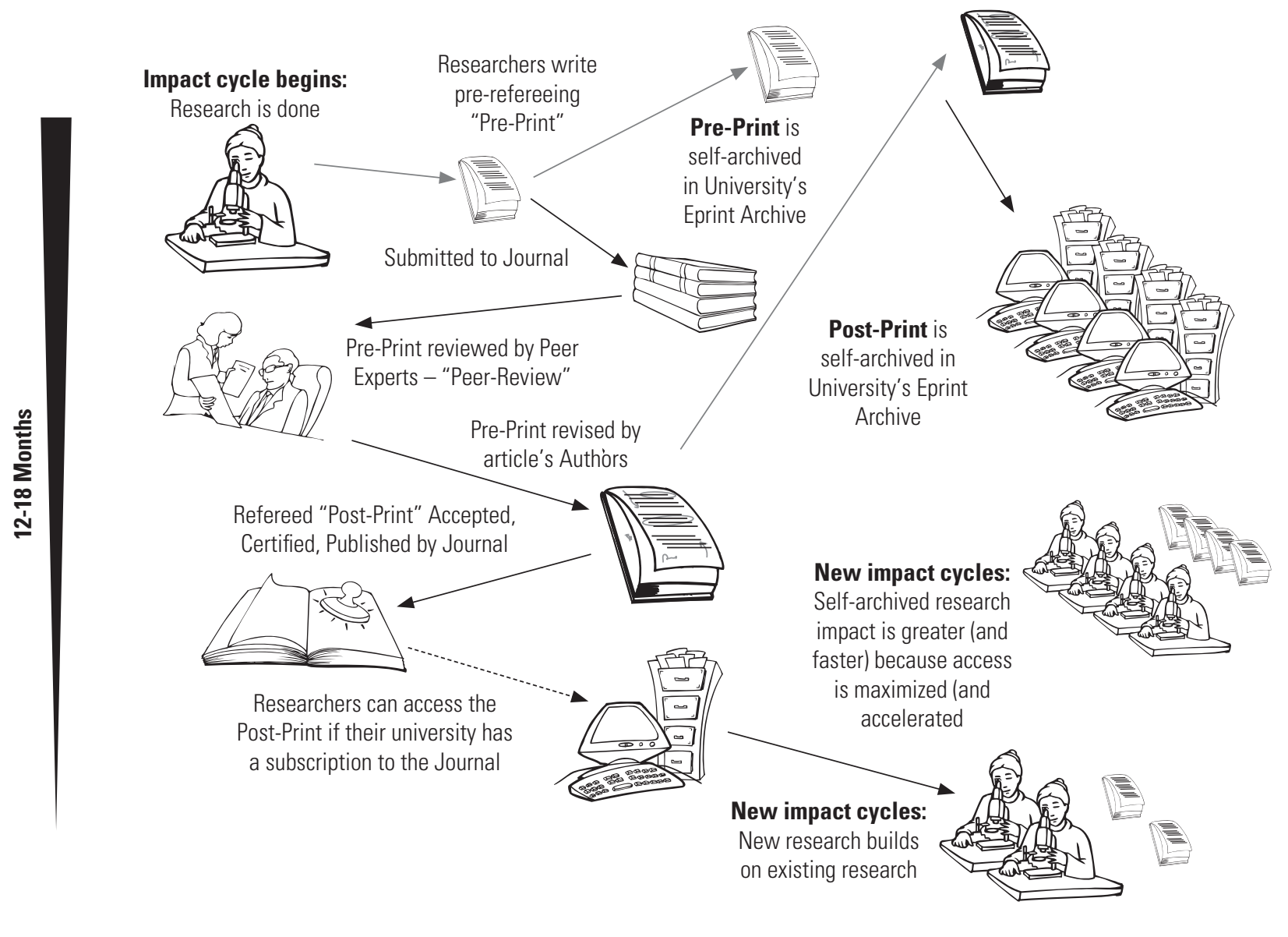

Visibility and promotion of the research output of institutions;

- more complete records of scholarship;

access for the wider public including teachers, students, tax-payers;

alleviation of the access problems of the developing world;

- creating flexible and free re-use options for articles: open access articles may be read, downloaded, copied, distributed, printed, searched, linked to, translated as long as authorship is acknowledged and they are not used for profit making. This will lead to a reduction in royalties paid to foreign publishing companies operating offshore, even for articles describing local research;

- international access to research generated in developing countries which is currently invisible to the developed world and which is important for research on global problems;

alleviation of the budgetary problems of libraries all over the world, especially in the developing world;

- contribution to the digital preservation of scholarship;

- a shift from competition for authors rather than for subscribers, creating a healthier model;

- facilitating peer review and other forms of quality control by giving reviewers, supervisors and examiners easy access to all the papers referred to in a new manuscript (Harnad 2005, Chan, Kirsop \& Arunachalam 2005);

- failed research can be reported, and may lead to the identification and subsequent avoidance of blind alleys (Houghton 2005).

Not all role-players are enthusiastic, however. In November 2005 the Royal Society (London) issued a statement (http://www.royalsoc.ac.uk/page.asp?id=3882) cautioning against overhasty pressurizing of researchers to publish in accessible archives, claiming that the business models on which some of these are based are not proven and urging restraint while more cautious investigation is carried out. That 61 Fellows (including 5 Nobel prizewinners) promptly issued an open letter (http://www.frsopenletter.org/) criticizing the Society's stand on the matter, confirms that Open Access Archiving is receiving acceptance from key stakeholders, but also that the debate is not yet over!

Figure 4: Maximized impact with Open Access (Harnad 2005)

In November 2005 the Royal Society (London) issued a statement cautioning against over-hasty pressurizing of researchers to publish in accessible archives, claiming that the business models on which some of these are based are not proven and urging restraint while more cautious investigation is carried out 
A 2004 study by the Thomson Corporation, publishers of the ISI citation databases, described a study of the 239 OA journals in the Web of Science (WoS) and the Web of Knowledge (WoK). These journals constituted $20 \%$ of the then universe of 1190 OA titles but only $2.6 \%$ of the WoS titles and $1 \%$ of the WoK titles. Generally, they ranked in the lower $50 \%$ in terms of impact factors, although 14 journals ranked in the top $10 \%$ of particular categories. OA journals fared better with regard to immediacy of impact where 20 titles were in the top $10 \%$. This last finding confirms the view that $\mathrm{OA}$ journals may influence the research cycle by diminishing the time lag between completed research and the results being used and cited (Mc Veigh 2004).

At the article level, advantages appear to be more pronounced. Brody et al. (2004) found that self-archived articles have 50-250\% more citations than others otherwise matched with them. In a study of Philosophy, Political Science, Electrical and Electronic Engineering and Mathematics journals, Antelman (2005) found increases in citation rates ranging from 45-91\%. A research team from the Université du Québec à Montréal, Southampton University and Universität Oldenburg, in collaboration with ISI, are in the process of studying a 10-year sample of 14 million articles across all disciplines to see whether these findings will hold up in the system as a whole.

Other measurement tools are in the process of development, and these will influence the evolving scenario. Online article downloads can easily be measured and there seems to be a correlation between downloads and citation (Harnad \& Brody 2004, Perneger 2004) which may make it easier in future to measure the impact of OA. CiteSeer or ParaCite assesses the impact of individual articles. A partnership between ISI and CiteSeer has been set up to create a new citation measurement tool. (http://www.isinet.com/press/2004 /8217120).

It is well known that many publishers and authors exploit the citation system in order to increase the impact of their journals and articles (Monastersky 2005). This practice, also known as 'gaming the system' becomes inevitable when impact factors are regarded as the dominant quality measure. There is a rising need for a multidimensional model to measure influence and impact (Academies of Science 2004). The Public Library of Science journals have recently come out in favour of content which does not necessarily have the potential for high citations but which will have an impact on public awareness and healthy debate (Parthasarathy 2005)

Open Access has a lot in common with disruptive technologies: it has put in motion processes that may change scholarly communication profoundly. The next meaningful step has already been taken by institutions such as the CCLRC Rutherford Appleton Laboratory who link an OA repository with research data in the GRID + ambient computing environment (Jeffery, 2005).

\section{The slow uptake of Open Access}

In light of these advantages, it is amazing that the uptake of Open Access has been so slow. Bjork (2004) identified six barriers to OA success and plotted them against the three major OA modes: OA journals, institutional repositories and archiving on personal web sites. In the case of OA journals, the major problems seemed to be:

- business models - where the cost of the journal has shifted from subscription cost to publishing cost and has to be borne by the researcher or his organisation - this seemed to be a particular problem for research organizations with high output;

- academic reward system - until OA journals are included in the ISI system on the strength of the impact of their articles or until they are deliberately selected by the reward system, researchers will probably choose other journals to publish in;

- marketing and critical mass - researchers will have to come to know OA journals in their fields and trust their content before considering publishing in them.

A recent study by Rowlands and Nichols (2005) revealed, however, that authors' awareness of OA has increased by $10 \%$ over the last year while the percentage of authors publishing in OA journals has risen from $11 \%$ to $29 \%$.

In the case of institutional repositories, the problem appears to lie with:

- indexing services and standards - which explains why good harvesting and value-added services are so important,

- marketing and critical mass - merely creating the capability (mostly technical) to run an institutional repository will not be enough. Awareness, support, skills, advantages and policies will have to be used to make this the logical conclusion of the scholarly process, and to a lesser extent 
copyright - which will be discussed separately.

In the case of repositories, by far the most effective strategy seems to be to mandate the activity. Institutions who have done so, such as University of Southampton, Max Planck Society, Lund University and University of Amsterdam, have seen dramatic increases in server content without having to waste resources on unnecessary marketing and lobbying. This is supported by the findings of a recent JISC-funded worldwide study by Swan and Brown (2005) where 81\% of researchers were positively inclined and would comply willingly with a mandate from their employer or research funder to deposit copies of their articles in an institutional or subject-based repository. A further 14 per cent would comply reluctantly, and only 5 per cent would not comply.

\section{Open Access archives and copyright}

Authors often use copyright as an excuse for their reluctance to self-archive, claiming that it will harm their relationship with conventional publishers and jeopardize future publishing opportunities. This stems from a lack of awareness of publishers' policies although these are readily available on the Romeo and SHERPA web sites (http://www.sherpa.ac.uk, http:// romeo.eprints. org/stats.php). More than 79\% of publishers allow postprint archiving and $13 \%$ allow preprint archiving without the need to apply for permission. For the remaining 8\% it will be necessary to negotiate with the publishers concerned.

To be able to interpret publishers' policies correctly authors need to take note of the following:

- Copyright to a pre-refereeing preprint belongs to the author who may self archive it if the publisher permits.

- Once the article has been peer-reviewed, copy-edited and accepted for publication (the socalled post print), it may be self-archived only with the permission of the publisher if the author assigned exclusive copyright to a publisher.

- The online version of the article may not be used as a postprint unless explicitly permitted.

- Authors should be aware of the policies of publishers and should [at least try to] exercise their right to have self-archiving restrictions removed from their contracts.

- Authors and repository owners need to be aware that the respective rights of co-authors and their employers need to be clarified (Houghton 2005).

Well aligned with the Open Access movement is Creative Commons (CC) (http:// creativecommons.org/) which is working on a broad front to develop licences that will protect the rights of authors according to their specifications without restricting reuse. CC licences are used by the Public Library of Science, BioMed Central and Springer OpenChoice ${ }^{\mathrm{TM}}$. Taking this even further is the CC subsidiary, Science Commons (SC), launched in early 2005. SC will expand these activities to the making of tools and data available for reuse, associating research articles and data and standardizing metadata associated with both. (Wilbanks 2005).

The most exciting initiatives with real potential to advance research come from bold experiments where the best options provided by these new technologies are combined within a climate of openness to create knowledge environments.

- The Social Science Research Network (http://www.ssrn.com/home_hd.html) is collaborating with a variety of role players to provide a real participative environment for nine groups of social scientists.

- The Signal Transduction Knowledge Environment (STKE) (http://stke.sciencemag.org) provides a community environment with relevant tools and resources for the creation of new knowledge and collaboration. The STKE virtual journal gives full-text access to articles from nineteen different publishers.

- Faculty of 1000 (http://www.facultyof1000.com) is a next generation literature awareness tool, based on the recommendations of the leading researchers, with the potential of reducing information overload.

\section{Open Access implications for South African research journals}

- OA journals (the so-called OA Gold option), a subset of e-journals, are emerging as a viable alternative to commercial e-journal publishing. Access is free to all and the cost of publication is covered by other means such as author charges. Some of these journals are already included in the ISI databases.
The most exciting initiatives with real potential to advance research come from bold experiments where the best options provided by these new technologies are combined within a climate of openness to create knowledge environments 
The visibility of South African researchers and hence their interaction with their peers internationally is clearly at risk if we cannot afford subscriptions to online and print publications and are hampered in our ability to publish in the most visible (high-impact) journals

South African researchers are particularly disadvantaged, in global communication

terms, by the high

cost of Internet bandwidth and

even, in some cases, poor institutional infrastructure
- OA repositories with archived copies of articles that are published in regular journals (the so-called OA Green option), whether subject specific, such as arXiv, or institutional, provide additional access and visibility. This has advantages for readers who do not have subscription access or who cannot pay the pay-per-view fee, as well as for authors who achieve greatly enhanced visibility.

- OA repositories have to be created, branded, managed, marketed and maintained. The costs to archive are minimal, but ongoing curation costs will accumulate. The barriers for changing the commercially oriented communication system have been greatly underestimated and need to be managed.

- OA is significantly devalued where harvesting of the published material is sub-standard: this very important activity should be planned for if impact is to be maximized.

- The barriers to changing the commercially oriented communication system were greatly underestimated and this needs to be managed.

- Vested interests are emerging - the 'commercial' publishers have a business with a profit motive, while governments/other funders are resisting ongoing copyright "raiding" by publishers.

- Parallel print with electronic (delayed or immediate) OA has been demonstrated as no real threat to conventional publishing from the viewpoint of declining subscriptions, and has shown evidence of increased citation.

\section{SOUTH AFRICAN DEVELOPMENTS IN PERSPECTIVE}

Most of the issues that apply to research in developed countries apply also in South Africa as a developing country of a particular kind. We have many university-based and other researchers who are competing/participating in research at a global level, despite significant infrastructure handicaps in many cases, while others wish to enter that league and need help from the managers of the system. At the same time, typical 'developing country' cries of discrimination, needs for better allocation of more research resources, and better dissemination of research outputs can be heard. Which of these issues is relevant to the state and future of research publication in South Africa?

The visibility of South African researchers and hence their interaction with their peers internationally is clearly at risk if we cannot afford subscriptions to online and print publications and are hampered in our ability to publish in the most visible (high-impact) journals. Publishing in low-visibility journals does not solve any problems. South African journals play a valuable role in providing publication options for researchers, especially young researchers, and should be supported and encouraged to align with best publication practice and quality trends, including e-publishing options and listing on international databases with strong linking capabilities. Listing on international databases is particularly important in the light of an unpublished Elsevier study regarding the usage of ScienceDirect: $60-70 \%$ of Life Sciences users enter articles by an external link. The incentive schemes that operate need to be carefully tailored to exact desirable responses.

The nature and impact of SA research publication is summed up in chapters 2-3. What is the status quo in respect of infrastructure and publishing activities?

\section{Limited access to global scholarship is harming our research capacity}

South African researchers are particularly disadvantaged, in global communication terms, by the high cost of Internet bandwidth and even, in some cases, poor institutional infrastructure. This has led to a local adherence to the print publication medium whereas our developed country counterparts are moving steadily towards online publication. The exceptions to this trend are set out below.

Inadequate funding for library subscriptions is another cause. It has been correctly pointed out (Hunter, 2004) that the increase in funding for scientific research over the past decades has not been paralleled by an increase in library funding anywhere in the world, and many SA university libraries are even worse off in comparative terms. In this respect, the payment-per-view approach emerging for some of the platforms enables only researchers who are funded relatively well individually to hurdle the general library barrier faced by their colleagues. 


\section{Online publishing initiatives presently under way}

The dominant player on the South African scene is Sabinet Online, which launched a platform, SA ePublications (http://www.journals.co.za/ej/), in June 2004 with 40 online journals, from a universe of 700 that already existed in print and which they considered to be suitable targets for e-publishing. To date (September 2005), 192 journals have been signed on, and negotiations are underway with the publishers of another 300. (Their original plans included other African countries but two unsuccessful experiments relegated this effort to the background).

- 84 of the 192 appear on the DoE list of accredited journals.

- Fifteen of these journals are in the ISI database, although only one of these (Perspectives in Education), is accredited by the DoE; seven are in the International Bibliography of Social Sciences (IBSS).

Sabinet Online adds value by aggregating the titles from many different publishers under one interface and search system, while simultaneously increasing market awareness of the publications and growing their revenue streams. They do not play any role in peer review and content definition which is left in the hands of the organisations to which the journals belong, which makes them the real publishers. Sabinet Online contracts with publishers are not exclusive, and the right to publish in an OA repository is granted by the publisher. Publishers must, however, adhere to a negotiated publishing schedule and they retain copyright.

Sabinet Online prices its input at 10-20\% of the publishing cost, which includes:

- abstracting the content of each article by indexing it according to keyword, broad subject, author(s), and title categories;

- making all articles fully searchable, with complete ease of access;

- marketing the publications both locally and internationally, making them readily accessible not only to the present core of subscribers, but also to the vast global population;

acting as intermediary between publishers and subscribers; and

compiling articles in PDF with metadata in XML.

JSTOR (http://www.jstor.org) and LOCKSS (http://lockss.stanford.edu/) are considered as possible platforms for eventual preservation of back numbers in fully indexed and accessible formats.

From 2002 - 2003 there was a doubling in downloads from the Sabinet Online e-journals, which is a good indication of use although it is also influenced by increased content.

Subscribers can subscribe to the entire package or to any of the following 6 collections: Business \& Finance, Law, Medical and Health, Religion, Science, Technology and Agriculture, Social Sciences and Humanities. Subscription prices are not standard and are negotiated in each case. In the case of a library, the subscription model is similar to that of ScienceDirect, ie the licence fee is based on the cost of the journals to which users can subscribe in hard copy. Many of the journals are free. Six overseas universities subscribe to one or more packages. An extensive international marketing campaign is being planned.

In financial terms, most publishers have gained a lot from going the e-route. Journal subscriptions have increased, and in 2005 Sabinet Online paid out in excess of R1 million in royalties to the publishers, many of whom had never been able to make any margin.

Another prominent player is NISC-SA in Grahamstown. In addition to being the online publisher of ten South African journals they also host African Journals online (AJOL) and a number of other databases with South African and African content. Two of these NISC-SA journals are listed by the ISI, while another three appear in the DoE accreditation list.

The South African Journal of Science Website (www.nrf.ac.za/sajs/index.stm), as an example of the local situation, is not yet on par with the best international journals. The online version is on the SA ePublications platform. A few observations:

- The existence of the online version is mentioned as an announcement on the index page, but not on the subscription page; it looks as though it is something totally different.

- The current online copy is not synchronized with the current print copy creating the impression that it is not the same publication.

- Linking to the full text of the articles is more or less non-existent unless subscribers enter through another route.

- Online versions of the articles are in PDF only, and the journal lacks the vibrant feel of a Community of Practice of Scientists that is visible in other online sources, e.g. 
- www.nature.com/index.html

- www.sciencemag.org/content/current/

- www.sciencemag.org/

- www.scienceonline.org/

To sum up: the modern trend for a flagship journal is to offer:

quality content collected as part of a process with integrity;

publication online (in addition to a print copy);

- each article available as an abstract, full text (HTML) and PDF, sometimes even with supporting online material;

- CrossRef to link content between journals and publishing platforms, and other forms of static and dynamic linking, including links to data;

- strong customized linking from all web sites taking the reader directly to full text entitlements;

additional journal web sites or portals acting as a meeting place for the community of interest around the journal or group of journals, and providing tools and services;

a flexible policy regarding $O A$ archiving and any embargo period; and

indexing in major bibliographic databases, preferably inclusion in ISI.

\section{Dissemination of the content of South African journals}

South African research findings need not only to be published: they should also be discoverable by search engines and "crawlers", and should be included in leading bibliographic databases as far as is possible.

South African journals are included in international databases on the EbscoHOST, Proquest and Infotrac platforms as well as in numerous subject-specific databases. It may be worth the effort to determine the extent of inclusion in these databases and the impact it has on article usage. Guidelines on how to have a journal listed in databases other than the ISI suite may also be of help to SA journal publishers. NISCSA in Grahamstown publishes a number of databases particularly aimed at disseminating African research (http://www.nisc.com).

African Journals Online (AJOL) (http://www.ajol.info) is an initiative of INASP ${ }^{3}$ to increase the visibility of African journals amongst the global research community. The service consists of an online catalogue and current awareness system, as well as document delivery on a per article basis. The journals owners receive $\$ 5$ for each article delivered. Participation is free for all SA journals. Currently there are 195 journals from 21 countries comprising 13000+ article abstracts. The entire operation was recently relocated to NISC-SA in Grahamstown.

At present, these two entities (Sabinet Online and NISC/AJOL) are seen as competitors. It may be in the interests of SA Research to encourage collaboration.

\section{Open Access institutional repositories in South Africa}

Locally the success rate for archiving in institutional repositories is thus far extremely low, although a number of initiatives are underway. No local university as yet has an institutional repository for archiving locally produced journal articles either as pre- or post-prints although a number of institutions are in the process of setting up repositories. The UCT Computer Science Department has a Research Document Repository that contains journal articles as well as other documents. OA repositories for theses and dissertations exist at the Universities of Pretoria and Johannesburg, while the University of the Witwatersrand (Wits), Rhodes University, the University of the Free State and the University of South Africa have non-OA thesis repositories. There is an arXiv mirror site at Wits. In most cases, there is as yet no formal requirement by institutions for Masters or Doctoral candidates to lodge digital copies of their theses in repositories, although this model has been adopted widely elsewhere in the world.

Comprehensive harvesting of South African OA repositories has not received any attention so far, but a few repositories are listed in the Registry of Institutional Open Access Repositories

3 With financial support from UNESCO, the National Academy of Sciences (USA), the Norwegian Agency for Development Cooperation (NORAD), the Swedish International Cooperation Agency (SIDA) and the UK Dept of International Development (DFID) 


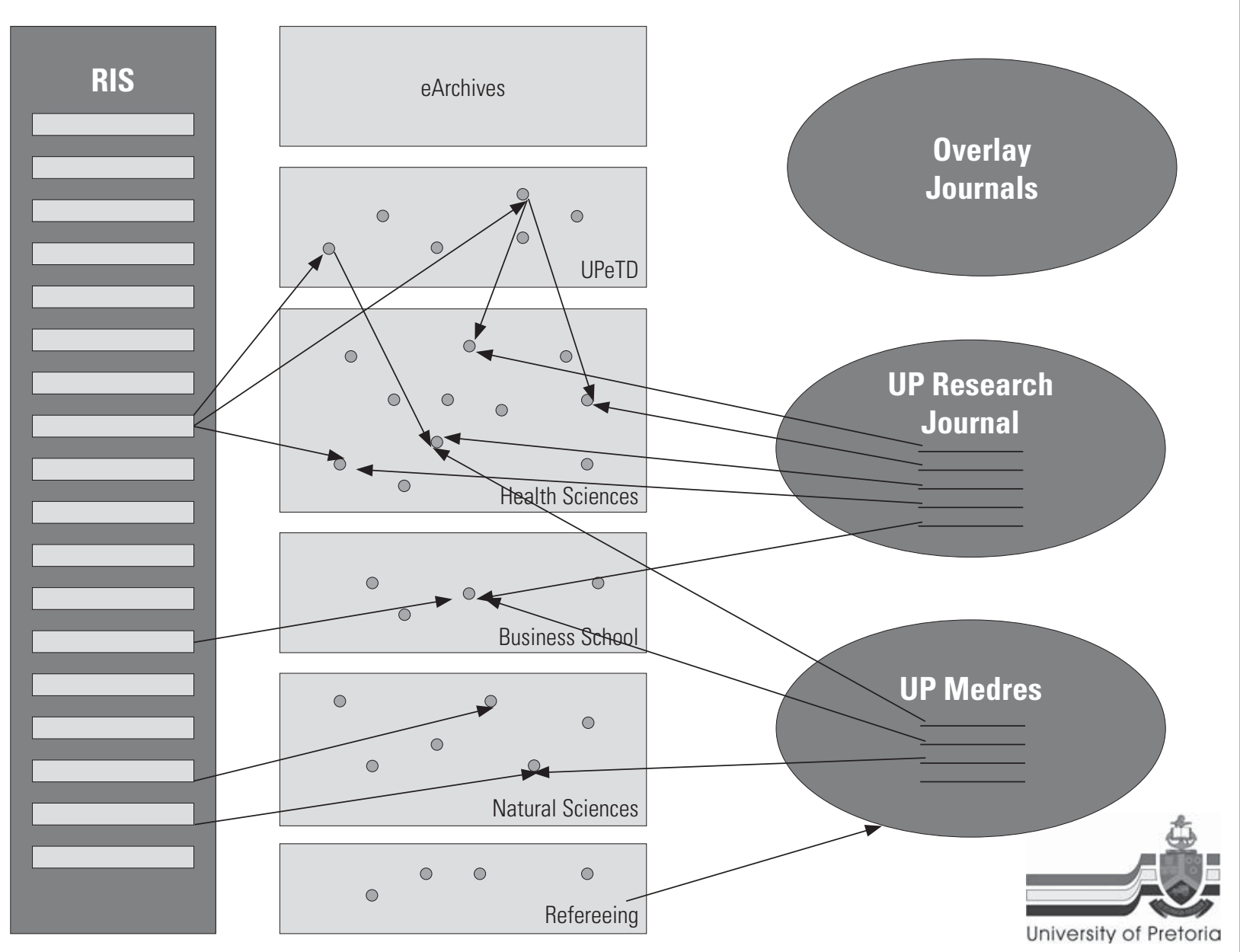

(http://archives.eprints.org/) and are harvested by OAIster and the NDLTD Union Catalog (http://alcme.oclc.org/ndltd/index.html).

Another possibility arising from OA repositories is that of overlay journals. These virtual journals which are merely a web interface pointing to articles in various repositories provide a means for repackaging articles in new formats or brands. The Lund Virtual Medical Journal (http:// LVMJ.medfak.lu.se) and the ST Virtual Journal (http://stke.sciencemag.org/vj/) which forms part of STKE are examples of such an arrangement. ASSAF could for instance have a couple of "Research SA" brands highlighting the best results of a certain period, additional certification and bringing together SA research published in SA journals with SA research published elsewhere. The Cream of Science initiative resulting from DARE (http://www.surf.nl/en/themas/index2. php?oid=7) in the Netherlands is worth noting. Fig 5 shows an overlay arrangement designed for the University of Pretoria. This is a real option for 'national' journals.

\section{Publication incentives in South Africa}

It is worth repeating here that researchers are motivated to publish for one or more of the five reasons quoted by Roosendal and Geurts. (Roosendaal \& Geurts 1997)), viz.

- Registration, which allows claims of precedence for a scholarly finding;

- Certification, which establishes the validity of a registered scholarly claim;

- Awareness, which allows actors in the scholarly system to remain aware of new claims and findings, and enhances collaborative opportunities;

- Archiving, which preserves the scholarly record over time; and

- Rewarding, which rewards actors for their performance in the communication system, based on metrics derived from that system.

The academic research system in SA is currently strongly driven by the Department of Education's (supply-side) subsidy system which pays the institution a subsidy per publication in one of the peer-reviewed journals listed in the two accredited international databases and

Figure 5: Illustration of an Overlay Journal concept 
in the DoE list of accredited journals. This is expected to be R70 000 for each "unit" of the 2004 publications. Many institutions share some of this income, directly or indirectly, with the authors; which has introduced an extraordinary (in global terms) emphasis on item 5, viz Rewarding, in the above list.

Open Access publishing will need to attract the same benefits if researchers are to be induced to use this mode: OA journals should obviously be considered for inclusion in the DoE list. Incentives for self-archiving should also be considered. Alternatively, it could be a precondition for NRF and other funding. OA actually complicates the incentive picture; despite its obvious advantages justifying OA publication in an institutional or other repository, without incentives, this process will not flourish.

Any more locally focussed incentive scheme would, however, have to meet the peer-review and editorial discernment requirements. Some organisations (e.g. the HSRC) self- publish in their Green Route repository, with a parallel print on demand scheme, on the grounds that their internal systems are sufficiently robust to maintain quality standards.

\section{Article and data curation, standards and it applications}

Another feature of the modern eResearch world, namely the need for long-term data curation, links to the need for article curation and archiving, to reassure researchers that their output will be persistently available for scrutiny. Institutional repositories in well-resourced establishments may appear safe in the long run, but no institution is permanent in terms of either existence or management philosophy, and a 2005 guarantee of persistence may not be honoured in 2025 . The South African eResearch Support Service proposal (Page-Shipp et al, 2005) is intended to create a coordinated effort in this regard.

For any such effort to succeed there must be an agreed set of standards for meta-data attribution, data-structure etc and preferably a common information technology application, or at least a simple interface between those that are chosen.

\section{The main South Africa - specific implications for research journals summarised}

- It will be essential to have strategic management of national publication policy which is aimed at the future, and not at the present or the past.

- The application of national and institutional resources (people, energy, money) should be aligned as possible with the agreed strategic objectives.

- Nationally coordinated efforts are required to provide infrastructural services cost-effectively. e.g. Digital Curation; shared negotiation for access rights (institutional and national subscriptions); aggregation of 'atomised' journals and of their editorial, subscription and production needs; aligned standards and possibly locations for digital repositories; national harvesting of $\mathrm{OA}$ repositories.

- Encouragement and incentives are required for South African authors to publish in recognized Open Access journals by way of awareness and provision in grants of cover for author fees.

- There needs to be recognition of the fact that OA and other online initiatives merely make innovative and system-improving alternatives possible; for researchers to be willing to participate, we will need a thoughtful and enlightened set of 'carrot and stick' incentives.

- Restrictions on the reuse of research publications by the for-profit publishers combined with the cost of copyright to South African higher education (millions of Rand leaving the country), should act as an incentive to strengthen the local publishing and Open Access dispensation.

- There needs to be a strategic decision on the best balance between visibility in global terms and local relevance and capacity building:

- The value of local journals as professional communications medium (e.g. the South African Medical Journal, SAMJ) against their global science role.

- The need to develop/retain local editorial and peer review capacity.

- Realistic assessment of requirements for publishing skills and the costs.

- Opportunities for global involvement versus local/regional translation and benefit.

- The country's ability to attract overseas researchers to publish in local journals and/or to work in South Africa.

- Removal of real and perceived copyright obstacles. 
Table 4: Roosendal and Geurts Model applied to the role-players in Research Publishing

\begin{tabular}{|c|c|c|c|}
\hline Role player & Role & Roosendaal /Geurts & Driver \\
\hline Author & $\begin{array}{l}\text { Reports on research conducted; quality of article } \\
\text { linked to quality of research and author's ability } \\
\text { to convey the message }\end{array}$ & $\begin{array}{c}\text { Registration, Certification, } \\
\text { Archiving Reward and } \\
\text { Visibility }\end{array}$ & $\begin{array}{l}\text { Satisfiers } \\
\text { Motivators }\end{array}$ \\
\hline $\begin{array}{l}\text { Editorial Committee (appointed } \\
\text { by ....) }\end{array}$ & $\begin{array}{l}\text { Responsible for the quality of the journal's } \\
\text { content }\end{array}$ & Certification & $\begin{array}{l}\text { Responsibility to discipline, or 'science' in } \\
\text { general. }\end{array}$ \\
\hline $\begin{array}{l}\text { Journal Owner (Publisher, } \\
\text { Scientific Society, Organisation) }\end{array}$ & Provides the resources to make it happen & & As above or profit or both \\
\hline $\begin{array}{l}\text { Publisher (International High } \\
\text { Profile, Local Small; sometimes } \\
\text { the same as Journal Owner }\end{array}$ & $\begin{array}{l}\text { Organises the activities required to make it } \\
\text { happen, including copy-editing }\end{array}$ & $\begin{array}{l}\text { Registration, Awareness } \\
\text { Archiving } \\
\text { Rewarding }\end{array}$ & Profit \\
\hline $\begin{array}{l}\text { Online Publisher (often the } \\
\text { same as Publisher }\end{array}$ & $\begin{array}{l}\text { Provides access to the full text and additional } \\
\text { functionality }\end{array}$ & $\begin{array}{l}\text { Registration, Awareness } \\
\text { Archiving } \\
\text { Rewarding }\end{array}$ & Profits, protection of print rights \\
\hline Secondary Publisher(s) & $\begin{array}{l}\text { Provide visibility eg reviewing articles or by } \\
\text { including them in bibliographies }\end{array}$ & $\begin{array}{l}\text { Awareness } \\
\text { Rewarding }\end{array}$ & Profit \\
\hline $\begin{array}{l}\text { Journal Website if separate } \\
\text { from Online Publication }\end{array}$ & $\begin{array}{l}\text { Provides a community space for discussion } \\
\text { and exchange of additional information; adds } \\
\text { visibility by highlighting articles }\end{array}$ & $\begin{array}{l}\text { Awareness } \\
\text { Rewarding }\end{array}$ & Needs of community \\
\hline Repository(ies) & $\begin{array}{l}\text { Add additional visibility to articles that are } \\
\text { normally inaccessible for non-subscribers }\end{array}$ & $\begin{array}{l}\text { Awareness } \\
\text { Archiving } \\
\text { Registration in some cases } \\
\text { Certification in some cases } \\
\text { Rewarding* }\end{array}$ & $\begin{array}{l}\text { If institutional, to maintain inst reputation and } \\
\text { satisfy reqt of accountability for dissemination } \\
\text { If subject based to speed up communication and } \\
\text { scietific progress in general }\end{array}$ \\
\hline Harvester(s) & Make open access discoverable & $\begin{array}{l}\text { Awareness } \\
\text { Rewarding* }\end{array}$ & To enhance open access \\
\hline $\begin{array}{l}\text { OAI Service Providers, eg } \\
\text { OAlster and Citebase }\end{array}$ & $\begin{array}{l}\text { Provide value added content on top of harvested } \\
\text { OA records }\end{array}$ & $\begin{array}{c}\text { Awareness } \\
\text { Rewarding ... }\end{array}$ & To enhance open access \\
\hline$|S|$ & $\begin{array}{l}\text { Provide visibility and measure impact/provide } \\
\text { metrics }\end{array}$ & Rewarding & Profit and visibility \\
\hline Funding System & $\begin{array}{l}\text { Provides incentives that impact on the behaviour } \\
\text { of other role players }\end{array}$ & Rewarding & Promotion of knowledge generation \\
\hline
\end{tabular}

- A massive education effort, aimed at local researchers, editors and publishers, will need to be launched to ensure that informed and realistic decisions are taken at as many levels as possible. Realism relating to costs of publishing should prevail.

- Secondary publishing of SA journals and articles in commercial databases with wellestablished subscription bases; review journals; OA harvesting; and search engines should be developed actively.

- The parallel world of data should be factored into the strategic model.

- South African research publishing needs continuous systemic review. The success of South African-based research journals will depend on a value chain with different role players (not necessarily people): their relative contributions to the final quality should be understood and investigated, both as separate entities and as links in the chain in order to create synergies.

- We have a window of opportunity to embrace some of these new trends and to include them beneficially in the incentive scheme.

- The application of the Roosendal and Geurts model (Registration, Certification, Awareness, Archiving, Rewarding) to the various role-players is illustrated in Table 4.

Finally, this Chapter has outlined some of the most likely scenarios within which the future of research publishing in South Africa must be strategically directed. Scenarios are useful because they force us to remember that recommendations predicated on the assumption that the past and present are smoothly continuous with the future may be wholly inadequate or inappropriate. In moving forward from this point, we need to identify strategies that will be robust or flexible enough to cope with future reality. 


\section{REFERENCES}

Antelman, K. 2004. 'Do open-access articles have greater research impact?' College E Research Libraries News, vol.65, no.5, September 2004, pp. 372-382, viewed 22 December 2005, <http://eprints.rclis. org/archive/00002309/>.

Association of Learned and Society Publishers, 2005. The truth about open access. ALPSP, Worthing, viewed 22 December 2005, <http://www.alpsp.org/publications /FAOAcomplete.pdf>.

Bergstrom, C.T. \& Bergstrom, T.C. 2001. 'The economics of scholarly journal publishing', viewed 22 December 2005, <http://octavia.zoology.washington.edu/ publishing/intro.html>.

Bosc, H. \& Harnad, S., 2004. 'In a paperless world a new role for academic libraries: Providing Open Access', in Spreading the word: who profits from scientific publications? A symposium within ESOF 2004. 26 August 2004, Stockholm, viewed 22 December 2005, <http://cogprints.org/4200/01/boscharnadLP.htm>.

Bjork, B-C. 2004. 'Open access to scientific publications - an analysis to the barriers of change', Information Research, vol. 9, no. 2, January 2004, viewed 22 December 2005, <http://informationr.net/ir/9-2/paperl70.html>.

Brody, T., Kampa, S., Harnad, S., Carr, L. \& Hitchcock, S. 2003. 'Digitometric services for Open Access environments', in Proceedings of European Conference on Digital Libraries 2003, Trondheim.

Chan, L., Kirsop, B. \& Arunachalam, S. 2005. Open Access archiving: the fast track to building research capacity in developing countries, viewed 22 December 2005, <http://www.scidev.net/ms/openaccess>.

Djorgovski S.G. 2004. 'Virtual observatory, cyber-science and the rebirth of libraries', in E-Research and Supporting Cyberinfrastructure: A Forum to Consider the Implications for Research Libraries E Research Institutions, 15 October 2004, Washington, viewed 22 December 2005, <http://www.arl.org/forum04/djorgovski_files/djorgovski.ppt>.

Harnad, S. 2005. 'Open Access: to what?', in 8th International Symposium on Electronic Theses E Dissertations, 2830 September 2005, Sydney, viewed 22 December 2005, <http://adt.caul.edu.au/etd2005/etd2005.html>.

Harnad, S. \& Brody T. 2004. 'Comparing the Impact of Open Access (OA) vs. Non-OA Articles in the Same Journals', D-Lib Magazine, vol. 10, no.6, June 2004, viewed 22 December 2005, <http://www.dlib.org/dlib/ june04/harnad/06harnad.html>

Houghton, J.W. 2005. 'Scholarly communication in a knowledge-based economy', in 8th International Symposium on Electronic Theses E Dissertations, 28-30 September 2005, Sydney, viewed 22 December 2005, <http://adt. caul.edu.au/etd2005/etd2005.html>.

Hitchcock, S. 2003. 'Lessons from the Open Citations Project', in Seminar on the Application and Exploitation of the OAI Protocol for Metadata Harvesting, 14 May 2003, London, viewed 22 December 2005, <http://opcit. eprints.org/talks/uksg-oai/uksg-oai.ppt>.

Hunter, K. Open Access: yes, no, maybe, Nature Web Focus, viewed 22 December 2005, <http://www.nature. $\mathrm{com} /$ nature/focus/accessdebate/3.html>

Jeffery, K. G. 2005. 'CRIS + Open Access = The route to research knowledge on the GRID. World Library $E$ Information Congress: 715t IFLA General Conference and Council, 14-18 August 2005, Oslo, Norway, viewed 22 December 2005, <www.ifla.org/IV/ifla71/papers/007e-Jeffery.pdf>.

JISC 2005. Open Access, viewed 22 December 2005, <http://www.jisc.ac.ul/index.cfm?name=pub_ openaccess>

OCLC 2004. 2004 Information Format Trends: Content, Not Containers, viewed 22 December 2005, <http://www. oclc.org/reports/2004format.htm>.

Lucier, R.E. 1990. 'Knowledge Management: Refining Roles in Scientific

Communication', EDUCOM Review, Fall 1990.

McVeigh, M.E. 2004. Open Access journals in the ISI citation databases: analysis of impact factors and citation patterns. Thomson Corporation, viewed 22 December 2005, <http://scientific.thomson.com/404/>

Monastersky, R. 2005. 'The number that's devouring science', Chronicle of Higher Education, 14 October 2005, viewed 22 December 2004, http://chronicle.com/free/v52/i08/08a01201.htm.

Morris, S. 2002. 'Getting started in electronic journal publishing', 4the ed. Oxford, INASP, viewed 22 December 2005, <http://www.inasp.info/psi/ejp/morris.html>

National Academies, 2004. Electronic scientific, technical, and medical publishing and its implications: report of a symposium. Washington, DC: National Academies Press.

Nursing Standard (Editorial), 1991 "Blacklisting: send off foul referees", Jul 3-9;5(41):51.

Odlyzco, A. 2002. 'The Rapid evolution of scholarly communication', Learned Publishing, vol.15, pp 7-19.

Page-Shipp, R. J., Hammes, M., Pienaar, H., Reagon, F., Thomas, G., van Deventer, M.J. \& Veldsman, S . 2005. 'eResearch support services: responding to a challenge facing the South African research and information communities', SA Journal of Information Management, vol. 7, no.4. 2005. 
Parsatharathy, H. 2005. 'Measures of impact', PLoS - Biology, vol. 3, issue 8, August 2005, viewed 22 December 2005, <http://biology.plosjournals.org/perlserv/?request=get-document\&doi=10.1371/journal.pbio.0030296>.

Peek, R. 2003. 'Could peer-review be wrong?', Information Today, vol. 20, no. 4, April 2003, viewed 22 December 2005, <http://www.infotoday.com/it/apr03/peek.shtml>

Perneger, T. 2004. Relation between online "hit-counts" and subsequent citations: prospective study of research papers in the BMJ. British Medical Journal, vol 329, pp 546-547, 4 September 2004, viewed 22 December 2005, <bmj.bmjjournals.com/cgi/content/full/329/7465/546>.

Peters, D. P. \& Ceci, S. J. 1982. 'Peer-review practices of psychological journals: the fate of published articles, submitted again', Behavioral and Brain Sciences, vol.5, 187-195.

Rzepa, H.S. \& Murray-Rust, P. 2001 'A New Publishing Paradigm: STM Articles as part of the Semantic Web' Learned Publishing, vol. 14, no. 3, July 2001, viewed 22 December 2005, <http://www.ch.ic. ac.ul/rzepa/learned/>.

Rzepa, H.S. \& Murray-Rust, P. 2004. 'Disseminating, archiving, retrieving and preserving scientific knowledge', in Spreading the word: who profits from scientific publications? A symposium within ESOF 2004. 26 August 2004, Stockholm.

Roosendaal, H. \& Geurts, P. 1997, 'Forces and functions in scientific communication: an analysis of their interplay', in Cooperative Research Information Systems in Physics, August 31-September 4 1997, Oldenburg, Germany, viewed 22 December 2005, <http://www.physik.uni-oldenburg.de/conferences/crisp97/roosendaal.html>.

Rowlands, I. \& Nichols, D. 2005. New Journal Publishing Models: An International Survey of Senior Researchers, CIBER (Centre for Information Behaviour and the Evaluation of Research), September 22, 2005, viewed 22 December 2005,<http://www.slais.ucl.ac.uk/papers/dni-20050925.pdf>.

Spreading the Word: who profits from scientific publishing 2004, viewed 22 December 2005, <http://www. esof2004.org/pdf_ppt/session_material/praderie_content.pdf>.

Swan, A. \& Brown, S.N. 2004. JISC/OSI Journal Authors Survey Report, viewed 22 December 2005, <http://www. jisc.ac.uk/uploaded_documents/JISCOAreportl.pdf>.

Swan, A. 2005. Open and shut: interview with Richard Poynder, 6 April 2005, viewed 22 December 2005 , <http://poynder.blogspot.com/2005/04/to-benefit-of-scholarship-interview.html>.

Tenopir, C. and King, D. W. 2000. Towards Electronic Journals: realities for scientists, librarians and publishers, Special Libraries Association, Washington DC.

Terry, R. 2004. 'Publication costs are research costs', in Spreading the word: who profits from scientific publications? A symposium within ESOF 2004. 26 August, viewed 22 December 2005, <http://www.esof2004.org/pdf_ppt/ session_material/praderie_content. pdf>.

Van de Sompel, H., Payette, S., Erickson, J., Lagoze, C. \& Warner, S. 2004. 'Building the System that Scholars Deserve', D-Lib Magazine, vol 10, no. 9, September 2004, viewed 22 December 2005, <http://www.dlib. org/dlib/september04/vandesompel /09vandesompel.html>

Warner, S. 2005. 'The transformation of scholarly communication', Learned Publishing, vol.18, no.3, July 2005.

Wilbanks, J. 2005. What is Science Commons?, viewed 22 December 2005, <http://creativecommons. org/weblog/entry/5695>

Willinsky, J. 2003. 'The Nine flavours of Open Access scholarly publishing', Jounal of Postgraduate Medicine, vol.49, pp 263-267.

Ziman, J. 2000, Real Science: what it is, and what it means, Cambridge University Press, Cambridge. 



\section{Conclusions and recommendations for a strategically enhanced role of research publishing in South Africa}

by Wieland Gevers ${ }^{1}$, Xola Mati ${ }^{2}$, Johann Mouton ${ }^{3}$, Roy Page-Shipp ${ }^{4}$, Monica Hammes ${ }^{5}$, and Anastassios Pouris ${ }^{6}$

This Report (Chapter 1) begins with a description and analysis of the present state of research publishing in South Africa, and presents a number of generic assertions on different but interrelated aspects of the subject, most of which can justifiably be said to have stood the test of empirical investigation described in the following chapters by their respective independent but collaborating authors. Most importantly, the test of continuing relevance of core best practice in a changing world publishing system has been confirmed, despite the urgent need for that core to undergo a safe passage into an evolved and adapted model in the modern cyber-world.

In this chapter we take up the challenge of updating our conclusions and strategic recommendations in the light of the outcomes of the investigations reported in Chapters 2-5. We have chosen to do so in a serial consideration of the assumed individual perspectives of important stakeholders in the field, building up from this a defining set of aggregate strategic recommendations that can most benefit the whole South African system of innovation, and our society and polity in general. We believe that this approach will allow stakeholders first to identify their own interests and objectives reflected in our analysis, and then to trace the path to the final recommendations where the interest and objectives of ALL stakeholders have been subsumed and prioritised, contradictions addressed and minimised, and the whole set of issues woven into a common framework for the common good.

The stakeholders who will be considered separately in the first phase of this concluding analysis are the following:

A Researchers at higher education and other institutions

B Direct and indirect funders and supporters/quality assurers of research

C National beneficiaries of research

D Editors and publishers of local research journals

E Analysts and evaluators of Research and Development (R\&D) activity

F Learners and teachers at South African schools

\section{A RESEARCHERS AT HIGHER EDUCATION AND OTHER INSTITUTIONS}

This is a sector which sees research journals as "core business" and has a tremendous stake in what is often called the "literature"- a ceaselessly growing number of knowledge sources, old and new, mostly unknown ("inputs into what one is doing", and what one is teaching) and the multi-choice route for the publication of one's papers and tangible contributions ("outputs to give self-worth and reputation, to achieve desired outcomes and to have an impact"). Research training, the co-option of fresh young minds into the enterprise, is a key component of many activities that broadly lock together research proposals, short- and longer-term funding streams,

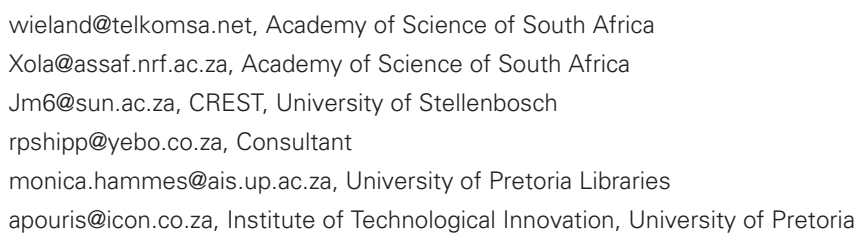


The "literature" (what has been published in reliably peerreviewed and editorapproved papers) is therefore a large and significant presence in the lives of researchers, whether based in higher education institutions or in other kinds of research-intensive organisations, public or private

In this sense, research journals are the life-blood of living and evolving science, whether they are print and/or electronic, and wherever they are published team- and asset building, and research production in the form of completed postgraduate qualifications, research publications, patent applications, and client-directed reports. This is true across a wide spectrum of different disciplines and their characteristic approaches to enquiry.

The "literature" (what has been published in reliably peer-reviewed and editor-approved papers) is therefore a large and significant presence in the lives of researchers, whether based in higher education institutions or in other kinds of research-intensive organisations, public or private. From their perspective, it must be possible to:

publish one's work in journals that are respected for high standards of editorial discretion, peer review and accurate presentation;

- reach the largest possible readership (preferably everybody who matters to the authoring scholar), in order to achieve the five core functions of publication described by Roosendaal and Guerts (1997), namely those of registration, certification, making aware (inviting collaboration), archiving and reward- seeking; and

- stimulate and hone the scientific effort by "forcing" the periodic publication of completed parts of work in a format that requires extreme rigour, reproducibility or results, appropriate reference to the work published previously by others, robust interaction with critically constructive reviewers and editors, and a tight relationship between the evidence presented and the conclusions drawn therefrom.

One cannot over-emphasise the importance to the broad scientific enterprise of the lastmentioned three requirements for the publication of research. They underpin research training in the most explicit way, as students or post-doctoral fellows cannot generally be assumed to be properly trained if original research results obtained during supervised study have not been published (ideally, but not necessarily, as first and primarily responsible author), in the full sequence of drafting - redrafting - submission-response to peer reviewers - editorial discretion applied - acceptance - publication. The completed process, preferably repeated many times, is literally the best guarantor of the kind of personal intellectual/conceptual growth that characterises a successfully trained and capacitated-for-life researcher. While research cultures and practice vary significantly between, for example, the natural sciences and the social/human sciences, in that peer-reviewed articles are more systematically important for the former than they are for the latter, the basic discipline of producing a formal, original publication, whether it be an article or a book, provides the same benefits to both authors and readers. In the context of this Report, journals of high quality, sustainably functioning in the "literature" (few things can be worse than having published in a defunct journal) are a primary requirement of the great majority of active scientists/scholars.

In this sense, research journals are the life-blood of living and evolving science, whether they are print and/or electronic, and wherever they are published. Good textbooks and reviews cannot be written in the absence of the published evidence and insight traceable in the "literature". Publications are the "open domain" of continued scientific progress through verification by others, (occasional but necessary) retractions and errata, citations and crossreferences, and the building up of "bigger and more accurate pictures", always subject to the Popperian test of "consistency with hypothesis". To subserve these important functions, individual articles should as far as is possible:

- adopt a consistent format, using precise, concise and unambiguous language ("universal author" style);

- present an adequate and fairly selected background of contextually relevant previous published work;

- include a description of methods adequate to permit replication by others;

- present results clearly, with proper statistical treatment;

- draw only conclusions that are compatible with the new and previously known data; and

- employ a standard referencing format of cited work to facilitate bibliometric analysis.

A fundamental and practical aspect of journal content and size is the key issue of the individual article, standing on its own in a universe of other articles (as in a large contemporary repository), as against an article appearing in a particular issue of a journal devoted to different aspects of a discipline. While repositories are easily searchable through key words, and enable many similar articles to be traced along with a single target item, only journals regularly containing 
an assortment of current articles, grouped according to the topic/focus area of the host journal, permitting the habit to be developed of scanning laterally relevant articles that may contain keys to the opening up of methodological or conceptual cul de sacs in research projects otherwise anchored only in a particular topic's habitually narrow window of ideas. Experience teaches that journal size is a critical factor in this role - too many articles dilute or exhaust the scanning reader's attention, while too few leave expectations unfulfilled and approximate to the individual article situation.

International journals (i.e. those that are listed and indexed in important databases used internationally, and/or those which are distinctly international in terms of article authorships and circulation to subscribers and libraries) present attractive targets for South African researchers who seek the publication functionalities described above. Most attractive, of course, are the journals with high impact factors (see Chapters 2 and 3) which enjoy the highest degree of visibility and the most emphatic attainment of the Roosendaal and Guerts (1997) functionalities listed above. It must be remembered, however, that the "Bradford principle" used as a core driver for limiting the size of bibliometrically accessible journal databases (by which is meant the self-fulfilling belief that a core set of high-quality journals is responsible for most citations and, by implication, most value in the system) must of necessity create instability in a journal system that is growing. This arises from increasingly intense competition for placement in the highest impact journals, expansion to saturation of the size (total articles) of these journals, increasing overflows to second-tier journals, and progressive narrowing of the gap between the "top group" and next-most successful competitors, until the rising input flow either nullifies the assumptions of the Bradford principle, or the gates have to be opened, to increase the size of the database to reach a new Bradford (un)steady state.

In these circumstances, the issue of developing countries being or becoming significant publishers of (local but internationally accessible) research journals requires attention, as South Africa is aspiring to be precisely such a "bigger producer". Clearly, South African journals can meet many of the needs of local (as well as international) researchers if they can enter the above-described journals-massification cycle as upwardly mobile players. If they meet the listing and indexing criteria of international databases such as those of Thomson ISI, only biased gate-keeping would prevent many South African journals not currently listed/indexed from becoming "international journals" as previously defined. While a statistical treatment of the distribution of editorial board memberships of 240 highly cited journals suggested that there was little difference between the numbers of "controlling" editors from different countries and those of research papers or citations (Braun and Diospatonyi, 2005), biased gate-keeping has been documented in terms of differential acceptance of papers from developing as opposed to developed countries (Gibbs, 1995). There are also editorial practices such as requiring authors to include citations to articles in the journals concerned (Monastersky, 2005), while the ISI policy of capping the number of indexed journals in particularly crowded fields, or of testing the citation records of candidate journals in the already indexed database, introduce a systematic bias against small and regional/national journals. In any case, and assuming that these practices will be discouraged in a better informed world system, it can be argued that good local journals can provide "double value" to local scientists/scholars in combining the virtues of international indexing with those of playing a significant local role.

Our investigation has high-lighted the importance of the issue of "visibility" of research publications. In a haystack of hundreds of thousands of items, the proverbial individual needle must be seen by as many of the people to whom the author(s) is speaking, both internationally and locally. General visibility of individual papers is enhanced by a combination of:

appearing in listed/indexed journals;

- publication in high-profile/impact/circulation journals;

- inclusion in widely read, focused, mono-disciplinary, usually large-size journals; and

- e-publication in Open Access mode, in journals or repositories, amenable to intelligent search and harvesting, by a wide variety of users.

Local visibility is often an important objective for researchers with strong local developmental agendas, or for those that effectively represent the richness of local social and natural diversity. The same enhancement factors would apply as listed above; the only difference would be that all the journal options would be local.
Our investigation

has high-lighted the importance of the issue of "visibility" of research publications. In a haystack of hundreds of thousands of items, the proverbial individual needle must be seen by as many of the people to whom the author(s) is speaking, both internationally and locally 
The accreditation function is critically important for the entire national system of innovation (NSI): it has to be credible, transparent, welladministered and generally promotive of higher standards and greater utility and significance, nationally and internationally
What then does the research community strategically require of the national publishers of research journals? From the specific and hugely important perspective of this group of stakeholders, one could summarise the requirements as follows:

- Research journals published within the country should aspire to the same quality as their international comparators, through best-practice and the use of a mix of both international and local reviewers, tested and tried by the editor(s) for full compliance with the kinds of models of peer-reviewing described in Chapter 1 .

- Local journals, besides their print versions, should provide electronic access (preferably in a sustainable mode as close to Open Access as possible) to ensure the widest distribution of potential readers and users.

- Local journals should provide the enrichment features that give them their special local value described extensively in Chapter 1, namely wide participation of the foremost South African scholars in publishing, editing and peer reviewing; effective networking of local scholars and research trainees; presenting local research to others in a high-impact way; accessibly reflecting local focus, depth and strength in particular fields; professional enrichment and expert contextualisation of content; fostering of disciplinary coherence; and maintaining and sustaining demonstrably high quality.

- Locally published journals should seek indexing in international databases in order to enhance their impact, make themselves amenable to judicious bibliometric analysis; and enable our researchers to be internationally recognised, funded and generally connected.

- Local journals should accept that peer review of their overall functionality and quality will be a natural component of the national system, ensuring that articles in local journals can be considered for most policy purposes to be, in effect and in context, broadly and reliably equivalent to those appearing in international journals, and representing a critical part of the national effort to promote training of young scientists and enhancement of the quality and scope of research activity and innovation generally, distributed across South Africa.

Finally, the issue of the accreditation system of the Department of Education will need to be addressed in the system. The accreditation step in respect of every single research publication, over which the DoE has complete control, feeds decisively into the policy frameworks of other organisations such as the CHE/HEQC (in terms of its functions of quality assurance of research and postgraduate training at higher education institutions), the NRF (for general grant-making and bursaries at the same institutions), the Department of Science and Technology, NACI and the scientometric compilers of annual S\&T indicators (as one of the key the determinants of output units), and the higher education institutions and science councils (in terms of internal planning and resourcing policies and reward systems), not to mention the journals themselves. In this sense, the accreditation function is critically important for the entire national system of innovation (NSI): it has to be credible, transparent, well-administered and generally promotive of higher standards and greater utility and significance, nationally and internationally.

As in the institutional accreditation models of the CHE/HEQC, a developmental approach to the accreditation of research journals requires implementation through a combination of widely accepted best-practice guidelines and quality promotion, with periodic peer review and assessment against criteria that can meet the needs of ALL the users of the system as listed above. The present accreditation model operated by the DoE is one where the Department, after wide consultation, makes the decisions on policy, listing and delisting of titles, consulting ASSAf in an informal and ad hoc way when it feels the need to do so (no agreement or contract exists). The issue is whether as a result of this Report, the interaction between the policymaking functions of the Department of Education and the research-based competence of the Academy should be strengthened and formalised, especially if the Academy is to be involved in the research publishing system in related, significant ways (see below for proposals for a quality assurance system for South African research journals, possibly conducted by ASSAf, and proposals for a general development programme for publishers, editors and reviewers coordinated and overseen by the Academy). It is obvious that the important stakeholders in the system need jointly to contribute to the design of a robust, accountable and effective accreditation system for national research journals that satisfies their individual but mostly converging requirements to the greatest degree possible; it is also obvious that the present system does not fulfil its basic function in this way. 


\section{B DIRECT AND INDIRECT FUNDERS AND SUPPORTERS OF RESEARCH/OUALITY ASSURERS OF RESEARCH}

Research publications are highly significant outputs of research activity, together with dissertations (qualified people), patents, technical reports and applications in society. In order to support research in a strategic way, funders have to be able to determine the likelihood that resources will be effectively and efficiently used, and that the public goods of productive research will be generated to the greatest possible extent, in the short, medium and long term.

Since original, peer-reviewed research publications play a double role in the research system, serving both as training vehicles for developing researchers and as the most easily recognised and valued contribution to the growth of both the global and the national knowledge and skills base, reliable assumptions as to their quality and value-added character are fundamental to any policy approach that seeks to foster the national system of innovation. From the perspective of government departments, (especially the DST and the Department of Education), and that of funding and support agencies (especially the NRF, MRC and other research funding bodies), an integrated approach to the assessment of publications is essential - no simple (and evidently incorrect) assumption of "international papers are good, local papers are bad" will suffice. An integrated approach taking into account all the appropriate contextual value-judgements is needed, as already discussed in extenso above, and the approach will need to keep pace with new developments.

The points of departure for funders and supporters of research, as well as quality assurers looking at research activity in institutional settings, could be taken as follows:

- Research work that is unpublished (or, worse, unpublishable) is essentially valueless, in that it cannot be replicated or validated by others; has not been subjected to the rigorous process of drafting, review and editorial discretion; is not in the open domain of scientific knowledge; and amounts to a null return on the funding and support investment.

- Results presented at conferences and publicised only as un-reviewed abstracts are similarly of little systemic value in the knowledge matrix, for the same reasons, despite their value in giving young researchers experience in presentation and public discussion of their work.

- Dissertation work (especially at the doctoral level) that is not published in the peerreviewed literature is little better, despite the efforts that have been made to collect them in repositories (to this point must be added the fact that failure to publish work from a doctoral project means the project has basically failed in one of its most important experiential training intentions).

- The translational aspect of research output must be seen to be distinct from the publication aspect, i.e. the effort that must ideally go into turning most research into public benefit is not an excuse for not publishing the work in the open literature.

- Research journals that attain and maintain high process and content quality are important both in providing outlets for publishable research work and in permitting accurate value judgments about the work to be made, for a host of operational purposes in the funding/ support systems, whether indirect (supply-side) or direct in the form of funds, equipment, bursaries, travel support, etc.

- The fact that journals used for publication are local need not attract negative value judgments, provided that the journals concerned offer the kinds of "adding value features" (as well as absolute quality) discussed above in the context of local versus international journals. Particular importance should be attached to the role that can and should be played by good local journals in the schools and research-training institutions (see above).

The successful implementation of the new South African quality assurance system for Higher Education institutions by the Council on Higher Education (CHE) and its Higher Education Quality Committee (HEQC) suggests that a smaller-scale, analogously structured quality assurance system for (clustered) research journals would also be both effective and acceptable to all stakeholders as a value-adding exercise. The fact that principles for quality assessment and developmental guidelines for best practice were first set up and "talked through" with the affected institutions before the start of the actual audit/review programme makes it likely that an organisation such as ASSAf could be entrusted with an analogous national research journals quality assurance programme, informed by principles and guidelines developed in this Report, underpinned by continuous observation and analysis of the realm of research publishing in
Since original, peerreviewed research publications play a double role in the research system, serving both as training vehicles for developing researchers and as the most easily recognised and valued contribution to the growth of both the global and the national knowledge and skills base, reliable assumptions as to their quality and value-added character are fundamental to any policy approach that seeks to foster the national system of innovation

\section{A smaller-scale} quality assurance system for (clustered) research journals would also be both effective and acceptable to all stakeholders as a value-adding exercise 
It is likely that all these potential beneficiaries are best served by a national science system that recognises that publication of research in the peer-reviewed open literature is the best guarantor of both its quality and utility both the national and international domains. Re-design of the critically important journal accreditation model (see above) would also be a fundamental requirement of an effective quality assurance function.

\section{NATIONAL BENEFICIARIES OF RESEARCH}

Two categories of beneficiaries of research that is published in research journals come immediately to mind: government departments and agencies that are looking for research-based solutions to important practical problems (whether social, technical or in some other domain), and industrial undertakings looking for sources of possible product or process innovation. In the first instance, the end-user does not in principle care greatly about the niceties of the research publication process or the novelty of the findings, the main concern is that the recommended solution is robust, affordable, implementable and ultimately beneficial. In the second instance, the end-user is very worried about adequate and appropriate protection of intellectual property and the solidity of the science behind the work.

Other categories of beneficiary are no less important. Research in the social and human sciences is a reliable source of direction and good practice for community-based and nongovermental organisations, international and national development agencies, educational institutions; and civil society at large.

It is likely that all these potential beneficiaries are best served by a national science system that recognises that publication of research in the peer-reviewed open literature is the best guarantor of both its quality and utility. The very process of carefully writing up one's results, in the required rigorous and thorough way, and subjection of the account to the scrutiny of peers, means that everything has to be thought of, and looked at, in a way that makes it likely that solutions coming out of the work will in fact be real solutions and not phantoms. Publishing scientists and scholars are also demonstrably better industrial innovation partners than those who do not publish or properly present their work to the general gaze; they also understand more readily how intellectual property considerations can and should be addressed.

Another form of beneficiation is that of producing large numbers of well-trained, researchexperienced thinkers and doers for the national economy. These will be immeasurably more capable in their various enterprises if they have become accustomed to the rigour and discipline of regularly publishing original research work in the recognised literature.

Well-edited and -distributed local journals can be a significant resource for the different kinds of beneficiaries mentioned above, in providing a concentrated source of information about local research projects and possibilities, points of contact between end-users and researchers, and signs of real capacity in the whole "iceberg" of activities that makes the published research papers possible.

\section{EDITORS AND PUBLISHERS OF LOCAL RESEARCH JOURNALS}

We have already commented in Chapter 1 on the enormous efforts that are voluntarily made to edit and publish a very large number of local research journals, many appearing infrequently, containing few articles, and drawing few citations in articles appearing in other journals. The survey reported in Chapter 4 showed that the editors of these journals mostly believe that they are doing something that's important, and are trying to do the best job possible, often finding novel survival solutions to keep going. The most significant of these solutions may well be the inclusion in a journal of much material that is not peer-reviewed research, even though the editors surveyed collectively estimated this to be less than $10-15 \%$ of the content of their journals. This is contradicted by direct inspection of some journals that have maintained their circulation and national role in the face of strong international competition: for example, recent issues of the South African Medical Journal have devoted only about 20\% of the printed pages to peer-reviewed articles.

Few editors referred to financial difficulties in their responses to the survey questionnaire. This is puzzling, as each has had to address the issue of financial and logistic sustainability ab initio, so to speak, employing a wide-ranging set of approaches and partial or temporary solutions, of which page charges and subsidies from host institutions or associations have probably been most important. The device of putting out issues of a journal infrequently and with thin content is widely deployed; ad hoc financing and sponsorship have become a way 
of life in some quarters; and some journals may still exist only because of the subsidy paid for articles in accredited journals to higher education institutions. The ending of state support in the form of consolidated publishing services for the subset of journals previously produced by the Bureau of Scientific Publications (BSP) after the release of the Richter and Pouris Report (1998) was not associated with deterioration of their quality or sustainability, in fact the reverse (Pouris, 2005), and there has been no pressure for a return to some kind of consolidated service support for editors, whether state-run or private, with the exception of the expanding service now provided to a number of local journals by NISC (National Inquiry Service Centre) from Grahamstown.

An interesting and possibly instructive example of a large-scale, consolidated publishing service is that of the CSIRO Publishing in Australia, a "commercial entity" from which no fewer than 20 research journals are published, together with a number of magazines, books, etc. Of the journals, 14 are owned by the CSIRO while the rest are partnerships with various societies. Most of the country's other significant journals are published by multi-national companies or by national disciplinary societies.

The advent of online publishing has significantly changed the way in which the editors and publishers of South African research journals view their future. Costs can be greatly reduced if a decision to stop print publishing is made in favour of the electronic mode; an entirely different distribution/readership model can be generated; and new and different kinds of commercial interest can be introduced as conventional advertising revenues fall but a (perhaps still to be fully documented) world-wide market for both article sales and on line subscriptions become dominant elements of business plans.

Summarising the requirements of the editors and publishers of South African research journals in the context of this chapter is made difficult by the fact that their collective voice has already been heard in Chapter 4. It is possible, however, to pursue the "different perspectives" approach in this instance also, by presenting a scenario that embeds the perspectives of this particular group of stakeholders in the wider system. This would essentially mean that:

- editors and editorial boards of South African research journals would subscribe to a general code of best practice similar to that described in Chapterl and in this chapter;

- indexing in internationally recognised databases would be energetically sought (and supported by relevant agencies);

- online publishing, with or without print, would be standard;

- open access, in both Gold and/or Green Route mode, would be a prime target, using payments by authors (contributed on their behalf by the respective host institutions as part of a nationally agreed model) and other income streams to achieve sustainable functioning;

- local journals would provide a significant amount of enrichment content to enhance their value to their different stakeholders;

- substantive editing and peer-reviewing work would be recognised in the general reward systems as valuable and highly skilled service;

- training programmes would readily be available for all kinds of aspects of the industry;

- the possible expansion of (private sector) consolidated editorial and publishing services would be explored, to permit editors to concentrate on their critical editorial functions; and

- training and skills-upgrading opportunities for editors, editorial assistants and aspirant professionals in the field would be available in the country.

- The Academy of Science of South Africa would take responsibility for coordinating and overseeing a programmatic approach to the developmental support of research journals through active involvement in the proposed new accreditation model, quality assurance, and policy-based and other measures to strengthen the research publishing domain as a whole (see above).

\section{E ANALYSTS AND EVALUATORS OF RESEARCH AND DEVELOPMENT (R\&D) ACTIVITY}

Increasing importance is now attached to the analysis and evaluation of research activity, in all its facets, in order inter alia to make judgments about the effectiveness and efficiency of the system, to identify significant trends, and to assess the need for new policy or resourcing. 
It goes without saying that indicators can only be useful if they reflect real quanta. Inputs in terms of funding and human resources must be compared with outputs that are valid in terms of verifiable standards or criteria. For example, diverse conference presentations and student dissertations are not easy to accept as outputs because there is no agreed standard for what they ought to be. Publications in the peer-reviewed literature, on the other hand, are much easier to accept because

- there is (nearly always) a quality-process standard;

(if listed and indexed) bibliometric analysis is possible; and

the results and conclusions can be confirmed, rebutted or built on, in the vast matrix of published science.

We have sought in this Chapter to avoid simple value judgments on journals that are published in South Africa or elsewhere, on journals that are presently listed/indexed in international databases or not, and on journals that set out to be focused assemblies of peer-reviewed articles or those that also provide other forms of content in response to user needs. This position does not mean that contextually appropriate and valid value judgments do not need to be made if critically important and widely used output indicators for research activity in the country are to have their proper meaning (see previous sections).

What is required to achieve greater interpretative insight, and a better understanding of the relationship between inputs and outputs than is currently possible, is that

units of publication used in system evaluation and analysis must reliably and in fact represent the full house of "value-addedness" implied by the term "an original, peer-reviewed, editordiscerned, fully composed contribution to knowledge" (through an improved accreditation function, see above);

strict authorship guidelines must be followed in each case, and address attributions specified;

acknowledgment of funding sources must be made; and

- the applicability and the shortcomings of bibliometric analysis must have been made clear. Estimates of R\&D expenditure have the notorious shortcoming they cannot readily be linked to productivity and thus yield efficiency indicators. Amongst the many outputs of research activity, peer-reviewed original publications are amongst the most direct and quantifiable, especially if also treated to informed bibliometric and other scientometric analysis. Use of bibliometric indicators for South African purposes makes assumptions, however, for example that:

the main contribution to the research that has been reported was made by an author(s) who has actually done the work (mostly, or all of it) in South Africa or while affiliated with a South African institution;

- the journal concerned has met criteria for good editorial and peer review practice, even if not internationally listed and indexed, through accreditation in a robust and generally accepted process; and

- information available in the public domain about impact factors and citation rates is not ignored simply because these indicators cannot easily be derived for a significant subset of articles in the sample (i.e. those in unlisted/un-indexed journals; note, however, that this Report presents the first-ever (partial) analysis of this kind, fully described in Chapter 3).

From the point of view of evaluation and analysis of large research systems, there can be no doubt that the best model would be one which reflects a pervasive culture that places a premium on high-quality publication of all research and associated training that has been performed; that regards locally published research journals as potential winners, in terms of both international AND national exposure (provided that best-practice norms are observed); and that sees publication outputs as important but not exclusive forms of return on the overall investment of funds and effort, along with patents, highly skilled postgraduate qualifiers, and translated socio-economic benefits.

The fact that a developing country has examined its research-publishing activity in fine detail, and particularly that this has been done partly through engaged or consultative research, partly through stakeholder consultation, and partly through the internal debates of a committed team brought together by the Academy of Science of South Africa, may be significant in the global context. It may be an example of a country "pulling itself up by its bootstraps", and contributing significantly to the global issues underlying science in the modern era - the 
widening North-South divide, the problems of brain drain, and the crucial issue of whether developing countries (especially those located in Africa) can be more than passengers on the $21^{\text {st }}$ Century train.

\section{F LEARNERS AND TEACHERS AT SOUTH AFRICAN SCHOOLS}

The role of South African research journals in the life and times of school-children and their teachers can at present be said to be a minimal, possibly miniscule one. That does not mean that this role could or should not be expanded with great benefit to all concerned and the nation at large. As the perceived gap in scientific achievement between developed and developing countries widens, few things can be more important than to make learners aware of the fact that significant research is in fact being done and reported in South Africa, that people like themselves have worked hard to establish their research groups and activities inside the country, and that it may be possible to make a personal contribution to positioning South Africa as a major (and distinctly African) player in the modern world. Teachers obviously need to be aware of what is being done and reported in South African science and technology, in the broad sense of scientific enquiry, in order to bring this effectively to what is talked about and written up in their classrooms as project work, reading assignments and individual mentoring activities.

Few experienced teachers at any level will deny that the "flame" present mostly latently in many of their charges is usually "lit" through contact with well-read teachers who can transform rote-learning into inspiration, building morale and confidence through enhanced conceptual understanding and beginning mastery of how and why things happen, and how things can be measured and outcomes predicted on the basis of appropriate theory. The unpredictability of such transformations does not mean that an environment cannot be created where the probability of their occurrence is significantly raised, and this is where we re-connect with our main theme - the potential positive role of South African research publications in the huge leaning and teaching system represented by the nation's schools.

National research journals (and science magazines drawing on them for highly accessible material) that provide regular access to the summaries and full text of good local research work, combined with the kinds of enriching features that help cultivate rewarding life-long learning habits (editorials, reviews, "news and views" commentaries on current papers, debates, etc) can make a big contribution to:

- teacher training and upgrading, including classroom best-practice;

- teacher materials/exemplars/hands-on learning modules/project points-of-departure;

- school libraries, classroom resources, mentoring references;

- curriculum enrichment through real-world examples and cross-talk between different subjects;

- pride in national achievements, and motivated career choices;

- connecting highly visible media stories to the underlying science; and

- internet-user skills that lead to expansion of knowledge and stimulation of enquiry. International journals and magazines, while obviously able to provide some of these beneficial outcomes, would not be sufficiently focused on science and technology produced in this country, nor connected to everyday topics and media happenings, to exert the full potential range of good effects that high-quality local journals and science magazines quite clearly could if they were promoted and deliberately used in a full range of applications in the entire schoolbased teaching-and-learning system. The presumption, however, is that the local journals and magazines would succeed in presenting their content in ways that enhanced their utilisation as partially listed above, through regularity and accompanying high visibility and trust; highquality content matched to general disciplines (as opposed to extreme specialisation); enhancing features; attractive presentation; relevant advertising; and (most important) low cost.

One could summarise the kind of local research journal system that would optimally support school-level learning and teaching as follows:

- A smallish number of broadly disciplinary journals that appear regularly throughout the year, and have a wide distribution and application throughout the school system, and wherever teachers are trained and/or undergo skills upgrading (carefully selected for wise use out of the pool of national journals);
National research journals (and science magazines drawing on them for highly accessible material) that provide regular access to the summaries and full text of good local research work, combined with the kinds of enriching features that help cultivate rewarding life-long learning habits (editorials, reviews, "news and views" commentaries on current papers, debates, etc) can make a big contribution 
How does research publishing fit into such a demanding vision, especially in the context of rapid change? It has its place, and an important one, through its role as the actual vehicle of science-based progress and effective attainment of sufficient high-level human capacity to address the most challenging problems and to provide inspiration to the brightest minds amongst the youth

In addition, it plays a key role in training by furnishing the most rigorous tests of resolve and originality.

It also connects the people carrying the science system of a country to the best of their international counterparts. Not trivially, it helps establish a country's reputation and thereby attracts investment and foreign support
- Another subset of selected national journals that are attractively packaged, and contain enriching features that help greatly in promoting involvement in, and understanding of, new developments in the country's broad array of scientific enquiry;

- Magazines (such as "Quest: Science for South Africa", published by ASSAf), preferably available free on line, that present the best scientific work done in the country, and contextualise it in such a way that pride, inspiration and motivation follow quite naturally; and

- Multi-revenue financial models for sustainably publishing the kinds of journals mentioned above.

\section{AGGREGATED AND INTEGRATED RECOMMENDATIONS}

We now come to the final task of framing recommendations in this Report that can satisfy the original brief (see Chapter 1) and provide a strategic approach to the question of research publishing in South Africa.

A strategy is a future-directed, broad-based plan to reach a particular goal. In this case, the goal could be said to be to develop and maintain a robust national system of innovation that contributes materially to the sustainable prosperity of all South Africa's people. In other words, a scenario where large numbers of lively, enquiring and enterprising people have scope for productive careers and involvement as leaders in science-based efforts to promote the development of the whole nation's skills and resources.

How does research publishing fit into such a demanding vision, especially in the context of rapid change? It has its place, and an important one, through its role as the actual vehicle of science-based progress and effective attainment of sufficient high-level human capacity to address the most challenging problems and to provide inspiration to the brightest minds amongst the youth. In addition, it plays a key role in training by furnishing the most rigorous tests of resolve and originality. It also connects the people carrying the science system of a country to the best of their international counterparts. Not trivially, it helps establish a country's reputation and thereby attracts investment and foreign support.

Recommendation No 1: that all stakeholders in the South African research enterprise should each in their own way support local/national research journals that actively seek to be of international quality and are indexed in an internationally recognised, bibliometrically accessible database, through following best-practice in editorial discernment and peer review, including adaptations

that address inherent problems and capitalise on technological innovations;

- that judiciously enrich content to promote coherence and value-adding functions;

that provide the local scholarly community with opportunities for participating in the full range of scholarship-enhancing activities associated with the process of publishing original research outputs;

that vigorously seek financial sustainability from multiple income streams; and

that accept systemic peer review and periodic audit which has a marked developmental focus.

(The rationale for this broad recommendation has been fully laid out in the chapters of this Report. In respect of financial viability of South Africa research journals, the general acceptance, in the special South African context where accredited institutional publication outputs are subsidised, of a per-article charge system (linked in the case of higher education institutions to an agreed fraction of output publication subsidies, and in the case of other research-producing institutions to adapted budgeting practice), would produce marked benefits at minimum cost, and naturally lead to a more rapid expansion of the Open Access mode of online publication, on the basis of "institution pays (a little), the whole nation/world benefits (a lot)". Key actors in bringing about the necessary policy and organisational frameworks would be research funders and supporters, including the Departments of Education and Science and Technology, the NRF and the MRC, all working with the Academy of Science of South Africa in downstream implementation mode following 
the release and general discussion of this Report. Data presented in this Report show that a fixed per-article institutional charge of R 1000, by an accredited journal that should be able annually to publish at least 100 articles, would provide a reliable income stream to that journal of R 100 000, which when added to subscription and other existing and probably expandable income streams, would create a basis for sustainable publication not now in place for most South African research journals. At the same time, the diversion to research journals of $1.43 \%$ of the publication subsidy stream would be insignificant against the benefits of the improvement in the quality and visibility of the publication outputs of the institutions concerned, not to mention the secondary benefits of enhanced scholarly functioning in general.)

Recommendation No 2: that both high-level (Departments of Education and of Science and Technology, CHE/HEQC, NACI and NRF) and wide-ranging (higher education institutions, science councils) discussions be held to design a robust, well-informed and accountable mechanism for the accreditation of research journals (and probably also of books and other outputs of scholarship), that will meet the different although often convergent requirements of the multiple stakeholders in the national system of innovation.

(The current accreditation system of the Department of Education is not designed to meet the needs of other participants in the national system of innovation. Thus the accreditation step in respect of every single research publication, over which the DoE has complete control, feeds decisively into the policy frameworks of other organisations such as the CHE/HEQC (in terms of its functions of quality assurance of research and postgraduate training at higher education institutions), the NRF (for general grant-making and bursaries at the same institutions), the Department of Science and Technology, NACI and the scientometric compilers of annual S\&T indicators (as one of the key determinants of output units), and the higher education institutions and science councils (in terms of internal planning and resourcing policies and reward systems), not to mention the journals themselves. The accreditation function has to be credible, transparent, well-administered and generally promotive of higher standards and greater general utility and significance, nationally and internationally. A developmental approach to the accreditation of research journals requires implementation through a combination of widely accepted best-practice guidelines and quality promotion, with periodic peer review and assessment against criteria that can meet the needs of ALL the users of the system as listed above. If the Academy is to be involved in the national research publishing system in related, significant ways (see recommendation below for a quality assurance system for South African research journals, and for a general development programme for publishers, editors and reviewers, both coordinated and overseen by the Academy), this needs to be taken into account by the important stakeholders in the system when designing a robust, accountable and effective accreditation system for national research journals that satisfies their individual but mostly converging requirements to the greatest degree possible.)

Recommendation No 3: that the proposed best-practice guidelines presented in Chapters 1 and 6 of this Report be widely discussed under the aegis of the Academy of Science of South Africa, formulated into a concise readable document, and then publicly adopted by editors and publishers throughout South Africa, especially those relating to effective peer review and wise and appropriate editorial discernment.

(Particularly important aspects are the training/guidance of editors and reviewers in their critical respective functions in the publication process, and the enhancement of recognition of this kind of work in general academic reward mechanisms. The Academy of Science of South Africa could work with a number of different institutions to ensure that a spread of courses, workshops and online offerings is available on a regular basis, that a national editors' network is formed, and that it mediates in conveying the collective or individual concerns of publishers and editors to the relevant authorities.) 
Recommendation No 4: that the quality assurance system now being put into place by the Council of Higher Education/Higher Education Quality Committee (CHE/HEQC) be used by that agency and by its partner higher education institutions to promote best-practice in publishing of original research work, and to emphasise and enhance the training function served by the whole exercise of publishing original papers in the peer-reviewed literature.

(The CHE/HEQC has achieved much in its best-practice guidelines for teaching and learning in higher education institutions, and is currently approaching postgraduate education and associated training in the same manner. Amongst the publication-related aspects of the latter, much good would come if all stakeholders emphasised the desirable and necessary relationship of conference presentations and dissertations to peer-reviewed publications emanating from the same work or study. A second benefit would come from systematically removing the perception that the (valuable) translation of research results into public benefits necessarily means that proper publication of the work concerned is not needed or should enjoy much lower priority.)

Recommendation No 5: that ASSAf be mandated jointly by the Departments of Education and Science and Technology to carry out external peer review and associated quality audit of all South African research journals in 5-year cycles, probably best done in relation to groups of titles sharing a particular broad disciplinary focus, in order to make recommendations for improved functioning of each journal in the national and international system.

(A light-touch but robust review and audit system, analogous to the periodic quality assurance reviews of the functioning of higher education institutions now routinely conducted by the Council on Higher Education/Higher Education Quality Committee, would help greatly to address problem areas and encourage enhanced functioning of research journals published in South Africa. Such functioning would include: quality of editorial and review process; fitness of purpose; positioning in the global cycle of new and old journals listed and indexed in databases; financial sustainability; and scope and size issues. Following on the momentum generated by the activities carried out as part of its research journals project and the production of this Report, the Academy of Science of South Africa would be the most suitable agency to oversee and be accountable for this work, obtaining system support for the best-practice guidelines, and appointing review panels and managing their work; some of the reviews could be done in respect of groups of journals with broadly similar focus.)

Recommendation No 6: that the Department of Science and Technology takes responsibility for ensuring that Open Access initiatives are promoted to enhance the visibility of all South African research articles and to make them accessible to the entire international research community. Specifically:

- online, open access ("Gold route") versions of South African research journals should be funded in significant part through a per-article charge system (linked in the case of higher education institutions to an agreed fraction of output publication subsidies, and in the case of other research- producing institutions to adapted budgeting practice), but publishers should still sell subscriptions to print copies and should maximise other sources of income to lower the article-charge burden;

a federation of institutional Open Access repositories, adhering to common standards, should be established ("Green route"), with resources made available to help institutions in the preliminary stage, this virtual repository to be augmented by a central repository for those institutions which are unable to run a sustainable repository;

national harvesting of South African Open Access repositories should be undertaken as a matter of urgency, preferably by the NRF; and

the importance of affordable bandwidth for research communications for this purpose be drawn to the attention of DST officials negotiating for better rates. 
(This proposal holds significant logistic implications for the development and maintenance of adequate broadband connectivity and related infrastructure, but the imminent high-speed/ broadband national system or "superhighway", envisaged for use by research-active institutions and others, will make things possible that have only been dreamt of up to the present time. The virtual repository would capitalise on institutional efforts, provided agreed standards were adopted, and provide a publication route for researchers in institutions without such a repository. The emphasis should be on "leapfrogging" the present turmoil and confusion in the system. The clear need for caution in assessing the presently somewhat vaguely defined business models for open access systems should not prevent the country from moving forward resolutely with a well-resourced programme for expanding its electronic access to the global and national scientific literature.)

Recommendation No 7: that a consortium of agencies be asked by the Department of Science and Technology to form a virtual "national research publications information and research centre", probably best overseen by the Academy of Science of South Africa, which will continuously gather and analyse information on South African journals as well as on publications in foreign journals emanating from authors working in this country, following up on the studies presented in this Report and in the (rather few) previous relevant publications. This entity could also be used to support the training function envisaged in Recommendation 2.

(The proposed managed consortium would supply a number of government departments with reliable information for policy implementation purposes - the Department of Education and/or ASSAf, for accreditation of local journals; the National Research Foundation, for assisting valuebased grant-making; the Council on Higher Education/Higher Education Quality Committee, for enhanced quality assurance at research-active institutions; agencies carrying out large-scale evaluations of R\&D such as the HSRC, reliable bases for validating output data; and higher education institutions and other research producers, for accelerated researcher development and overall research planning.)

Recommendation No 8: that a wide-ranging project be initiated by the national Department of Education and the provincial education authorities that will sharply increase the exposure of teachers, teachers-in-training and learners to local science journals and magazines that present the country's foremost scientific work in accessible form, and are effectively linked to the media.

(One of the most cogent reasons for publishing research journals locally is the opportunity beneficially to reach the next generation in ways that are not possible with expensive international periodicals; this needs to be planned in partnership mode, however, and will not happen without strong top-down sponsorship and appropriate resourcing.)

Recommendation No 9: that the Department of Science and Technology should assume responsibility for seeing to it that the South African science/innovation community, including itself and other government agencies, becomes involved in international action to promote the rapid but evolutionary development of a non-commercial, expanded, diversified and more inclusive international listing and indexing system for research journals, including those published in developing countries, within the evolving electronic knowledge-disseminating and -archiving system.

(There are clear needs for a new, consultative and collaborative approach to meeting the requirements of developing as well as developed countries; of countries using languages other than English as vehicles for doing and reporting research; of disciplines with systems of scholarly practice differing from the "natural sciences standard"; in a system that provides full 
transparency and low-cost access to data in terms of the databases to be used and maintained. It could be argued that this need is on a par with other more well-publicised and public requirements to level the playing fields in a structurally unequal world (ICSU Report on "Scientific Data and Information", 2004). The lead organisations in this effort should be the Departments of Science and Technology and of Education and the NRF, working closely with the Academy in terms of its international partners and other relevant agencies.)

Recommendation No 10: that the findings and recommendations contained in this Report be presented to key stakeholders in a series of consultative workshops, and that the outcomes and the impact of the publication of the Report be evaluated in three years time.

(This Report could have made radical proposals and recommendations supported by evidence presented in the various chapters. This approach has not been taken, however, because of the large number of inter-dependent stakeholders, the extreme fluidity of the sector in global terms, and the conviction of the authors that only a consultative process is likely to achieve the recommended results. We believe the present Report provides a necessary but obviously not sufficient basis for important reforms and considerable advancement of South Africa's research potential and actual performance - joint downstream efforts will be needed, at both the widely distributed knowledge production and more focused governance levels.) 


\section{About the authors}

Wieland Gevers, MASSAf was Senior Deputy Vice-Chancellor responsible for planning and academic process at the University of Cape Town from 1992-2002. He was twice President of the South African Biochemical Society, and President of the Academy of Science of South Africa from 1998-2004 (he is now its Executive Officer). He is a Fellow of the Academy of Sciences of the Developing World, was Acting Chairperson of the Education Committee of the South African Universities' Vice-Chancellors Association during 2001-2, and represented all South African Universities on the South African Qualifications Authority from 19962002. Gevers was awarded the Wellcome Gold Medal for Medical Research, and the Gold Medals of both the South African Society for Biochemistry and Molecular Biology, and the South African MRC. In 2004, Gevers was given the NSTF's "Achievements as an Individual over a Lifetime" Award.

Monica Hammes is Assistant Director of the University of Pretoria's Academic Information Service (AIS) responsible for scholarship issues and quality assurance. In this position she oversees the University's journal articles and e-theses repositories, and leads quality audits. In a 22-year career at the University, Ms Hammes inter alia championed electronic journal licensing in South Africa in 1998 and launched initiatives such as TYD@TUKS, UPeTD and UP-Against-Plagiarism, adding to the University's reputation as one of the leading South African university libraries in the field of e-services. She has served the GAELIC Library Consortium in various capacities and introduced the annual Marketing Fair. She regularly participates in conferences and workshops. In 2005 Ms Hammes was one of the first recipients of an award for outstanding support services to the University.

Xola Mati is Supervisory Project Officer of the Academy of Science of South Africa, and has previously worked at a high school, a College of Education, the University of Cape Town and the Human Sciences Research Council. He has done research on language policy at schools, coordinated the Molteno Project's primary schools evaluation programme, been a language coordinator for both the Quality Learning Project of the National Business Trust and the District Development Support Programme, and convened the Further Diploma in Multi-lingual Education at UCT. He is Study Director of ASSAf's South African Research Journals Project of which this Report is the principal product.

Johann Mouton, MASSAf is Director of the Centre for Research on Science and Technology (CREST) and Professor in the Department of Sociology at the University of Stellenbosch. He has taught Philosophy at Potchefstroom and Rand Afrikaans Universities, and been Head of the Centre for Research Methodology, Director of the Group for Information Dynamics and Executive Director of the Centre for Science Development at the Human Sciences Research Council. He has been project manager of more than 15 large-scale surveys including the South African Values Survey, the Survey on Scholarship, Research and Development, and the NACI Survey on Knowledge Utilization. He is member of the editorial board of a number of S A journals, as well as three international journals: Sociological Research Online, the International Journal of Research Methodology and Science and Public Policy.

Roy Page-Shipp retired from the CSIR at the end of 2002, concluding a career that spanned 27 years in that institution and included periods as Director of the newly formed Division of Building Technology, secondee to the RDP Office in President Mandela's Office, and Director of Strategy Support. In the latter capacity, he was involved in IT Strategy development, championed Knowledge Management and refocused the Information Services. He now practices as a consultant; recent projects have included the leadership of the SA Research Information Services (SARIS) Project, which has recommended the creation of eResearch Support Services for South Africa.

Anastassios Pouris is Director of the Institute for Technological Innovation (ITI) of the University of Pretoria, and specializes in science, technology and innovation policy development studies, including assessments and priority-related exercises. He has acted as Director in, and Chief Executive Officer of a number of South African government 
organizations (most recently the Foundation for Education, Science and Technology, FEST, now SAASTA), as well as consultant to a number of government departments and various international organisations such as UNESCO and NEPAD. His educational background includes Engineering from the University of Thessaloniki (Greece), Economics from the University of Surrey Guildford (England) and PhD from the University of Cape Town. 


\section{About the Academy of Science of South Africa}

Parliament unanimously passed the Academy of Science of South Africa Bill on 26 October 2001, and the Act formally came into operation on 15 May 2002. This allocates to the Academy the domain of the science system of this country that is characteristically occupied by national science academies. Such academies are:

- independent of government (but able to be funded for performing specific tasks);

- self-perpetuating in the sense that new members or fellows are elected by all existing Members or Fellows, forming a meritocracy as defined in the particular academy's constitution;

- multidisciplinary, striving to represent science as a consilient continuum of knowledge, insight and practical conclusions;

- held in high public regard, and

- connected to the national science academies of other countries through strong bonds and mechanism of co-operation and exchange.

\section{THE ORIGINS OF THE ASSAF}

The best way to describe the ASSAf's beginning is to quote key sections from its 2001 'Plan Document':

\section{Historical background}

"The Academy idea has been presented in South Africa in various guises for over 150 years. One historical sequence led from the formation of the South African Institution in 1825 to the South African Philosophical Society in 1877 that developed into the Royal Society of South Africa in 1980, which by virtue of its statutes is dedicated to the furtherance of science but flourishing mostly in English-speaking circles and institutions. In 1909 a separate historical strand was initiated by a parliamentary statute that called into being the Zuid-Afrikaansche Akademie voor Taal, Lettere en Kunste. In 1941 it developed into the Suid-Afrikaanse Akademie vir Wetenskap en Kuns, largely but entirely pre-occupied with the promotion of the Afrikaans language in the arts and sciences. Yet another significant development was the creation of the Science and Engineering Academy of South African in 1986; while a true academy in its mission, it has been forced by the needs of the of the time temporary to address mainly the serious educational and professionalisation issues which confront blacks in the natural sciences and engineering. Each of these three 'Academies' has a form which has made it, to a lesser or greater extent, and for different reasons in each case, a potential rather than a real academy. In one sense, their coexistence in this country shows the importance of the idea of an academy even in a society fragmented in its historical crucible.

Many other bodies in South Africa were either dedicated to the furtherance of individual disciplines or to the coordination and/or promotion of scientific activities in a limited or broader context. None thus far, however, combined the autonomy, very high quality, and public trust that, together, provide the hallmark of an academy in the true sense - that is, a body with a responsibility to the community as a whole and not to a section of it. A number of scientists, therefore, discussed the possibility of setting up a new academy to fill this gap, and the Plan Document described the process."

\section{The present initiative}

"The Foundation for Research Development sponsored informal meetings of a small number of individuals over the period from October 1989 to April 1990. This action had its origin in an enquiry conducted by the Suid Afrikaanse Akademie vir Wetenskap en Kuns, which concluded that the Akademie did not function as an academy of science and was not likely to do so in the future. While no such conclusion was formally reached by the Royal Society of South Africa 
and the Science and Engineering Academy of South Africa, various members of these two bodies agreed to meet with two senior black scientists and several members of the Akademie, in order to seek answers to the following three questions:

1. was there a compelling case for the creation of an Academy of Science? and if so

2. what general from should the Academy take? and

3. how could it be brought into being?

Mindful of the failure of previous attempts to develop an Academy of Science for South Africa, the group decided to seek informal consensus on these questions and then developed the issue in a wider context. This informal group did not aim for a scholarly analysis of the situation, but viewed itself rather as a gathering of 'concerned citizens' whose goal was the rapid facilitation and stimulation of further actions and events that might be needed.

The group concluded that 'a new Academy of Science would be most valuable at a time when there are better prospects than ever before for commonality of purpose amongst South Africans and when the potential for good and effective action by such an Academy is especially great; this applies to both the internal and external terrains of scientific activities'. The mission of the Academy, as defined at the time, would be 'to apply the highest level of scientific thinking in the service of the nation and especially to the instrument for conveying considered scientific opinion and advice to government, the people and the world at large".

To enable the ASSAf to fulfil its mission, the Plan Document contained the following outline of an enabling organisational structure:"

\section{The position and structure of the Academy}

"With respect to the optimal form of an Academy of Science of South Africa, the group believes that the new body should be centrally placed in the system of science in the country; it should not adapt to other existing organisation, but the latter should rather be encouraged to adapt to it in a synergistic manner. The Academy should be autonomous and independent of government control. (Note: this does not exclude an enabling parliamentary Act that would clearly define the powers of the Academy to elect its own members and office bearers, to operate its own financial affairs and to speak its mind at any time on any matter within its competence, limited in all instances solely by codified civil and criminal law). The Academy should elect its members on the basis of general as well as special scientific abilities, since the intention is to create a body of persons who will be activists in the good sense of the word. The cardinal emphasis in the Academy would thus be on service as well as on recognition or reward for past achievements, on the solution of problems through scientific analysis rather than the stimulation of individual scientific disciplines, and on the promotion of scientific thinking and activity in the broad rather than the narrow sense.

The Academy of Science, as a premier, non-governmental, scientific body, should be in a particular favourable position to act as a link with international scientific unions and related organisation. It should also be to establish fruitful links with academies (or equivalents) that exists in other countries. In Africa, especially, it should interact with equivalent academies, and form regional or continental organisation with common purposes and objectives."

\section{THE ASSAF IN THE NEW MILLENNIUM}

The preamble to the Constitution of the ASSAf as adopted in 1996 formalises the way in which this particular Academy is specific to South Africa as well as part of the international 'academy vision':

"Scientific thought and activity enrich us profoundly; they empower us to understand and to shape our living environment; they are keys that can open the doors to a peaceful and prosperous future.

The function of science is to create in a disciplined and systematic way, a continuum of coherent, rational and universally valid insight into observable reality in all its various facets. Scientific thinking and knowledge are fundamental to the best work done in the applied natural sciences and in technology, and this applies also to much of the human and social sciences.

An Academy, which effectively harnesses the minds and energies of the most able practitioners of scientific thought, reflects, as almost nothing else does, the strong bonds 
between scientific disciplines and the unique character of the scientific contributions to the lives of all citizens. The Academy of Science of South Africa is constituted to ensure that leading scientists, acting in concert and across all disciplines, can promote the advancement of science and technology, can provide effective advice and can facilitate appropriate action in relation to the collective needs, threats, opportunities, and challenges of all South Africans."

The ASSAf's constitution gives its key objectives as that of promoting and applying scientific thinking in the service of society. To this end, the Academy's role is to:

1. use the common ground of scientific knowledge and activity to remove barriers between people and obstacles to full development of their intellectual capacity;

2. endeavour in every possible way to inspire, promote and recognise excellence in science and technical practice;

3. investigate and publicly report on various matters, in its own discretion or at the request of government or organisations in civil society, in order to promote and apply scientific in the service of society;

4. promote science education and a culture of science in the population at large;

5. maintain strict independence while consulting other organisations and individuals in the widest manner possible;

6. endeavour to establish and develop close relations with scientific organisations in South Africa and with similar academies in other countries; and

7. take any other action that it may consider as necessary towards the attainment of its key objective.

\section{Membership}

After nominated by four existing Members (at least two of whom do so from personal knowledge of the candidate), new Members of the Academy are elected in a secret ballot. The normal criterion for election is significant achievement in the advancement or application of science, and, in addition, Members should be persons who can be expected significantly to assist the Academy in achieving its objectives. By December 2005, the ASSAf had 265 Members representing a number of categories as shown in Table 1.

Table 1: Membership of ASSAf, Oct 2005

\begin{tabular}{|l|c|c|c|c|c|}
\hline \multicolumn{1}{|c|}{ Catogories } & Male & Female & White & Black & Total \\
\hline Earth Sciences & 8 & 2 & 8 & 2 & 10 \\
\hline Economic Sciences & 8 & 2 & 5 & 5 & 10 \\
\hline Humanities & 34 & 16 & 32 & 18 & 50 \\
\hline Life, Health and Agricultural Sciences & 58 & 13 & 53 & 18 & 71 \\
\hline Mathematical Sciences & 13 & 1 & 9 & 5 & 14 \\
\hline Physical and Chemical Sciences & 33 & 3 & 27 & 9 & 36 \\
\hline Social Sciences & 26 & 12 & 23 & 15 & 38 \\
\hline Technological Sciences & 26 & 5 & 27 & 4 & 31 \\
\hline Education & 4 & 1 & 2 & 3 & 5 \\
\hline Total & 210 & 55 & 186 & 79 & 265 \\
\hline
\end{tabular}

\section{The Council}

A Council, comprising 12 members, each of whom holds office for four years at a time, governs the affairs of the Academy. The Members elect this Council every two years. For the sake of continuity, six members continue to serve a further term, while six new members are elected once they have been nominated according to the constitutional mechanism. To provide a better balance of race, gender or disciplinary area, the Council can co-opt additional members from persons who were nominated for election to the Council.

The Office bearers are, respectively, the President, two Vice-Presidents, a General Secretary and a Treasurer. 
Committees can be formed in order to carry out specific functions but each must be chaired by a Member of the Academy or, preferably, of its Council. The Council approves reports drawn up by its committees or ad hoc task groups before entering the public domain.

The present members of the ASSAf Council are: Professor S. Benatar, Professor A. ChinsamyTuran (Vice-President), Professor R. Crewe (President), Professor V de Klerk (Treasurer), Professor M. Hellberg, Professor J. Jansen, Dr C. Johnson, Professor B. Khotseng, Professor C. Manganyi, Dr P. Mjwara (General Secretary), Professor L. Nassimbeni, Prof J. Thomson and Professor J. Volmink.

\section{Activities}

From the start ASSAf was accepted as part of the international system of academies. Many of the world's premier academies sent representative to its founding meeting in 1996, and a number of international exchange and cooperation agreements have been signed. ASSAf is a member of the InterAcademy Panel (IAP), which has over 90 members and headquarters at the Academy of Sciences of the Developing World (TWAS) in Trieste, Italy. ASSAf was a member of the InterAcademy Council (IAC) from 2002-2005 as the only national science academy from Africa in this 15-member body. ASSAf became an "intense partner" of the US National Academies (together with the Nigerian and Ugandan Academies of Science) as part of the African Science Academy Development Initiative (ASADI), receiving a substantial 5-year grant to build its capacity for generating evidence-based advice for the government and the nation in general

The Vision Statement ASSAf adopted in 2005 states that:

"National science academies are assuming increasing importance in the world science system, both as unique and potentially valuable entities in their respective national systems of innovation and science-based development generally, and in regional or other supranational configurations, up to the global body called the InterAcademy Panel (IAP), with its dedicated subsidiary unit (the InterAcademy Council, or IAC), generating science-based reports and recommendations for the global community of nations.

Like democratic South Africa in general, ASSAf aspires to play both a national and an international role, particularly with respect to the African continent. We see the Academy as usefully at arms length from Government and other organized sections of the state, comprising an assembly of excellent scientists from many disciplines who have shown their interest in and capacity for promoting the science-based development of a prosperous and a fully enabled society. Membership of the Academy (by election) is both an honour and an obligation to work individually and collectively (as the Academy) to ensure that decision-making requiring scientific scrutiny and analysis is based on the best and most integrated understandings and insights available to the country. The Academicians thus represent an organized, independent but responsive voice of science to help guide the development of the country and its people.

The high-level plans of ASSAf are thus:

- to become increasingly associated in the mind of the nation with the highest levels of scholarly achievement and excellence in the application of science for the benefit of society;

to consolidate its infrastructure and capacity, and to expand and mobilize the Membership to ensure that scientists from a full disciplinary spectrum are available for its work, and that these are indeed both thinkers and doers, willing to put significant effort into the Academy's activities;

- to embark on a programme of systematic studies of science-based issues of national importance, some proposed by government or other sectors, and some identified by the Academy itself; to develop a sound and robust methodology for constituting study panels, organizing their work, including conferences and workshops; and producing authoritative reports that are well-disseminated and have significant impact;

- to publish science-focused periodicals, especially a multi-disciplinary science journal of high quality (the "South African Journal of Science") and a science magazine that will showcase the best of South African science to a wide national (and international) audience ("QUEST Science for South Africa"), and to promote the development in South Africa of an indigenous system of research journals of internationally recognized quality and usefulness;

- to develop productive partnerships with other organizations of the national system of innovation, especially (but not only) the Departments of Science and Technology, Education, 
Health and Agriculture; NACI; science councils; universities, etc. with a view to the building of capacity in science and its applications within the National System of Innovation (NSI);

to create new and diversified sources of funding for the sustainable functioning of an independent Academy;

- to develop a plan for the expansion of the activities of ASSAf in partnership with the United States National Academies; and

- to play a significant role in the international science system, particularly in Africa, through organizations such as the IAP/IAC and TWAS (the Academy of Sciences for the Developing World), as well as NASAC (Network of African Science Academies), in the context of NEPAD (the New Partnership for Africa's Development)."

The Academy of Science of South Africa

Physical Address

First Floor,

Didacta Building

211 Skinner Street,

Pretoria 0001

\section{Website}

www.assaf.co.za
Postal Address

P O Box 72135 ,

Lynnwoodridge 0040

Telecommunication

Telephone: 012-392 9377

Fax: 012-320 2099

e-mail: fundi@assaf.nrf.ac.za 

2006

\section{Report on a Strategic Approach to Research Publishing in South Africa}

\section{Academy of Science of South Africa (ASSAf)}

Academy of Science of South Africa

Academy of Science of South Africa (ASSAf), (2006). Report on a Strategic Approach to

Research Publishing in South Africa. [Online] Available at: DOI http://dx.doi.org/10.17159/assaf/0038 http://hdl.handle.net/20.500.11911/49

Downloaded from ASSAf Research Repository, Academy of Science of South Africa (ASSAf) 